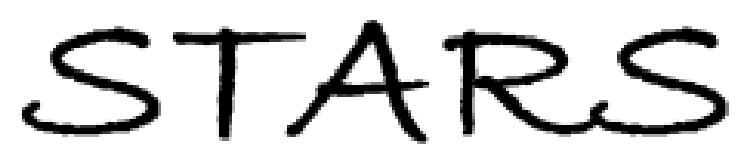

University of Central Florida

STARS

2-7-2017

\title{
Comparative Performance Of Two Ventilation Strategies In A Hot- Humid Climate
}

Florida Solar Energy Center

Sarah Widder

Florida Solar Energy Center

Part of the Energy Systems Commons

Find similar works at: https://stars.library.ucf.edu/fsec

University of Central Florida Libraries http://library.ucf.edu

This Contract Report is brought to you for free and open access by STARS. It has been accepted for inclusion in FSEC Energy Research Center ${ }^{\circledR}$ by an authorized administrator of STARS. For more information, please contact STARS@ucf.edu.

\section{STARS Citation}

Florida Solar Energy Center and Widder, Sarah, "Comparative Performance Of Two Ventilation Strategies In A Hot-Humid Climate" (2017). FSEC Energy Research Center®. 91.

https://stars.library.ucf.edu/fsec/91

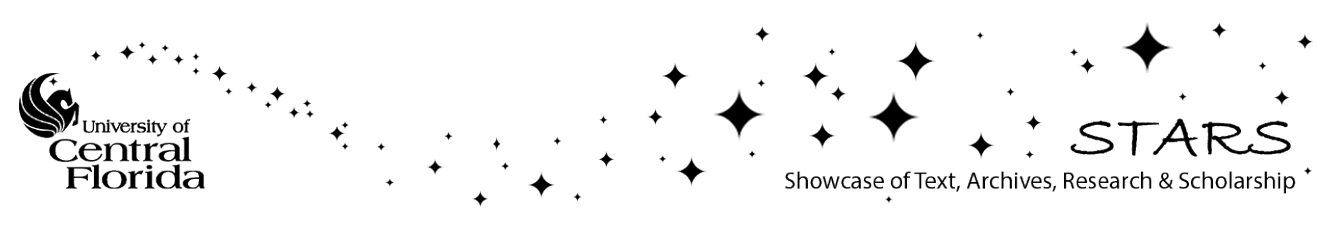




\title{
FLORIDA SOLAR ENERGY CENTER \\ Creating Energy Independence
}

\section{Comparative Performance of Two Ventilation Strategies in a Hot- Humid Climate}

\author{
FSEC-CR-2058-17
}

\section{Final Report}

February 2017

\begin{abstract}
Authors
Sarah Widder-PNNL

Eric Martin, Dave Chasar, Janet McIlvaine, and Bryan Amos-BAPIRC

Ken Fonorow-Florida HERO
\end{abstract}

C 2017 University of Central Florida.

All Rights Reserved.

\section{Clearlake Road}

Cocoa, Florida 32922, USA

(321) 638-1000

www.floridaenergycenter.org 


\section{Disclaimer}

The Florida Solar Energy Center/University of Central Florida nor any agency thereof, nor any of their employees, makes any warranty, express or implied, or assumes any legal liability or responsibility for the accuracy, completeness, or usefulness of any information, apparatus, product, or process disclosed, or represents that its use would not infringe privately owned rights. Reference herein to any specific commercial product, process, or service by trade name, trademark, manufacturer, or otherwise does not necessarily constitute or imply its endorsement, recommendation, or favoring by the Florida Solar Energy Center/University of Central Florida or any agency thereof. The views and opinions of authors expressed herein do not necessarily state or reflect those of the Florida Solar Energy Center/University of Central Florida or any agency thereof. 


\section{Comparative Performance of Two Ventilation Strategies in a Hot-Humid Climate}

Sarah Widder-PNNL

Eric Martin, Dave Chasar, Janet Mcllvaine, and Bryan Amos-BAPIRC Ken Fonorow-Florida HERO

February 2017 


\section{NOTICE}

This report was prepared as an account of work sponsored by an agency of the United States government. Neither the United States government nor any agency thereof, nor any of their employees, subcontractors, or affiliated partners makes any warranty, express or implied, or assumes any legal liability or responsibility for the accuracy, completeness, or usefulness of any information, apparatus, product, or process disclosed, or represents that its use would not infringe privately owned rights. Reference herein to any specific commercial product, process, or service by trade name, trademark, manufacturer, or otherwise does not necessarily constitute or imply its endorsement, recommendation, or favoring by the United States government or any agency thereof. The views and opinions of authors expressed herein do not necessarily state or reflect those of the United States government or any agency thereof.

This report is available at no cost from the National Renewable Energy Laboratory (NREL) at www.nrel.gov/publications.

Available electronically at SciTech Connect http:/www.osti.gov/scitech

Available for a processing fee to U.S. Department of Energy and its contractors, in paper, from:

U.S. Department of Energy

Office of Scientific and Technical Information

P.O. Box 62

Oak Ridge, TN 37831-0062

OSTI http://www.osti.gov

Phone: 865.576.8401

Fax: 865.576.5728

Email: reports@osti.gov

Available for sale to the public, in paper, from:

U.S. Department of Commerce

National Technical Information Service

5301 Shawnee Road

Alexandria, VA 22312

NTIS http://www.ntis.gov

Phone: 800.553 .6847 or 703.605 .6000

Fax: 703.605.6900

Email: orders@ntis.gov 


\title{
Comparative Performance of Two Ventilation Strategies in a Hot-Humid Climate
}

\author{
Prepared for: \\ The National Renewable Energy Laboratory \\ On behalf of the U.S. Department of Energy's Building America Program \\ Office of Energy Efficiency and Renewable Energy \\ 15013 Denver West Parkway \\ Golden, CO 80401 \\ NREL Contract No. DE-AC36-08GO28308 \\ Prepared by: \\ Sarah Widder-Pacific Northwest National Laboratory \\ Eric Martin, Dave Chasar, Janet McIlvaine, and Bryan Amos- \\ Building America Partnership for Improved Residential Construction \\ Ken Fonorow-Florida HERO
}

NREL Technical Monitor: Stacey Rothgeb

Prepared under Subcontract No. KNDJ-0-40339-05

PNNL Clearance Number 24201

February 2017 
The work presented in this report does not represent performance of any product relative to regulated minimum efficiency requirements.

The laboratory and/or field sites used for this work are not certified rating test facilities. The conditions and methods under which products were characterized for this work differ from standard rating conditions, as described.

Because the methods and conditions differ, the reported results are not comparable to rated product performance and should only be used to estimate performance under the measured conditions. 


\section{Table of Contents}

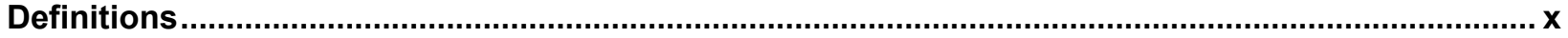

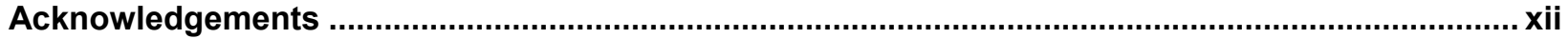

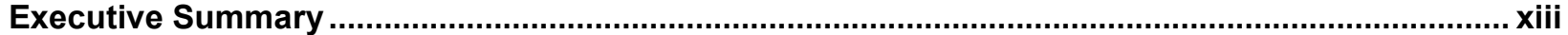

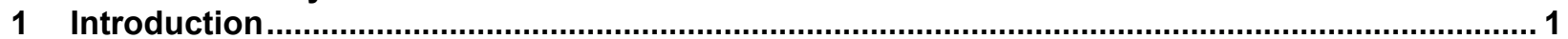

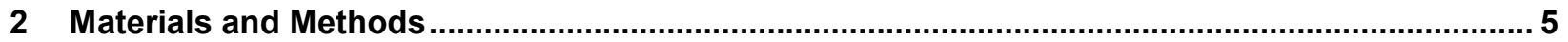

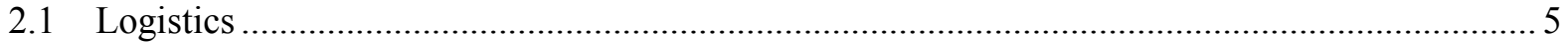

2.1.1 Study Location and Study Homes ................................................................... 5

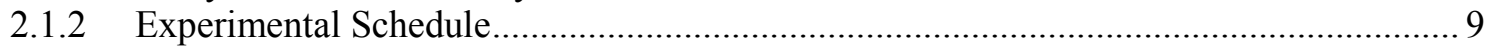

2.1.3 IAQ Contaminants of Concern..................................................................... 10

2.2 Monitoring Equipment and Methodology .................................................................. 11

2.2.1 Whole-House Mechanical Ventilation Fan Flow Rate............................................. 13

2.2.2 Building Envelope and Duct System Performance ................................................... 13

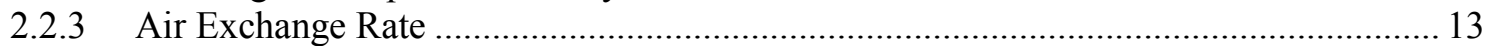

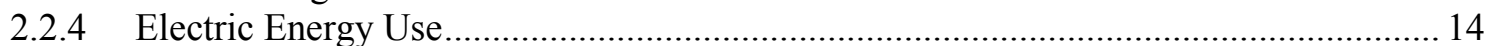

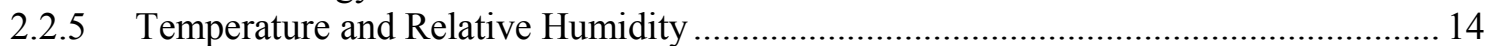

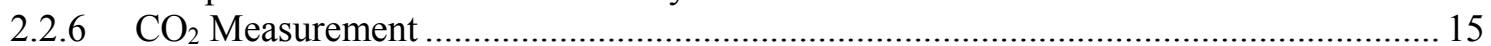

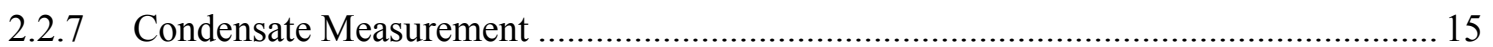

2.2.8 Total Volatile Organic Compounds ..................................................................... 15

2.2.9 Formaldehyde and Acetaldehyde ................................................................. 15

2.2.10 Nitrogen Dioxide.................................................................................... 16

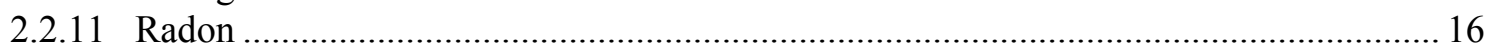

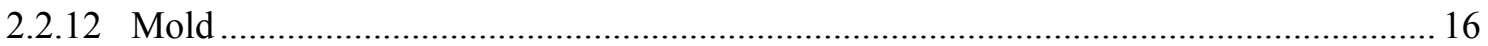

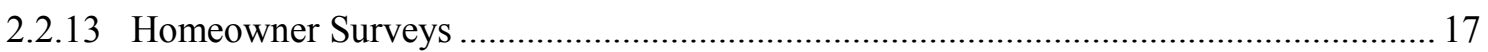

3 Results and Discussion .......................................................................................................... 18

3.1 Continuously Monitored Parameters: Energy Use, Temperature, Relative Humidity, and Carbon

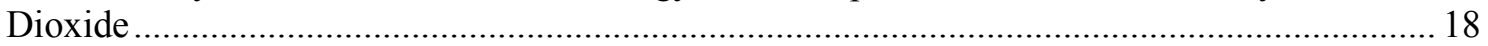

3.1.1 2013 Cooling Season Data and Analysis (6/28/13-10/15/13) ................................. 19

3.1.2 Summer Condensate Data and Analysis (6/24/2014-8/19/2014) ............................. 25

3.1.3 Heating Season Data and Analysis................................................................... 26

3.1.4 Mixed Season and Annual Data and Analysis ..................................................... 30

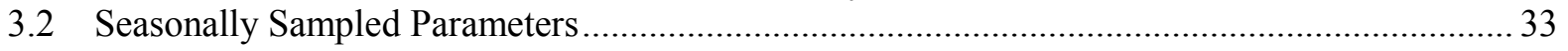

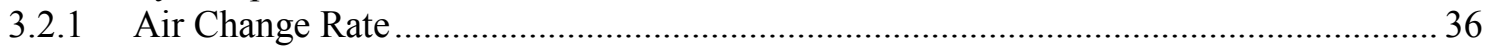

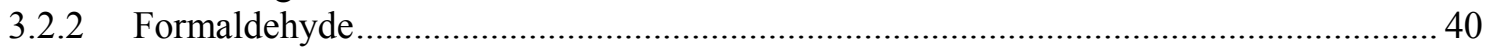

3.2.3 Acetaldehyde ........................................................................................... 46

3.2.4 Volatile Organic Compounds .......................................................................... 50

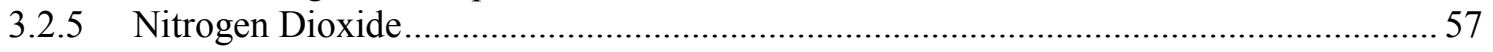

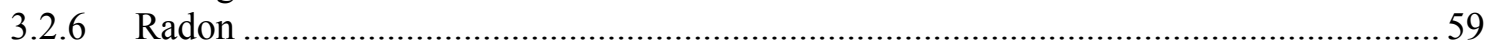

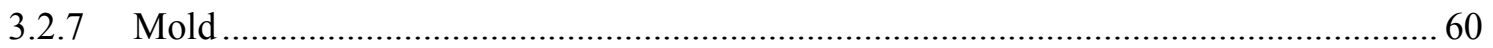

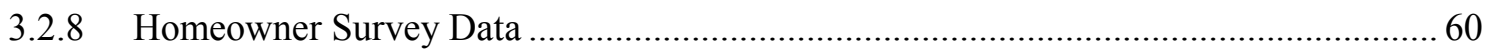

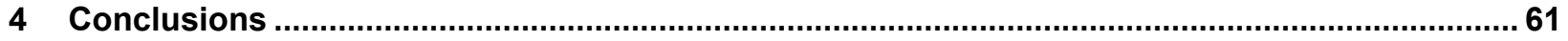

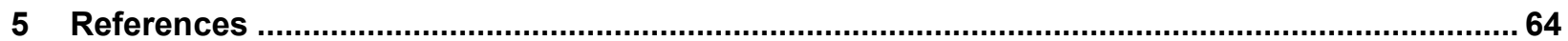

Appendix A. Sampling Protocol ................................................................................................68

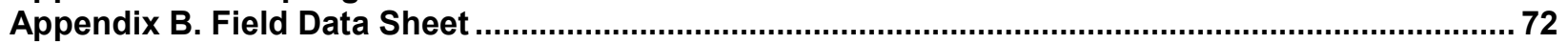

Appendix C. Quality Assurance and Quality Control ...................................................................... 73

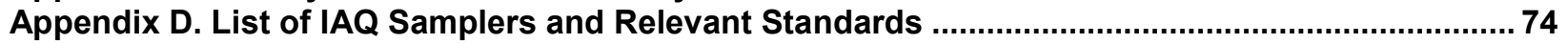

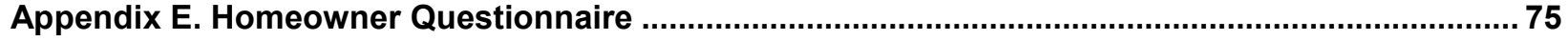

Appendix F. Laboratory Analysis Summary ............................................................................ 78

Appendix G. Weather Conditions in Gainesville, Florida, During the Monitoring Period ............... 82

Appendix H. Indoor Home Plots ................................................................................................ 83

Appendix I. Space-Heating Analysis, Linear Regressions ...................................................... 93 


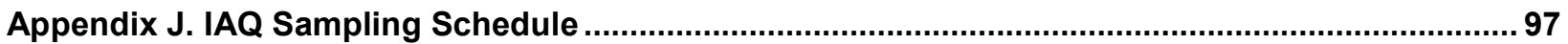

Appendix K. Air Exchange Rate and Indoor Air Quality Data Tables ............................................... 99

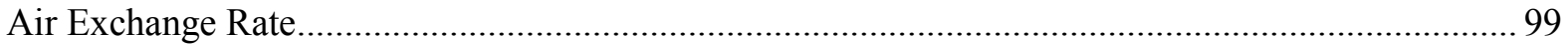

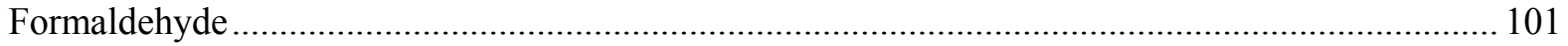

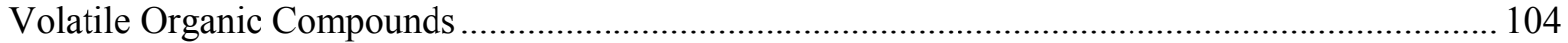

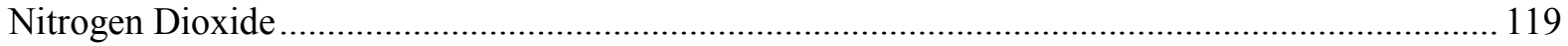




\section{List of Figures}

Figure 1. Average and range of monthly RH for fully ducted return (FDR) and single return with transoms (SRT) homes with the runtime ventilation system in Gainesville, Florida................ 3

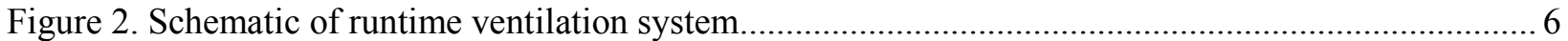

Figure 3. Whole-house source energy use predicted by BEopt software ................................................ 9

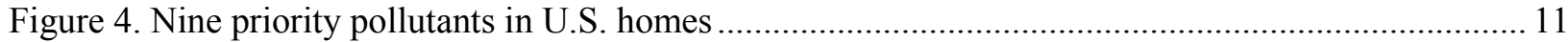

Figure 5. Outdoor dry bulb and dew point temperatures from the local National Weather Service station and average indoor dew point temperature among the flip-flop homes............................... 18

Figure 6. Distribution of hours at various percent (\%) RH ranges during summer 2013, broken into runtime ventilation (left bar) and continuous exhaust ventilation (right bar) periods, each corresponding to the left axis

Figure 7. Average cooling energy use per day, broken into runtime ventilation (left bar) and continuous exhaust (right bar) periods

Figure 8. HVAC energy use as a function of differences in indoor and outdoor temperatures ................. 22

Figure 9. Average hourly indoor and outdoor dew point temperatures and cooling energy use for the flipflop homes in the runtime ventilation (RTV) and continuous exhaust (CEV) configurations23

Figure 10. Daily average $\mathrm{CO}_{2}$ concentration, broken into runtime ventilation (left bar) and continuous exhaust (right bar) periods

Figure 11. Average, minimum, and maximum daily condensate volumes collected from $6 / 24 / 14$ to $8 / 19 / 14$

Figure 12. Daily heating energy in four flip-flop and four control homes.......................................... 28

Figure 13. Example of daily heating energy regressions for Home 2 (a flip-flop home) exhibiting welldefined results with a high R-squared value

Figure 14. Example of daily heating energy regressions for Home 5 (a CEV control home) exhibiting poorly defined results with a low R-squared value

Figure 15. Number of hours $>60 \% \mathrm{RH}$, and their relative distribution among the cooling and mixed periods for CEV-control Homes 3 and 5 and RTV-control Homes 7 and 10 ....................... 31

Figure 16. Daily average $\mathrm{CO}_{2}$ concentration during the mixed period, broken into runtime ventilation (left bar) and continuous exhaust (right bar) periods ................................................................... 33

Figure 17. Overall AER determined in each of the RTV and CEV homes in the first summer sampling

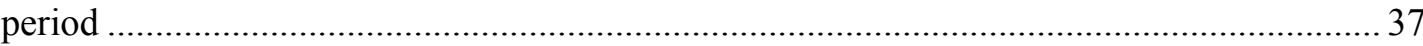

Figure 18. Overall AER determined in each of the RTV and CEV homes in the winter sampling period. 37

Figure 19. Overall AER determined in each of the RTV and CEV homes in the second summer sampling period

Figure 20. Relationship of percent difference in AER (calculated as [CEV-RTV]/RTV) and percent difference in $\mathrm{CO}_{2}$ concentration (calculated as [RTV-CEV]/RTV) for first summer sampling

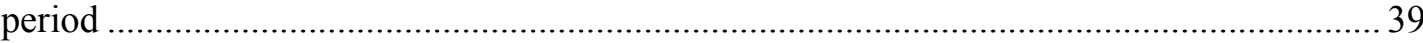

Figure 21. Relationship of percent difference in AER (calculated as [CEV-RTV]/RTV) and percent difference in $\mathrm{CO}_{2}$ concentration (calculated as [RTV-CEV]/RTV) for winter/mixed sampling period

Figure 22. Relationship of percent difference in AER (calculated as [CEV-RTV]/RTV) and percent difference in $\mathrm{CO}_{2}$ concentration (calculated as [RTV-CEV]/RTV) for second summer sampling period

Figure 23. Concentrations of formaldehyde (ppb) in Home 1 through Home 10 during the first summer IAQ sampling period.

Figure 24. Concentrations of formaldehyde ( $\mathrm{ppb}$ ) in Home 1 through Home 10 during the winter IAQ sampling period.

Figure 25. Concentrations of formaldehyde (ppb) in Home 1 through Home 10 during the second summer IAQ sampling period. 
Figure 26. Absolute (ppb) and percent (\%) difference in concentrations of formaldehyde in Home 1 through Home 10 during the first summer IAQ sampling period

Figure 27. Absolute (ppb) and percent (\%) difference in concentrations of formaldehyde in Home 1 through Home 10 during the winter IAQ sampling period

Figure 28. Absolute (ppb) and percent (\%) difference in concentrations of formaldehyde in Home 1 through Home 10 during the second summer IAQ sampling period

Figure 29. Concentrations of formaldehyde (ppb) in all homes during all sampling periods.................... 46

Figure 30. Concentrations of acetaldehyde (ppb) in all homes during all sampling periods .................... 47

Figure 31. Concentrations of acetaldehyde (ppb) in Home 1 through Home 10 during the first summer IAQ sampling period

Figure 32. Concentrations of acetaldehyde (ppb) in Home 1 through Home 10 during the winter IAQ sampling period

Figure 33. Concentrations of acetaldehyde (ppb) in Home 1 through Home 10 during the second summer IAQ sampling period. 48

Figure 34. Absolute (ppb) and percent (\%) difference in concentrations of acetaldehyde in Home 1 through Home 10 during the first summer IAQ sampling period

Figure 35. Absolute (ppb) and percent (\%) difference in concentrations of acetaldehyde in Home 1 through Home 10 during the winter IAQ sampling period

Figure 36. Absolute (ppb) and percent (\%) difference in concentrations of acetaldehyde in Home 1 through Home 10 during the second summer IAQ sampling period.

Figure 37. Total concentration of 10 detected VOCs of concern (ppb) in Home 1 through Home 10 during

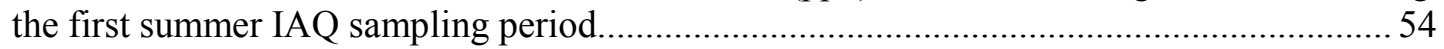

Figure 38. Total concentration of 10 detected VOCs of concern (ppb) in Home 1 through Home 10 during

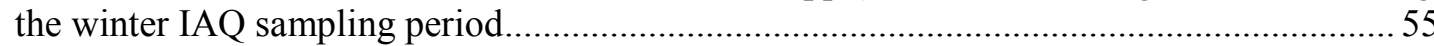

Figure 39. Total concentration of 10 detected VOCs of concern (ppb) in Home 1 through Home 10 during

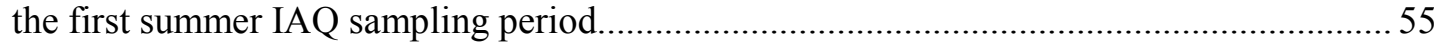

Figure 40. Concentration of total volatile organic compounds (TVOC; ppb) in Home 1 through Home 10

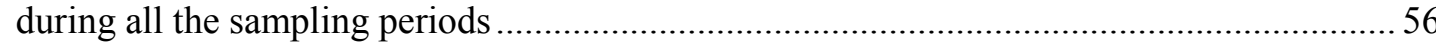

Figure 41. Total concentration of 10 detected VOCs of concern (ppb) in Home 1 through Home 10 during the all of the sampling periods . .56

Figure 42. Average concentration of $\mathrm{NO}_{2}(\mathrm{ppb})$ in homes with gas cooking and homes without gas cooking in the RTV and CEV configurations, corrected for outdoors..................................58

Figure 43. Average decrease in concentration of $\mathrm{NO}_{2}(\mathrm{ppb})$ as a result of switching from RTV to CEV configurations in homes with gas cooking and homes without, corrected for outdoors .........58

Figure G-1. Full year plot of average hourly indoor dew point temperature for six flip-flop homes plus hourly outdoor dew point and average daily dry bulb temperatures from 6/28/2013 to $8 / 19 / 2014$

Figure H-1. Hourly indoor conditions for Home 1

Figure H-2. Hourly indoor conditions for Home 2

Figure H-3. Hourly indoor conditions for Home 3

Figure H-4. Hourly indoor conditions for Home 4

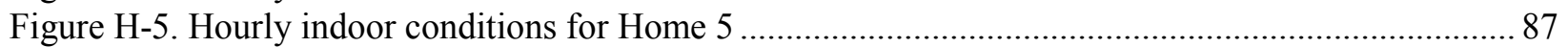

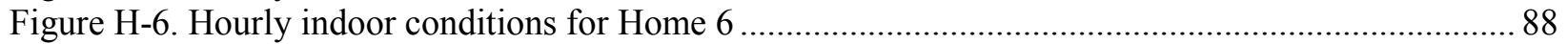

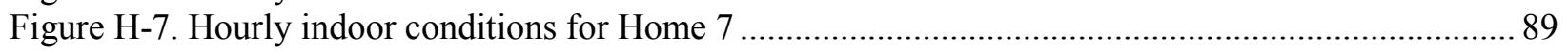

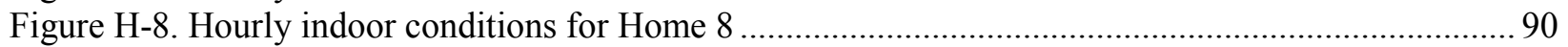

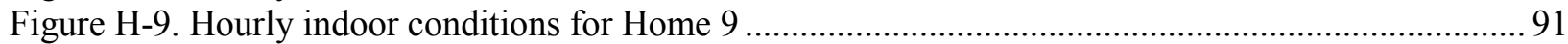

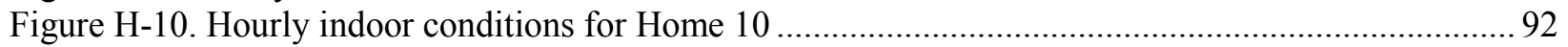




\section{List of Tables}

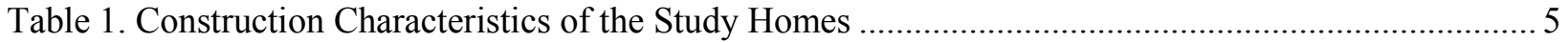

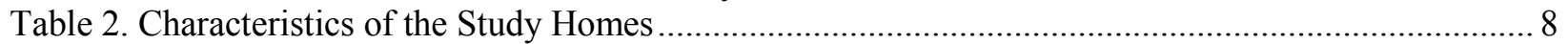

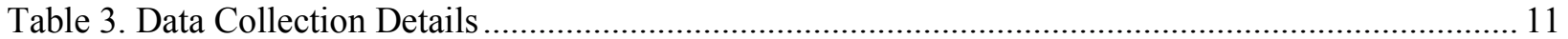

Table 4. Summary of Monitored Data over the Summer Period, Averaged for the Six Flip-Flop Homes. 24

Table 5. Comparison of Monitored and Simulated Data over the Summer 2013 Period ......................... 25

Table 6. IAQ Sampling Time Periods and Configuration of Flip-Flop Homes ........................................ 34

Table 7. Timing of IAQ Sampling and Ventilation Flip-Flop During the First Summer Sampling Period 34

Table 8. Forty-Four "Overall VOC" Pollutants .................................................................................... 51

Table 9. Average Concentration (ppb) of 30 Most Commonly Observed VOCs in Each House over All Sampling Periods, in All Houses over All Sampling Periods, and Total Concentration (ppb) of 30 Most Commonly Observed VOCs in Each House over All Sampling Periods ............. 52

Table 10. Average Radon Concentration (pCi/L) in All Houses over the Entire Sampling Period (June

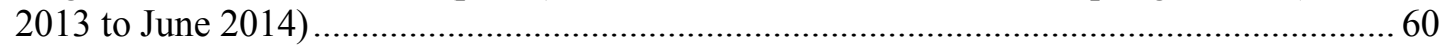

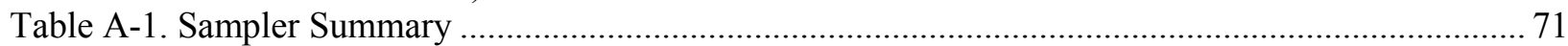

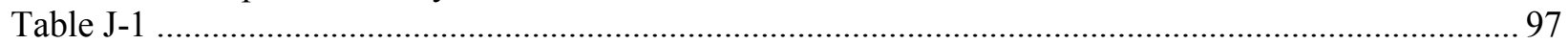

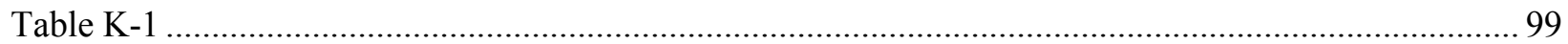

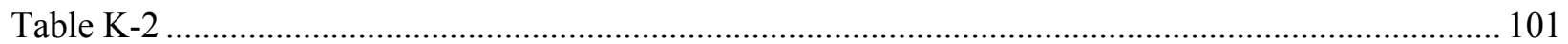

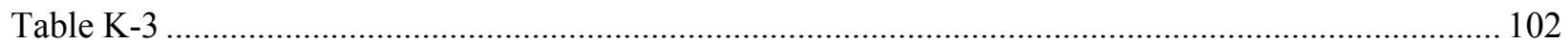

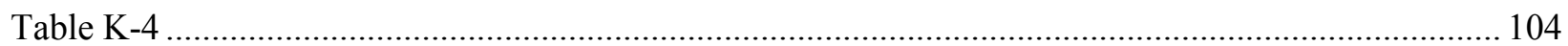

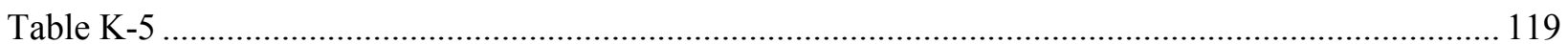




\section{Definitions}

ACH 50

AER

AHU

BEopt

cfm

CEV

CFIS

CFM 50

CFM 25 out $/ \mathrm{ft}^{2}$

$\mathrm{CO}_{2}$

CT

DNPH

DOE

EPA

${ }^{\circ} \mathrm{F}$

Florida HERO

FSEC

$\mathrm{ft}^{2}$

GCMS

$\mathrm{HCHO}$

HPLC-UV

$\mathrm{hr}$

HVAC

IAQ

IC

LBNL

$\mathrm{mg}$

$\min$

$\mathrm{mL}$

$\mathrm{mm}$

n.d.

NIOSH

$\mathrm{NO}_{2}$

NREL

OSHA

$\mathrm{pCi} / \mathrm{L}$

PFT

PM2.5

$\mathrm{PMCH}$

PNNL

ppb air changes per hour at 50 pascals of depressurization with respect to the outside

air exchange rate

air handling unit

Building Energy Optimization

cubic feet per minute

continuous exhaust ventilation

central fan integrated supply

cubic feet per minute at 50 pascals of depressurization with respect to the outside

cubic feet per minute at 25 pascals of depressurization with respect to the house per conditioned square footage

carbon dioxide

current transducer

2,4-dinitrophenylhydrazine

U.S. Department of Energy

U.S. Environmental Protection Agency

degree(s) Fahrenheit

Florida Home Energy \& Resources Organization

Florida Solar Energy Center

square feet

gas chromatography with mass spectrometry

formaldehyde

high-performance liquid chromatography with ultraviolet detector hour(s)

heating, ventilation, and air-conditioning

indoor air quality

ion chromatography

Lawrence Berkeley National Laboratory

milligram(s)

minute(s)

milliliter(s)

millimeters

no date

National Institute for Occupational Safety and Health

nitrogen dioxide

National Renewable Energy Laboratory

Occupational Safety and Health Administration

picocuries per liter

perfluorocarbon tracer

particulate matter with aerodynamic diameter less than $2.5 \mu \mathrm{m}$

perfluoromethylcyclohexane

Pacific Northwest National Laboratory

parts per billion 
ppm

$\mathrm{RH}$

RTF

RTV

SEER

SOP

SRT

$\mathrm{T}$

TD

TEA

TVOC

VOC

Wh

$\mu \mathrm{g} / \mathrm{m}^{3}$ parts per million

relative humidity

runtime fraction

runtime ventilation

seasonal energy efficiency rating

standard operating procedure

single return with transoms

temperature

thermal desorption

triethanolamine

total volatile organic compounds

volatile organic compounds

watt-hour

micrograms per cubic meter 


\section{Acknowledgments}

The authors are grateful to Kevin Veach of Green Energy Options for conducting a portion of the field work, tirelessly troubleshooting monitoring equipment, and patiently interacting with the homeowners. The research team is also indebted to the homeowners, who opened their homes to the researchers and exhibited exceptional patience with the ambiguities and unpredictability of research. Rand Potter of ALS Laboratories/DataChem and his analysis team were helpful in analyzing indoor air quality samplers and Linda Coyne at SKC Inc. provided assistance in preparing the perfluorocarbon samplers and emitters for field deployment. The authors are also grateful to Brett Singer of Lawrence Berkeley National Laboratory, who provided valuable technical assistance, review of the experimental approach, and detailed review and suggestions for the final report.

Thank you also to Kathy Ertell, who guided the research team on the Human Subjects Review submission process; Michael Baechler, the PNNL project manager for this work; and the National Renewable Energy Laboratory for managing Building America activities at the team level. Also, this research would not be possible without the support of the project sponsors, Eric Werling and Sam Rashkin, the U.S. Department of Energy Project Managers for the Building America Program. 


\section{Executive Summary}

ASHRAE Standard 62.2, "Ventilation and Indoor Air Quality in Low-Rise Buildings," is the most commonly referenced residential ventilation standard in the United States. It is currently required by ENERGY STAR Version 3 (V3), the 2012 International Energy Conservation Code, the U.S. Department of Energy's Zero Energy Ready Home Program, many state weatherization programs, and many other home performance programs. The standard calls for ventilation levels that are perceived by some builders and contractors to cause indoor moisture issues in hot-humid climates unless mitigated by supplemental dehumidification systems, which increase overall energy consumption. Therefore, many high-performance home builders in a hot-humid climate use a supply ventilation strategy that delivers outside air only in conjunction with operation of the home's central heating and cooling system (runtime ventilation [RTV]), which results in ventilation air exchange rates that are significantly lower than ASHRAE 62.2.

In 2012 and 2013, Pacific Northwest National Laboratory (PNNL), Florida Solar Energy Center (FSEC), and Florida Home Energy \& Resources Organization (Florida HERO) began a collaborative effort to evaluate the impact of two different ventilation strategies on interior comfort conditions, space-conditioning energy use, and certain indoor air contaminant concentrations. Specifically, this report compares the builder-standard RTV system to an ASHRAE 62.2-compliant ventilation system using a continuous exhaust fan. The ASHRAE 62.2-compliant system was selected to represent the most likely ventilation system builders would employ were they required to comply with the ASHRAE 62.2 requirements because it is the least cost solution in most instances. Relevant parameters were measured in 10 homes in Gainesville, Florida, along with corresponding outdoor conditions, to characterize the impact of the two differing ventilation strategies. The study design grouped the homes into two cohorts: flip-flop homes and control homes. The first cohort of homes consisted of six of the 10 homes that were flip-flopped between the two ventilation strategies approximately every two weeks. The second cohort of homes consisted of two homes that remained in the RTV configuration throughout the study period and two homes that were maintained in the CEV configuration throughout the study period. This study design allows for the effects of individual occupants, inconsistencies between the homes, as well as the impact of climate, outdoor concentrations, or other biasing variables to be identified and accounted for in the analysis.

This report provides information about the data collection method and results from more than one year of data collection during a period from summer 2013 through summer 2014. Indoor air quality was sampled in three discrete periods with the first occurring in August/September 2013 (summer 1), the second occurring in March/April 2014 (winter/mixed), and the third occurring in August 2014 (summer 2).

During summer conditions the continuous exhaust ventilation (CEV) systems resulted in approximately $9 \%$ more cooling energy use on average to maintain the desired temperature set points in the homes. Ventilation strategy was found to be among the most significant variables driving the runtime of the air conditioners. Despite the added air conditioner runtime, the resulting relative humidity $(\mathrm{RH})$ was higher in the homes while under continuous exhaust, resulting in the CEV homes experiencing more hours of elevated $\mathrm{RH}(>60 \%$ and $>65 \% \mathrm{RH})$ than while under RTV. Regression analysis showed that ventilation strategy was the most significant 
variable tested in predicting hours $>60 \% \mathrm{RH}$, and slightly less significant in predicting hours $>65 \%$ RH. However, the extent and persistence of the elevated RH is variable among homes, suggesting other parameters are also impactful. In the short term, the observed elevated RH levels are not expected to cause durability problems, but they may impact occupant comfort. During the visits to the homes no signs of mold were observed, and few comfort complaints were logged. Because of the duration of the study, the long-term effect of elevated RH in these homes is unknown. Condensate collected during the summer of 2014 showed a causal relationship to ventilation strategy, and regression analysis revealed that condensate volumes are more highly correlated to occupancy. The relationship with occupancy suggests that interior moisture generation is not only a significant source of moisture; it is highly variable from day to day. Conditioned house size was also found to be significant, but in an inverse relationship; the larger the house, the less condensate was generated. One explanation is that a larger house has more capacity to buffer moisture than a smaller house.

During the mixed season between October and April, homes operated under a mix of heating, cooling, and floating space-conditioning operations. Space-conditioning and natural ventilation preferences are highly variable during this period, and analysis of limited heating data did not show a significant impact related to ventilation strategy. Ventilation strategy appears to have a statistically significant, but overall minor impact on indoor RH during the mixed period compared to the summer period, and RH trends seem to be dominated by other factors including outdoor conditions and occupant preferences.

Carbon dioxide $\left(\mathrm{CO}_{2}\right)$ data, which show higher average $\mathrm{CO}_{2}$ levels in homes with RTV systems, indicate that such systems may generate less air exchange and less of a dilution effect than the continuous exhaust systems. However, preferences for enhanced natural ventilation during the mixed period that could counteract this effect and variable occupancy and operation of the homes do not allow a definitive conclusion to be drawn. The estimated air exchange rate (AER) calculated during the indoor air quality (IAQ) sampling periods also corroborated such trends in the winter or mixed sampling periods. Specifically, the CEV ventilation strategy resulted in 30\% higher AERs than the RTV configuration in the flip-flop homes and 79\% higher mechanical ventilation rates on average. However, comparing the relative increase in estimated AER to the relative decrease in $\mathrm{CO}_{2}$ shows that an increase in AER did not consistently result in a decrease in average $\mathrm{CO}_{2}$ concentration during the IAQ sampling periods. While concentrations of $\mathrm{CO}_{2}$ may be variable due to occupancy or other factors, this may suggest that the CEV ventilation strategy is not in fact increasing the dilution rate in all areas of the home as much as the increase in AER might suggest.

Despite the fact that CEV systems may generate greater air exchange in some seasons, there is also some question about the unknown source of the ventilation air, and therefore the potential for a negative impact on IAQ.

Concentrations of formaldehyde, acetaldehyde, volatile organic compounds (VOCs), and nitrogen dioxide $\left(\mathrm{NO}_{2}\right)$ were determined in paired sampling periods during the summer of 2013, winter of 2013/2014, and summer of 2014. While the observed concentrations of sampled contaminants are variable among the homes and suggest the importance of occupant activities and behavior, analyses of the data indicate that increased ventilation via a continuous exhaust 
fan, as was employed in the CEV strategy, may not be effective in decreasing concentrations of all IAQ contaminants, consistent with the findings for $\mathrm{CO}_{2}$. Concentrations of formaldehyde, acetaldehyde, and VOCs did not show a significant dependence on ventilation approach, despite the presumed increased ventilation achieved via the CEV method, especially in the winter/mixed season. That is, operation using the CEV method, which provides significantly higher continuous mechanical ventilation rates than the RTV method, did not significantly decrease observed concentrations of formaldehyde, acetaldehyde, and VOCs. Generally, the concentrations of VOCs and aldehydes appeared slightly higher in the RTV homes compared to the CEV homes, although in some cases concentrations were observed to increase in the CEV configuration. As a result, consistent and significant trends were not discernable from the data due to variability among the homes and between sampling periods in the same home.

This contradicts findings from previous researchers that concentrations of IAQ contaminants exhibit an inverse relationship to ventilation rate (Lajoie et al. 2015; Hult et al. 2014). The fact that the concentrations of formaldehyde, acetaldehyde, and VOCs measured in this study were variable and not correlated to a change in ventilation strategy, despite the higher ventilation rates achieved by the CEV system, suggests that other factors in addition to ventilation rate, such as ventilation system design (i.e., balanced versus supply-only versus exhaust-only and distributed versus non-distributed), may be important in determining the efficacy of a ventilation system in achieving the desired dilution effect. Hun et al. (2014) has also observed that supply-based systems may be more effective at reducing formaldehyde concentrations than exhaust-based systems. Conversely, $\mathrm{NO}_{2}$, which was measured in two homes (one with gas cooking and one without) during each sampling period, appeared to be effectively mitigated by the CEV method. While this may suggest that for some sources of pollutants, such as those generated by cooking, the efficacy of the ventilation system may be less affected by ventilation system design, the data are not sufficient to draw definitive conclusions.

While the concentrations of acetaldehyde, $\mathrm{VOCs}$, and $\mathrm{NO}_{2}$ were far below exposure levels established by health-based exposure guidelines and are not likely to cause negative health effects at these low levels, formaldehyde concentrations were, on average, above the exposure limit of 16 parts per billion ( $\mathrm{ppb}$ ) recommended by the National Institute for Occupational Safety and Health. Future work to further explore the efficacy of different ventilation systems and disaggregate the impact of ventilation rate and system type is necessary to understand how to apply these findings in the field to achieve optimum IAQ and homeowner comfort in new homes for the least cost and lowest energy impacts. 


\section{Introduction}

Whole-building air exchange is required to maintain healthy indoor air quality (IAQ) in residential buildings. Air exchange is intended to dilute indoor air pollutants with outdoor air with the goal of maintaining concentrations below levels that may lead to negative health impacts. Other components that make up a comprehensive strategy for IAQ include limiting materials and activities that provide the source of pollutants, and employing local exhaust in dedicated areas where high concentrations of contaminants are likely to occur (e.g., kitchens).

Several residential codes and standards require whole-building mechanical ventilation in addition to natural air exchange (Martin 2014). The various differences among these requirements, along with the lack of mechanical ventilation requirements in many state and local codes, indicate that there is some uncertainty regarding the perceived appropriate level of ventilation in different geographic or climate regions. ASHRAE Standard 62.2, "Ventilation and Indoor Air Quality in Low-Rise Buildings" (ASHRAE 2013b) is the most commonly referenced residential ventilation standard in the United States. It is currently required by ENERGY STAR Version 3 (V3), the 2012 International Energy Conservation Code, U.S. Department of Energy's (DOE's) Zero Energy Ready Home Program, many state weatherization programs, and many other home performance programs (EPA 2013; DOE 2014).

However, in a hot-humid climate, many builders of high-performance homes and their mechanical contractors have expressed concern that the ventilation rates prescribed by ASHRAE Standard 62.2-2013 call for greater amounts of whole-building controlled ventilation than what they have grown accustomed to and are comfortable with. Some state that the ASHRAE 62.22013 ventilation rates are too high and believe they will lead to increased energy consumption, increased risk of mold growth, and comfort concerns. While whole-building mechanical ventilation is important to maintain good IAQ, in high-performance housing, humidity control is becoming increasingly important to maintain good IAQ, occupants' comfort, and the durability of the home. Reduced sensible loads in new and existing high-performance houses call for reduced space-conditioning capacity and runtime, thereby reducing incidental dehumidification from air-conditioning operation. In addition, latent generation in high-performance homes is typically not reduced along with the sensible loads. Given this, some builders and contractors in hot-humid climate regions are concerned about the implications associated with introducing additional humid outside air via ventilation systems into new high-performance houses that have a decreased capacity to remove excess moisture.

Data directly relating the effect of mechanical ventilation to IAQ in occupied homes in a hothumid climate are limited. Several studies have demonstrated that contaminant concentrations typically decrease with higher ventilation rates (Lajoie et al. 2015; Hult et al. 2014; Offermann 2009; Hun et al. 2014). However, Hun et al. (2014) and Rudd and Bergey (2013) have demonstrated that supply-based systems may be more effective at reducing formaldehyde concentrations than exhaust-only systems.

In practice, effective IAQ is often judged by perceptions of odor and moisture control, which have little to do with occupants' health. 
Regarding the energy and comfort impacts of different ventilation strategies, the DOE Building America Program has been conducting research leading to optimization of residential building energy performance, durability, quality, affordability, and comfort for more than 15 years. Integrating whole-house mechanical ventilation has been an ongoing aspect of the program's research. Tens of thousands of homes have been constructed as part of this research, and many different approaches to whole-house mechanical ventilation have been incorporated and evaluated. Martin (2014) reviewed some of this experience and provided detailed results of simulations conducted to quantify the relationship between ventilation rate and supplemental dehumidification energy required to maintain comfort. However, few monitored data are available that compare energy use and moisture levels of differing ventilation approaches in homes in a hot-humid climate.

To balance factors related to comfort, energy use, and odor and moisture control, some builders of high-performance homes in hot-humid climates are using a supply-based whole-house mechanical ventilation strategy linked to the runtime of the central heating, ventilation, and airconditioning (HVAC) system - often termed "central fan integrated supply" or CFIS (Chandra 2008; Rudd and Lstiburek 2008). This system has been employed since the mid-1990s and has been implemented in thousands of homes (Chandra 2008; Rudd and Lstiburek 2008). Outdoor air flow rates induced by the central system fan, and hence ventilation air volumes, have varied from $1 \%$ to more than $100 \%$ of ASHRAE 62.2-2013-required rates for continuous fan flow. Because of energy and comfort concerns, rather than delivering the outdoor air continuously-many builders that implement a CFIS whole-house mechanical ventilation system include a fan-cycling controller that enables delivery of outdoor air on a timed schedule, often 10 minutes on and 20 minutes off. Other builders have opted to only deliver mechanical ventilation during heating and cooling operation, which is termed runtime ventilation (RTV).

Some data have been collected on indoor relative humidity $(\mathrm{RH})$ and space-conditioning energy use in homes with CFIS systems, but these data do not address the potential for health issues associated with ventilation provided by such systems. Kerrigan (2014) reported results from homes with CFIS systems and fan cycling controllers in a hot-humid climate, both with and without supplemental dehumidifiers (Kerrigan 2014). Some data on temperature and RH have been collected in homes using the RTV system as well. In general, surveyed homeowners have expressed satisfaction with the resulting conditions. Figure 1 shows representative data from a study conducted by Pacific Northwest National Laboratory involving 10 recently constructed high-performance homes in Gainesville (Alachua County), Florida. ${ }^{1}$ As seen in the figure, $\mathrm{RH}$ is maintained well below $60 \%$ on average during months with consistent air conditioner operation. Excursions approaching and exceeding $60 \%$ are evident during swing season months that feature inconsistent and little air conditioner operation. However, the authors note that while comfort and homeowner satisfaction are important metrics for determining overall HVAC performance, they are not good indicators of IAQ because some IAQ contaminants are not easily perceived by humans at chronic levels that can be harmful to human health. RH is also elevated during the winter months with sporadic heating operation resulting in minimal mechanically induced air

\footnotetext{
${ }^{1}$ Widder S., and K. Fonorow. 2013 [unpublished]. "Don’t Waste Your Money: The Performance of Passive Transom Returns as a Return Air Strategy in High Performance Homes."
} 
exchange. The temperature was maintained, on average, between 71 and $76^{\circ} \mathrm{F}$ throughout the period studied.

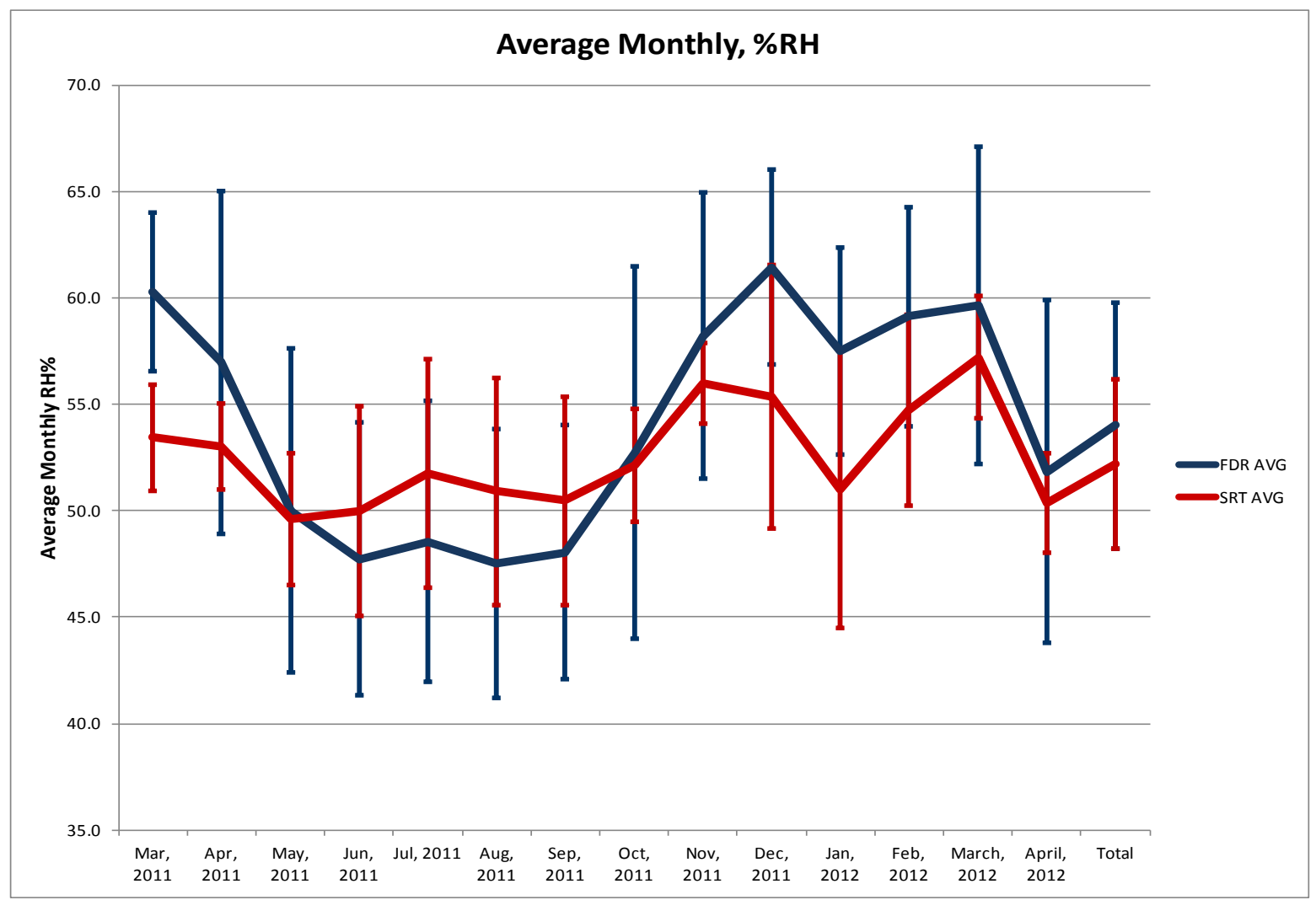

Figure 1. Average and range of monthly RH for fully ducted return (FDR) and single return with transoms (SRT) homes with the runtime ventilation system in Gainesville, Florida

This report describes a yearlong field study in which PNNL, Florida Solar Energy Center (FSEC), and Florida Home Energy \& Resources Organization (Florida HERO) collected data to evaluate the impact of ventilation on energy use, interior moisture levels, and indoor air contaminant concentrations. Specifically, concentrations of indoor air contaminants, ventilation system flow rates, building infiltration rates, space-conditioning energy use and condensate generation, indoor temperatures, and RH were measured in 10 occupied high-performance homes in Gainesville, Florida, that operated with two different ventilation strategies:

- The runtime ventilation (RTV) system originally provided with the homes, which delivers approximately $16 \%$ of ASHRAE 62.2-2013 requirements annually ${ }^{2}$ and provides an average flow rate of 35 cubic feet per minute $(\mathrm{cfm})$ during heating/cooling operation.

\footnotetext{
${ }^{2}$ This figure was calculated based on the run time of the air handling unit and measured flow through the supply air duct; see Section 3.2.1.
} 
- A continuous exhaust ventilation (CEV) approach that approximates ASHRAE 62.2-2013 requirements for whole-house mechanical ventilation and provides an average of $60 \mathrm{cfm} 24$ hours a day.

To achieve the target continuous exhaust flow, a bathroom exhaust fan in each home was replaced with a larger capacity fan. The study design grouped the homes into two cohorts: "flipflop" homes and control homes. The first cohort consisted of 6 of the 10 homes that were flipflopped between the two ventilation strategies approximately every two weeks. The second cohort consisted of two homes that remained in the RTV configuration throughout the study period and two homes that were maintained in the CEV configuration throughout the study period. This study design allowed for the effects of individual occupants and inconsistencies among homes to be mitigated by the flip-flop homes because the two ventilation strategies were compared in the same home. The design assumed that behavior and home operation are substantially the same from one week to another in each home. In addition, the control homes (RTV and CEV) allowed for the impacts of climate, outdoor concentrations, or other biasing variables impacting all the houses to be identified and accounted for in the analysis. The control house cohorts also allowed for the observation of any long-term or seasonal impacts resulting from the different ventilation strategies.

The remainder of this report describes the materials and methods, results, and conclusions from this yearlong study. Section 2 presents the methods used for data collection, including details on the study design and instrumentation. Section 3.1 describes the study results for the continuously monitored variables, including temperature, relative humidity, energy, and carbon dioxide $\left(\mathrm{CO}_{2}\right)$. Section 3.2 describes the IAQ results. Section 4 presents the key conclusions from the study and highlights opportunities for future work. 


\section{Materials and Methods}

Precise equipment and data collection methods are required to collect robust data and reduce measurement errors. The following sections describe the study logistics, including the study location and schedule (Section 2.1) and the monitoring equipment and data collection procedure (Section 2.2).

\subsection{Logistics}

Space-conditioning energy use, indoor temperature, indoor RH, and outdoor conditions were monitored continuously throughout the study, which spanned the summer of 2013 and the summer of 2014. Condensate was collected during the summer of 2014 only. IAQ sampling was conducted in three paired IAQ analysis periods, designed to capture the difference between higher and lower levels of ventilation produced by the RTV systems, which are driven by spaceconditioning system runtime, during different seasons in a hot-humid climate. The IAQ analysis periods occurred in August/September 2013, March/April 2014, and August 2014. The following sections describe the10 study homes in Gainesville, Florida (Section 2.1.1), the IAQ sampling schedule (Section 2.1.2), and the IAQ contaminants of concern identified for monitoring in this study (Section 2.1.3).

\subsubsection{Study Location and Study Homes}

Some of the 10 homes in which data were collected were selected based on occupants' participation in a previous study, while other similar homes in the same community constructed at the same time by the same builder were recruited specifically for this study. The homes were all newly occupied in 2009 and 2010, are in the same subdivision, have similar specifications, and were built to Builders Challenge 1.0 guidelines (see Table 1). ${ }^{3}$ Most homes are single story, ${ }^{4}$ slab-on-grade, with ductwork located in vented attics. The HVAC systems in the homes are single-stage heat pumps with a seasonal energy efficiency rating (SEER) of 15 or 16 that employ the RTV system.

Table 1. Construction Characteristics of the Study Homes

\begin{tabular}{l|l}
\hline Building Envelope & Characteristics \\
\hline Roof finish/attic & Medium shingle roof, radiant barrier, and vented attic \\
\hline Roof/ceiling insulation & R30 blown, 10" heel truss/R19 knee walls \\
\hline Wall type & $2 \times 416 "$ on-center frame with ladder T and two-stud corners \\
\hline Wall insulation & R-13 cellulose \\
\hline Windows & Double pane, low-E (U-0.34, SHGC-0.25) \\
\hline Floors & Slab-on-grade, 70\% tile, and 30\% carpet \\
\hline
\end{tabular}

\footnotetext{
${ }^{3}$ The Builders Challenge was a program sponsored by the U.S. Department of Energy's Building America program to promote high-performance new homes and new home builders. Since the construction of the study homes, the program has been revised and renamed it is now referred to as the Zero Energy Ready Home (ZERH) program. For more information, see http://energy.gov/eere/buildings/zero-energy-ready-home.

${ }^{4}$ One home has a second-floor "bonus" room.
} 


\begin{tabular}{l|l}
\hline Building Envelope & Characteristics \\
\hline HVAC System & \\
\hline Heating and cooling system & $\begin{array}{l}\text { Air source heat pump, 15-16 SEER/9-9.6 HSPF, program. } \\
\text { T-stat }\end{array}$ \\
\hline Capacity & $\begin{array}{l}2.0 \text { to } 2.5 \text { tons } \\
\text { Interior closet }\end{array}$ \\
\hline Air handler location & Runtime ventilation system, kitchen and bath exhaust to out \\
\hline Ducts and location & Supply: R6 flex in vented attic; return: mix of ducted and un-ducted \\
\hline Water heating & "Tankless" gas EF-0.82 \\
\hline Lighting & $100 \%$ fluorescent \\
\hline Appliances & Energy Star \\
\hline
\end{tabular}

A schematic of the RTV system is shown in Figure 2. The RTV system only delivers outdoor air during heating or cooling operation, and it has no provisions for enhanced humidity control beyond the standard latent capacity of the air conditioner.

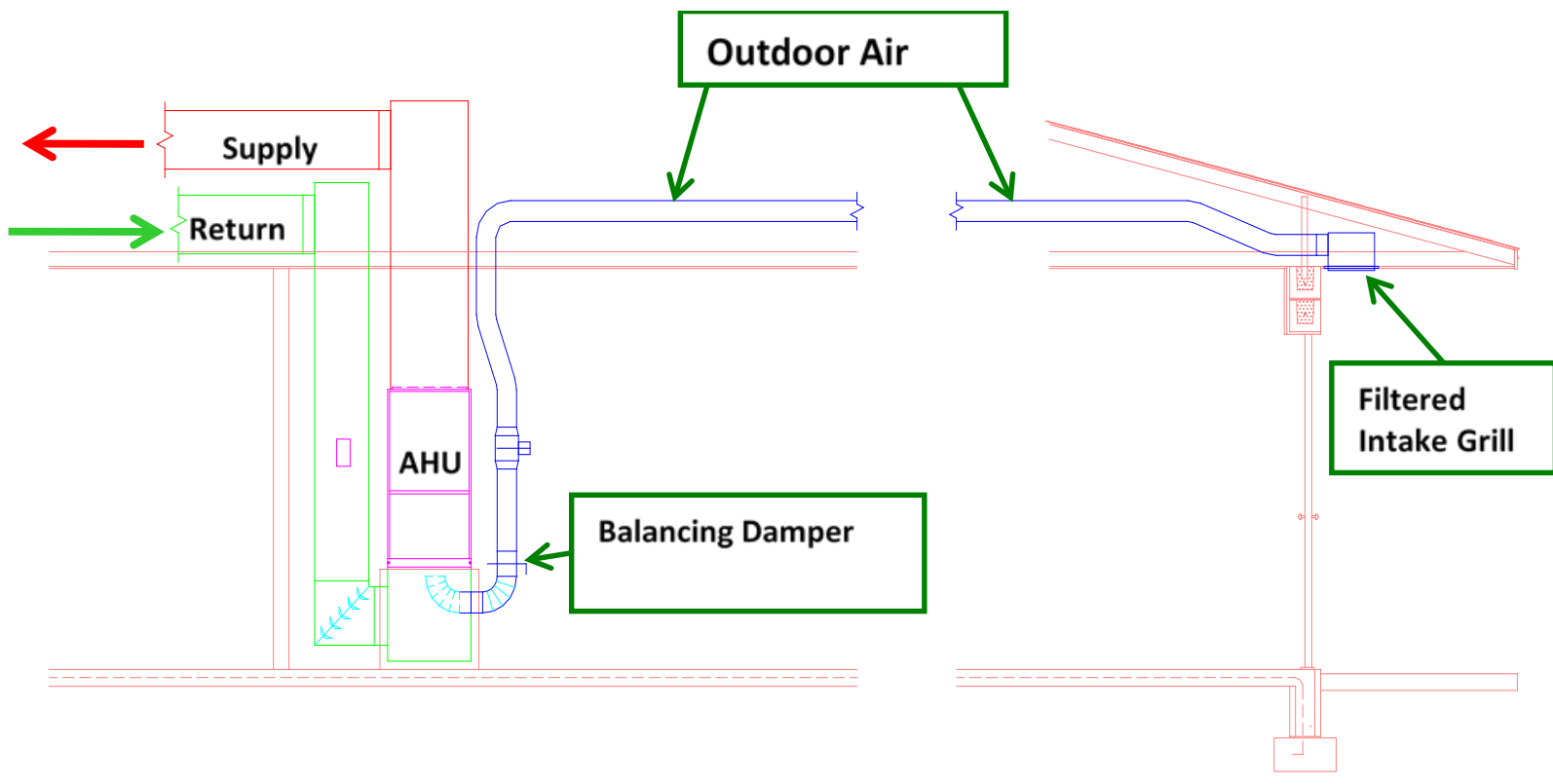

Figure 2. Schematic of runtime ventilation system

$\mathrm{AHU}=$ air handling unit

CEV was induced in flip-flop and CEV control homes through continuous operation of a bathroom exhaust fan. An existing bath fan was replaced with an ENERGY STAR fan, rated at $110 \mathrm{cfm}$, for this purpose, along with 6" insulated flex duct connecting the fans to the existing 
roof jack. Restrictions in fan ducting and roof terminations severely degraded the capacity of the newly installed fans, with installed flow rates ranging from 54 to $78 \mathrm{cfm}^{5}$ (see Table 2).

Occupants were instructed to operate the homes and use the fans as they normally do. During periods of CEV, switch posts were installed under existing switches to control fan operation and lock them in the "on" position to prevent accidental disruption of the continuous ventilation flow by the occupants, and the RTV outdoor air flow was blocked at the intake (external to the home).

Characteristics specific to the homes, including parameters measured as part of this study are shown in Table 2. These include whether the home was part of the flip-flop group or the RTV/CEV control group, the conditioned floor area in square feet $\left(\mathrm{ft}^{2}\right)$, building air leakage in air changes per hour at 50 pascals of depressurization with respect to the outside (ACH50), relative duct leakage to the outside in terms of cubic feet per minute at 25 pascals of depressurization with respect to outdoors per conditioned square footage (CFM $\left.25 \mathrm{out} / 100 \mathrm{ft}^{2}\right)$, the steady-state RTV flow rate in cubic feet per minute $(\mathrm{cfm})$, the CEV fan flow rate in $\mathrm{cfm}$, the ASHRAE 62.2-2010 ventilation fan requirement in $\mathrm{cfm}$, and the higher ASHRAE 62.2-2013 ventilation fan requirement. Except for one case, the ventilation rates provided by the exhaust fans in the homes achieved the ventilation required by ASHRAE 62.2-2010, but most did not achieve the flow rate required by ASHRAE 62.2-2013. Both the ASHRAE 62.2-2010 and ASHRAE 62.2013 ventilation flow rates were calculated using the infiltration credits allowed for in the standards, based on the measured infiltration rate (ACH50) of the homes.

\footnotetext{
${ }^{5}$ One home had a very short exhaust duct run that enabled it to achieve $78 \mathrm{cfm}$ while the remainder of the homes were in 55-64 cfm range.
} 
Table 2. Characteristics of the Study Homes

\begin{tabular}{l|l|l|l|l|l|l|l|l|l}
\hline Home & Cohort & $\begin{array}{l}\text { Area } \\
\mathbf{f t t}^{2} \text { ) }\end{array}$ & $\begin{array}{l}\text { Bedro } \\
\text { oms }\end{array}$ & $\begin{array}{l}\text { Occupants } \\
\text { (Adult/Child) }\end{array}$ & ACH50 & Qn, out & $\begin{array}{l}\text { RTV } \\
\text { Flow }\end{array}$ & $\begin{array}{l}\text { Exhaust } \\
\text { Fan Flow }\end{array}$ & $\begin{array}{l}\mathbf{6 2 . 2 - 2 0 1 0 / 2 0 1 3 ~ F a n ~} \\
\text { Req. (cfm) }\end{array}$ \\
\hline $1^{\text {a }}$ & Flip-flop & 2,158 & 5 & $2 / 2$ & 5.1 & 3.4 & 40 & 57 & $67 / 71$ \\
2 & Flip-flop & 1,508 & 3 & $2 / 2$ & 4.4 & NA & 34 & 55 & $45 / 52$ \\
\hline 3 & CEV & 1,542 & 3 & $1 / 2$ & 3.0 & 2.2 & N/A & 54 & $45 / 60$ \\
\hline 4 & Flip-flop & 1,984 & 4 & $2 / 0$ & 3.4 & 3.0 & 26 & 55 & $57 / 73$ \\
\hline 5 & CEV & 1,950 & 4 & $2 / 2^{\text {c }}$ & 3.0 & 1.6 & NA & 59 & $57 / 75$ \\
\hline 6 & Flip-flop & 1,679 & 3 & $2 / 0$ & 3.5 & 1.8 & 42 & 55 & $47 / 60$ \\
\hline $\mathbf{8}$ & RTV & 1,878 & 4 & $2 / 3$ & 3.4 & 1.0 & 35 & NA & $56 / 71$ \\
\hline 9 & Flip-flop & 1,508 & 3 & $1 / 1$ & 2.9 & 1.5 & 39 & 78 & $45 / 60$ \\
\hline \hline & Flip-flop & 1,542 & 3 & $3 / 0$ & 4.8 & 2.0 & 24 & 64 & $45 / 50$ \\
\hline & RTV & 2,416 & 4 & $2 / 1$ & 2.6 & 4.6 & 37 & NA & $62 / 87$ \\
\hline & $\begin{array}{l}\text { Flip-flop } \\
\text { average }\end{array}$ & $\mathbf{1 , 7 3 0}$ & $\mathbf{3 . 5}$ & $\mathbf{2 . 0 / 0 . 8}$ & $\mathbf{4 . 0}$ & $\mathbf{2 . 1}$ & $\mathbf{3 4}$ & $\mathbf{6 1}$ & $\mathbf{5 1 / 6 1}$ \\
\hline
\end{tabular}

a Home 1 dropped from the study in January 2014.

b Duct leakage for Home 2 was not obtained.

c Home 5 dropped from the study in July 2014.

${ }^{d}$ Home 6 became an RTV control home in June 2014.

e Home 8 was sold in June 2014. 
Figure 3 shows the general specification for the homes results in a predicted annual source energy savings of $26 \%$ and $29 \%$ over the Building America Benchmark ${ }^{6}$ for continuous exhaust (modeled as ASHRAE 62.2-2010) and runtime ventilation systems, respectively. Simulations were conducted using the National Renewable Energy Laboratory's (NREL's) Building Energy Optimization (BEopt) software Version 2.1.0.2.

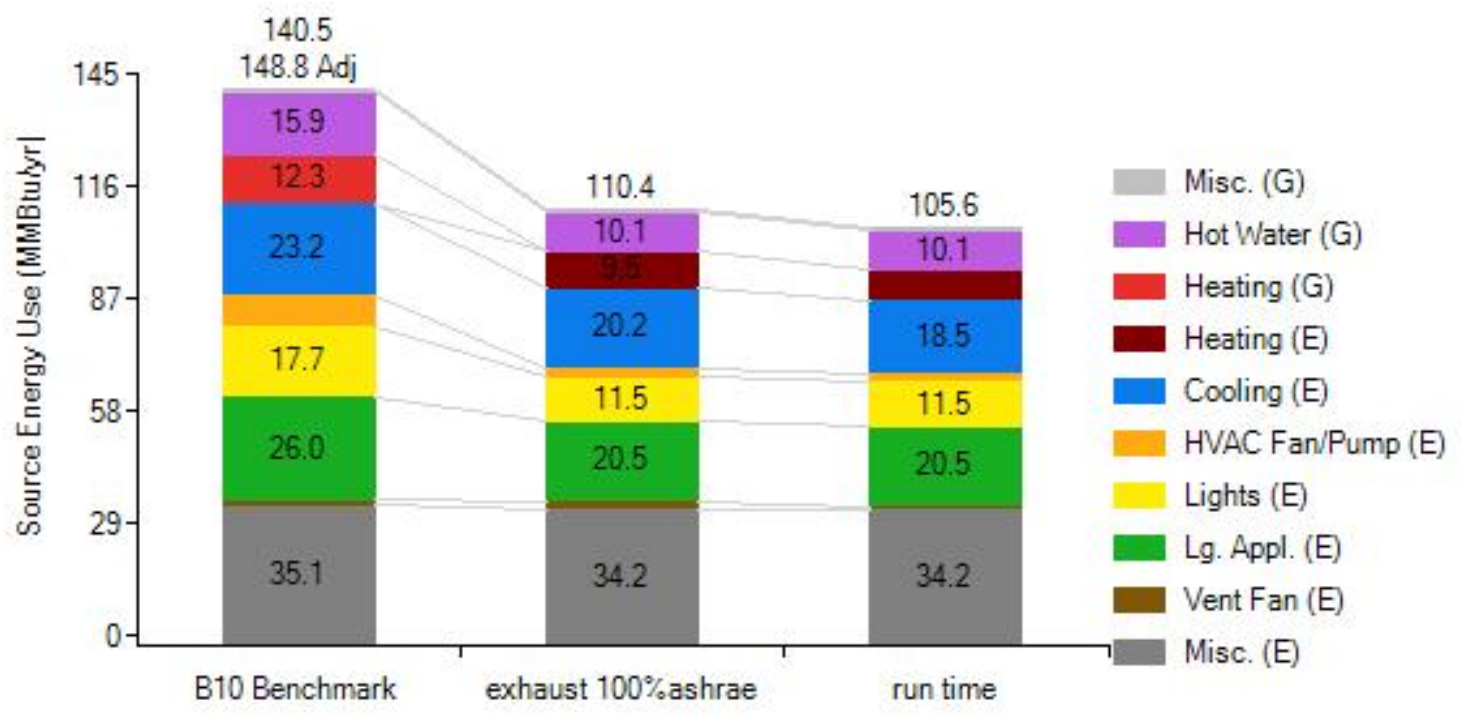

Figure 3. Whole-house source energy use predicted by BEopt software

\subsubsection{Experimental Schedule}

The homes were divided into two cohorts: (1) four control homes that are maintained in the same ventilation operating strategy for the duration of the study, consisting of two CEV control homes and two unmodified RTV control homes and (2) six homes that are varied, or "flip-flopped," biweekly (i.e., every other week) between CEV and RTV. The control cohort of homes provides useful data regarding the seasonality of moisture and IAQ levels in homes, and it may provide additional insights regarding any longer-term effects of increased ventilation rates. The homes that were flip-flopped enable comparison of the two ventilation systems in the same home during similar weather and occupancy periods.

Approximately once each season, in the second week of a two-week ventilation period (to enable achievement of equilibrium), IAQ sampling and tracer gas sampling took place. One-week sampling periods were chosen to characterize longer-term exposures in homes, including any weekly or daily variations. For example, different occupancy patterns on weekdays versus weekends could affect the average concentrations of constituents of concern. While the passive sampling method does not allow for quantifying the time-dependent variation of these parameters, the average long-term impact of any increased or decreased concentrations are

${ }^{6}$ The Building America Benchmark is consistent with the 2009 International Energy Conservation Code, with additional definitions that allow evaluation of all residential end uses consistent with typical homes built in 2010. 
reflected in the weekly time-averaged sample. IAQ sampling events were planned to differentiate seasonal changes in contaminants of concern. In the flip-flop homes, two week-long sampling periods were necessary for each sampling event to measure differences between continuous exhaust and runtime ventilation. In the side-by-side homes, each week-long sampling period could be compared to give an indication of the consistency of measured concentrations within each season in addition to the comparison between seasons.

This study evaluated radon concentrations on an annual basis to provide better resolution of the low levels of radon expected in the moderate risk area of Alachua County, where Gainesville, Florida, is located. To characterize the presence of mold or moisture-related problems, homes were visually inspected for mold and mildew during each IAQ sampling event and interior RH levels were continuously monitored throughout the study period.

\subsubsection{IAQ Contaminants of Concern}

The contaminants of concern in this study were chosen to characterize the IAQ in residential homes in Florida. Indoor air pollutants are introduced by a range of sources, including building materials or activities within the building, mold growth, combustion appliances, and outdoor pollutants (Spengler and Sexton 1983). Building-related pollutant sources consist of cleaning products, paints, adhesives, carpets and fabrics, pesticides, and synthetic building materials (Spengler and Sexton 1983; Weschler and Nazaroff 2008). The indoor air pollutants most commonly associated with building materials and building-related activities are formaldehyde and volatile organic compounds (VOCs) (Dales et al. 2008). A recent meta-analysis by Lawrence Berkeley National Laboratory (LBNL) identified 15 pollutants as chronic hazards in more than $50 \%$ of homes studied and 9 as priority pollutants in U.S. homes (Logue et al. 2010). The priority pollutants identified are select total volatile organic compounds (TVOC; acrolein, benzene, 1,3 butadiene, 1,4-dichlorobenzene, napthalene), formaldehyde and acetaldehyde, nitrogen dioxide $\left(\mathrm{NO}_{2}\right)$, and fine particulate matter (PM2.5). The concentrations of these contaminants are compared to relevant standard levels in Figure 4. In addition, radon and mold have been identified as constituents of concern in some climates (Committee on Health Risks of Exposure to Radon [BIER IV] 1999; Tsongas 2009). 


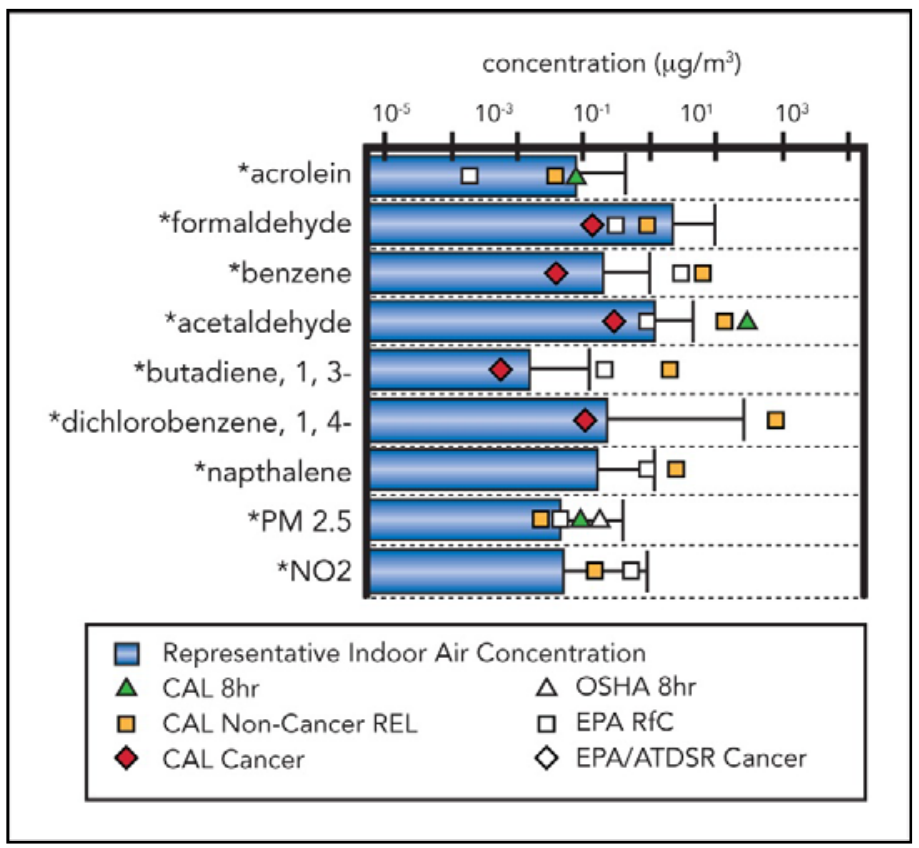

Figure 4. Nine priority pollutants in U.S. homes

Source: Logue et al. 2010

Higher levels of ventilation are expected to lower concentrations of pollutants that mostly originate from indoor sources via dilution, and many pollutants exhibit an inverse relationship to increased ventilation rate (i.e., 1/ $\mathrm{ACH}_{\mathrm{n}}$ ) (Lajoie et al. 2015; Hult et al. 2014). However, research has also shown that formaldehyde exhibits a nonlinear, or concentration-dependent, emission rate, whereby increased ventilation rates do not decrease concentrations as much as would be expected based on the increased dilution rate (Hult et al. 2014). In addition, the degree to which increased ventilation air reduces concentrations of some contaminants has been shown to be dependent on the ventilation system type, particularly with respect to formaldehyde concentrations (Hun et al. 2014; Offerman 2009; Rudd and Bergey 2013).

\subsection{Monitoring Equipment and Methodology}

Table 3 lists the various measurement parameters, measurement equipment, and sampling rates for the environmental, energy, and IAQ metrics.

Table 3. Data Collection Details

\begin{tabular}{|l|l|l|}
\hline \multicolumn{1}{|l|}{ Measurement } & Equipment Used & $\begin{array}{l}\text { Sampling/Storage } \\
\text { Interval }\end{array}$ \\
\hline $\begin{array}{l}\text { Initial Baseline Measurements } \\
\text { Infiltration (CFM 50) }\end{array}$ & Blower door & Initial baseline \\
$\begin{array}{l}\text { Runtime ventilation supply airflow } \\
\text { (cfm) }\end{array}$ & Exhaust fan flow meter & Initial baseline \\
\hline Exhaust fan flow (cfm) & Exhaust fan flow meter/powered flow & Initial baseline \\
\hline
\end{tabular}




\begin{tabular}{|c|c|c|}
\hline Measurement & Equipment Used & $\begin{array}{l}\text { Sampling/Storage } \\
\text { Interval }\end{array}$ \\
\hline & hood & \\
\hline \multicolumn{3}{|c|}{ Continuously Monitored Parameters } \\
\hline Total energy (Wh) & eMonitor (current transducer [CT]) & Hourly \\
\hline Air handler energy (Wh) & eMonitor (CT) & Hourly \\
\hline Condenser energy (Wh) & eMonitor (CT) & Hourly \\
\hline Bath fan circuit power (Wh) & eMonitor (CT) or U-12 HOBO (CT) & Hourly \\
\hline AC condensate $(\mathrm{mL} / \mathrm{hr})$ & HOBO Rain Gauge - RG3 & Hourly \\
\hline $\begin{array}{l}\text { Space temperature and } \mathrm{RH} \text { (4 } \\
\text { interior locations) }\end{array}$ & $\begin{array}{l}\text { (1) Extecha T/RH/CO } \\
\text { (3) U-10 HOBOs }\end{array}$ & $15 \mathrm{~min}$ \\
\hline Outdoor temperature and $\mathrm{RH}$ & Extech $\mathrm{T} / \mathrm{RH} / \mathrm{CO}_{2}$ & $15 \mathrm{~min}$ \\
\hline Interior $\mathrm{CO}_{2}(\mathrm{ppm})$ & Extech $\mathrm{CO}_{2} / \mathrm{T} / \mathrm{RH}$ & $15 \mathrm{~min}$ \\
\hline Outdoor $\mathrm{CO}_{2}(\mathrm{ppm})$ & Extech $\mathrm{CO}_{2} / \mathrm{T} / \mathrm{RH}$ & $15 \mathrm{~min}$ \\
\hline \multicolumn{3}{|l|}{ Seasonally Sampled Parameters } \\
\hline Formaldehyde (ppb) & Passive sorbent badge ${ }^{b}$ & $\begin{array}{l}\text { Weekly, four } \\
\text { events/year }\end{array}$ \\
\hline Acetaldehyde (ppb) & Passive sorbent badge ${ }^{b}$ & $\begin{array}{l}\text { Weekly, four } \\
\text { events/year }\end{array}$ \\
\hline VOCs (ppb) & Passive sorbent badge ${ }^{b}$ & $\begin{array}{l}\text { Weekly, four } \\
\text { events/year }\end{array}$ \\
\hline $\mathrm{NO}_{2} /$ nitrogen dioxide $(\mathrm{ppb})$ & Passive sorbent badge ${ }^{b}$ & $\begin{array}{l}\text { Weekly, four } \\
\text { events/year }\end{array}$ \\
\hline Infiltration $(\mathrm{ACH})$ & Perfluorocarbon Tracer (PFT) ${ }^{b}$ & Weekly, two events \\
\hline Mold ${ }^{c}$ & Visual inspection & $\begin{array}{l}\text { Every other week with } \\
\text { ventilation flip-flop } \\
\text { events }\end{array}$ \\
\hline Radon $^{d}$ & Charcoal passive badge & $\begin{array}{l}\text { Once-duration of } \\
\text { study }\end{array}$ \\
\hline
\end{tabular}

a The Extech device uses infrared technology to measure $\mathrm{CO}_{2}$.

${ }^{b}$ Passive infiltration and IAQ samplers were mailed to a laboratory for analysis. Analysis was performed using standard U.S. Environmental Protection Agency protocols for the identification of volatile organics (TO-17) and formaldehyde/acetaldehyde (TO-11A).

${ }^{c}$ Mold was sampled sporadically (i.e., it was observed every other week on flip-flop visits and especially in conjunction with the IAQ surveys prior to IAQ sampling events).

d Radon was sampled once with a passive measurement that extended through the duration of the study period (June 2013-June 2014).

IAQ sampling occurred at one to three indoor locations indoors in each home and at one outdoor location during each sampling period. Outdoor samples were collected in an open area, away from large trees, above the ground, and in areas sheltered from the elements. Indoor samples 
were collected in a commonly used room, usually the living room, as well as the master bedroom, a bedroom located farthest away from the return air grille, or both bedrooms.

Details about the sample collection methodology are discussed below. A detailed sampling protocol is included in Appendix A. A field data sheet is included in Appendix B. Quality assurance and quality control procedures are included in Appendix C. A table summarizing samplers, sensitivities, detection ranges, accuracy, and relevant standard levels is included in Appendix D. For additional information about the IAQ sample analysis, refer to the Laboratory Analysis Summary in Appendix F. Analysis of TVOC, formaldehyde ( $\mathrm{HCHO}), \mathrm{NO}_{2}$, and perfluorocarbon tracer (PFT) sample badges was conducted at ALS Laboratory Group (formerly DataChem Laboratories, Inc.), an American Industrial Hygiene Association-accredited laboratory, using the methods described below.

\subsubsection{Whole-House Mechanical Ventilation Fan Flow Rate}

All mechanical ventilation fan flow measurements occurred as a one-time measurement during the initial audit. The Energy Conservatory Exhaust Fan Flow Meter was primarily used to measure mechanical ventilation flows in the homes. The accuracy of the device was initially a concern, especially considering the small flows being measured in this study, typically around 30-70 cfm. So, during the audit of the 10 homes, results were periodically spot-checked with a powered flow hood, which has been shown to yield improved accuracy (Wray et al. 2002). The powered flow hood apparatus consists of a FlowBlaster Capture Hood, a DG-700 Digital Pressure Gauge, and a DuctBlaster fan, all produced by Minneapolis Blower Door. Results obtained with both measurement techniques yielded appreciable similarities, especially considering the variable wind conditions.

\subsubsection{Building Envelope and Duct System Performance}

Building envelope leakage testing was conducted during the initial audit using a Minneapolis Blower Door apparatus in accordance with ASTM E779, "Standard Test Method for Determining Air Leakage Rate by Fan Depressurization” (ASTM 2010).

Duct leakage testing was conducted during the initial audit using a Minneapolis Duct Blaster apparatus in accordance with ASHRAE 152, "Method of Test for Determining the Design and Seasonal Efficiencies of Residential Thermal Distribution Systems" (ASHRAE 2004). The test determines total duct leakage and duct leakage to the outside by measuring the quantity of air required to reach a depressurization of -25 pascals with respect to outside air.

\subsubsection{Air Exchange Rate}

The air exchange rate (AER) is a measure of total air movement into or out of the house, including natural infiltration/exfiltration and mechanical ventilation. The AER was determined based on perflouromethylcyclohexane $(\mathrm{PMCH})$ tracer gas measurements. PMCH emitters, consisting of a 2-dram $(7.5-\mathrm{mL})$ glass vial filled with $\mathrm{PMCH}$, were placed throughout the home (approximately three emitters per home). The emitter was placed right side up in the air distribution pathway to encourage mixing. Each vial septum cap was modified to provide the same amount of diffusion through each cap and maintain emission rates throughout the week. The emission rate of the PMCH emitters has been preliminarily determined in the laboratory to be approximately 1 milligram per hour $(\mathrm{mg} / \mathrm{hr})$, and it is determined in the field by weighing the 
emitters before and after each week-long IAQ sampling event, as well as over time. The PMCH samplers are passive charcoal badges that have been verified in the laboratory to have a sampling rate of 10.2 milliliters per minute $(\mathrm{mL} / \mathrm{min})$ and a sensitivity of 6.7 parts per billion $(\mathrm{ppb})$. Analysis occurred through an accredited laboratory (DataChem/ALS Laboratories) via gas chromatography with mass spectrometry (GCMS).

\subsubsection{Electric Energy Use}

Whole-house electricity use, as well as disaggregated energy use consisting of air handler, condenser, water heater, ${ }^{7}$ clothes dryer, and bath fan circuit were monitored using the Powerwise 14-channel eMonitor4-14 home energy monitor, which relies on circuit transducers (CTs) to directly measure current. Voltage was measured on one phase of the split-phase systems. The eMonitor stores data at a frequency of one minute and collects data based on a user-specified setting. Data were stored on the eMonitor and transferred to a data collection gateway via a wireless 2.4-GHz signal. The gateway uploads the data to a server via the home's internet connection. The data from the eMonitor server was accessed and archived by FSEC's Infomonitors system. Energy-use data were stored on an hourly basis for this study.

\subsubsection{Temperature and Relative Humidity}

Temperature and RH were measured primarily using HOBO U12-011 loggers, ${ }^{8}$ which record temperature and $\mathrm{RH}$ in the ranges expected in homes: $-4^{\circ} \mathrm{F}$ to $158^{\circ} \mathrm{F}$ and $5 \%$ to $95 \% \mathrm{RH}$, respectively. The accuracy of the HOBO U12-011 over the range of interest is $\pm 0.35^{\circ} \mathrm{F}$ and $0.3 \%$ $\mathrm{RH}$, which is more than sufficient to resolve differences resulting from changes in ventilation rate. The meters were set up to sample every 15 seconds and average over 5 minutes, or 20 measurements. The meters measure and record data every 15 minutes. HOBO data were downloaded every two weeks and loaded into the FSEC Infomonitors system for archiving and analysis.

Each home was equipped with three HOBO loggers: one near the main return, one in the master bedroom, and one in another bedroom. A Lacrosse TX-60U-SET online wireless temperature and RH sensor was also temporarily employed in the main living space to provide near real-time, hourly data for temperature and RH and to help monitor whether RH levels and home conditions were within acceptable ranges. Data collected by the Lacrosse sensor proved to be unreliable and were not used for analysis purposes.

Each home also had a combined $\mathrm{CO}_{2} / \mathrm{T} / \mathrm{RH}$ data logger, discussed below. A model center home in the community hosts a $\mathrm{CO}_{2} / \mathrm{T} / \mathrm{RH}$ data logger on its exterior that monitors outdoor conditions. Weather data from the Gainesville Regional Airport (KGNV) were also processed through the FSEC Infomonitors system and were available for analysis.

\footnotetext{
7 The electricity use of the "tankless" gas water heaters is measured. Gas use is not measured.

${ }^{8}$ http://www.onsetcomp.com/products/data-loggers/u12-011
} 


\subsection{6 $\mathrm{CO}_{2}$ Measurement}

The Extech SD $800 \mathrm{CO}_{2} /$ Humidity/Temperature Datalogger ${ }^{9}$ was used to continuously record temperature, $\mathrm{RH}$, and $\mathrm{CO}_{2}$ throughout the measurement period. The $\mathrm{CO}_{2}$ sensor is a nondispersive infrared sensor with an accuracy of $\pm 5 \%$ of the reading for concentrations greater than 1,000 parts per million (ppm) and \pm 40 ppm for concentrations less than $1,000 \mathrm{ppm}$, and it is capable of resolving $\mathrm{CO}_{2}$ concentrations from 0 to $4,000 \mathrm{ppm}$, which is appropriate for the expected outdoor and indoor concentrations of 380 to $2,000 \mathrm{ppm}$ and the expected variation in $\mathrm{CO}_{2}$ resulting from changes in ventilation strategy.

One Extech data logger was placed in the main body of each home. One of the homes also hosted an Extech on the back porch for an outdoor measurement. Data were downloaded from each Extech data logger every two weeks, and they were processed through the FSEC Infomonitors system for archiving and analysis.

\subsubsection{Condensate Measurement}

Condensate was measured by tipping bucket rain gauges with the number of tips stored to a HOBO data logger (HOBO Pendant Event Data Logger - UA-003-64). Using the event logger memory capacity created difficulties because it would reach its limit within about a week to 10 days depending on the volume of condensate measured. This resulted in periods of lost data.

The rain gauges can be prone to clogging from debris in the condensate water. Condensate was directed through a loose filter material to reduce backups, but clogs did occur in two cases resulting in lost data.

\subsubsection{Total Volatile Organic Compounds}

Sampling of speciated VOCs was accomplished using the SKC Ultra III sorbent badge ${ }^{10}$ with Carbograph 5 thermal desorption (TD) sorbent. SCK Ultra III sorbent badges operate on a passive air transfer and diffusion mechanism to deposit the constituent of concern on the sorbent. Carbograph 5 was selected as the sorbent based on previous research by Coyne et al. (n.d.), who evaluated the Ultra III passive sampler with Carbograph 5 sorbent for a suite of VOCs as compared to canisters, 226-01 charcoal sorbent tubes, and 575-001 sorbent badges (Coyne et al. n.d). This work has shown sensitivity of 0.027 to 0.4 micrograms per cubic meter $(\mu \mathrm{g} / \mathrm{m} 3)$, depending on the compound and accuracy that is similar to that of sorbent badges over a sevenday period. Sampling rates are determined for each compound experimentally (Coyne et al. n.d.). Analysis was performed using GCMS in accordance with the U.S. Environmental Protection Agency's (EPA's) TO-17 method to identify and quantify the full suite of VOCs (EPA 1999b).

\subsubsection{Formaldehyde and Acetaldehyde}

Formaldehyde and acetaldehyde sampling was conducted with a UMEx 100 passive sampler, ${ }^{11}$ which uses tape treated with 2,4-dinitrophenylhydrazine (DNPH) for collection of formaldehyde and other aldehydes. These passive samplers can measure formaldehyde concentrations as low

\footnotetext{
${ }^{9} \mathrm{http}: / /$ www.extech.com/instruments/product.asp?catid $=7$ \&prodid $=628$

${ }^{10} \mathrm{http}: / / \mathrm{www}$. skcinc.com/prod/690-101.asp

11 http://www.skcinc.com/prod/500-100.asp
} 
as $0.2 \mathrm{ppb}$ for a seven-day sampling period, although the sampling rate has not been evaluated experimentally over seven days. Analysis was performed using high-performance liquid chromatography with an ultraviolet high-performance liquid chromatography with ultraviolet detector (HPLC-UV) in accordance with EPA IP-6C, "Determination of Formaldehyde and Other Aldehydes in Indoor Air using Solid Adsorbent Cartridge" (EPA 1990) and EPA TO-11A, "Methods for Determination of Formaldehyde in Ambient Air" (EPA 1999a). Duplicate formaldehyde sampling occurred for the first one-week IAQ sampling period using the Waters Sep Pak XPoSure sampler, which also employs DNPH-coated silica as the sampling media. Analysis was performed using HPLC at LBNL. However, duplicate sampling was not repeated for subsequent sampling periods.

\subsubsection{Nitrogen Dioxide}

For $\mathrm{NO}_{2}$ measurement, samples were taken using an SKC Inc. UMEx 200 passive sampler ${ }^{12}$ treated with triethanolamine (TEA). The passive $\mathrm{NO}_{2}$ sampler has been validated between 0.4 ppm and 8 ppm but only for periods up to eight hours (Kuhlman and Zovack 2013). The accuracy of the sampler is $\pm 30 \%$. The sampler was then sent to an accredited laboratory for analysis by solvent extraction ion chromatography (IC) with conductivity detection. During all sampling periods, $\mathrm{NO}_{2}$ sampling only occurred in two homes: one with gas cooking and one without gas cooking. An outdoor sample was also collected.

\subsubsection{Radon}

For radon sampling, passive radon detectors were used. The passive samplers employ the charcoal liquid scintillation method with a diffusion barrier to maintain relatively constant radon diffusion rates over the long-term sampling period. The mechanism for liquid scintillation measurement is described by Prichard and Marien (1985). Radon analysis occurred at ProLab Inc., the manufacturer of the radon detectors. ${ }^{13}$

Radon sampling occurred on a long-term basis and was deployed during the first sampling event and was collected after a little more than one year (60 weeks) of passive sampling after the end of the last IAQ sample period. Long-term sampling was selected because it would increase the sensitivity and accuracy of the radon measurements at low levels, which were expected due to the moderate radon risk in Alachua County (where Gainesville is located). Moderate radon risk is associated with predicted average indoor radon screening levels between 2 and 4 picocuries per liter $(\mathrm{pCi} / \mathrm{L})$.

\subsubsection{Mold}

The presence of mold was assessed based on visual inspection biweekly during the visit to flipflop ventilation rates in the flip-flop homes (six homes in the second cohort) and during every IAQ event in the side-by-side homes (four homes in the first cohort).

\footnotetext{
12 http://www.skcinc.com/prod/500-200.asp

${ }_{13}$ http://www.prolabinc.com/radon-test-kits $2 . a s p$
} 


\subsubsection{Homeowner Surveys}

The purpose of the homeowner surveys was to determine activities that may affect IAQ that occurred during sampling and address general homeowner comfort and satisfaction. The homeowner survey consisted of three sections:

1. An initial HVAC questionnaire that was to be administered once at the beginning of sampling to gauge homeowners' existing perceptions of their comfort and HVAC system performance

2. A follow-on HVAC questionnaire that was to be administered following every change in ventilation approach

3. An IAQ supplement that was to be administered following every IAQ sampling period.

A complete copy of the homeowner survey is included in Appendix E. The questions included in the Indoor Air Quality Supplement were used primarily to identify and document activities conducted in the homes that may affect the IAQ sample collection or results and yield unrepresentative information. Homeowners were also given information prior to every IAQ sampling event regarding any prohibited activities that should be avoided during and immediately prior to the IAQ sampling events. 


\section{Results and Discussion}

The results from this study are presented as continuously monitored parameters (Section 3.1) and seasonally sampled parameters (Section 3.2). Specifically, Section 3.1 presents the energy use, temperature relative humidity, and $\mathrm{CO}_{2}$ results, while Section 3.2 discusses the IAQ results.

\subsection{Continuously Monitored Parameters: Energy Use, Temperature, Relative Humidity, and Carbon Dioxide}

Data collected during the yearlong monitoring period spanning June 2013 to June 2014 have been broken into different periods for analysis: summer $2013(6 / 24 / 2013-10 / 15 / 2013)$, mixed (10/16/2013-4/16/2014), and summer 2014 (4/17/2014-6/24/2014). Figure 5 characterizes the weather conditions in Gainesville, Florida, during the yearlong monitoring period; the plot in the figure is shown in a larger format in Appendix G. Average daily outdoor dry bulb temperature is shown along with average hourly outdoor dew point temperature. Both parameters remain relatively constant throughout the first summer period, with a peak occurring around August 20. After this peak, outdoor dry bulb and dew point temperatures begin to trend downward, and they become increasingly variable toward the end of October. Also shown in Figure 5 is the average indoor dew point temperature among the flip-flop homes. Red indicates periods when these homes were operating with $\mathrm{CEV}$, and blue indicates periods when these homes were operating with RTV. During the first summer, the indoor dew point data, in general, show lower moisture content inside the homes than that found outdoors. This is because the air-conditioning system removes much of the moisture introduced through both air exchange and internal generation. While indoor dew point can be seen as somewhat influenced by outdoor dry bulb temperature driving the runtime of the air conditioner, an overall trend is apparent showing lower average indoor dew point temperatures during RTV than during continuous exhaust.

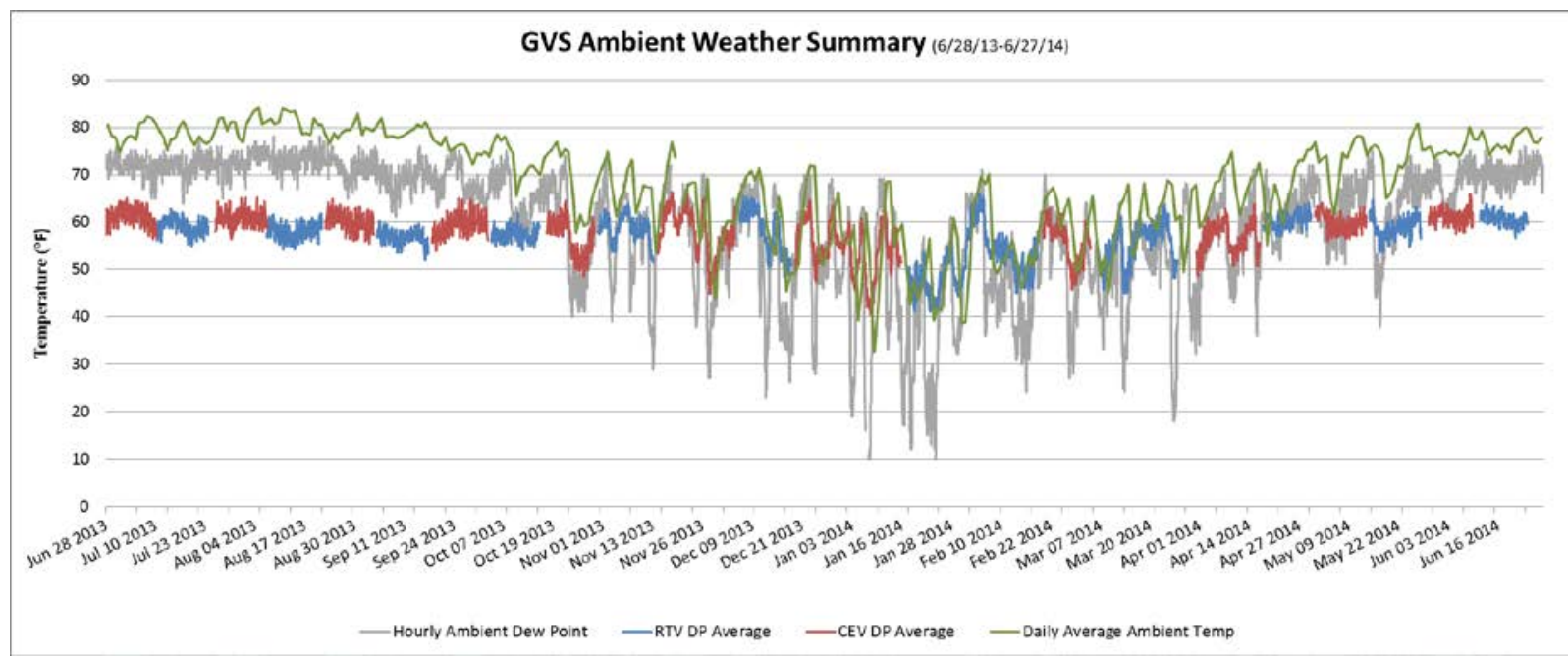

Figure 5. Outdoor dry bulb and dew point temperatures from the local National Weather Service station and average indoor dew point temperature among the flip-flop homes

Red indicates continuous exhaust (CEV in the figure) configuration and blue indicates the runtime ventilation (RTV in the figure) configuration. 
As the summer cooling season concludes toward the middle of October, indoor dew point is observed to be largely influenced by outdoor dew point, with no noticeable influence by ventilation strategy. This trend continues through the "mixed" period of late October through mid-April, when homes operate under an intermittent mix of heating, cooling, and floating space conditioning. By the beginning of May, the trends observed the previous summer return for the summer of 2014. Appendix H contains plots for each home illustrating variations in indoor and outdoor conditions for the yearlong monitoring period.

\subsubsection{Cooling Season Data and Analysis (6/28/13-10/15/13) ${ }^{14}$}

As seen in Appendix H, individual homes show generally similar RH response to the different ventilation strategies. In general, homes operating under RTV show lower average RH, with less variation, than homes operating under $\mathrm{CEV}$. $\mathrm{RH}$ is maintained, on average, below $60 \%$ under both ventilation configurations, but intermittent episodes exceeding $65 \% \mathrm{RH}$ are more common under CEV. Figure 6 shows the number of hours during the 2013 summer period each of the homes spent in specific RH ranges $(<60 \%, 60 \%-65 \%$, and $>65 \%)$, broken into the two ventilation periods. The left bar for each home shows the hours during the RTV periods and the right bar shows the CEV periods. The total number of hours varies among homes and periods because logistics prevent the flip-flop homes from all being switched over on the same day. Data have also been removed from this plot and all subsequent analysis representing extended vacation periods (Home 5 and Home 6) and air conditioner failures/repairs (Home 1 and Home 10). In Figure 6, control home data have also been broken into two periods representing the average date ranges the flip-flop homes spent in each ventilation configuration. In general, the hours that are $>60 \%$ for the control homes are two times greater in the continuous exhaust (right bar) periods than in the RTV periods (left bar). The increase largely occurs in the hours between $60 \%$ and $65 \% \mathrm{RH}$, and it could be explained by slight differences in average outdoor dew point between the periods. However, the flip-flop homes log significantly more hours $>60 \%$ RH during the continuous exhaust periods than the RTV periods, including in hours $>65 \%$ RH.

Also displayed in Figure 6 are average interior temperatures, which are seen to vary slightly among the periods in some homes. To isolate the influence that ventilation strategy has on $\mathrm{RH}$, a multivariable regression was performed. Ventilation strategy was found to be the most significant driver of hours $>60 \% \mathrm{RH}$, with CEV adding 3.7 hours per day $>60 \% \mathrm{RH}$ on average, and nearly one hour per day $>65 \% \mathrm{RH}$. Other parameters found to be significant at the $99 \%$ level or better include indoor/outdoor temperature difference (which is an indicator of air conditioner runtime), outdoor dew point, conditioned house size, and ACH50.

\footnotetext{
${ }^{14}$ Temperature and RH data collected from the HOBO in the main bedroom are used for this analysis because the HOBOs near the return grilles in the main body of a few homes showed periods of unexplainably high RH. These HOBOs were later moved to be adjacent to the homes' thermostats.
} 


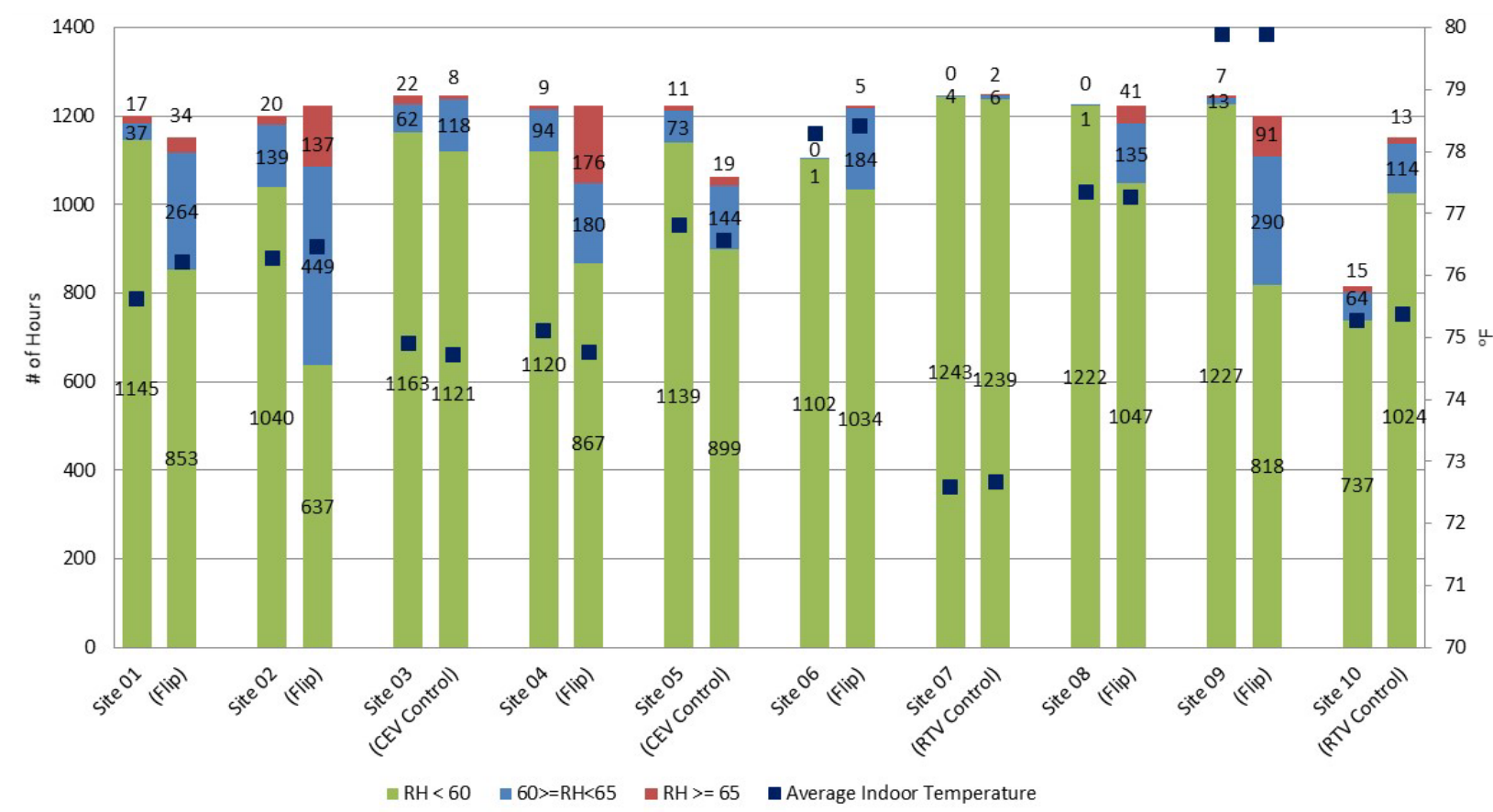

Figure 6. Distribution of hours at various percent (\%) RH ranges during summer 2013, broken into runtime ventilation (left bar) and continuous exhaust ventilation (right bar) periods, each corresponding to the left axis

Numeric data labels correspond to hours, and black squares correspond to average indoor temperature (on the right axis). Home 3 and Home 5 always operate with continuous exhaust ventilation, and Home 7 and Home 10 always operate with runtime ventilation.

Figure 7 shows the average daily cooling energy use per day for each of the homes, broken into the different ventilation periods. This energy use includes both the air handler fan and the compressor, but it does not include bathroom exhaust fan energy for the continuous exhaust condition. With the exception of Home 10, whose trend is unexplained, the control homes (Homes 3, 5, 7, and 10) show little variation in cooling energy use among the periods. The flipflop homes, however, show greater cooling energy use during the CEV period indicating as expected that the additional ventilation places additional load on the air conditioner.

There is no correlation between minor differences in average indoor temperature between the periods in a given home (black squares in Figure 6) and differences in average daily cooling energy between the periods in a given home. However, the thermostat set points are a driver of differences in cooling energy use among homes. To remove the influence of differing indoor and outdoor temperatures from the comparison of cooling energy between the two ventilation strategies, Figure 8 plots average daily cooling energy versus average daily outdoor and indoor temperature difference for the flip-flop homes. Similar analysis has been used to compare the performance of various highly efficient homes to conventional counterparts (Chasar et al. 2006). In this plot, each data point represents a single day. The $\mathrm{x}$-axis coordinate is the difference between average outdoor temperature for the day and the average indoor temperature averaged for the flip-flop homes for that day. The y-axis coordinate is the average of the total cooling 
energy use for each flip-flop home for that day. Assuming the area under each line is directly proportional to cooling energy use, the flip-flop homes use approximately $9 \%$ more cooling energy while operating under $\mathrm{CEV}$, over the delta temperature range of $-4^{\circ} \mathrm{F}$ to $6^{\circ} \mathrm{F}$.

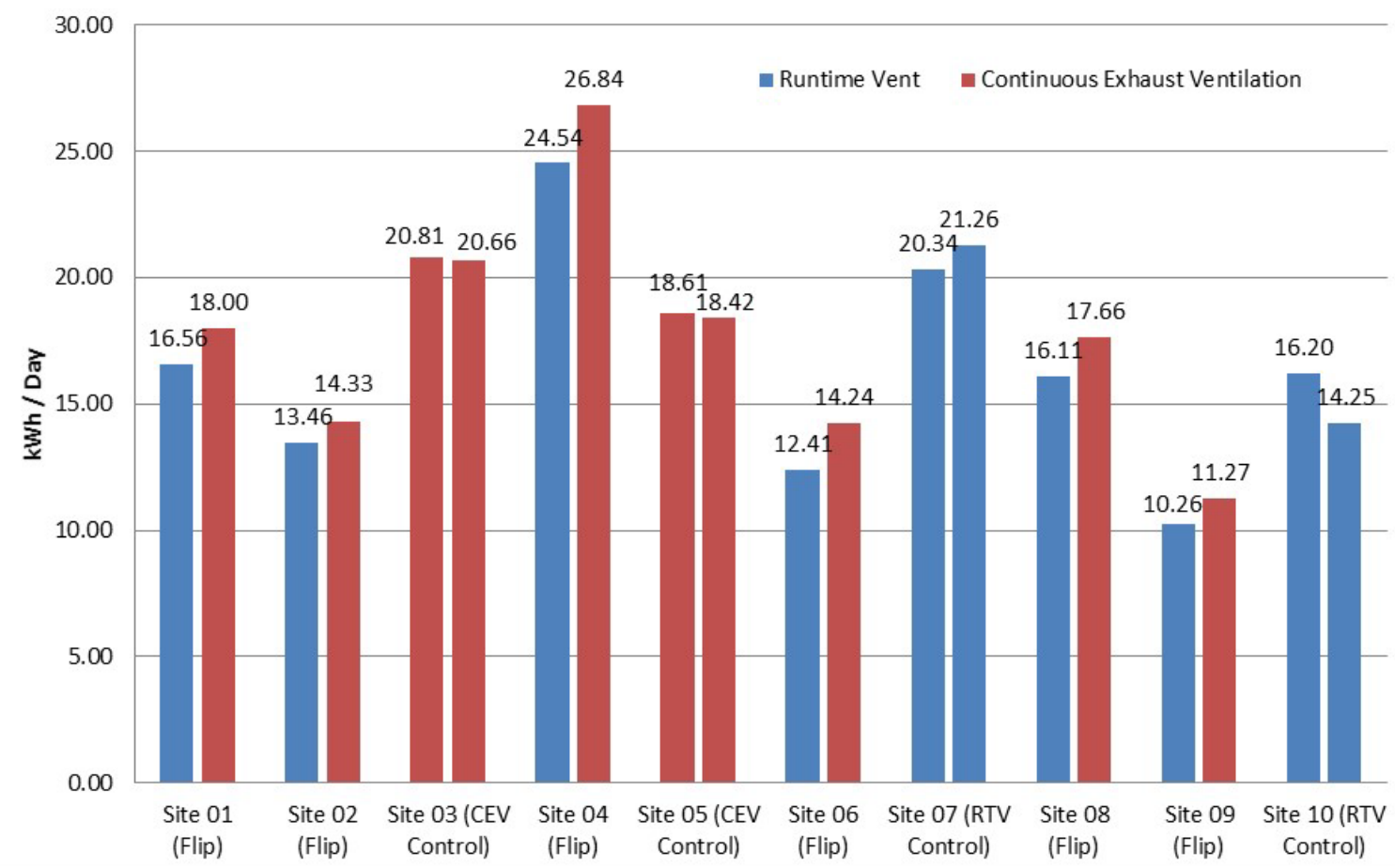

Figure 7. Average cooling energy use per day, broken into runtime ventilation (left bar) and continuous exhaust (right bar) periods

Home 3 and Home 5 always operate with continuous exhaust, and Home 7 and Home 10 always operate with runtime vent. 


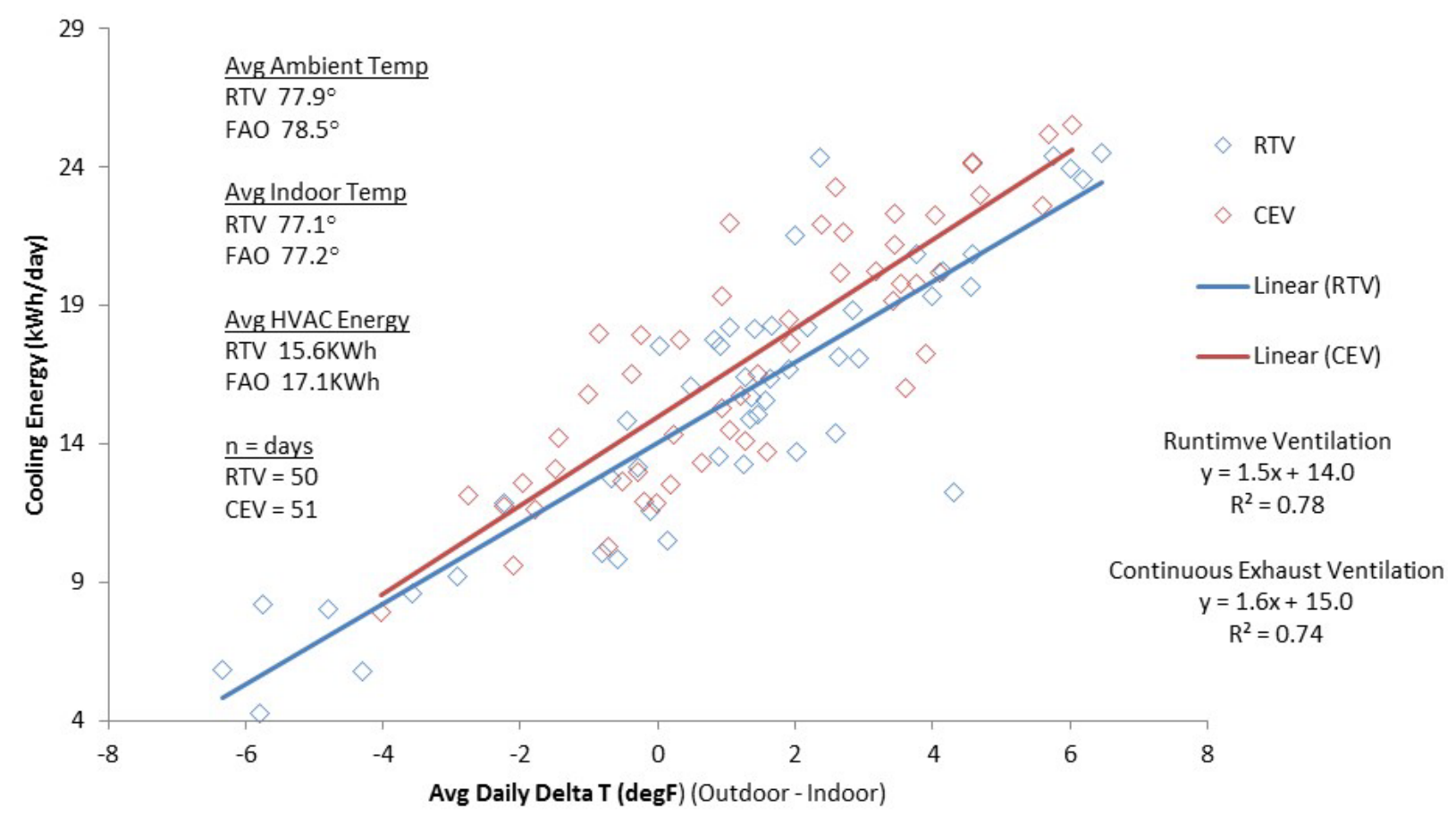

Figure 8. HVAC energy use as a function of differences in indoor and outdoor temperatures

To further isolate the effect of ventilation strategy on cooling energy use, a multivariable regression was performed with data from all flip-flop and control homes. While air conditioner runtime and conditioned house size were found to be the most significant variables affecting cooling energy use, ventilation strategy was also found to be significant at the $99 \%$ level, with CEV adding 2 kilowatt-hours ( $\mathrm{kWh}$ ) of cooling energy per day on average. Outdoor dew point and ACH50 were also found to be significant variables at the $99 \%$ level.

The general trend for the continuous exhaust configuration to result in greater cooling energy use and slightly higher dew point temperatures is seen in Figure 9, which displays a representative average day profile for the flip-flop homes operating under the two ventilation configurations. This plot is generated by averaging hourly data for all flip-flop homes while in each of the two configurations. Much of the difference in cooling energy occurs during the daytime hours, when outdoor temperatures are at their warmest. By 12 p.m., the extra load placed on the systems by the CEV strategy has enough of an effect on air conditioner runtime that the indoor dew point (red squares in the figure) begins to trend downward, while the indoor dew point in the RTV homes (blue triangles in the figure) continues to trend upward. Around 5 p.m., thermostats are set back, and indoor dew point is seen to steadily decrease in both the CEV and RTV cases. 


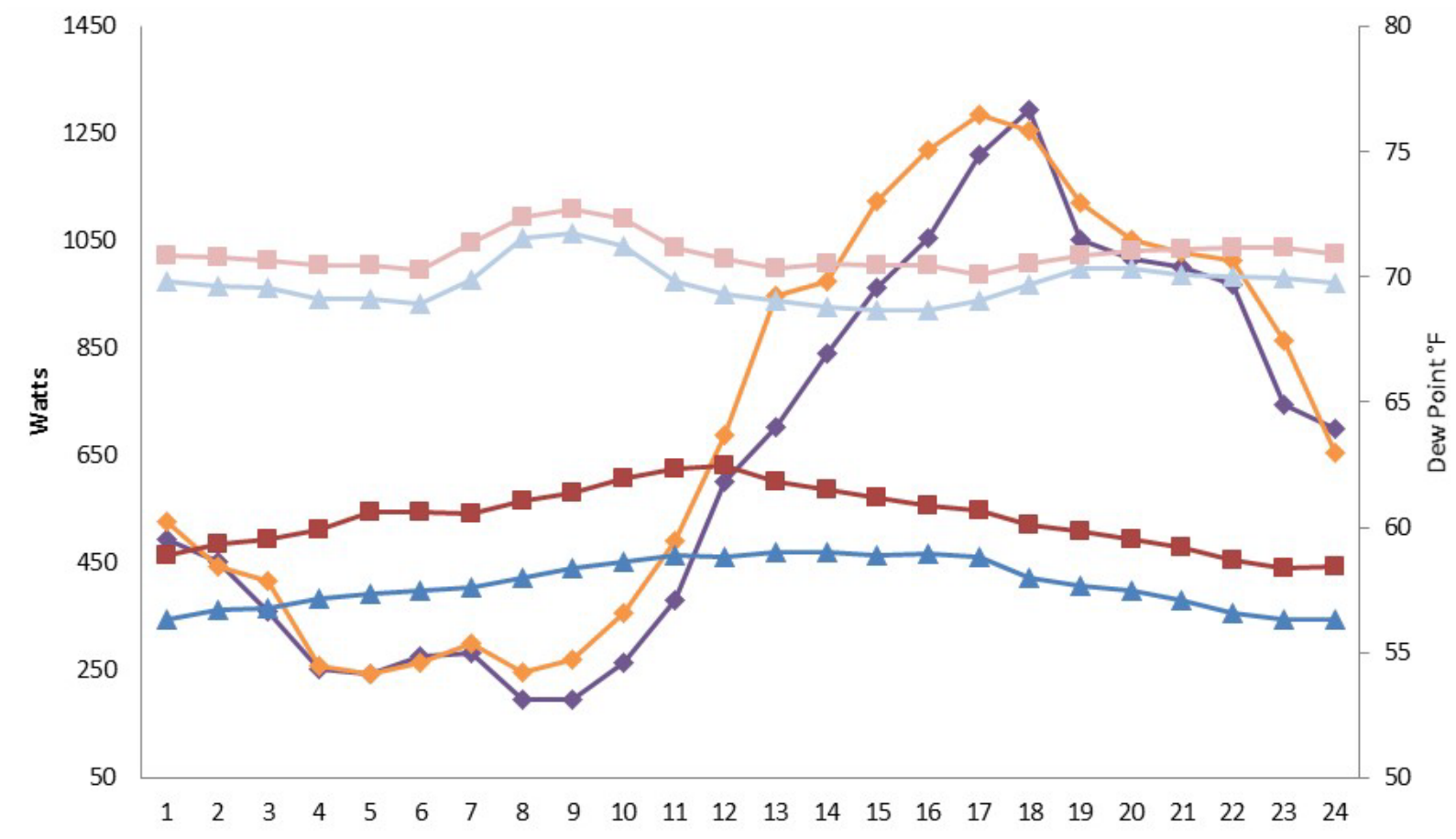

$\multimap$ HVAC Pwr RTV $\multimap$ HVAC Pwr CEV - Outdoor DP RTV - -Outdoor DP CEV $\longleftarrow$ Indoor DP RTV - Indoor DP CEV

Figure 9. Average hourly indoor and outdoor dew point temperatures and cooling energy use for the flip-flop homes in the runtime ventilation (RTV) and continuous exhaust (CEV) configurations

As can be seen in the individual home plots in Appendix $\mathrm{H}$, indoor $\mathrm{CO}_{2}$ concentration is noticeably affected by ventilation strategy, with CEV producing consistently lower indoor $\mathrm{CO}_{2}$ concentrations. Figure 10 shows daily average $\mathrm{CO}_{2}$ concentrations for all homes for 8/15/2013 through 10/15/2013. It is clear that $\mathrm{CO}_{2}$ concentration is reduced in the flip-flop homes when operating with continuous exhaust. With the exception of Home 10, the control homes also show a reduction in $\mathrm{CO}_{2}$ concentration during the continuous exhaust period despite the outdoor concentration remaining nearly constant, which is unexplained. The difference could be related to occupancy, which was not tracked in detail. It could also be related to the accuracy of the Extech SD $800 \mathrm{CO}_{2}$ sensor (+/- $\left.40 \mathrm{ppm}\right)$. However, the reduction in $\mathrm{CO}_{2}$ concentration in the flip-flop homes is two times greater on average than the reduction in $\mathrm{CO}_{2}$ in the control homes during the same periods, which indicates the additional ventilation provided via the continuous exhaust system is likely producing a dilution effect. 


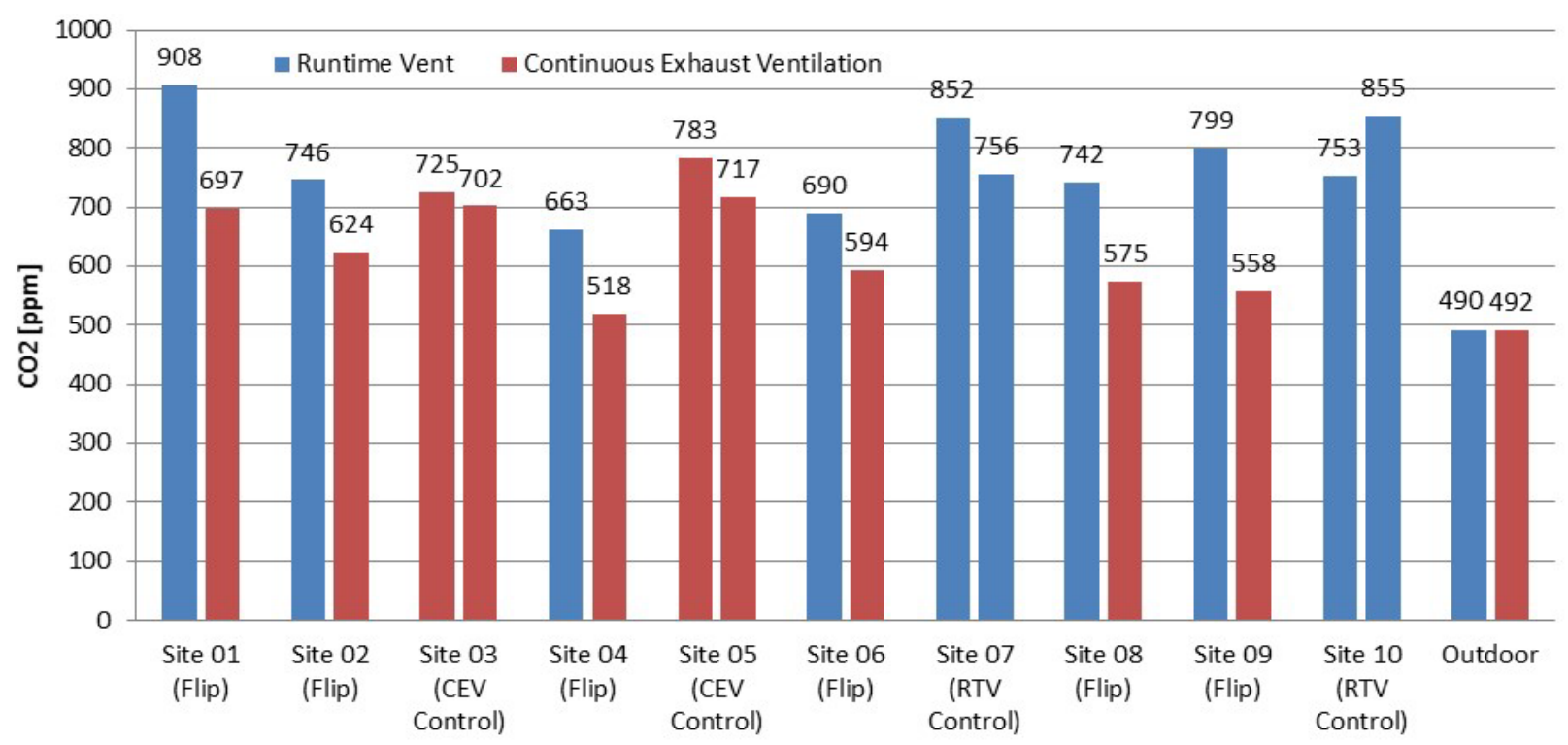

Figure 10. Daily average $\mathrm{CO}_{2}$ concentration, broken into runtime ventilation (left bar) and continuous exhaust (right bar) periods

Home 3 and Home 5 always operate with continuous exhaust, and Home 7 and Home 10 always operate with runtime ventilation.

To isolate the effect of ventilation strategy on $\mathrm{CO}_{2}$ concentration, a multivariable regression was performed with data from flip-flop and control homes. Ventilation strategy was found to be the most significant variable with $\mathrm{CEV}$ reducing daily average $\mathrm{CO}_{2}$ concentration by an average of $148 \mathrm{ppm} /$ day. Other variables found to be significant to the $99 \%$ level were occupancy, which is expressed generically as the number of persons per household and water heating energy, which provides a more detailed indication of occupancy patterns.

Table 4 summarizes the monitored data collected over the summer period for the six flip-flop homes. Outdoor conditions were relatively consistent among the ventilation periods. As expected, the CEV system requires slightly more cooling energy use to maintain the desired temperature set points in the homes. Also, because these homes have no mechanism to control $\mathrm{RH}$, the resulting $\mathrm{RH}$ and dew point are higher in the homes while under CEV.

Table 4. Summary of Monitored Data over the Summer Period, Averaged for the Six Flip-Flop Homes

\begin{tabular}{l|l|l|l}
\hline & $\begin{array}{l}\text { Continuous } \\
\text { Exhaust }\end{array}$ & Runtime Ventilation & $\Delta$ \\
\hline Indoor temperature $\left({ }^{\circ} \mathrm{F}\right)$ & 77.2 & 77.1 & 0.1 \\
\hline Indoor $\mathrm{RH}(\%)$ & 56.5 & 51.6 & 5.1 \\
\hline Indoor dew point $\left({ }^{\circ} \mathrm{F}\right)$ & 60.4 & 57.8 & 2.6 \\
\hline Hours $60 \%-65 \% \mathrm{RH}$ & 250 & 48 & 202 \\
\hline Hours $>65 \% \mathrm{RH}$ & 80 & 9 & 71 \\
\hline
\end{tabular}




\begin{tabular}{l|l|l|l}
\hline & $\begin{array}{l}\text { Continuous } \\
\text { Exhaust }\end{array}$ & Runtime Ventilation & $\Delta$ \\
\hline AC energy $(\mathrm{kWh} /$ day) & 17.1 & 15.6 & 1.5 \\
\hline Indoor $\mathrm{CO}_{2}$ concentration $(\mathrm{ppm})$ & 594 & 758 & -164 \\
\hline \hline Outdoor temperature $\left({ }^{\circ} \mathrm{F}\right)$ & 78.5 & 77.9 & 0.6 \\
\hline Outdoor $\mathrm{RH}(\%)$ & 79.4 & 78.3 & 1.1 \\
\hline Outdoor dew point $\left({ }^{\circ} \mathrm{F}\right)$ & 70.9 & 69.8 & 1.1 \\
\hline Outdoor $\mathrm{CO}_{2}$ concentration $(\mathrm{ppm})$ & 492 & 490 & 2 \\
\hline
\end{tabular}

These trends correspond with the hourly predictions from BEopt simulation, which uses TMY3 weather data (Table 5). BEopt does not predict any hours $>65 \% \mathrm{RH}$, while some hours are evident at this condition in the monitored data.

Table 5. Comparison of Monitored and Simulated Data over the Summer 2013 Period

\begin{tabular}{|l|l|l|l|l|}
\hline \multicolumn{2}{|c|}{} & CEV & RTV & $\Delta$ \\
\hline \multirow{4}{*}{$\begin{array}{l}\text { Monitored } \\
\text { Data }\end{array}$} & Indoor Temperature $\left({ }^{\circ} \mathrm{F}\right)$ & 77.2 & 77.1 & 0.1 \\
\cline { 2 - 5 } & Hours $60 \%-65 \% \mathrm{RH}$ & 250 & 48 & 202 \\
\cline { 2 - 5 } & Hours $>65 \% \mathrm{RH}$ & 80 & 9 & 71 \\
\cline { 2 - 5 } & AC Power $(\mathrm{kWh} /$ day) & 17.1 & 15.6 & 1.5 \\
\hline \hline \multirow{4}{*}{$\begin{array}{l}\text { Simulated } \\
\text { Data }\end{array}$} & Indoor Temperature $\left({ }^{\circ} \mathrm{F}\right)$ & 76 & 76 & 0 \\
\cline { 2 - 5 } & Hours $60 \%-65 \% \mathrm{RH}$ & 249 & 0 & 249 \\
\cline { 2 - 5 } & Hours $>65 \% \mathrm{RH}$ & 0 & 0 & 0 \\
\cline { 2 - 5 } & AC Power $(\mathrm{kWh} /$ day) & 11.5 & 10.3 & 1.2 \\
\hline
\end{tabular}

\subsubsection{Summer Condensate Data and Analysis (6/24/2014-8/19/2014)}

Data collection actually continued beyond June 2014 and lasted until August 2014. However, by June 2014, several changes had taken place in some of the homes, including changes in occupancy, ownership, and ventilation schedule. These changes, along with subtle weather variations, make comparing summer 2014 data to summer 2013 data difficult. However, beginning in June 2014, collection of air conditioner condensate was instituted for approximately two months, and the associated data provide an opportunity to look at the relative contributions of different moisture sources, including outdoor air and occupancy. Daily condensate volumes varied widely from day to day for a given home, and between homes. Figure 11 shows the average, minimum, and maximum daily condensate volumes collected for each home during the summer 2014 condensate collection period. 


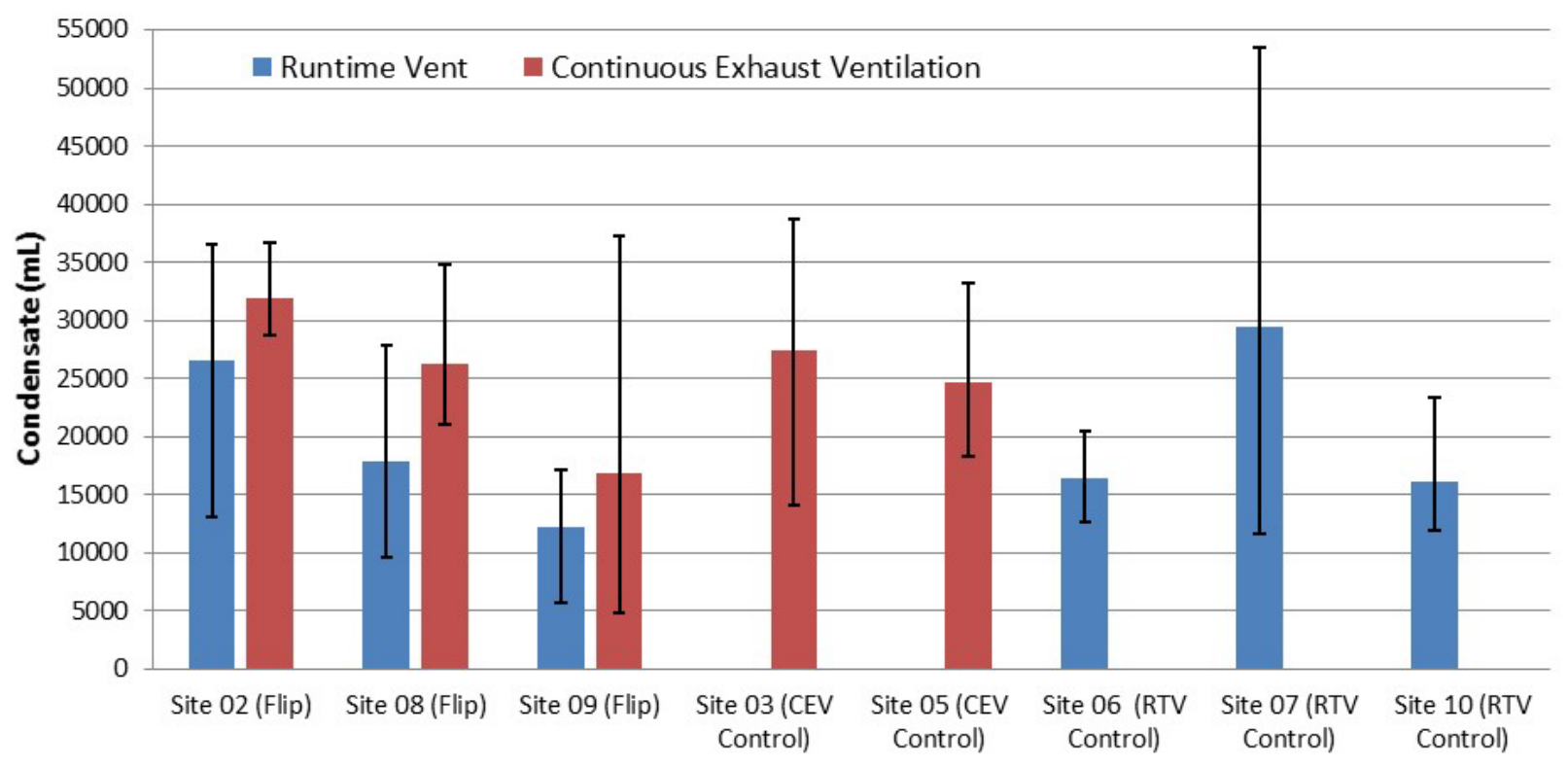

Figure 11. Average, minimum, and maximum daily condensate volumes collected from $6 / 24 / 14$ to $8 / 19 / 14$

Unlike with the bar graphs shown in figures above, flip-flop homes were not on the same cycle; therefore, control home data are presented as a single bar rather than broken into periods.

For homes that were flip-flopped between the two ventilation strategies during this period, CEV operation appears to generate more condensate. Condensate volumes collected in the CEV control homes are similarly higher than the condensate volumes collected in the RTV control homes, with the exception of Home 7; it maintains one of the lowest indoor temperature set points of the group, possibly accounting for the relatively large condensate volumes. To investigate the effect of ventilation strategy on condensate generation, a multivariable regression was performed with data from flip-flop and control homes. Ventilation strategy was not found to be significant, and outdoor dew point was only marginally significant. The largest drivers of condensate generation were occupancy (expressed as the number of persons per household) and temperature difference between outdoors and indoors (an indicator of air conditioner runtime). The relationship with occupancy suggests that interior moisture generation is not only a significant source of moisture but is also highly variable from day to day. Conditioned house size was also found to be significant, but an inverse relationship was found; the larger the house, the less condensate was generated. One explanation for this is that a larger house has more capacity to buffer moisture than a smaller house. ACH50 was also found to have a significant, yet inverse, relationship with condensate generation.

\subsubsection{Heating Season Data and Analysis}

Florida does not have long periods of consistent heating during a year. Rather, heating occurs sporadically and intermittently, typically in conjunction with passing cold fronts. Analysis of space heating was limited to a relatively short period from December 20, 2013, to February 6, 2014, which included most of the coldest winter days but also a few days when space cooling was evident. Twenty-day periods were chosen during each of the two ventilation strategies, 
excluding nine days between them when strategies were switched. Within each 20-day data set, four days were removed when cooling was evident in most homes. With the remaining data set of heating energy use, a linear regression was performed for each home by plotting total daily heating energy (compressor plus air handler) against the difference between average outdoor and indoor temperatures for 16 days during each of the two ventilation periods. Fan energy for the CEV strategy (bath fan) was not included in the analysis. Two of the 10 homes (Home 1 and Home 4) were dropped from the analysis due to lack of collected data. ${ }^{15}$

Heating thermostat settings varied widely among the eight homes analyzed $\left(66.3^{\circ} \mathrm{F}\right.$ to $\left.75.8^{\circ} \mathrm{F}\right)$. One home used space heating during all days in both periods, but the other seven homes had various numbers of days without heating. Space-heating regressions were refined by removing days with minimal or no heating activity. Figure 12 compares daily average heating energy in the homes during the two ventilation periods. The bars in Figure 12 result from evaluating each regression equation at the average temperature differential between outdoors and indoors during both heating periods. This helps account for varying heating set points in the homes (red and blue boxes) as well as the different outdoor conditions between periods. The ventilation strategy in each home is designated by color with CEV shown in red and RTV shown in blue. The results in Figure 12 drawn from this limited heating period imply no significant difference in spaceheating energy between the two ventilation strategies. ${ }^{15}$ Home 1 left the study permanently in January 2014, and the homeowner in Home 4 was not heard from between
April 2014 and August 2014. 


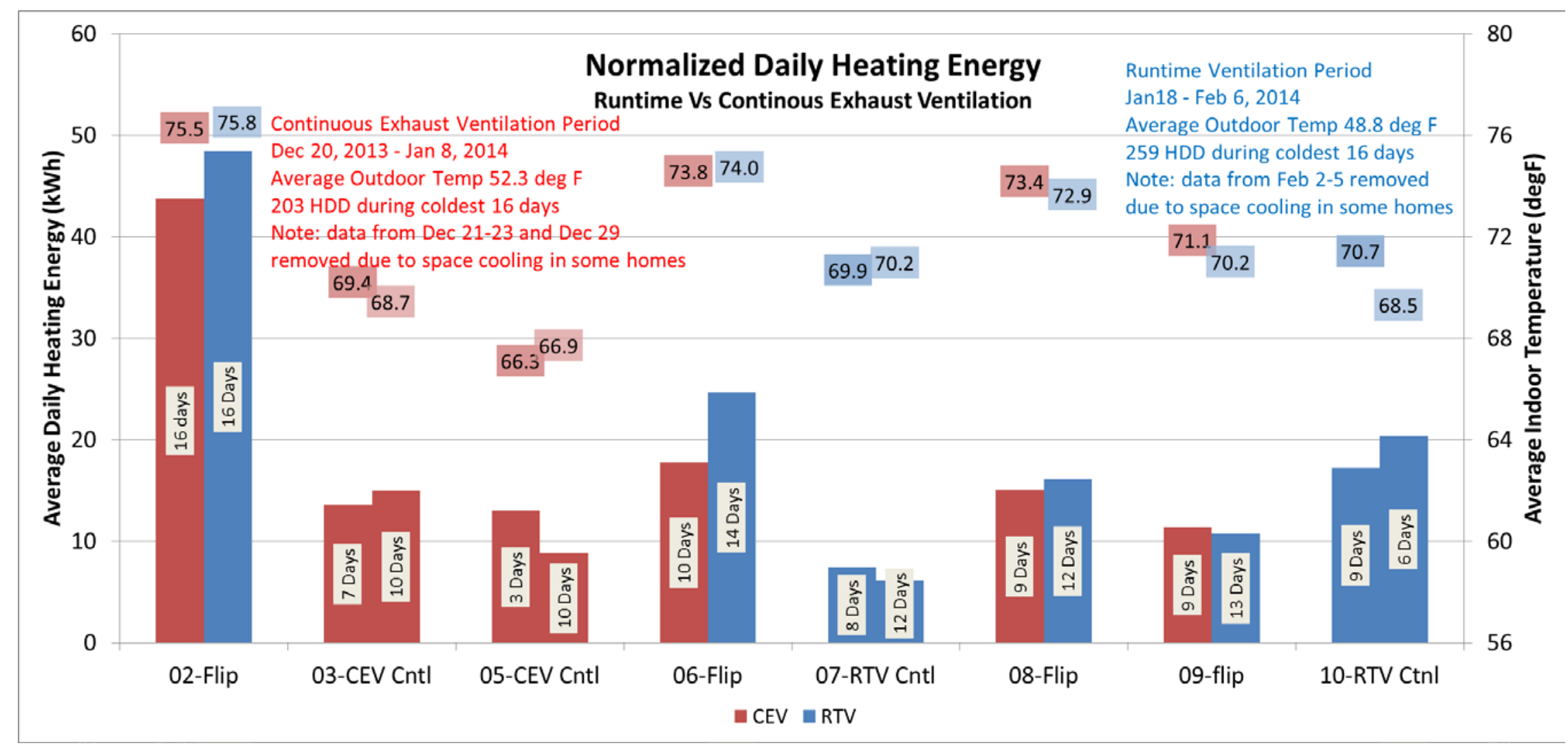

Figure 12. Daily heating energy in four flip-flop and four control homes

Red designates continuous exhaust (CEV) and blue designates runtime ventilation (RTV).

Data from two homes were lost during this period.

Examples of regressions for select homes are shown in Figure 13 and Figure 14. Home 2 (Figure 13) exhibits well-defined results as evidenced by the high R-squared value and space heating that occurred during all 16 days. Heating was much more limited at Home 5 (Figure 14), which results in poorly defined linear trends. Regressions for the remaining homes are included in Appendix I. 


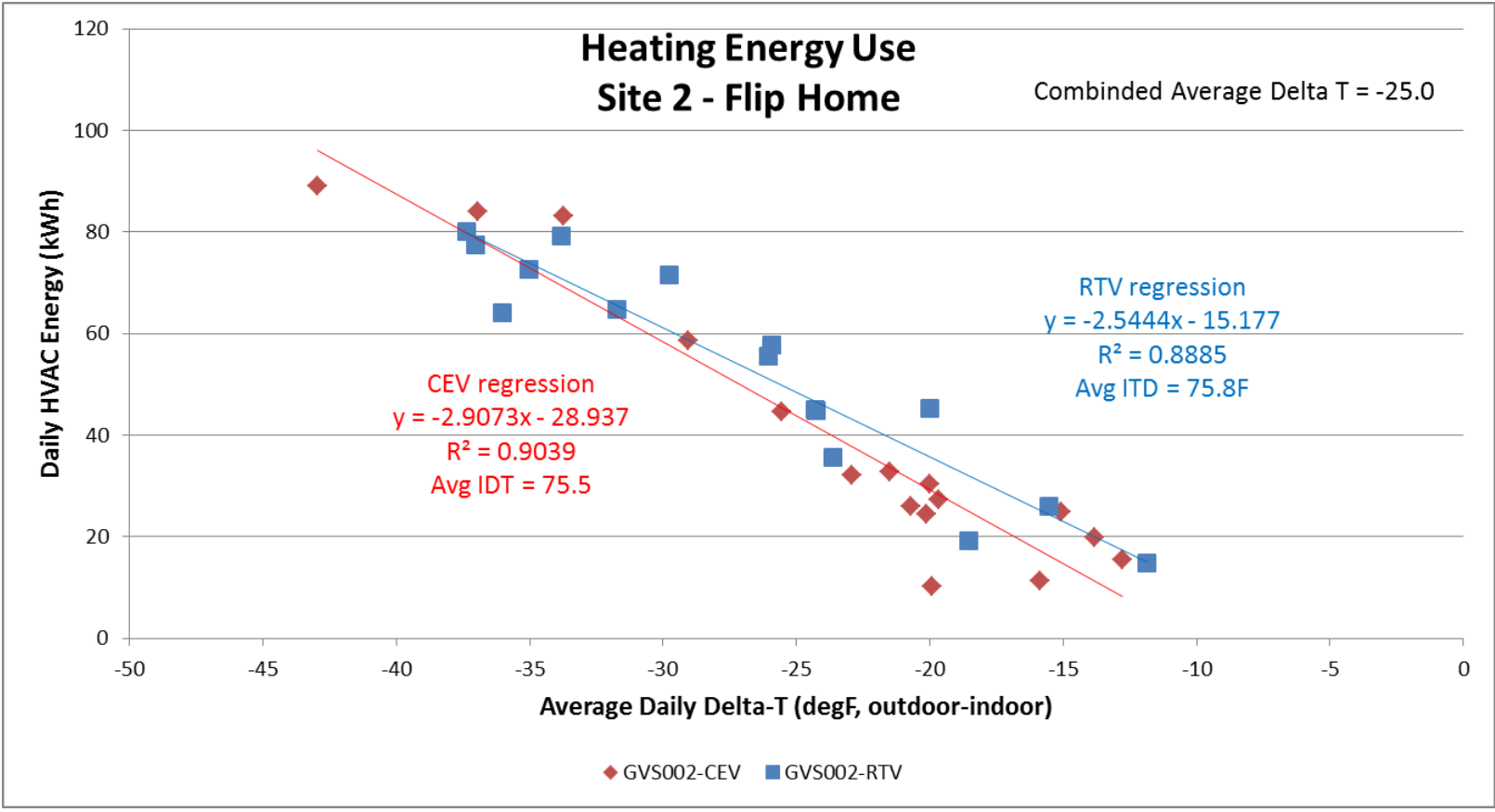

Figure 13. Example of daily heating energy regressions for Home 2 (a flip-flop home) exhibiting well-defined results with a high $\mathbf{R}$-squared value

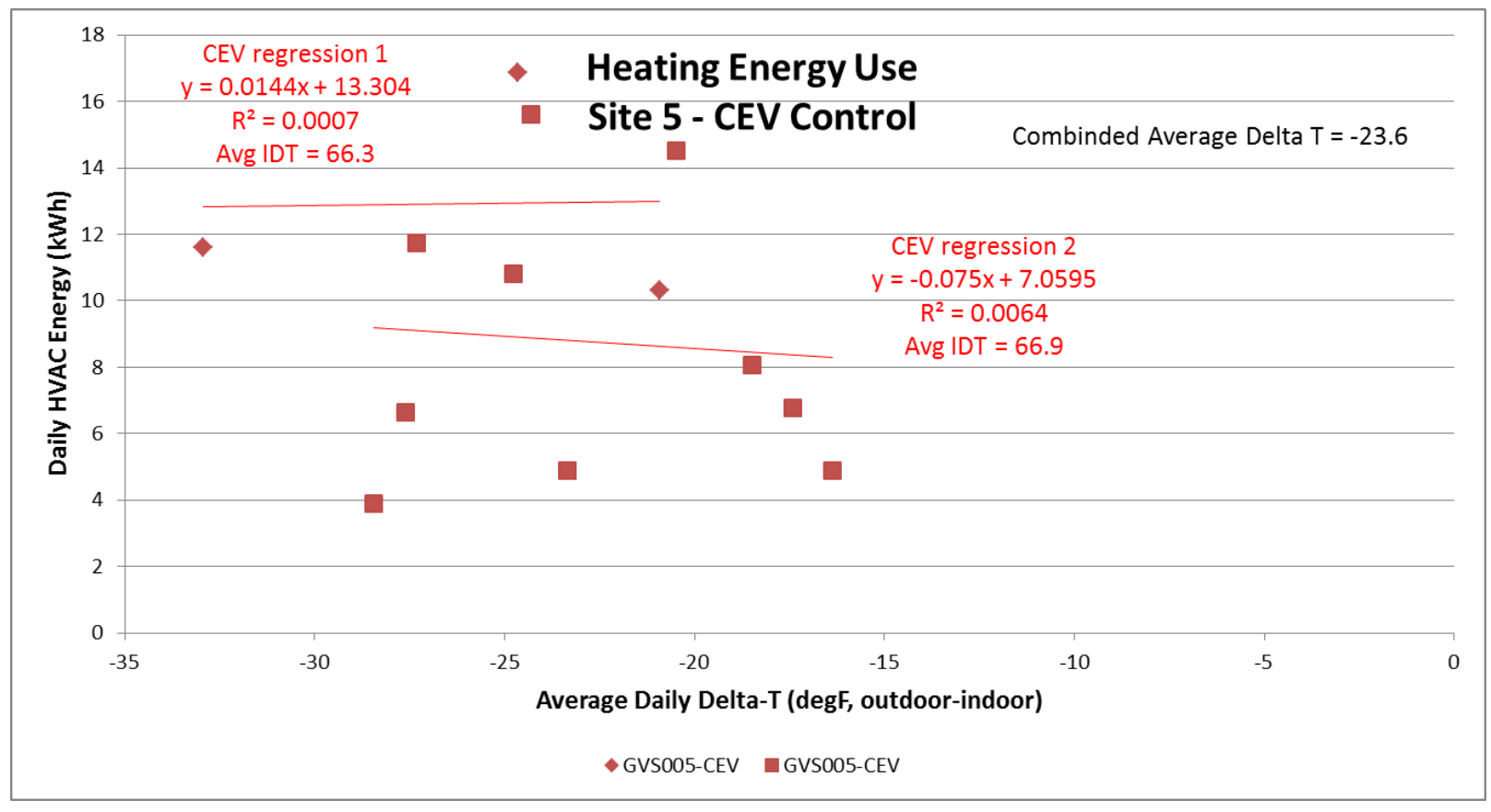

Figure 14. Example of daily heating energy regressions for Home 5 (a CEV control home) exhibiting poorly defined results with a low R-squared value 


\subsubsection{Mixed Season and Annual Data and Analysis}

To reiterate, data collected between June 2013 and June 2014 were broken into different periods for analysis: summer 2013 (6/24/2013-10/15/2013), mixed (10/16/2013-4/16/2014), and summer 2014 (4/17/2014-6/24/2014). As seen in the individual home plots in Appendix H, RH becomes highly variable in the homes during this period. The influence of consistently warmer indoor temperatures can be seen in Home 2, and the influence of consistently cooler indoor temperatures can be seen in Home 7. Quantifying relationships between ventilation strategy and RH or space-conditioning energy in the flip-flop homes during the mixed periodwhen homes have a combination of heating, cooling, and floating space-conditioning operation-is difficult for the following reasons:

- A perfect biweekly flip-flop schedule was not adhered to because of holidays, vacations, and homeowner preferences. This resulted in differing amounts of time flip-flop homes spent in ventilation configurations, and it introduces bias when counting hours $\mathrm{RH}>60 \%$ as was done and as shown in Figure 6.

- During this time of the year in Florida, weather can be highly variable from one week to another, resulting in different average outdoor conditions among ventilation periods, preventing simple comparisons as were done as shown in Figure 7.

- Homeowner preferences for heating and cooling versus natural ventilation in the mixed period are highly variable, sporadic, and unpredictable.

However, the CEV and RTV control homes provide an opportunity to look at how instances of $\mathrm{RH}>60 \%$ change seasonally in homes with different ventilation strategies. Figure 15 shows the total number of hours the CEV control homes (Home 3 and Home 5) and the RTV control homes (Home 7 and Home 10) spent at RH $>60 \%$. The pie charts show the relative distribution of those hours during consistent cooling operation (summer 2013 and summer 2014) and during inconsistent space-conditioning operation ("mixed"). The hatching defines hours when no spaceconditioning operation occurred ("floating"). In the case of RTV homes, this also indicates hours when no mechanical ventilation was occurring.

Annual hours $>60 \%$ RH in CEV Home 3 and Home 5 generally match the simulation results presented by Martin (2014) for similarly constructed high-performance homes achieving ASHRAE 62.2-2013 standards with CEV in Orlando, Florida. One principal difference is Martin (2014) finds a nearly even mix of hours $>60 \%$ in cooling and floating, where these data show that more than $80 \%$ of the hours $>60 \%$ RH occur during floating operation. The discrepancy is likely due to the robotic nature of simulations, which activate space cooling anytime throughout the year when the interior temperature is greater than the cooling set point. In reality, homeowners in Florida often let their homes float above the summer cooling set point during the mixed period, when outdoor dew point temperatures are reasonably low. Minimal cooling system operation, and therefore minimal dehumidification during the mixed period, in part, accounts for the fact that the majority of hours $>60 \% \mathrm{RH}$ occur during the mixed period.

RTV Homes 7 and 10 also show that the majority of their hours $>60 \%$ RH occur while floating, mostly during the mixed period. However, occupant preferences in these homes make comparison to the CEV homes to investigate effects of ventilation strategy difficult. Note that RTV 7 maintains an exceptionally low cooling set point, resulting in exceptionally high space- 
conditioning runtime fractions (RTFs), and therefore barely any hours $>60 \% \mathrm{RH}$. Also note that RTV 10, while maintaining a reasonable set point profile (average, setup, and setback), has exceptionally low space-conditioning RTFs, resulting in its being the home with the greatest number of hours $>60 \% \mathrm{RH}$. A close look at the data reveals that this home has an exceptional ability to "coast" from the early morning hours through midafternoon to late afternoon without space-cooling operation, yet it is able maintain a reasonable interior temperature, even on warm days. This could result from the home's favorable orientation, window area, and exterior/interior shading.

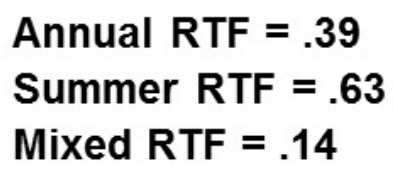

Avg. Summer Indoor Temp

$74.8(77 / 72){ }^{\circ} \mathrm{F}$

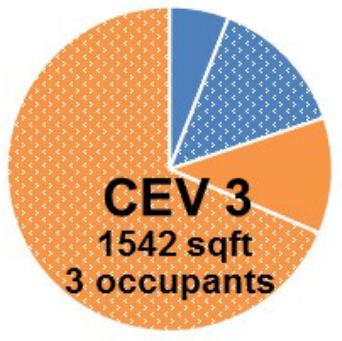

Annual Hrs $>60=2103$

Annual RTF $=.60$
Summer RTF $=.78$
Mixed RTF $=.42$

Avg. Summer Indoor Temp $72.6(74 / 71){ }^{\circ} \mathrm{F}$

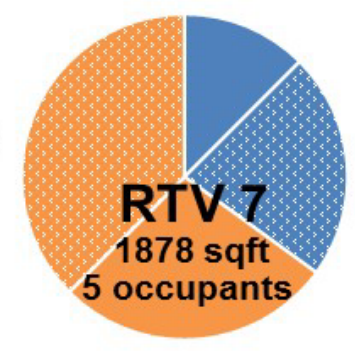

Annual Hrs $>60=40$

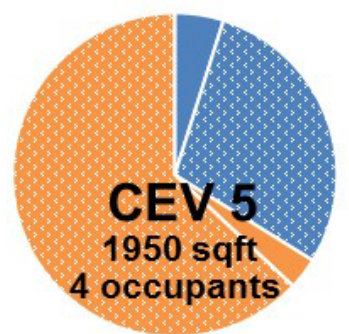

Annual Hrs $>60=1832$

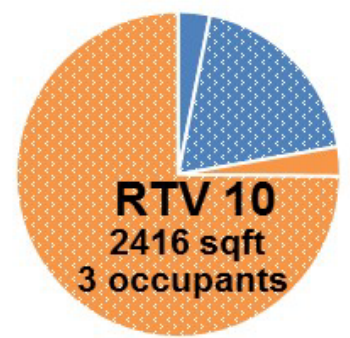

Annual Hrs $>60=2903$
Annual RTF $=.26$

Summer RTF $=.49$

Mixed RTF $=.03$

Avg. Summer Indoor Temp

$76.7(81 / 75){ }^{\circ} \mathrm{F}$
Annual RTF $=.18$

Summer RTF $=.30$

Mixed RTF $=.05$

Avg. Summer

Indoor Temp

$75.3(77 / 73){ }^{\circ} \mathrm{F}$

\section{Mixed}

\section{Summer (2013+2014)}

Floating

Figure 15. Number of hours $>60 \% \mathrm{RH}$, and their relative distribution among the cooling and mixed periods for CEV-control Homes $\mathbf{3}$ and 5 and RTV-control Homes 7 and 10

Space-conditioning runtime fractions (RTFs) are also shown along with the average summer indoor temperature (with monitored setup/setback profile).

The exceptional operational characteristics of RTV 7 and 10 make direct comparison for the purposes of identifying the influence of ventilation strategy on RH during a "swing" or "mixed" season difficult. However, it is evident from the control homes that whether CEV or RTV is in use, the vast majority of annual hours $>60 \% \mathrm{RH}$ occur in the absence of cooling system operation. This remains true even in RTV homes, where without space-conditioning operation, no mechanical ventilation is delivered. To some degree, this indicates that occupants, their preferences, and their habits play a large role in the resulting indoor RH during the variable mixed period. 
To isolate the effect of the mechanical ventilation strategy on indoor RH during the mixed period, a multivariable regression was performed with data from flip-flop and control homes. Ventilation strategy was found to be the least significant variable tested, with CEV adding 1.4 hours $>60 \%$ RH per day. This is much less than the 3.7 hours per day found in the summer 2013 regression. Considering the large increase in hours $>60 \% \mathrm{RH}$ in the mixed period compared to the summer 2013 cooling period, the regression underscores that other factors more significant than ventilation strategy are driving high $\mathrm{RH}$ during the mixed period. Variables found to be most significant for hours $>60 \% \mathrm{RH}$ during the mixed period were outdoor dew point temperature (as evident in Figure 5), the number of daily floating hours (as evident in Figure 15), indoor/outdoor temperature difference (an indicator of cooling system runtime - also evident in Figure 15), and conditioned house size. ACH50 was not found to be a significant variable during this period.

Analyzing $\mathrm{CO}_{2}$ data during the mixed period provides an opportunity to evaluate relative air change in homes operating under RTV during this period. Because RTV systems inherently depend on space-conditioning runtime to deliver ventilation, minimal runtime during the mixed season could likely result in minimal air change. However, occupant preferences for natural ventilation could produce air exchange rates similar to what was found in the summer 2013 season or rates that are even greater. Upon investigating the individual home plots in Appendix $\mathrm{H}$, it is evident that, compared to the summer 2013 period, the influence of ventilation strategy on indoor $\mathrm{CO}_{2}$ concentration among homes is less consistent. In some cases, such as in Home 6, $\mathrm{CO}_{2}$ concentration seems equally or even less variable among the ventilation strategies. In other cases, such as with Home 9, consistently higher average indoor $\mathrm{CO}_{2}$ concentrations are seen with RTV during the mixed period compared to the summer period. This variance is also seen in Figure 16, which compares daily average $\mathrm{CO}_{2}$ concentrations during the mixed period between RTV and CEV operation.

Comparing Figure 16 to Figure 10 does not reveal a direct correlation of $\mathrm{CO}_{2}$ concentration and time of year (summer versus mixed period). However, it is worth noting that in both the summer (Figure 10) and winter/mixed (Figure 16) analysis periods, the highest $\mathrm{CO}_{2}$ concentrations are observed in RTV homes, which may suggest that the RTV ventilation strategy is not providing as much dilution or air exchange as the CEV system (see Section 3.2.1). However, comparing Figure 16 to Figure 12 shows that Home 2 and Home 6- the two flip-flop homes with the least difference between the RTV and CEV periods in the heating season-also have among the highest heating energy of all homes. Because high heating energy use would also suggest higher space-conditioning runtime and, thus, increased ventilation during the RTV periods compared to the other RTV homes, it is possible that the effective ventilation achieved between the CEV and RTV systems in these homes is similar. However, as discussed in Section 3.2.1, the amount of ventilation air provided during the RTV periods is still 38\% and 44\% lower than the ventilation air provided during the $\mathrm{CEV}$ periods, suggesting system type may play a role in the amount of ventilation air required to reach a desired level of air exchange. 


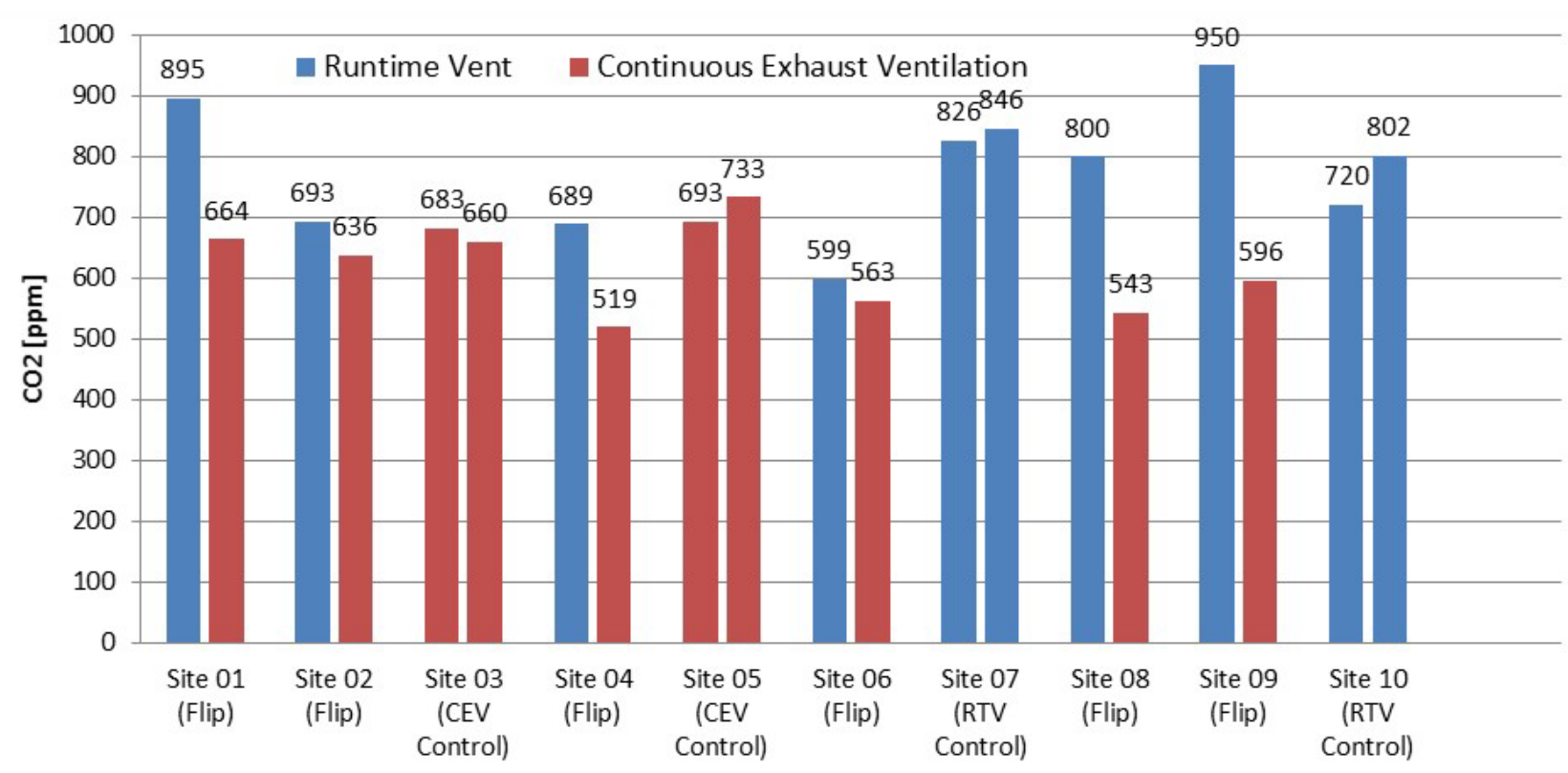

Figure 16. Daily average $\mathrm{CO}_{2}$ concentration during the mixed period, broken into runtime ventilation (left bar) and continuous exhaust (right bar) periods

To isolate whether there is a significant difference in air change in the RTV homes between the summer and mixed period, a multivariable regression was performed on data involving RTV operation only.

\subsection{Seasonally Sampled Parameters}

The data collected during the initial paired IAQ sampling periods were analyzed to determine the difference in interior concentrations of formaldehyde, acetaldehyde, VOCs during the IAQ sampling weeks. In addition, the AER was determined during each one-week IAQ sampling period. Over the course of the one-year study period, six one-week IAQ sampling periods were conducted. The IAQ sampling periods were conducted in pairs to enable the IAQ measurements to be sampled when the flip-flop homes were in both the RTV and the CEV configurations in each season, as shown in Table 6. 
Table 6. IAQ Sampling Time Periods and Configuration of Flip-Flop Homes

\begin{tabular}{|l|l|l|l|}
\hline \multirow{3}{*}{ Season } & $\begin{array}{l}\text { IAQ Sampling } \\
\text { Period }\end{array}$ & Dates & $\begin{array}{l}\text { Flip-Flop Homes } \\
\text { Configuration }\end{array}$ \\
\hline \multirow{2}{*}{ Summer 2013} & SUM1.1 & $8 / 14 / 2013-8 / 20 / 2014$ & RTV \\
\cline { 2 - 4 } & SUM1.2 & $9 / 18 / 2013-9 / 26 / 2013$ & CEV \\
\hline \multirow{2}{*}{ Winter/Mixed 2014 } & WIN1 & $3 / 19 / 2014-3 / 27 / 2013$ & RTV \\
\cline { 2 - 4 } & WIN2 & $4 / 10 / 2014-4 / 17 / 2014$ & CEV \\
\hline \multirow{2}{*}{ Summer 2014 } & SUM2.1 & $7 / 16 / 2014-7 / 23 / 2014$ & RTV \\
\cline { 2 - 4 } & SUM2.2 & $8 / 12 / 2014-8 / 20 / 2014$ & CEV \\
\hline
\end{tabular}

a Control homes are in the RTV or CEV state for all sampling periods.

The first IAQ sampling period occurred from August 14 to August 20, 2013, during a period when the flip-flop homes were in the RTV configuration. The second of the paired sampling periods occurred from September 18 to September 26, 2013, when the flip-flop homes were in the configuration with the exhaust fan in the bathroom always on to deliver the amount of ventilation air required by ASHRAE 62.2-2010 (CEV). For the first of the paired sampling periods, the IAQ sampling occurred the second week of the two-week period the homes were in the RTV configuration, while for the second of the paired sampling periods, the IAQ sampling occurred the first week of the two-week ventilation flip-flop. During this first summer sampling period, the second sampling was delayed because of homeowners or equipment were unavailable. The homes were flip-flopped every two weeks, as designed in the experimental plan. However, the second of the IAQ sampling periods was delayed until the subsequent CEV period, and a flip-flop occurred between the first and second sampling periods, as shown in Table 7.

Table 7. Timing of IAQ Sampling and Ventilation Flip-Flop During the First Summer Sampling Period

\begin{tabular}{|l|l|l|}
\hline Event & Dates & $\begin{array}{l}\text { Flip-Flop Homes } \\
\text { Configuration }\end{array}$ \\
\hline Switch to Ventilation Configuration A & $8 / 8 / 2013$ & RTV \\
\hline Deploy IAQ Samplers & $8 / 14 / 2013$ & RTV (no change) \\
\hline $\begin{array}{l}\text { Pick up IAQ Samplers and Switch to } \\
\text { Ventilation Configuration B }\end{array}$ & $8 / 20 / 2013$ & CEV \\
\hline Switch to Ventilation Configuration A & $9 / 3 / 2013$ & RTV \\
\hline Switch to Ventilation Configuration B & $9 / 17 / 2013$ & CEV \\
\hline Deploy IAQ Samplers & $4 / 10 / 2014$ & CEV (no change) \\
\hline Pick up IAQ Samplers & $4 / 17 / 2014$ & RTV \\
\hline
\end{tabular}

While this arrangement is different than those experienced in subsequent sampling periods, it is believed such an arrangement does not significantly affect the comparability of the results obtained, especially for the second sampling period. The weather between the first and second 
sampling periods was similar during this (and subsequent) paired sampling periods, such that climatic effects should not play a significant role. Further, the samples are taken indoors and corrected for changes in outdoor concentrations, and each home, for the most part, is maintained at a consistent indoor temperature. As noted above, some homes were maintained at warmer or cooler temperatures because of homeowner preference, which would affect the extent of chemical off-gassing.

With regard to the comparability of data depending on whether the IAQ sampling period occurred the first week or second week of the two-week flip-flop, the authors believe, based on previous studies, that such timing would be unlikely to significantly affect the measurements, as the IAQ samples were passive one-week samples. Data collected from Willem et al. (2013) suggest that the time to respond to a change in ventilation rate is two days. It is possible that in the first week, emission rates of certain contaminants may be temporarily higher or lower than their steady-state value as the home adjusts to a new ventilation configuration. However, such changes are generally believed to occur over the course of several hours and up to one day. Because the one-week IAQ sampling period would then capture at most one transition day and at least ${ }^{16}$ six steady-state days, we do not believe the effect of the transition day would significantly impact the ability of the measurement to represent the "steady-state" characteristics of a given ventilation period. It is also worth noting that many things do significantly affect IAQ measurements in occupied homes, including homeowner activities. While homeowners were asked to limit their activities during the IAQ sampling weeks to only "typical" activities that may affect IAQ, the variability from this factor likely far outweighs any variability incurred from the timing of IAQ sample weeks with respect to flip-flop ventilation periods.

The second paired IAQ sampling period occurred in March and April of 2014 in conditions that included some heating energy use, representative of the winter season for Florida. The first sample was taken from March 19 to March 27, 2014, and the flip-flop homes were in the RTV configuration. The second of this "winter/mixed" paired sample occurred from April 10 to April 17, 2014, when the flip-flop homes were in the CEV configuration. For this sampling period, the IAQ sampling occurred during the second week of the two-week ventilation flip-flop periods in both cases, and no flip flops occurred in between.

IAQ sampling was repeated in the summer of 2014 to investigate the repeatability and consistency of the observed trends in each season. This second summer paired sampling period occurred from July 16 to 23, 2014, and from August 12 to 20, 2014. For this sampling period, as with the previous sampling periods, the first IAQ samples were collected when the flip-flop homes were in the RTV configuration and the second IAQ samples were collected when the flipflop homes were in the CEV, or ASHRAE 62.2-compliant, configuration. In this case, both samples were also collected during the latter portion of the flip-flop period; that is, the home had already been in the sampled ventilation configuration for at least one week. It is worth noting that during this sampling period, an additional 19 days elapsed between the first sampling period and the second sampling period to accommodate homeowner vacation schedules. The authors

\footnotetext{
${ }^{16}$ Some sample periods were approximately one week long, but the sample periods ranged from six to eight days in most cases to accommodate homeowner schedules. In all cases, the specific sampling duration (in hours) was recorded and used for subsequent quantification of the sample volumes.
} 
elected to delay sampling to capture periods that would be representative of normal occupancy. During this 19-day period, the home was maintained in the CEV configuration throughout and no intermediate flip flops occurred.

Occasionally, sample deployment or retrieval occurred on the day before or after the date noted in Table 6 to accommodate homeowner schedules. In each case, the precise time and date of sampler deployment and retrieval were recorded for each sampler (or emitter) in each house so that the specific sample volume was known. However, the sample volume was sometimes up to 24 hours longer or shorter than the originally envisioned seven-day period.

Also, because sampling during the three paired IAQ sampling periods always involved first sampling the flip-flop homes in the RTV configuration and then in the CEV configuration, the order of ventilation configuration samples could have been a source of bias in results. The effect of any bias would depend on the storage capacity and change of emission rate of household materials as a function of any change in ventilation rate or spatial pressure distributions caused by the change in ventilation approach.

\subsubsection{Air Change Rate}

The observed AER was measured using passive PFT gas emitters and samplers over each oneweek sampling period. In each home, two to three PFT samplers were deployed, depending on the size of home.

Using the PFT data, the AER was calculated for each home as the total hourly emission rate of PFT for the emitters deployed in the home, divided by the volume of the home, divided by the average measured concentration of PFT, as shown in the following equation:

$$
A E R\left[h r^{-1}\right]=\frac{E_{\text {Total }}[\mu g / h r]}{V\left[m^{3}\right] \times C_{\text {avg }}\left[\mu g / m^{3}\right]}
$$

The AER was calculated for each home and each sampling period. However, because of the variability in the PFT data, the AERs calculated based on these measurements do not provide sufficient granularity to determine any changes based on the ventilation strategy. Therefore, the impact of different ventilation schemes was also calculated based on mechanical and infiltrationdriven air flows. Specifically, the unbalanced air flow rate from mechanical ventilation was calculated based on the runtime of the ventilation system and the measured flow rate, as installed. The measured flow rate was taken using an exhaust fan flow box at the time of installation, as described in Section 2.2.1.

For homes in the CEV configuration, the ventilation fan flow rate was that of the bathroom exhaust fan, and the runtime was $100 \%$. For homes in the RTV configuration, the ventilation fan flow rate was the air flow through the outdoor air duct connected to the air handling unit (AHU), and the runtime fraction was determined based on the measured energy consumption of the AHU in a given hour expressed as a percentage of energy consumption if the AHU ran continuously for an entire hour. The infiltration-related component of AER was calculated using the known air leakage measured with the blower door and characteristics of the homes. The calculated 
mechanical and infiltration-driven air flows were combined using quadrature in accordance with the methods described in the ASHRAE Fundamentals Handbook (ASHRAE 2013a).

The AERs for the two ventilation configurations were compared in each season based on the theoretical calculations described above; they are shown in Figures 17, 18, and 19.

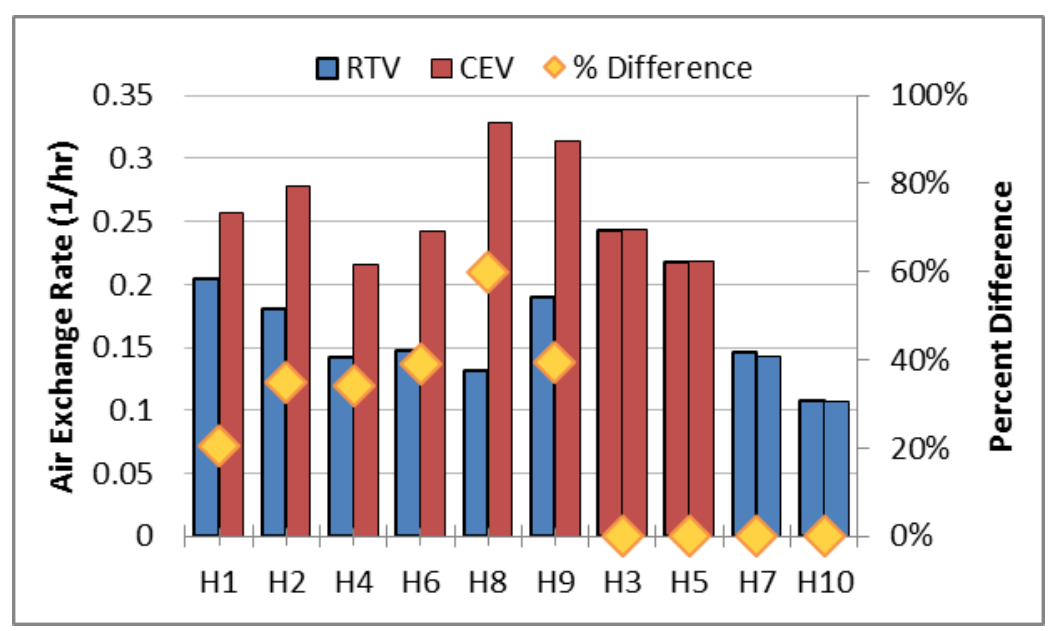

Figure 17. Overall AER determined in each of the RTV and CEV homes in the first summer sampling period

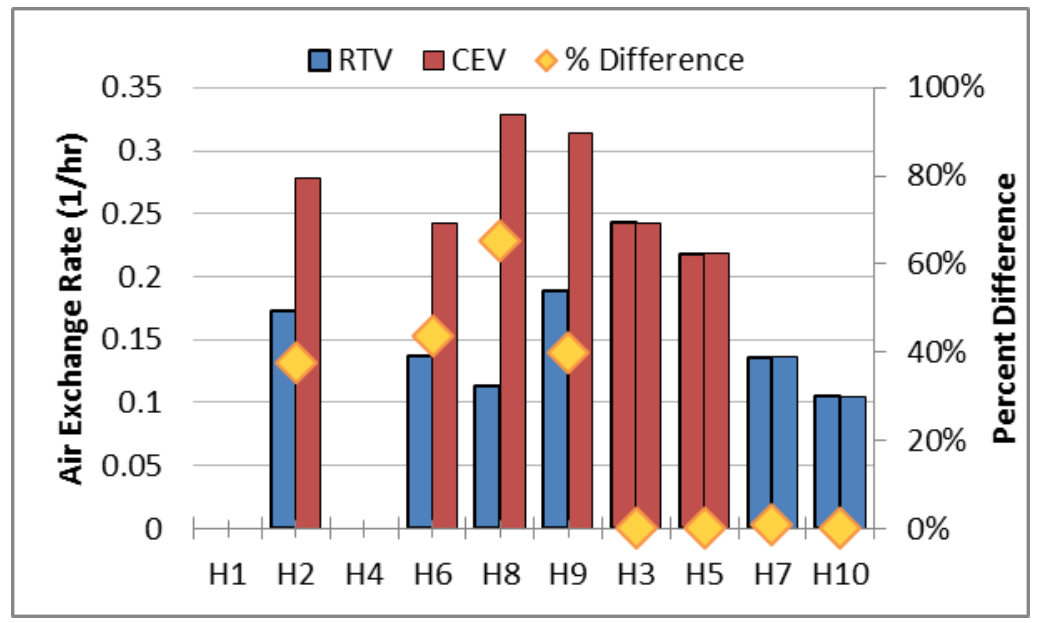

Figure 18. Overall AER determined in each of the RTV and CEV homes in the winter sampling period 


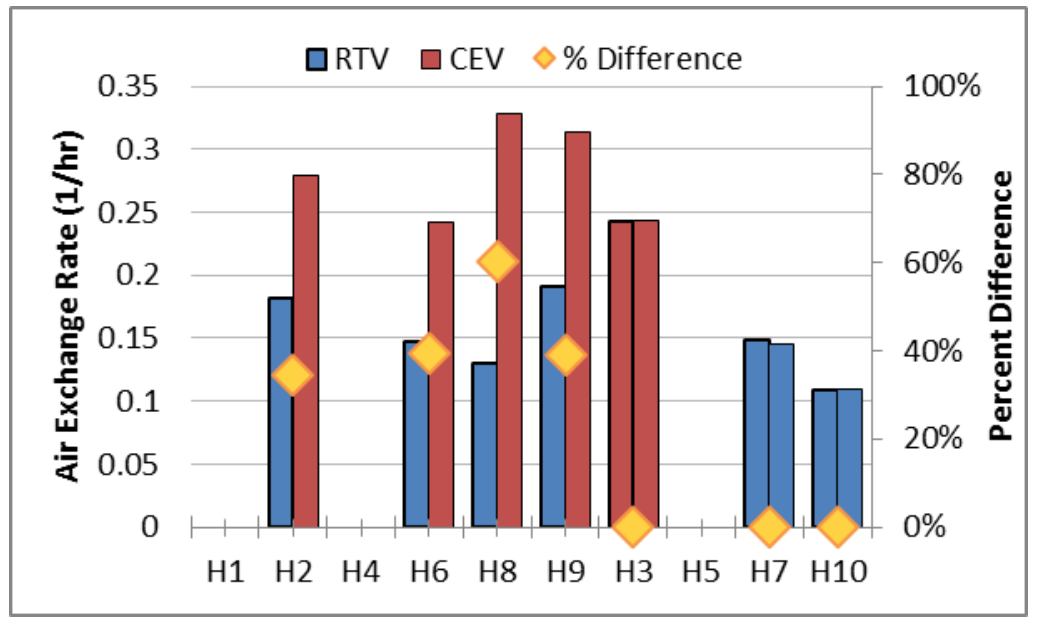

Figure 19. Overall AER determined in each of the RTV and CEV homes in the second summer sampling period

In general, the CEV ventilation strategy resulted in AERs that were 30\% higher than they were with the RTV configurations in the flip-flop homes and mechanical ventilation rates that were $79 \%$ higher. The difference in AER between the two ventilation strategies is less extreme than the difference in mechanical ventilation flow rate because of the impact of infiltration air on overall air exchange rate. For RTV homes, the unbalanced mechanical ventilation flow rate was an average of $28 \%$ of total mechanical and infiltration-driven ventilation airflow in the summer and $5 \%$ in the winter, while for CEV homes, the mechanical ventilation flow rates were $82 \%$ and $84 \%$ of the total airflow for the summer and winter, respectively.

Interestingly, despite significantly lower runtimes, the AERs in the winter/mixed season for the RTV homes were only 6\% lower than those determined in the summer. Specifically, during the summer season, RTFs were around 0.40, while in the winter, RTFs ranged from 0.05 to 0.19 , with an average of 0.12 . However, the infiltration component of the airflow dominates the calculated AER in both the summer and the winter season, resulting in less significant changes in overall AER even though the unbalanced mechanical ventilation provided in the summer is higher than it is in the winter.

In addition, the difference in AER calculated between the RTV and CEV ventilation periods was not observed to consistently impact the average $\mathrm{CO}_{2}$ concentration in each home and sampling period. In the first summer sampling period, in Homes 1, 2, 4, and 6, the percentage increase in AER due to the change in ventilation strategy was observed to decrease the $\mathrm{CO}_{2}$ concentration a similar amount, suggesting an inverse linear relationship, as shown in Figure 20. In the other homes, the change in AER was observed to decrease the $\mathrm{CO}_{2}$ concentration but not in proportion to the change in AER. 


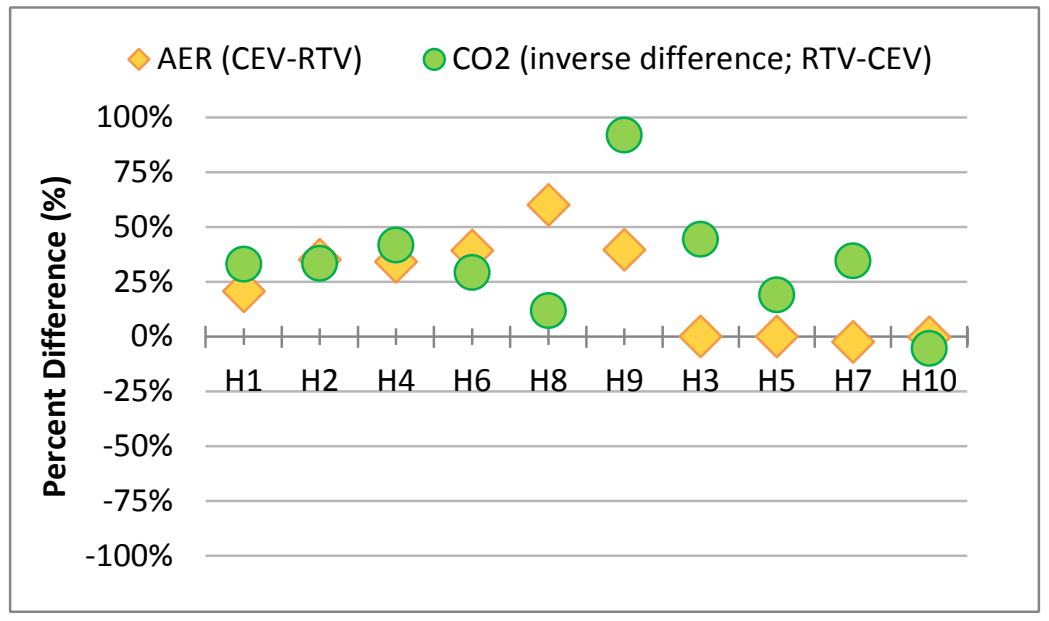

Figure 20. Relationship of percent difference in AER (calculated as [CEV-RTV]/RTV) and percent difference in $\mathrm{CO}_{2}$ concentration (calculated as [RTV-CEV]/RTV) for first summer sampling period

In subsequent sampling periods, most homes diverged from the previous inverse linear relationship (except one control home, Home 3, which did not change significantly in AER or $\mathrm{CO}_{2}$ concentration between the sampling weeks). In the winter/mixed sampling period, the average $\mathrm{CO}_{2}$ concentrations in all flip-flop homes increased when moving from RTV to CEV, even though the AER increased.

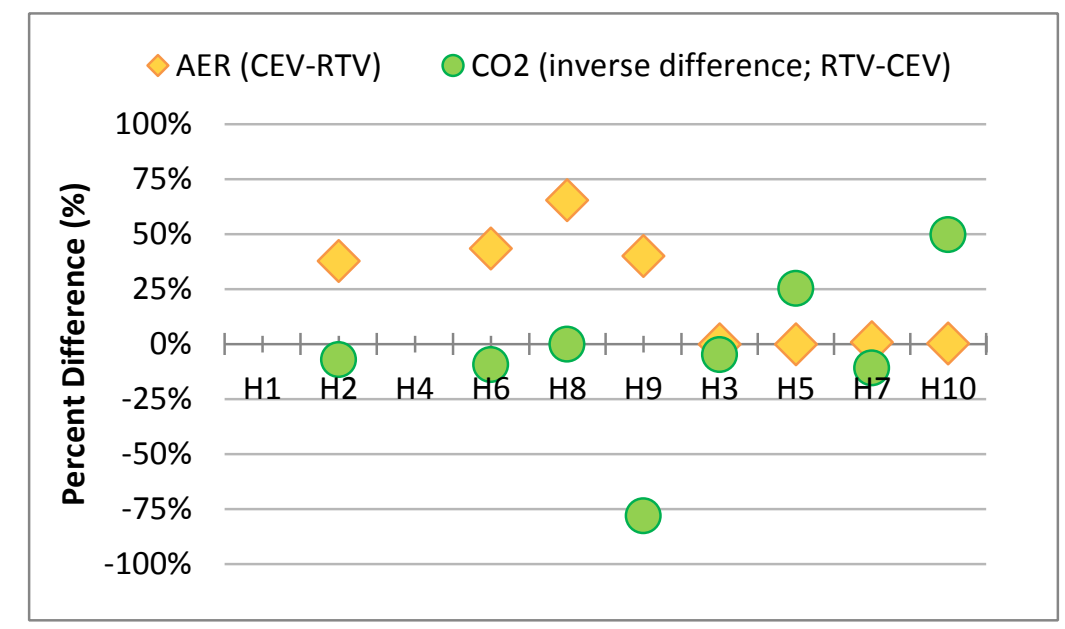

Figure 21. Relationship of percent difference in AER (calculated as [CEV-RTV]/RTV) and percent difference in $\mathrm{CO}_{2}$ concentration (calculated as [RTV-CEV]/RTV) for winter/mixed sampling period

In the second summer sampling period, the relationship between relative increase in AER and relative decrease in $\mathrm{CO}_{2}$ concentration is varied; in Home 1 and Home 3, the relationship is still somewhat inverse linear, although it is not proportional. In Home 6 and Home 9, the opposite trend is observed (i.e., an increase in $\mathrm{CO}_{2}$ concentration is observed despite an increase in AER). In Home 7 and Home 10, the AER did not change from one week to another, but the $\mathrm{CO}_{2}$ concentration in Home 7 decreased. If $\mathrm{CO}_{2}$ is a reasonable indicator for dilution effectiveness, these data suggest the $\mathrm{CEV}$ method may not provide better dilution in all cases. However, the 
variability of the $\mathrm{CO}_{2}$ data also suggest that many factors may affect the average $\mathrm{CO}_{2}$ concentration in homes, such as occupancy, and that these other factors may overwhelm the impact of different ventilation strategies.

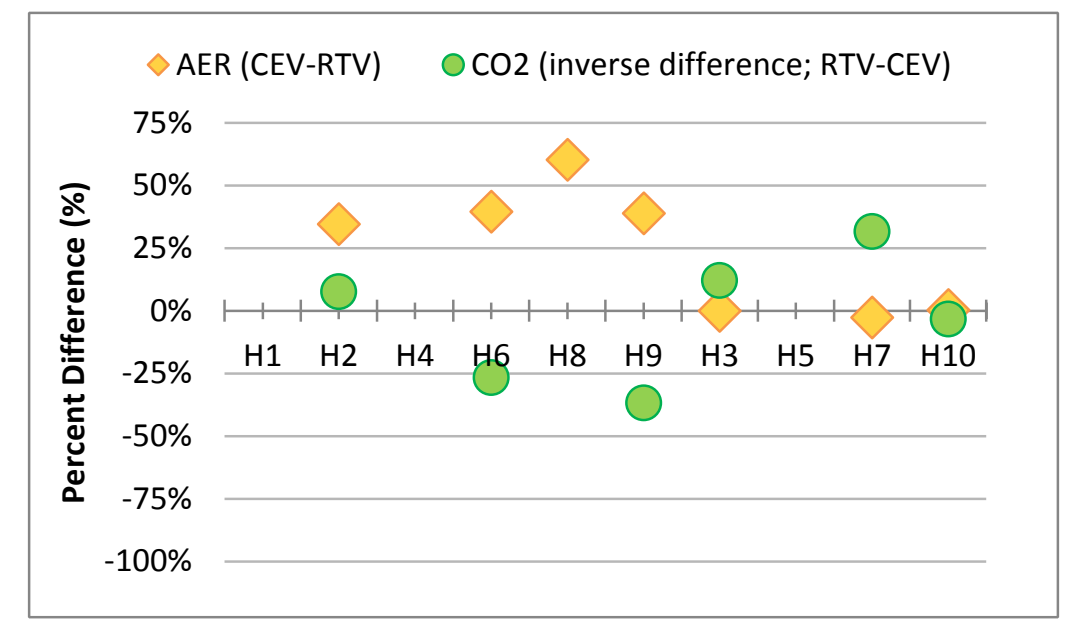

Figure 22. Relationship of percent difference in AER (calculated as [CEV-RTV]/RTV) and percent difference in $\mathrm{CO}_{2}$ concentration (calculated as [RTV-CEV]/RTV) for second summer sampling period

The complete calculated AER and ventilation flow rate data are provided in Appendix K.

\subsubsection{Formaldehyde}

Formaldehyde is one of the most important air contaminants measured in new homes, because it is frequently found in levels above the National Institute for Occupational Safety and Health (NIOSH)-recommended chronic exposure limit (chREL) of 16 ppb (CDC 2011; Rudd and Bergey 2014; Hun et al. 2014; Offerman 2009; Salthammer et al. 2010). In this study, formaldehyde levels in all of the study homes were similarly found to be higher than the NIOSHrecommended level, and the levels found were consistent with average concentrations measured in other newly constructed U.S. homes (Salthammer et al. 2010). It should be noted that the NIOSH-recommended exposure limit is one of the strictest in the world; the limit is set based on (1) the fact that formaldehyde is a known carcinogen (Salthammer et al. 2010) and (2) a philosophy that exposure to carcinogenic compounds should kept below the limit of detection (CDC 2011). By comparison, the Occupational Safety and Health Administration (OSHA)permissible level for chronic exposures to formaldehyde is much higher (750 ppb). However, the OSHA limit is designed primarily for work environments where eight-hour exposures are typical, while people are often in their homes significantly more than eight hours per day. The authors note that there is significant variability in the recommended standard limit for formaldehyde both domestically and internationally, indicating some disagreement on the potential for harmful effects resulting from chronic exposure to low levels of formaldehyde. Specifically, the NIOSH chREL is higher than that established in California by the Office of Environmental Health Hazard Assessment under the California Environmental Protection Agency, which establishes a chREL of 9 ppb (OEHHA 2014), and it is significantly lower than the "no observed adverse effect level" established by the World Health Organization of 
approximately $81 \mathrm{ppb}$ (specified as $0.1 \mu \mathrm{g} / \mathrm{m}^{3}$; WHO 2010) or the OSHA time-weighted average, permissible exposure limit.

Because formaldehyde concentrations will vary based on the materials used in home construction and the activities of the occupants, formaldehyde data were analyzed by comparing the changes in formaldehyde levels in the flip-flop homes to those observed in the control homes (which should account for any weather-related effects).

The formaldehyde concentrations in each home and each sampling period were also corrected to account for the outdoor concentration of formaldehyde measured during that sampling period and they were blank-corrected. The blank- and outdoor-corrected concentrations of formaldehyde measured in the homes in each of the sampling periods are presented in Figure 23, Figure 24, and Figure 25, for the summer, winter, and second summer sampling periods, respectively.

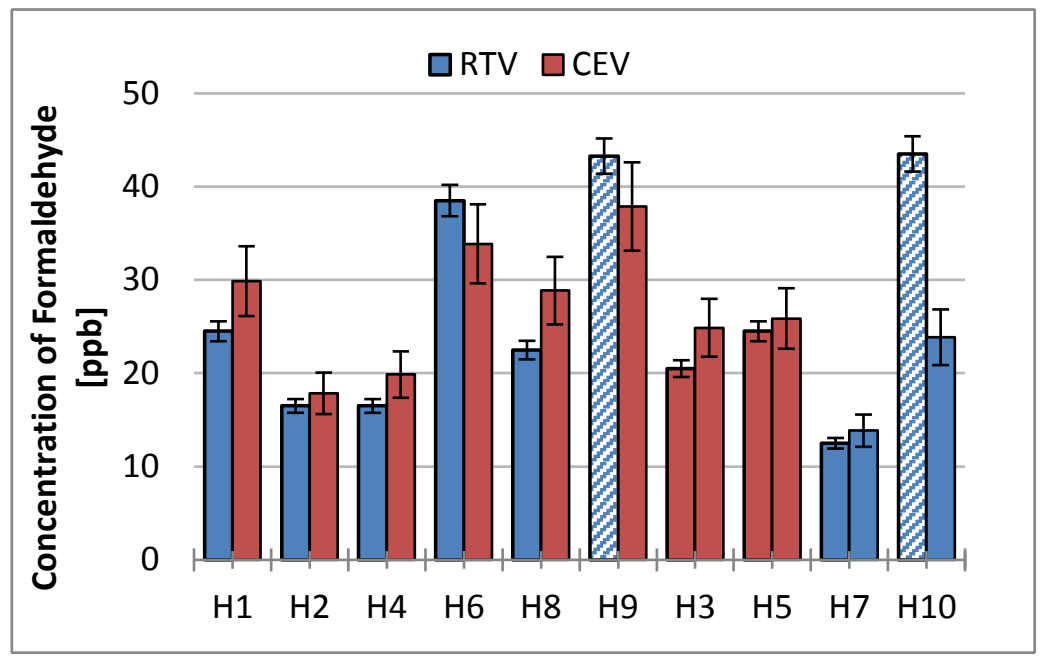

Figure 23. Concentrations of formaldehyde (ppb) in Home 1 through Home 10 during the first summer IAQ sampling period

Striped bars indicate unusual data. 


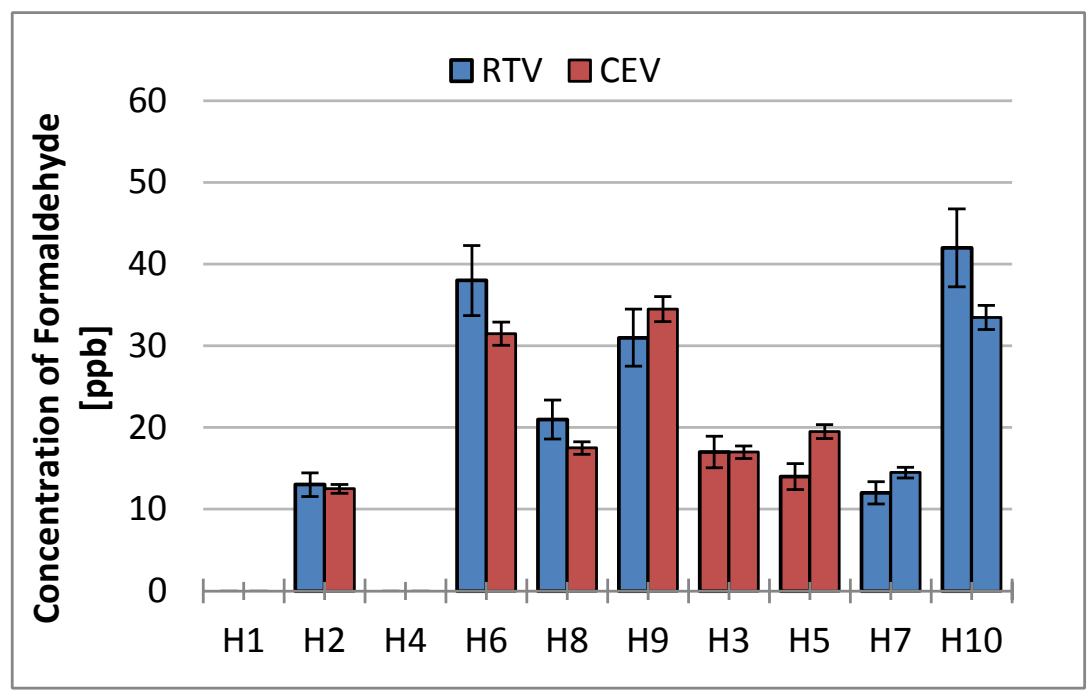

Figure 24. Concentrations of formaldehyde (ppb) in Home 1 through Home 10 during the winter IAQ sampling period

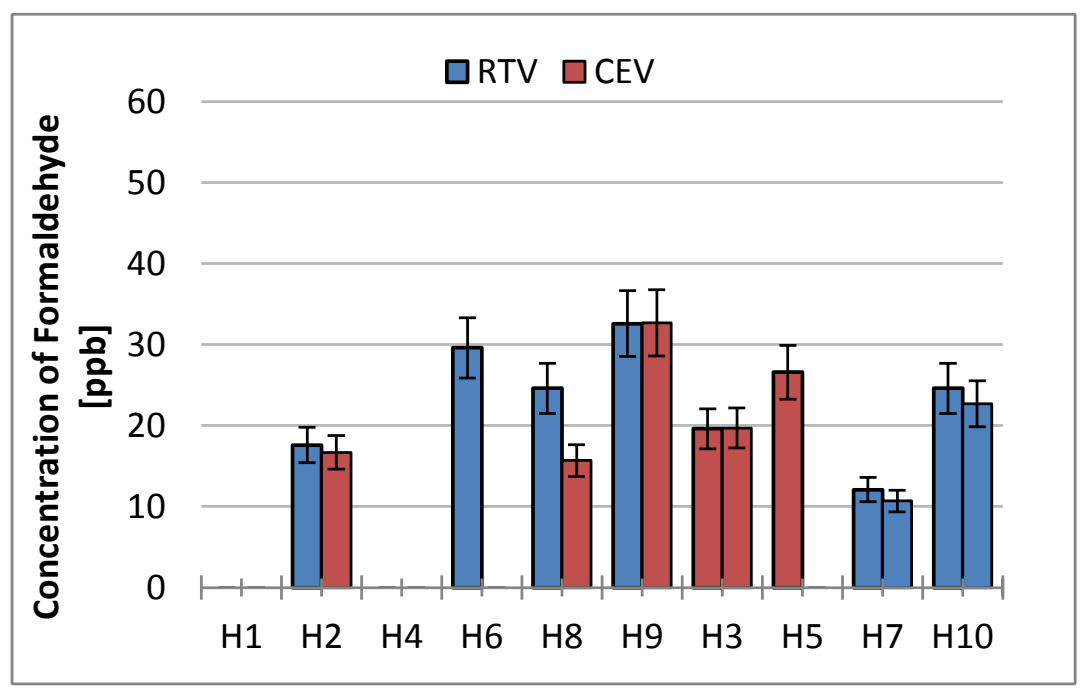

Figure 25. Concentrations of formaldehyde (ppb) in Home 1 through Home 10 during the second summer IAQ sampling period

The difference between homes with RTV versus those with CEV was variable among the homes, and it was difficult to discern clear trends as a function of ventilation strategy (e.g., RTV versus $\mathrm{CEV}$ ). In the first summer sampling period, formaldehyde levels increased in many of the flipflop homes between the RTV ventilation configuration (first week) and the CEV ventilation configuration (second week) despite an average increase in theoretical AER of $30 \%$ and an increase in mechanical ventilation flow rate of $79 \%$. However, slight increases were also observed in the CEV control homes (Home 3 and Home 5) and one of the RTV control homes (Home 7). Home 10 exhibited unusual behavior, with very high concentrations measured during the first summer sampling period and much lower concentrations measured during the second sampling period. The authors hypothesize this may be due to the introduction of new furnishings 
or a specific cleaning event that led to the unusually high concentrations. Notably, Home 10 had the lowest calculated AER (see Section 3.2.1); however, this does not explain the variability from one week to another in the house observed in the first summer sampling period.

In addition, the measurement in Home 9 during the first sampling period taken with the study samplers appears to be an outlier based on the data. After further investigation, it was determined that the sampling cap was erroneously left on the sampler. During the first summer sampling period, duplicate formaldehyde data were collected, using both UMEx 100 and Waters Sep Pak Xposure samplers. In general, the XPosure samplers reported 32\% higher concentrations of formaldehyde than the UMEx 100 samplers (see Appendix J). In the case of Home 9, the data from the duplicate XPosure data were used, and they were corrected for the average bias observed between the two samplers so that the data could be better compared to the other measurements collected using the UMEx 100 samplers. The formaldehyde concentration reported with the Xposure sampler-even after being corrected based on the average increased concentration reported by the Xposure samplers, compared to the UMEx 100 samplers - is the highest reported concentration among all the homes and sampling periods. Comparing Figure 10 with Figure 19, Home 9 also exhibited one of the highest $\mathrm{CO}_{2}$ concentrations during the first summer analysis period; while the data are inconclusive, high $\mathrm{CO}_{2}$ and $\mathrm{HCHO}$ measurements suggest a low effective AER in this home using the RTV method. The theoretical AER measurements discussed in Section 3.2.1 do not suggest lower AER than the other RTV homes; however, the theoretical calculations may not account for the effective dilution rate, which may be impacted by other factors, such as distribution and mixing.

In the winter and subsequent second summer sampling periods, there were also no clear relationships between the formaldehyde concentration and ventilation approach. Thus, it is difficult to make strong conclusions regarding the relationship of the absolute formaldehyde concentration to ventilation approach based on the data.

In addition to the absolute formaldehyde concentrations, the percentage change in formaldehyde concentrations was also analyzed and compared among the sampling periods and homes. Figure 26, Figure 27, and Figure 28 show the absolute difference (in ppb) and the percentage difference in formaldehyde concentration observed in each of the homes for each of the sampling periods. Based on these data, the percentage change between each of the sampling periods for the flipflop and control homes was compared. However, as discussed above, no significant difference or trend was observed with respect to ventilation strategy. 


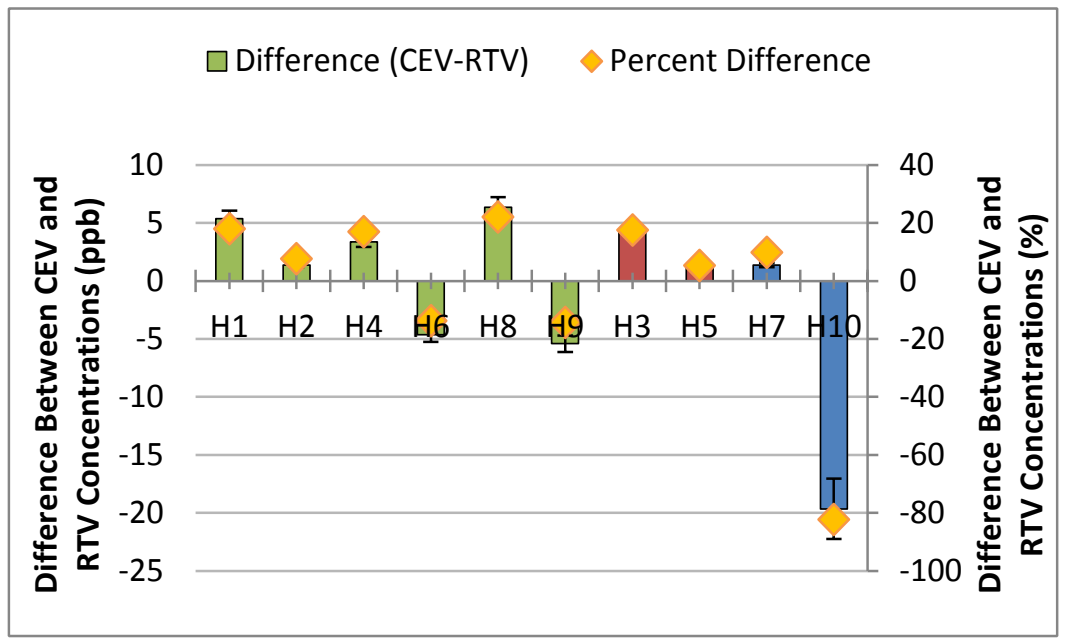

Figure 26. Absolute (ppb) and percent (\%) difference in concentrations of formaldehyde in Home 1 through Home 10 during the first summer IAQ sampling period

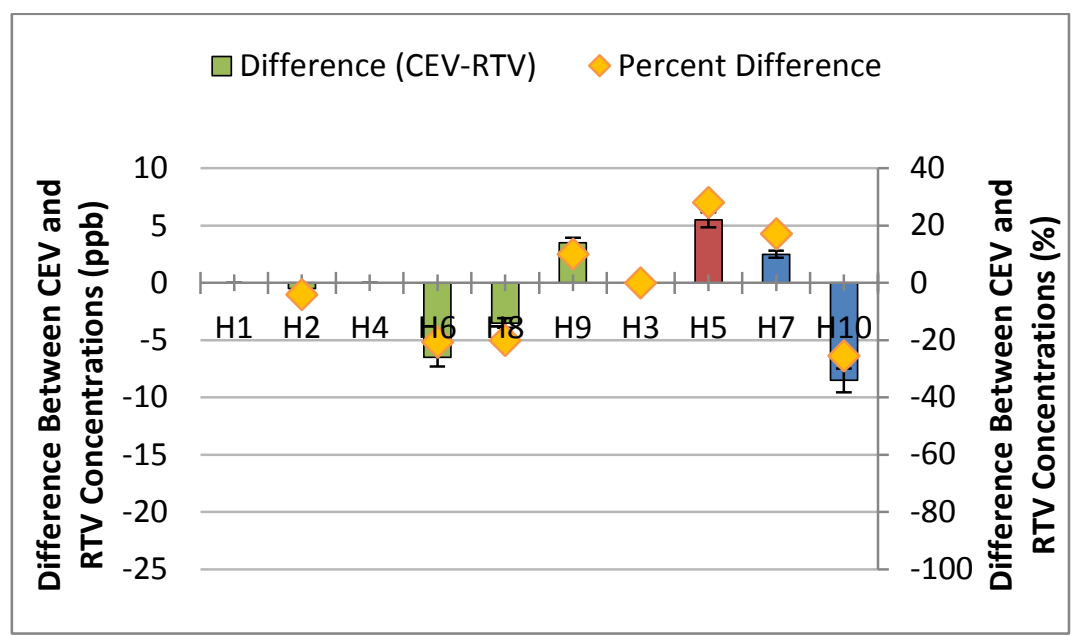

Figure 27. Absolute (ppb) and percent (\%) difference in concentrations of formaldehyde in Home 1 through Home 10 during the winter IAQ sampling period 


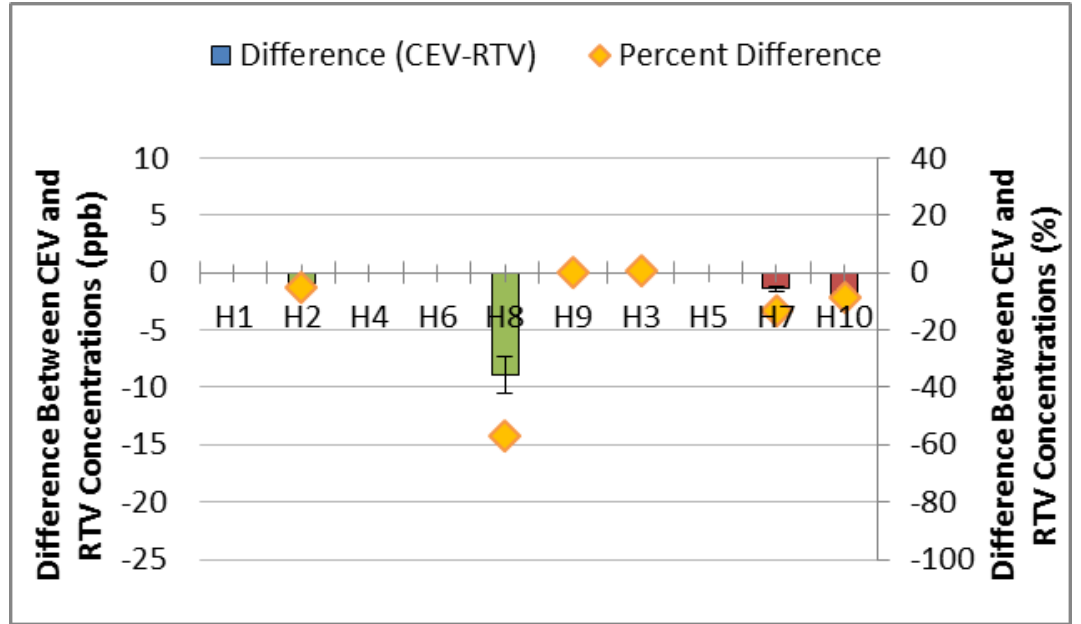

Figure 28. Absolute (ppb) and percent (\%) difference in concentrations of formaldehyde in Home 1 through Home 10 during the second summer IAQ sampling period

While no significant trend between ventilation approaches (RTV versus CEV) was observed, it is worth noting that the observed (estimated) AER was significantly higher in the homes in the CEV configuration than it was in homes in the RTV configuration, as shown in Section 3.2.1. Thus, it is somewhat unexpected that a commensurate decrease in formaldehyde concentration was not observed with increasing ventilation rate and overall AER. This finding conflicts with the results of previous research that have suggested, despite the dependence of formaldehyde emission rates on concentration, increasing ventilation rate will decrease formaldehyde concentrations (Lajoie et al. 2015; Hult et al. 2014). However, these previous studies isolated the impact of ventilation rate, which increases the amount of ventilation air provided with the same ventilation strategy. The results of this study suggest that ventilation strategy may be a significant factor in determining the overall efficiency of ventilation systems and that, despite significantly higher AER and mechanical ventilation flow rates, the CEV ventilation system was not more effective than the RTV system at diluting formaldehyde concentrations. This result is consistent with other research that has analyzed different ventilation system types. Specifically, Hun et al. (2014) have also observed reduced efficacy of exhaust-only ventilation in reducing formaldehyde concentrations. Rudd and Bergey (2013) measured lower formaldehyde concentrations in a study house ventilated with the supply-based continuous fan integrated supply (CFIS) system than in the same house when it was ventilated with an exhaust fan and similar effective ventilation rates. Though not comparing exhaust versus supply-based systems, Offerman (2009) also identified that formaldehyde concentrations were higher in homes with mechanical dedicated outdoor air ventilation systems than in homes with heat recovery ventilators, although this difference may have been due to a variety of factors, including effective ventilation rate, distribution, or differences in house characteristics and occupancy.

When the formaldehyde concentrations in each home (Figure 29) are analyzed, formaldehyde levels generally appear to decrease over time in some homes and more significantly in homes with higher initial concentrations. This confirms the general understanding of the nature of offgassing and emission rates over time in homes. However, because of changes in temperature and $\mathrm{RH}$ - as well as climate - between sampling periods (especially summer to winter/mixed), we 
may not expect to see a decrease over all sampling periods. Notably, in Homes 2, 3, and 5, the formaldehyde concentration during the second summer sampling period increased following the winter/mixed sampling period, and it returned to levels more consistent with the previous first summer sampling period.

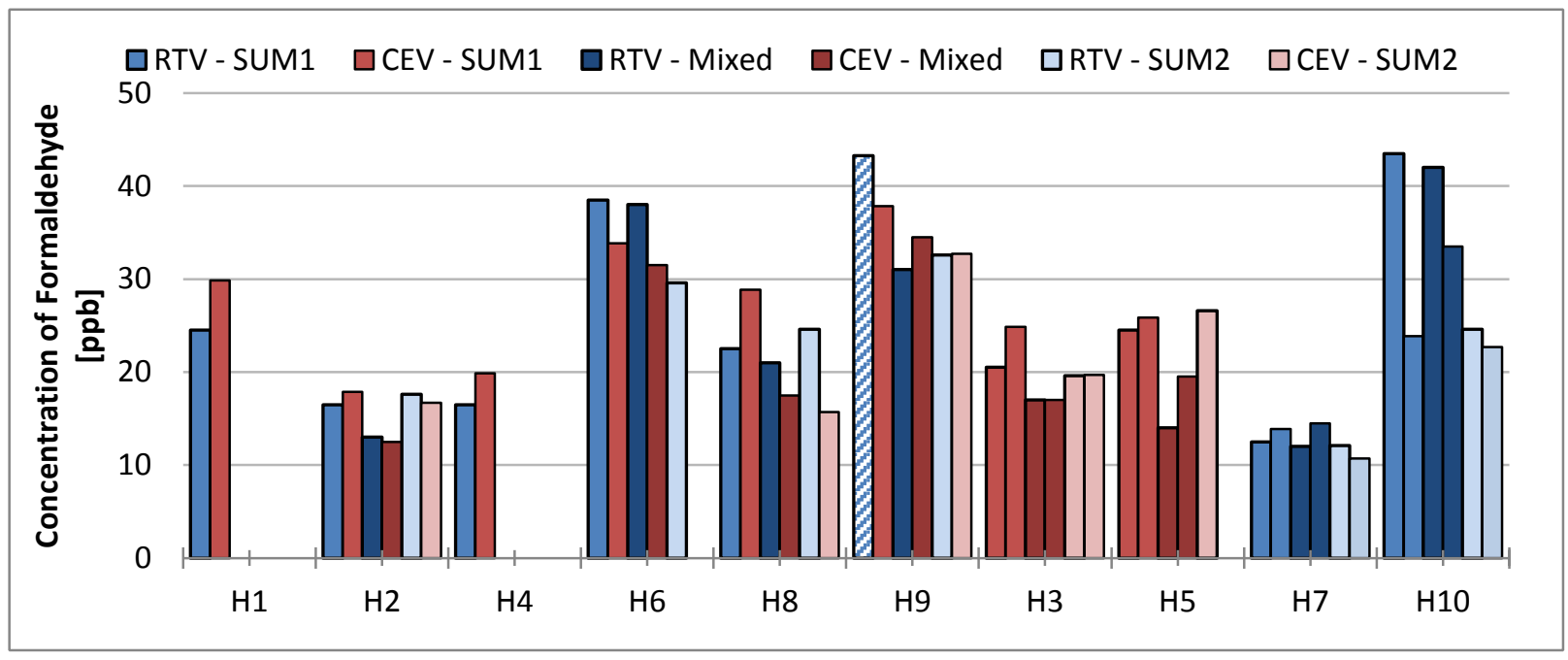

Figure 29. Concentrations of formaldehyde (ppb) in all homes during all sampling periods

\subsubsection{Acetaldehyde}

Acetaldehyde was also sampled in all of the homes and outdoors on the same aldehyde sampler as the formaldehyde measurements were made (see Section 1.1.1). In general, concentrations of acetaldehyde measured in these homes were very low, ranging from $0.7 \mathrm{ppb}$ to $6.0 \mathrm{ppb}$ during all the sampling periods, as shown in Figure 30. These levels are well below published recommended exposure limits for acetaldehyde. Acetaldehyde standard levels vary among organizations, based on the data used to inform the standards and the acceptable degree of risk based on the circumstances for which the standard is designed (EPA 2012). The OSHA limit, designed to protect workers in industrial environments, is 200 ppm (OSHA 2016), while the American Industrial Hygiene Association sets an Emergency Response Planning Guideline Level 1 limit of $10 \mathrm{ppm}$, which is meant to represent the maximum airborne concentration below which it is believed that nearly all individuals could be exposed for up to one hour without experiencing anything other than mild transient health effects or perceiving a clearly defined, objectionable odor (AIHA 2013). 


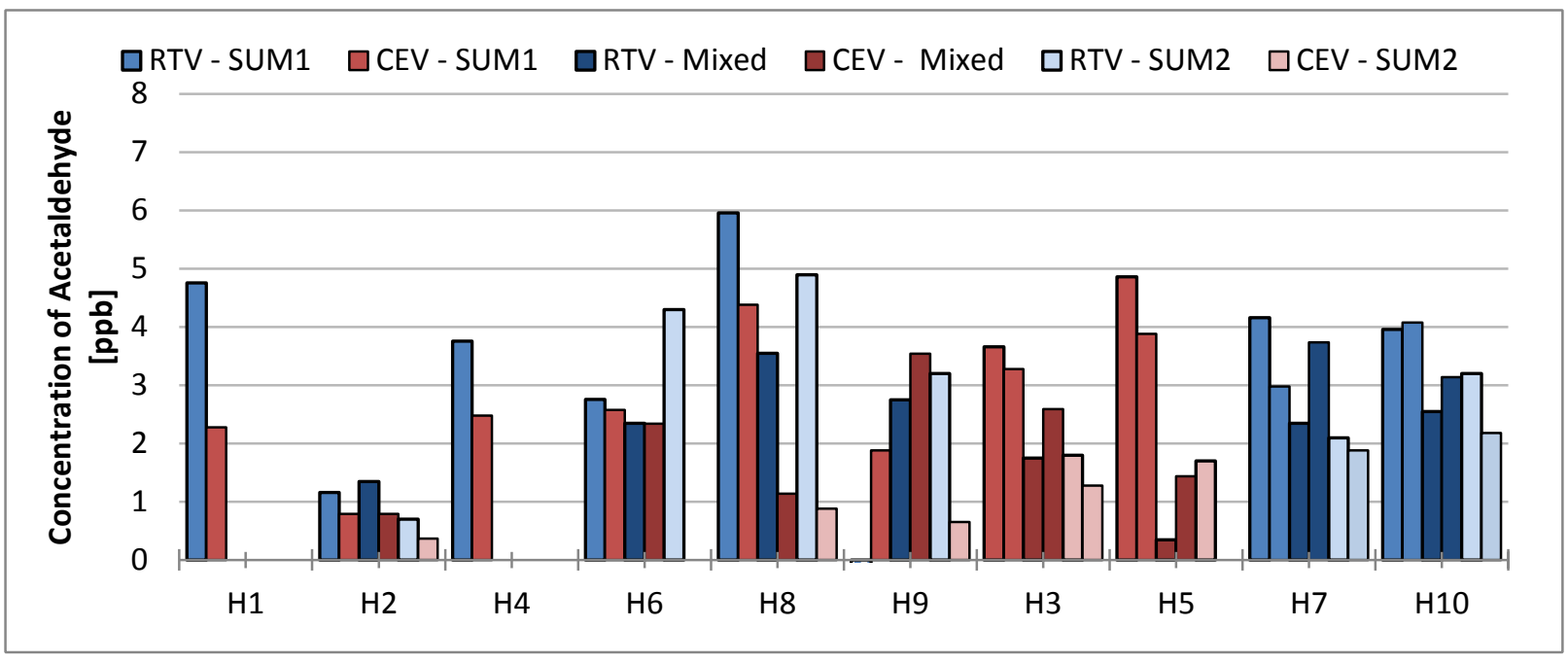

Figure 30. Concentrations of acetaldehyde ( $\mathrm{ppb}$ ) in all homes during all sampling periods

Figure 30 also depicts the temporal trend of acetaldehyde concentrations in each home. In some homes, acetaldehyde concentrations were observed to decrease over time, although a consistent decay was not observed. In addition, in other homes (e.g., Homes 6, 8, and 9), this was not the case, and concentrations were variable from one week to another. This may indicate that, while acetaldehyde is primarily introduced into the building as a constant source, typically as part of the building materials used in home construction, it may have more diverse and potentially more variable sources. Therefore, acetaldehyde may be reintroduced at different times into the indoor environment, which would confound the off-gassing decay trend.

Figure 31, Figure 32, and Figure 33 show the measured concentration of acetaldehyde in each home in the first summer, winter, and second summer IAQ sampling periods, respectively. In the first summer sampling period, the average concentration of acetaldehyde measured in the flipflop homes decreased from the first sampling week to the second or from the RTV condition to the CEV condition. However, the measured concentration in the control homes decreased by a similar amount, so it is not possible to determine the impact of the ventilation strategy on the measured concentrations of acetaldehyde. Similarly, in the winter and subsequent second summer sampling periods, no clear trends were observed between acetaldehyde concentration and ventilation strategy. In the winter sampling period, the acetaldehyde concentration increased in most homes, including the control homes. In the second summer sampling period, the acetaldehyde concentrations decreased in most homes, including the control homes. While the concentrations of acetaldehyde were observed to decrease significantly in Home 8 and Home 9, it is worth noting that the concentrations also decreased in the control homes and outdoors, making it difficult to discern the impact of the ventilation strategy from that of other environmental factors; however, the ventilation strategy is likely contributing to the more effective dilution of acetaldehyde in the CEV periods. Figures 31, 32, and 33 generally demonstrate the concentration of acetaldehyde to be lower in CEV homes than in RTV homes, although this is not true in every case. 


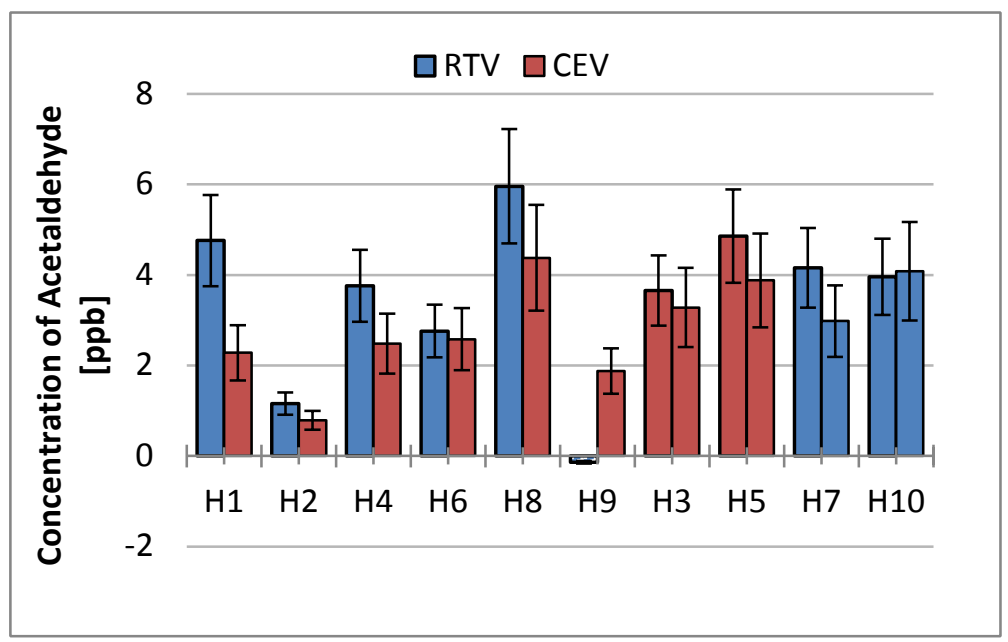

Figure 31. Concentrations of acetaldehyde (ppb) in Home 1 through Home 10 during the first summer IAQ sampling period

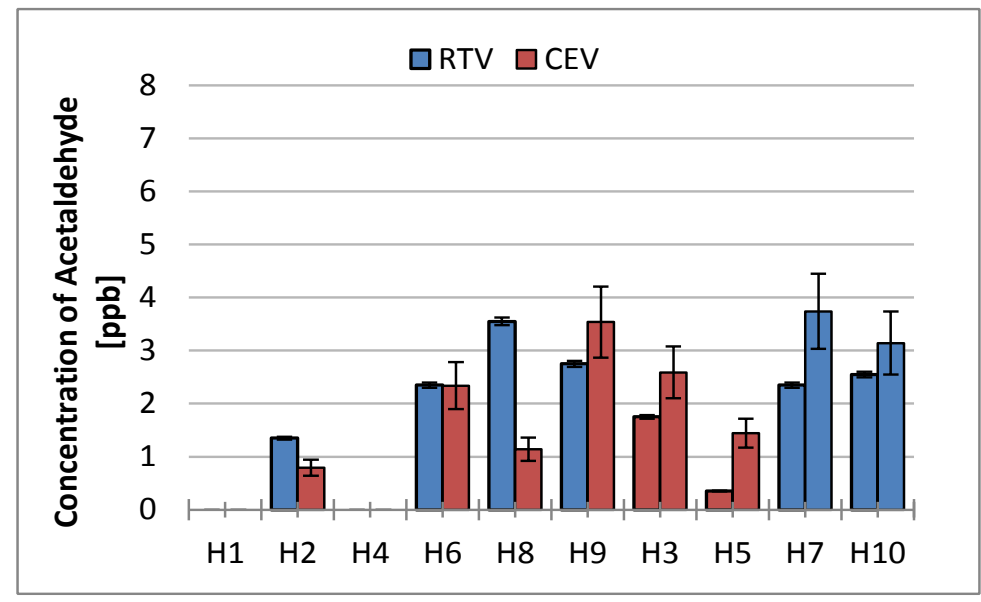

Figure 32. Concentrations of acetaldehyde (ppb) in Home 1 through Home 10 during the winter IAQ sampling period

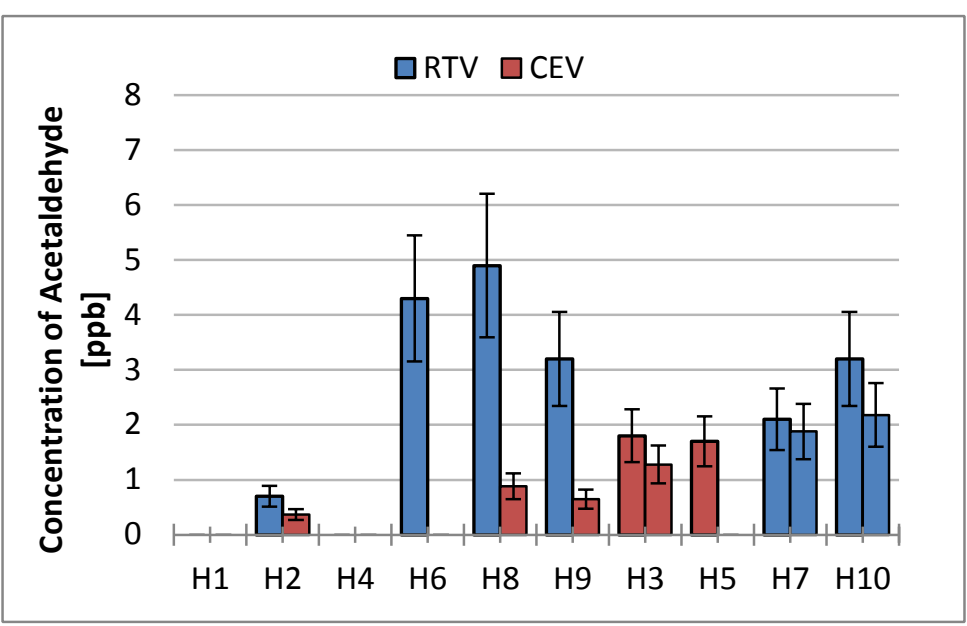

Figure 33. Concentrations of acetaldehyde (ppb) in Home 1 through Home 10 during the second summer IAQ sampling period 
As with formaldehyde, the absolute and percentage changes in acetaldehyde concentrations were compared and no statistically significant differences were observed between the RTV and CEV homes. Figure 34, Figure 35, and Figure 36 depict the absolute difference (in ppb) and percentage difference observed in the flip-flop and control homes during each sampling period.

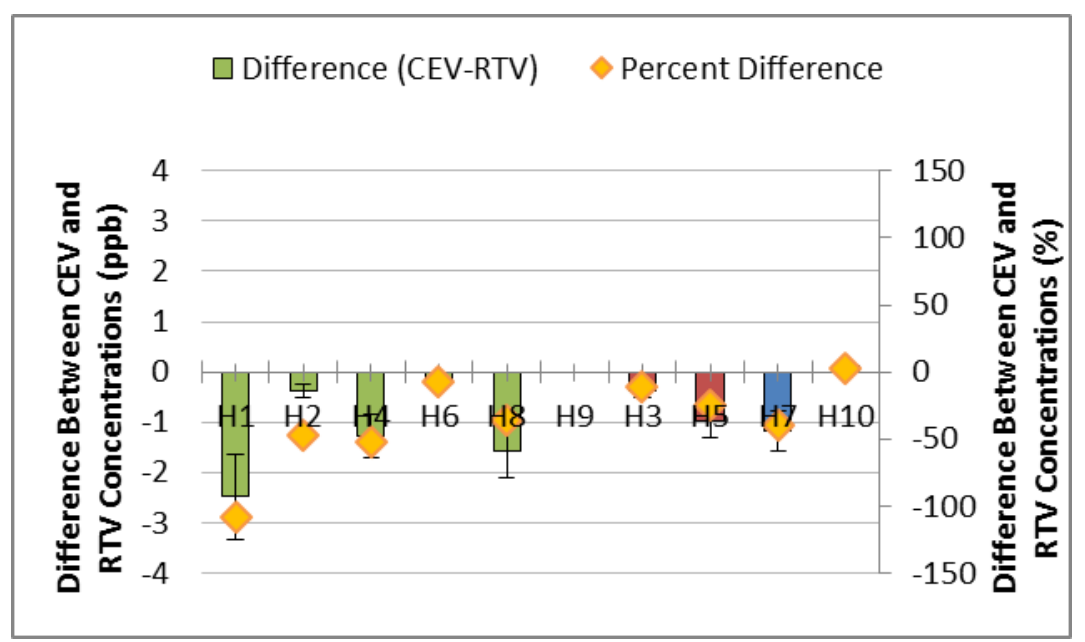

Figure 34. Absolute (ppb) and percent (\%) difference in concentrations of acetaldehyde in Home 1 through Home 10 during the first summer IAQ sampling period

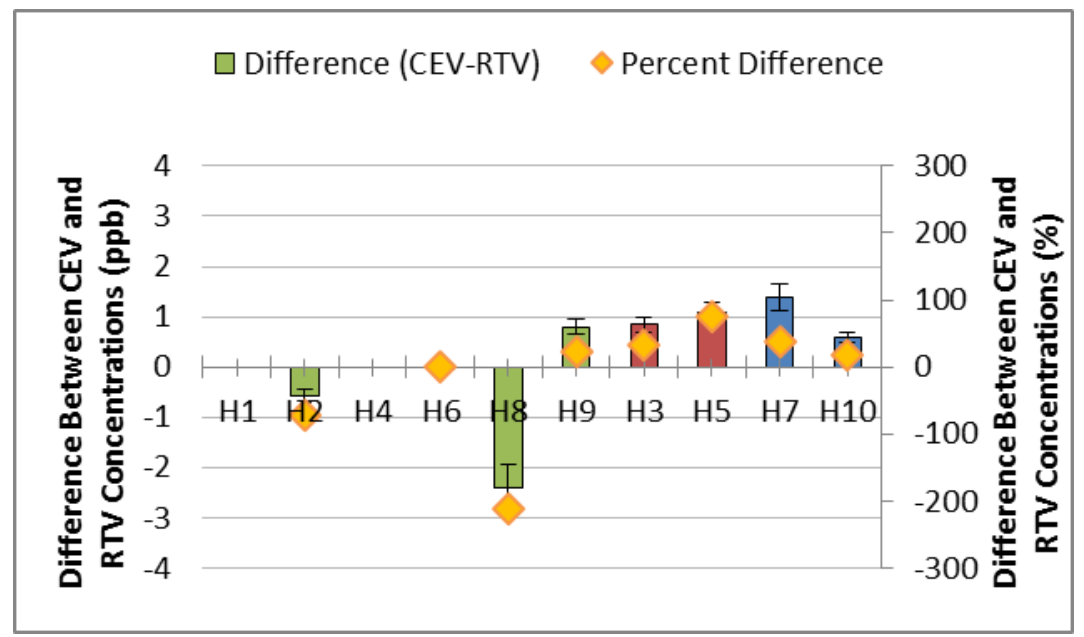

Figure 35. Absolute (ppb) and percent (\%) difference in concentrations of acetaldehyde in Home 1 through Home 10 during the winter IAQ sampling period 


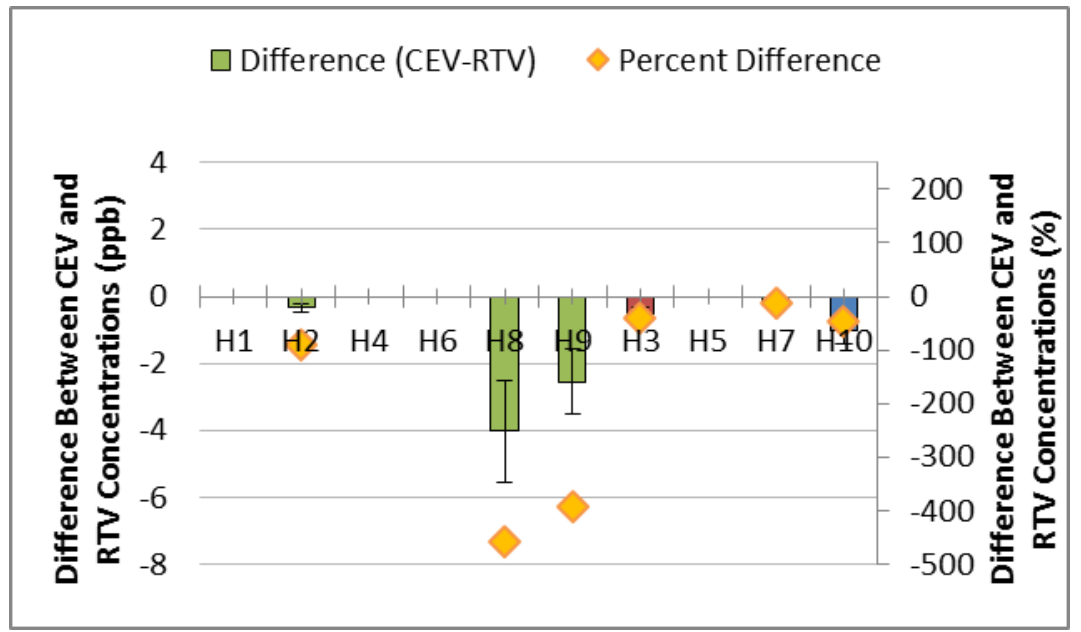

Figure 36. Absolute (ppb) and percent (\%) difference in concentrations of acetaldehyde in Home 1 through Home 10 during the second summer IAQ sampling period

Complete acetaldehyde data are provided in Appendix K.

\subsubsection{Volatile Organic Compounds}

Concentrations were determined for a suite of VOCs based on the passive sampler measurements in each home, and outdoors, for each sampling period. As for other compounds, all concentrations are presented as outdoor and blank-corrected concentrations. The full VOC data set of outdoor- and blank-corrected concentrations is presented in Appendix K.

Because the health effects caused by different VOCs vary greatly, from those that are highly toxic to those with no known health effects, increased levels of various VOCs may or may not result in negative health effects. ${ }^{17}$ Therefore, the VOC analysis presented in this section focuses on a specific set of VOCs that are better indicators of IAQ in homes.

To determine the impact of different ventilation strategies on overall VOC levels that are likely to affect IAQ, a unique "overall VOC" metric was calculated as the sum of 44 specific VOCs (listed in Table 8) that are likely found in the indoor environment and are potentially of health concern. The concentrations of these individual compounds were summed to obtain a metric for VOC concentrations generally.

\footnotetext{
${ }^{17}$ In general, VOCs tend to cause or contribute to eye, nose, and throat irritation; headaches, loss of coordination, nausea; and damage to the liver, kidney, and central nervous system. Some VOCs are likely or known carcinogens (EPA 2012).
} 
Table 8. Forty-Four "Overall VOC" Pollutants

\begin{tabular}{|l|l|l|l|}
\hline 1-Hexanol, 2-ethyl- & Butanal & Ethylbenzene & Octane \\
2-Butoxyethanol & D3 & g-Terpinene & o-Xylene \\
3-Carene & D4 & Heptanal & Phenol \\
a-Pinene & D5 & Heptane & Styrene \\
a-Terpineol & Decanal & Hexadecane & Tetrachloroethylene \\
Benzaldehyde & Decane & Hexanal & Tetradecane \\
Benzene & Dibutyl phthalate & Hexane & TMPD-DIB \\
Benzene, 1,2,3-trimethyl- & Diethyl phthalate & m/p-Xylene & TMPD-MIB \\
Benzene, 1,2,4-trimethyl- & Dimethyl phthalate & Naphthalene & Toluene \\
Benzene, 1,4-dichloro & D-Limonene & Nonanal & Trichloromethane \\
Benzene, butyl- & Dodecane & Octanal & Undecane \\
\hline
\end{tabular}

Of the 44 compounds shown in Table 8, only 10 were observed with any frequency in the homes during the two summer sampling periods and one winter paired sampling period. For reference, the 30 most commonly observed VOCs are listed in Table 9, with the 10 VOCs that are also included in the list of 44 VOCs of concern highlighted in orange. Table 9 also presents the average measured concentration in each home over all the sampling periods and the average concentration among all the homes for all the sampling periods. This gives an indication of the types of VOCs most commonly observed. In general, concentrations of VOCs were low, especially for those VOCs that may pose a risk to human health. 
Table 9. Average Concentration (ppb) of 30 Most Commonly Observed VOCs in Each House over All Sampling Periods, in All Houses over All Sampling Periods, and Total Concentration (ppb) of 30 Most Commonly Observed VOCs in Each House over All Sampling Periods

\begin{tabular}{|c|c|c|c|c|c|c|c|c|c|c|c|}
\hline $\begin{array}{l}\text { Specific Volatile } \\
\text { Organic Compound }\end{array}$ & H1 (FF) & H2 (FF) & H4 (FF) & H6 (FF) & H8 (FF) & H9 (FF) & $\begin{array}{l}\mathrm{H3} \\
\text { (CEV) }\end{array}$ & $\begin{array}{l}\text { H5 } \\
\text { (CEV) }\end{array}$ & $\begin{array}{l}\text { H7 } \\
\text { (RTV) }\end{array}$ & $\begin{array}{l}\text { H10 } \\
\text { (RTV) }\end{array}$ & $\begin{array}{l}\text { Overall } \\
\text { Average }\end{array}$ \\
\hline 1,2,4-Trimethylbenzene & 0.15 & & 0.07 & & & & & & & 0.13 & 0.12 \\
\hline 1,2-Dichloroethane & 4.05 & & 0.23 & & 0.72 & 1.73 & 0.12 & 0.15 & 1.00 & 0.98 & 1.12 \\
\hline 2-Hexanone & 0.19 & 0.11 & 0.18 & & 0.17 & 0.20 & 0.23 & 0.13 & 0.15 & 0.47 & 0.20 \\
\hline 4-Ethyl toluene & 0.20 & & & & & & & & & 0.27 & 0.24 \\
\hline Acetone & 8.15 & 10.40 & 4.10 & 7.80 & 17.04 & 74.45 & 19.64 & 10.10 & 10.32 & 11.80 & 17.38 \\
\hline Benzene & 2.45 & 0.23 & 1.32 & 0.07 & 0.37 & 1.05 & 0.60 & 0.61 & 1.01 & 1.53 & 0.92 \\
\hline Bromodichloromethane & 0.25 & 0.07 & & 0.08 & 0.10 & 0.08 & 0.09 & 0.09 & 0.14 & 0.22 & 0.12 \\
\hline Carbon disulfide & 0.60 & -0.12 & -0.06 & 0.10 & 0.30 & 1.96 & 1.00 & 0.23 & -0.14 & 0.11 & 0.61 \\
\hline Carbon tetrachloride & 0.04 & 0.04 & 0.04 & 0.05 & 0.06 & 0.09 & 0.05 & & 0.05 & 0.07 & 0.05 \\
\hline Chloroform & 0.38 & 0.20 & 1.20 & & 0.38 & 0.69 & 0.32 & 0.18 & 0.46 & 0.49 & 0.48 \\
\hline Cyclohexane & 1.03 & 0.17 & 0.77 & 0.11 & 0.19 & 0.85 & 0.54 & 0.77 & 0.90 & 1.06 & 0.64 \\
\hline Ethanol & 3.00 & -1.15 & 2.00 & 0.50 & 0.02 & 19.73 & 52.90 & -1.48 & -3.65 & -0.23 & 13.03 \\
\hline Ethyl acetate & 2.56 & 2.14 & 4.21 & 49.11 & 5.24 & 28.74 & 20.61 & 3.19 & 3.17 & 3.19 & 12.22 \\
\hline Ethyl benzene & 1.19 & 0.10 & 0.27 & 0.09 & 0.06 & 0.13 & 0.11 & 0.15 & 0.17 & 3.33 & 0.56 \\
\hline Freon 11 & -0.08 & 0.04 & -0.05 & -0.08 & -0.03 & 0.02 & 0.17 & -0.02 & -0.05 & 0.00 & 0.08 \\
\hline Freon 113 & & 0.03 & 0.00 & 0.20 & 0.02 & 0.05 & 0.09 & 0.02 & 0.00 & -0.01 & 0.06 \\
\hline Heptane & 1.60 & 0.12 & 2.00 & 0.26 & 0.65 & 0.31 & 0.37 & 0.22 & 0.41 & 0.99 & 0.69 \\
\hline Isopropyl alcohol & 2.01 & 3.67 & 2.76 & 6.80 & 252.80 & 31.95 & 15.97 & 9.40 & 23.56 & 5.70 & 35.46 \\
\hline m,p-Xylene & 1.17 & 0.01 & 0.19 & 0.08 & 0.04 & 0.09 & 0.09 & 0.08 & 0.10 & 2.50 & 0.43 \\
\hline Methyl ethyl ketone & 6.93 & 2.17 & 4.83 & 24.29 & 2.89 & 7.04 & 4.32 & 3.16 & 4.26 & 4.62 & 6.45 \\
\hline Methyl isobutyl ketone & 0.13 & 0.23 & 1.04 & 0.54 & 0.30 & 0.56 & 0.42 & 0.33 & 0.32 & 1.60 & 0.55 \\
\hline Methylene chloride & -6.90 & 14.84 & -4.80 & 15.60 & 1.09 & 20.62 & 64.66 & 9.28 & 2.72 & 6.10 & 16.86 \\
\hline
\end{tabular}




\begin{tabular}{|c|c|c|c|c|c|c|c|c|c|c|c|}
\hline $\begin{array}{l}\text { Specific Volatile } \\
\text { Organic Compound }\end{array}$ & H1 (FF) & H2 (FF) & H4 (FF) & H6 (FF) & H8 (FF) & H9 (FF) & $\begin{array}{l}\mathrm{H3} \\
\text { (CEV) }\end{array}$ & $\begin{array}{l}\text { H5 } \\
\text { (CEV) }\end{array}$ & $\begin{array}{l}\text { H7 } \\
\text { (RTV) }\end{array}$ & $\begin{array}{l}\text { H10 } \\
\text { (RTV) }\end{array}$ & $\begin{array}{l}\text { Overall } \\
\text { Average }\end{array}$ \\
\hline n-Hexane & 4.09 & 0.29 & 5.40 & -0.11 & 0.17 & 1.94 & 1.24 & 0.68 & 1.66 & 2.78 & 2.03 \\
\hline o-Xylene & 0.94 & & 0.28 & 0.07 & & 0.13 & 0.12 & 0.12 & 0.11 & 2.81 & 0.57 \\
\hline Styrene & 0.19 & 0.11 & 0.16 & 0.16 & & 0.14 & 0.07 & 0.04 & 0.14 & 0.61 & 0.18 \\
\hline Tetrachloroethene & 0.19 & 0.04 & 0.53 & & 0.08 & 0.05 & 0.12 & & 0.06 & 0.16 & 0.15 \\
\hline Tetrahydrofuran & 1.41 & 1.16 & 1.16 & 4.71 & 0.51 & 1.76 & 1.75 & 0.52 & 1.23 & 1.63 & 1.58 \\
\hline Toluene & 5.33 & 0.81 & 2.68 & 0.32 & 0.76 & 1.92 & 0.97 & 2.54 & 1.78 & 3.67 & 2.08 \\
\hline Trichloroethene & 0.52 & & & & 0.07 & & & & 0.03 & & 0.20 \\
\hline $\begin{array}{l}\text { Total of } 30 \text { Most } \\
\text { Common VOCs }\end{array}$ & 41.72 & 35.72 & 30.48 & 110.74 & 283.99 & 196.27 & 186.54 & 40.48 & 49.91 & 56.56 & 115.06 \\
\hline
\end{tabular}

VOCs in rows highlighted in orange are the VOCs that were frequently detected in the study home. 
In the first summer sampling period, the sum of the 10 frequently detected VOCs was observed to increase from the first week to the second week in all homes, including the control homes (except H10). However, the most significant increases were observed in the flip-flop homes. The sum of the 10 VOCs of concern that were detected in the homes for each of the homes for the two one-week samples in the first summer sampling period are shown in Figure 37.

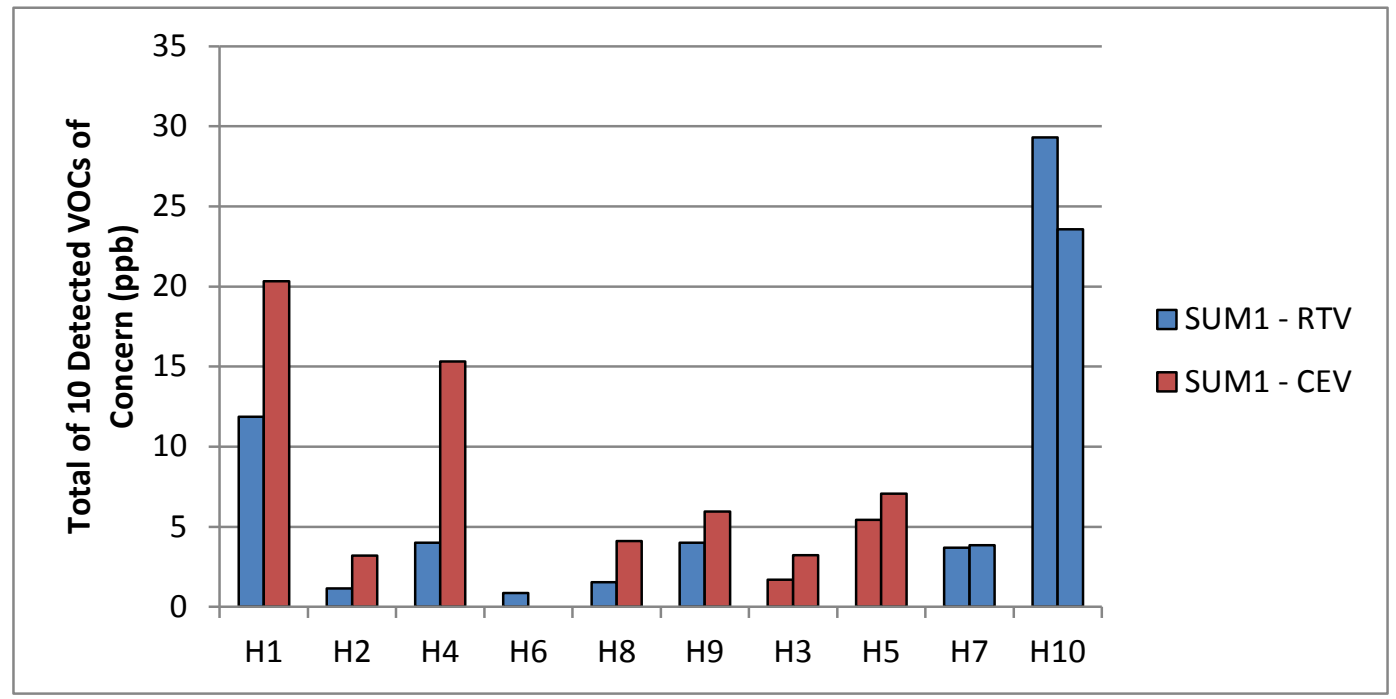

Figure 37. Total concentration of 10 detected VOCs of concern (ppb) in Home 1 through Home 10 during the first summer IAQ sampling period

While the presented data were corrected for the measured outdoor concentration, it is worth noting that the concentration of these 10 VOCs outdoors did not change significantly. And, the indoor climate conditions were similar between the sampling periods, so it is not clear why such an increasing trend was observed. The second sampling period was slightly cooler than the first IAQ sampling period, with an average outdoor temperature of $82^{\circ} \mathrm{F}$ in the first week versus $79^{\circ} \mathrm{F}$ in the second week, but that is not expected to significantly impact the overall VOC concentrations indoors. In addition, because the two sampling weeks were not consecutive, it is not likely that temporal changes in uptake, storage, or off-gassing of materials in the home affected the measurements.

In subsequent IAQ sampling periods, as can be seen in Figure 38 and Figure 39, the summed concentration of these 10 VOCs was significantly reduced. In the winter sampling period, for example, of the 10 detected VOCs of concern, only benzene, n-hexane, and toluene were detected consistently in most of the homes. 


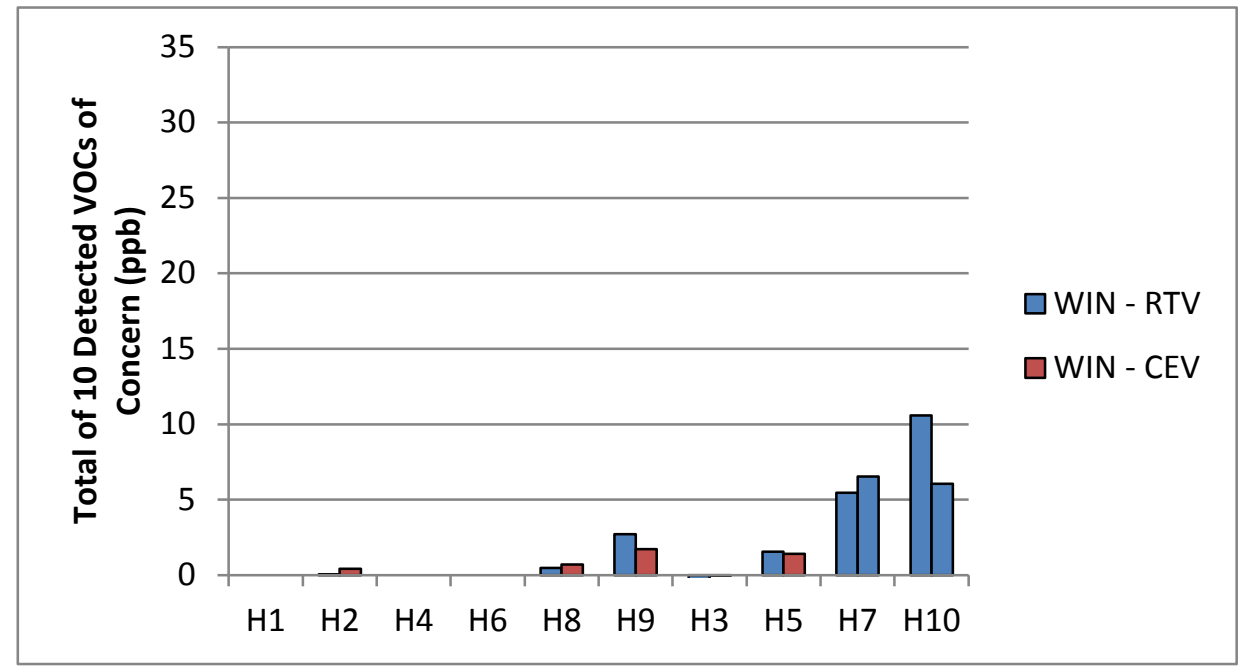

Figure 38. Total concentration of 10 detected VOCs of concern ( $p p b)$ in Home 1 through Home 10 during the winter IAQ sampling period

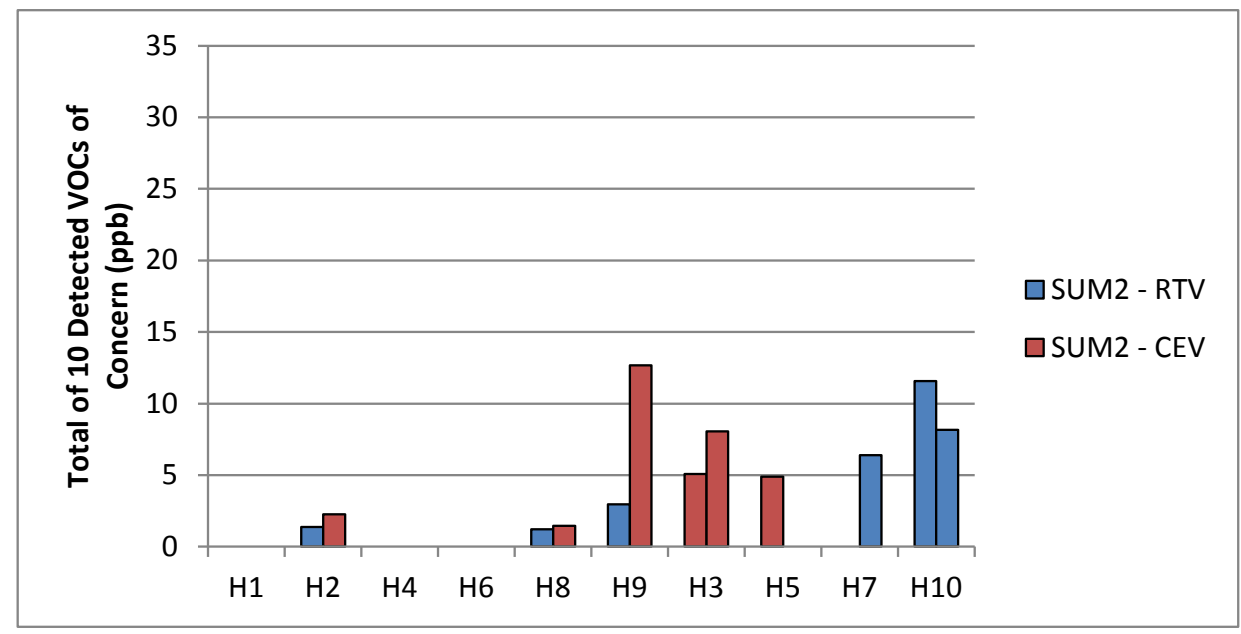

Figure 39. Total concentration of 10 detected VOCs of concern ( $p p b)$ in Home 1 through Home 10 during the first summer IAQ sampling period

Even though a course metric such a TVOC (representing all measured VOCs using the TO-17 method) was employed, concentrations of VOCs in the winter and second summer sampling periods were generally much lower than those measured in the first summer sampling period, as shown in Figure 40. 


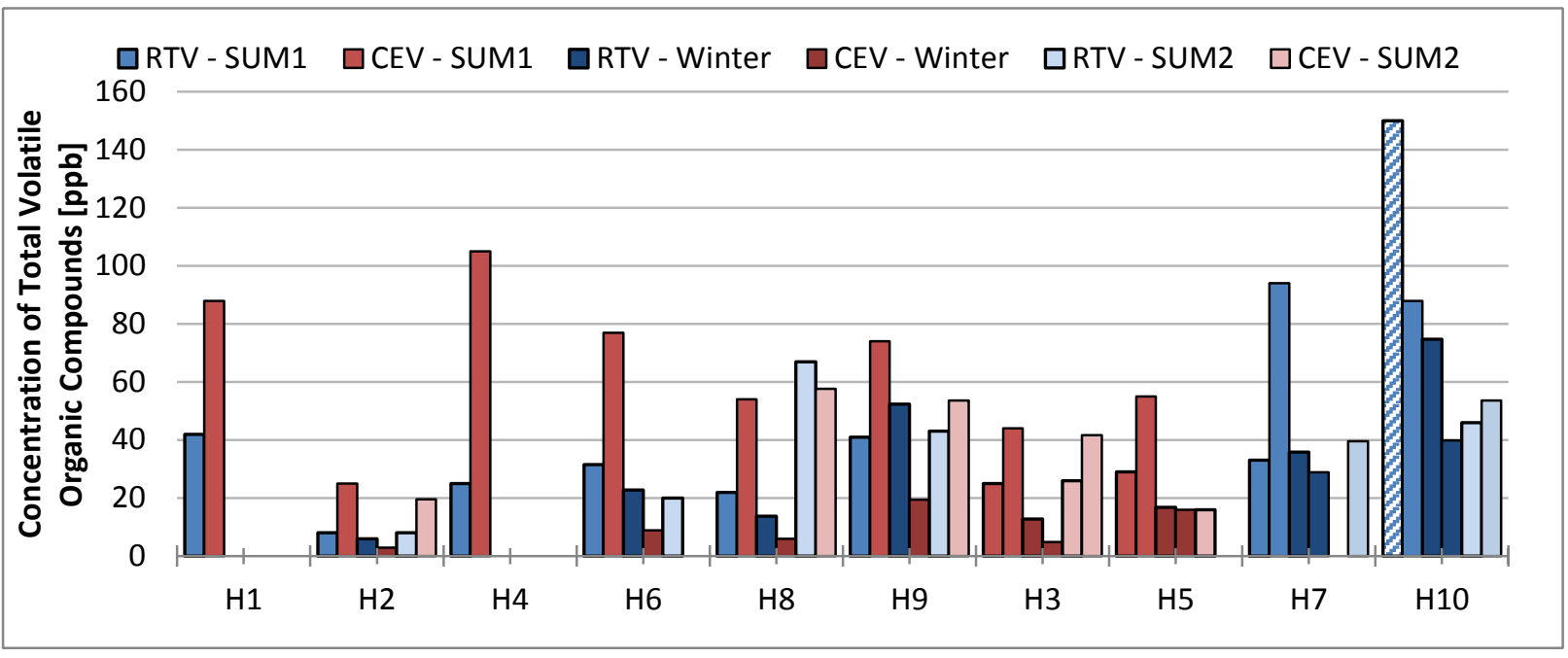

Figure 40. Concentration of total volatile organic compounds (TVOC; ppb) in Home 1 through Home 10 during all the sampling periods

The overall trend in the 10 detected VOCs of concern identified earlier (shown in Figure 41) demonstrates trends similar to those observed in the TVOC data (shown in Figure 40).

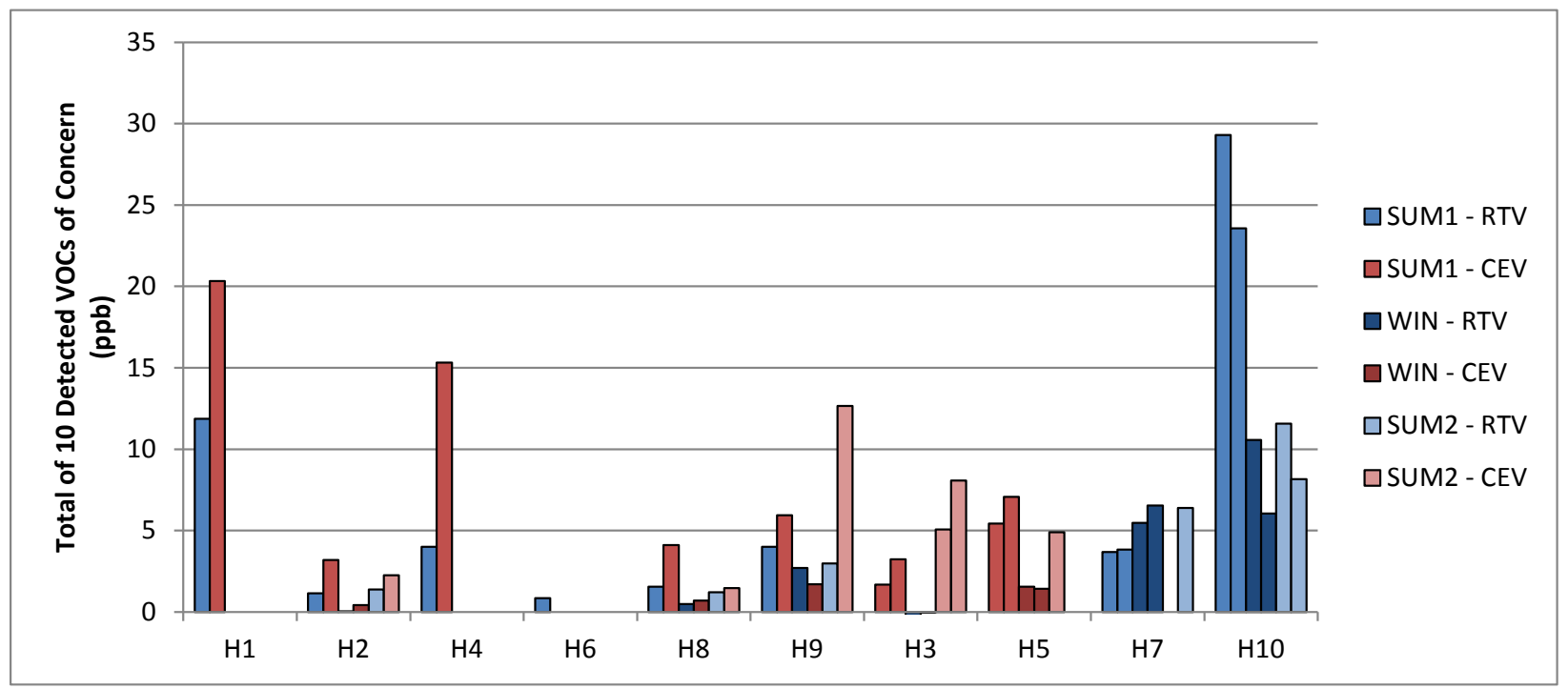

Figure 41. Total concentration of 10 detected VOCs of concern (ppb) in Home 1 through Home 10 during the all of the sampling periods

Overall, VOCs occur in the indoor environment due to a variety of sources with significant variability in time and space. For this reason, discerning trends between the ventilation approach and the measured concentration of VOCs is difficult. In addition, all measured VOCs concentrations were generally low, and the detected VOCs are not a known health concern at the observed levels. However, as with formaldehyde and acetaldehyde, increased ventilation via an exhaust-only system (CEV) was not observed to decrease the concentration of VOCs based on the TVOC, individual VOC, or 10-VOC analysis methods. In this case, especially in the first 
summer sampling period, it appears the CEV configuration may actually have increased VOC concentrations. While the cause of this effect is unknown, the authors hypothesize that this relationship may be due to the exhaust-only ventilation method employed in the CEV homes causing air to be pulled through the building envelope and, thus, increasing emission of VOCs indoors. In addition, this trend is not statistically significant due to the small sample sizes and variability observed in the control homes.

\subsubsection{Nitrogen Dioxide}

Nitrogen dioxide $\left(\mathrm{NO}_{2}\right)$ was sampled in one home with gas cooking equipment and one home without, as well as outside, during each sampling period. The sampled homes varied among the sampling periods (but one with gas and one without gas were always sampled), and the measured concentrations were corrected based on the outdoor concentration of $\mathrm{NO}_{2}$ and the field blank. ${ }^{18}$ As shown in Figure 42, $\mathrm{NO}_{2}$ exhibited a more predictable trend with respect to ventilation rate, where increased ventilation associated with the $\mathrm{CEV}$ approach resulted in decreased $\mathrm{NO}_{2}$ concentrations indoors. Figure 42 also illustrates that concentrations of $\mathrm{NO}_{2}$ were higher in the homes with gas cooking than in the homes without it, and CEV was effective in reducing the concentration to levels equivalent with those observed in the homes without gas cooking. Here all data sampled from homes with gas cooking in a given ventilation configuration were averaged, which potentially masks some seasonal variability. It is worth noting that the measured $\mathrm{NO}_{2}$ concentrations were generally higher in the winter than in the summer. There also is likely variability among homes, but the sample set is too small to quantify home-to-home variability for this analysis. The complete $\mathrm{NO}_{2}$ data are provided in Appendix $\mathrm{K}$.

\footnotetext{
${ }^{18}$ The $\mathrm{NO}_{2}$ concentration outdoors during the second week in the first summer sampling period did not resolve. For this reason, neither of the weeks in the first summer sampling period was corrected for the outdoor measurement to allow for better comparability between the samples.
} 


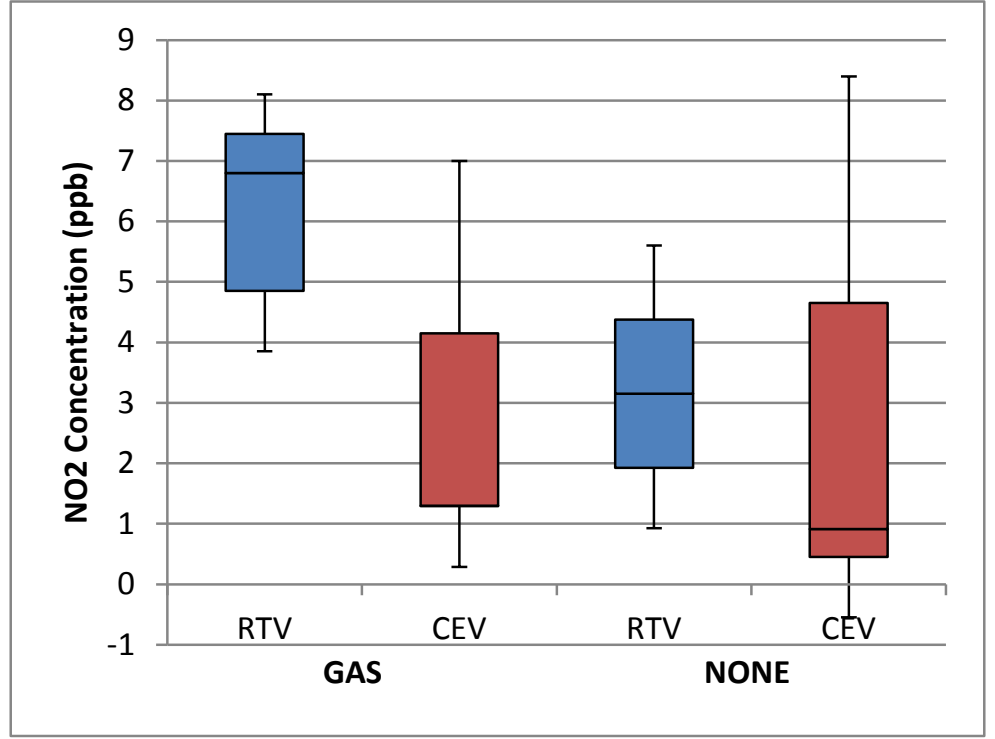

Figure 42. Average concentration of $\mathrm{NO}_{2}(\mathrm{ppb})$ in homes with gas cooking and homes without gas cooking in the RTV and CEV configurations, corrected for outdoors

$\mathrm{NO}_{2}$ was corrected for outdoor concentrations by subtracting the outdoor concentration from the indoor concentration, and, therefore, Figure 41 does not account for any indoor deposition of $\mathrm{NO}_{2}$.

Comparing the change in $\mathrm{NO}_{2}$ concentration resulting from switching from the RTV to the CEV strategy, Figure 43 shows that $C E V$ ventilation was effective in reducing the $\mathrm{NO}_{2}$ concentration indoors by a statistically significant amount in homes with gas cooking.

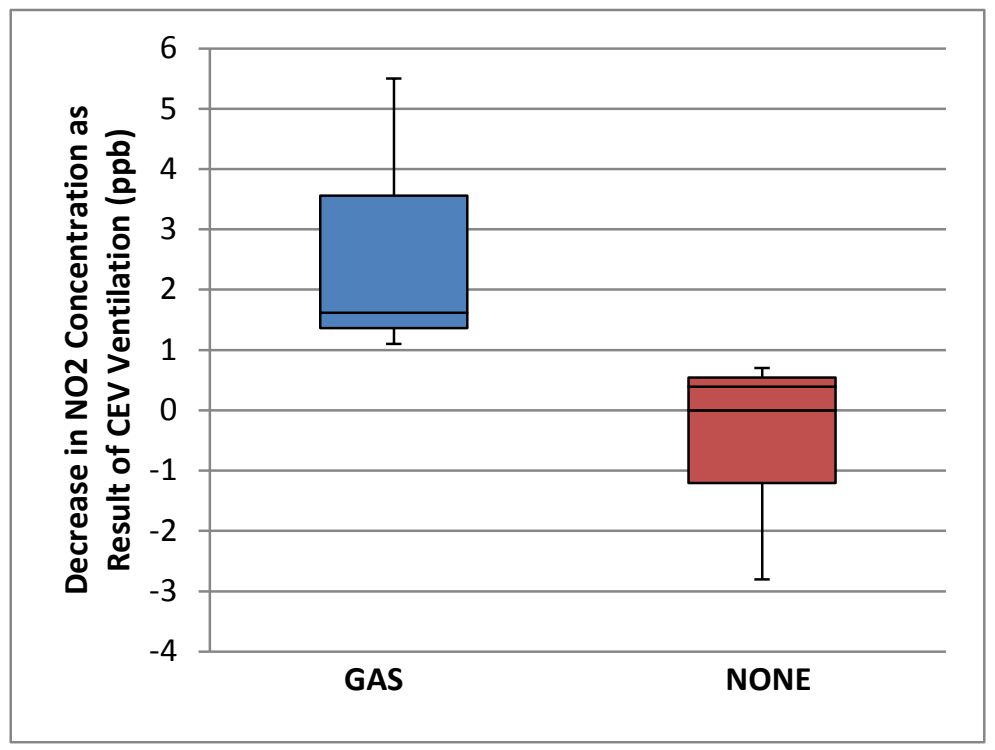

Figure 43. Average decrease in concentration of $\mathrm{NO}_{2}(\mathrm{ppb})$ as a result of switching from RTV to CEV configurations in homes with gas cooking and homes without, corrected for outdoors 
While a decrease in concentrations of $\mathrm{NO}_{2}$ is beneficial, because it illustrates a dilution of cooking-related contaminants resulting from the whole-house ventilation, no standards have been agreed upon for nitrogen oxides in indoor air. The concentrations measured here are an order of magnitude lower than the EPA's National Ambient Air Quality Standard of 53 ppb $\mathrm{NO}_{2}$ in outdoor air averaged over a 24-hour period.

\subsubsection{Radon}

As mentioned in Sections 2.1.3 and 2.2.11, radon is also a key contaminant of concern in residences in some areas of the United States, and it was passively sampled over the entire study period (June 2013-June 2014). No homes were observed to be above the EPA action limit of $4 \mathrm{pCi} / \mathrm{L}$ (EPA 2009). Average radon concentrations - which were assessed in the kitchen of each home; none of the homes had basements - ranged between 1.3 and $2.5 \mathrm{pCi} / \mathrm{L}$, and they are presented for each house in Table 10. Outdoor concentrations were not determined. For three homes, the radon sampler was not retrieved because homeowners moved or left the study before the sampler could be retrieved and analyzed. 
Table 10. Average Radon Concentration ( $\mathrm{pCi} / \mathrm{L}$ ) in All Houses over the Entire Sampling Period (June 2013 to June 2014)

\begin{tabular}{llll}
\hline $\begin{array}{l}\text { Ventilation } \\
\text { Configuration }\end{array}$ & House & Sampler ID & $\begin{array}{l}\text { Radon Concentration } \\
\text { (pCi/L) }\end{array}$ \\
\hline FF & H1 & 2522100 & not analyzed \\
FF & H2 & 2521944 & 1.4 \\
FF & H4 & 2521911 & not analyzed \\
FF & H6 & 2521996 & 1.3 \\
FF & H8 & 2521975 & 2.2 \\
FF & H9 & 2521955 & not analyzed \\
CEV & H3 & 2521947 & 1.4 \\
CEV & H5 & 2521903 & 1.5 \\
RTV & H7 & 2521920 & 1.4 \\
RTV & H10 & 2521956 & 2.5 \\
\hline
\end{tabular}

\subsubsection{Mold}

Each home was visually inspected for the presence of mold during each IAQ sampling period, and because of the brevity of the study, none was observed. In addition, the homeowners' HVAC systems worked to maintain reasonable temperature and $\mathrm{RH}$ conditions indoors that would effectively mitigate significant mold problems in the short term. However, the relationship between temperature, $\mathrm{RH}$ conditions, and mold growth over time is not as well known. It is unclear whether in the long term, conditions associated with RTV or CEV configurations would have led to mold and moisture problems.

\subsubsection{Homeowner Survey Data}

Homeowners were also surveyed regarding their perceptions of comfort and IAQ; the survey instrument is included in Appendix E. While anecdotal in nature, homeowner perceptions are an important data source when considering the persistence of any home performance measures or interventions. For example, if increased or decreased ventilation decreased homeowner comfort, it is less likely that the goal of any such ventilation would be achieved and maintained over time because homeowners may be inclined to modify or disable the ventilation system to better address their families' comfort concerns.

Consistent homeowner survey data are not available because surveys were not consistently conducted at regular intervals as initially envisioned. However, in this study, two significant homeowner reports are worth mentioning. One homeowner, very early in the study, reported sensing stuffy "stagnated air" during the CEV periods. Another homeowner, in June 2014 (the second summer), when the homes were left in the CEV configuration for a longer period of time than normal (outside IAQ sampling periods), reported their house smelling of "old socks" and feeling uncomfortable. They requested their home be returned to the "normal" (i.e., RTV) configuration. The authors followed up the next week to ensure the homeowner's concerns had been resolved, and the homeowner reported the smell and discomfort had dissipated within 24 hours of switching the ventilation system. At the request of the homeowner, the home was not flip-flopped for the remainder of the study period. 


\section{Conclusions}

Concentrations of certain indoor air contaminants, ventilation system flow rates, spaceconditioning energy consumption and condensate generation, and indoor and outdoor conditions were measured in 10 high-performance new homes in Gainesville, Florida, to characterize the impact of differing ventilation approaches on these parameters. Data were collected during June 2013 through August 2014. Continuous exhaust ventilation (CEV), with rates approximating rates required by ASHRAE 62.2-2013, was compared to intermittent runtime ventilation (RTV), which delivers approximately 16\% of ASHRAE 62.2-2013 requirements annually.

For summer conditions, the CEV systems result in approximately $9 \%$ more cooling energy use on average to maintain the desired temperature set points in the homes. Ventilation strategy was found to be among the most significant variables driving runtime of air conditioners. Despite the added air conditioner runtime, the resulting relative humidity $(\mathrm{RH})$ was higher in the homes while under CEV, causing them to $\log$ more hours $>60 \%$ and $>65 \%$ RH than while under RTV. Regression analysis showed that ventilation strategy was the most significant variable tested in predicting $>60 \% \mathrm{RH}$, and it was slightly less significant in predicting hours $>65 \% \mathrm{RH}$. However, the extent and persistence of the elevated RH was variable among homes, suggesting other parameters are also impactful. In the short term, the elevated RH was more likely to cause comfort issues than it was to cause durability or mold issues. During visits to the homes, no signs of mold were observed, and few comfort complaints were logged. The long-term effect of elevated RH in these homes is unknown. Condensate collected during the summer of 2014 showed a causal relationship to ventilation strategy, but regression analysis revealed that condensate volumes are more highly correlated to occupant behavior, suggesting significant and highly variable internal moisture generation rates. Conditioned house size was also found to be significant, but it revealed an inverse relationship, which may indicate that a larger house has more capacity to buffer moisture than a smaller house.

During the mixed season between October and April, homes operated under a mix of heating, cooling, and floating space-conditioning operation. Space-conditioning and natural ventilation preferences are highly variable during this period, and analysis of limited heating data did not show a significant impact related to ventilation strategy. Ventilation strategy appears to have a statistically significant but overall minor impact in indoor RH during the mixed period compared to the summer period, and RH trends seem dominated by outdoor conditions and occupant preferences.

$\mathrm{CO}_{2}$ data show that RTV systems, which inherently depend on space-conditioning system runtime, generate less air change than continuous exhaust systems. Preferences for enhanced natural ventilation during the mixed period that could counteract this effect seem variable.

In general, the CEV ventilation strategy resulted in 30\% higher estimated air exchange rates (AERs) than the RTV configurations in the flip-flop homes and 79\% higher mechanical ventilation rates. The difference in AER between the two ventilation strategies is less extreme than the difference in mechanical ventilation flow rate because of the impact of infiltration air on overall air exchange rate. For RTV homes, the unbalanced mechanical ventilation flow rate was an average of $28 \%$ of total mechanical and infiltration-driven ventilation airflow in the summer 
and $5 \%$ in the winter; for CEV homes, the mechanical ventilation flow rates were $82 \%$ and $84 \%$ of the total airflow for the summer and winter, respectively. However, it is worth noting that the increase in AER did not consistently decrease $\mathrm{CO}_{2}$ concentrations during the sampling periods in all homes. While concentrations of $\mathrm{CO}_{2}$ may be variable due to occupancy or other factors, this may suggest that the $\mathrm{CEV}$ ventilation strategy is not actually increasing the dilution rate in all areas of the home as much as the increase in AER might suggest.

Concentrations of formaldehyde, acetaldehyde, VOCs, and $\mathrm{NO}_{2}$ were determined in paired sampling periods during the summer of 2013, winter of 2013/2014, and summer of 2014. While the observed concentrations of sampled contaminants were variable among the homes and suggest the importance of occupant activities and behavior, analyses of the data indicate that increased ventilation via a continuous exhaust fan, as was employed in the CEV strategy, may not be effective in decreasing concentrations of all indoor air quality (IAQ) contaminants, which is consistent with the finding for $\mathrm{CO}_{2}$. Notably, despite significant increases in mechanical ventilation flow rate and AER during all IAQ sampling periods, concentrations of formaldehyde, acetaldehyde, and VOCs did not show a significant dependence on ventilation approach. That is, operation of the CEV approach at ventilation rates $79 \%$ higher than the RTV method did not significantly decrease observed concentrations of formaldehyde, acetaldehyde, or VOCs. Generally, the concentrations of VOCs and aldehydes appeared slightly higher in the RTV homes than in the CEV homes, although, in some cases, concentrations were observed to increase in the CEV configuration. As a result, consistent and significant trends were not discernable from the data because of variability among the homes and between sampling periods in the same home. This contradicts findings from previous researchers that concentrations of IAQ contaminants exhibit an inverse relationship to ventilation rate (Lajoie et al. 2015; Hult et al. 2014). The fact that the concentrations of formaldehyde, acetaldehyde, and VOCs measured in this study were variable and not correlated to a change in ventilation strategy-despite the higher ventilation rates achieved by the CEV system suggests that other factors in addition to ventilation rate- such as ventilation system design (e.g., balanced versus supply-only versus exhaust-only) may be important in determining the efficacy of a ventilation system in achieving the desired dilution effect. This result is consistent with other research that has analyzed different ventilation system types. Specifically, Hun et al. (2014) have also observed reduced efficacy of exhaust-only ventilation in reducing formaldehyde concentrations. Rudd and Bergey (2013) measured lower formaldehyde concentrations in a study house ventilated with the supply-based continuous fan integrated supply (CFIS) system than in the same house when ventilated with an exhaust fan and similar effective ventilation rates.

Conversely, $\mathrm{NO}_{2}$, which was measured in two homes (one with gas cooking and one without it) during each sampling period, appeared to be effectively mitigated by the CEV method, suggesting that for some sources of pollutants, the efficacy of the ventilation system may be less affected by ventilation system design.

While the concentrations of acetaldehyde, VOCs, and $\mathrm{NO}_{2}$ were far below published standard levels and are unlikely to cause negative health effects at these low levels, formaldehyde concentrations were, on average, above the NIOSH-recommended exposure limit of $16 \mathrm{ppb}$. 
Future work to further explore the efficacy of different ventilation systems and disaggregate the impact of ventilation rate and system type is necessary to understand how to apply these findings in the field to achieve optimum IAQ and homeowner comfort in new homes for the lowest cost and energy impacts. 


\section{References}

AIHA (American Industrial Hygiene Association). 2013. Emergency Response Planning Guidelines. American Industrial Hygiene Association. Falls Church, Virginia.

https://www.aiha.org/get-

involved/aihaguidelinefoundation/emergencyresponseplanningguidelines/Pages/default.aspx.

ASHRAE Standards Committee. 2013a. ASHRAE Fundamentals Handbook: Chapter 16Ventilation and Infiltration. Atlanta, Georgia.

- 2013b. ASHRAE Standard 62.2 - Ventilation and Acceptable Indoor Air Quality in LowRise Residential Buildings. Atlanta, Georgia.

-2004. ASHRAE Standard 152: Method of Test for Determining the Design and Seasonal Efficiencies of Residential Thermal Distribution Systems. Atlanta, GA.

ASTM International. 2010. ASTM E779-10: Standard Test Method for Determining Air Leakage Rate by Fan Pressurization. West Conshohocken, PA.

BIER IV (Committee on Health Risks of Exposure to Radon). 1999. Health Effects of Exposure to Radon: BIER IV. National Academies Press, Washington, D.C.

CDC (Center for Disease Control and Prevention). 2011. NIOSH Pocket Guide to Chemical Hazards: Appendix A - NIOSH Potential Occupational Carcinogens. Atlanta, Georgia. http://www.cdc.gov/niosh/npg/nengapdxa.html.

Chandra S., D. Parker, J. Sherwin, C. Colon, K. Fonorow, D. Stroer, E. Martin, J. McIlvaine, D. Chasar, N. Moyer, S. Thomas-Rees, D. Hoak, D. Beal, and C. Gil. 2008. "An Overview of Building America Industrialized Housing Partnership (BAIHP) Activities in Hot-Humid Climates." Sixteenth Symposium on Improving Building Systems in Hot and Humid Climates. December 15-17, 2008, Dallas, TX.

Chasar, D., S. Chandra, D. Parker, J. Sherwin, D. Beal, D. Hoak, N. Moyer, and J. McIlvaine. "Cooling Performance Assessment of Building America Homes." Fifteenth Symposium on Improving Building Systems in Hot and Humid Climates. July 24-26, 2006, Orlando, FL.

Coyne L., C. Kuhlman, and J. Chada. Validation of the 575 and the ULTRA Series Diffusive Samplers: Long-term Sampling in Indoor and Ambient Air Environments. SKC Inc., Eighty Four, Pennsylvania. http://www.skcinc.com/pdf/1812.pdf.

Dales R., L. Liu, A. J. Wheeler, and N. L. Gilbert. 2008. "Quality of Indoor Residential Air and Health." Canadian Medical Association Journal 179(2):147-152.

DOE (U.S. Department of Energy). 2014. DOE Zero Energy Ready Home National Program Requirements. Rev. 04. Washington, D.C.: U.S. Department of Energy Building Technologies Office.

http://energy.gov/sites/prod/files/2014/04/f15/doe_zero_energy_ready_home_requirements_rev0 4.pdf. 
EPA (U.S. Environmental Protection Agency). 1990. Determination of Formaldehyde and Other Aldehydes in Indoor Air using Solid Adsorbent Cartridge-Method IP-6A. Compendium of Methods for the Determination of Air. Cincinnati, OH. EPA-600/4-90-010.

- 1999a. Compendium Method TO-11A: Determination of Formaldehyde in Ambient Air Using Adsorbent Cartridge Followed by High-Performance Liquid Chromatography (HPLC) [Active Sampling Methodology]. Compendium of Methods for Determining Toxic Organic Compounds in Ambient Air. Cincinnati, OH. EPA/625/R-96/010b.

1999b. Compendium Method TO-17: Determination of Volatile Organic Compounds in Ambient Air Using Active Sampling Onto Sorbent Tubes. Compendium of Methods for Determining Toxic Organic Compounds in Ambient Air. Cincinnati, OH. EPA/625/R 96/010b.

—. 2009a. “A Citizen's Guide to Radon.” IE Division (ed.), Washington D.C. http://www.epa.gov/radon/pubs/citguide.html.

- 2012. An Introduction to Indoor Air Quality: Volatile Organic Compounds. Cincinnati, Ohio. Last updated July 29, 2012. http://www.epa.gov/iaq/voc.html.

- 2013. Energy Star Qualified Homes, Version 3 (Rev. 07): National Program Requirements. Cincinnati, OHL U.S. Environmental Protection Agency. http://www.energystar.gov/ia/partners/bldrs lenders_raters/downloads/National_Program_Requi rements.pdf?5fae-d76b.

Hult, E. L., H Willem, P. N. Price, T. Hotchi, M. L. Russell, and B. C. Singer. 2014. "Formaldehyde and Acetaldehyde Exposure Mitigation in US Residences: In-Home Measurements of Ventilation Control and Source Control." Indoor Air (5 November 2014):n/an/a. doi:10.1111/ina.12160. http://dx.doi.org/10.1111/ina.12160.

Hun, D., M. Jackson, and S. Shrestha. 2014. "Optimization of Ventilation Energy Demands and Indoor Air Quality in High-Performance Homes.” 2014 ACEEE Summer Study on Energy Efficiency in Buildings. August 2014, Pacific Grove, CA. American Council for an Energy Efficient Economy, Washington, D.C.

Kerrigan, P. 2014. Evaluation of the Performance of Houses With and Without Supplemental Dehumidification in a Hot-Humid Climate. Golden, CO: National Renewable Energy Laboratory. NREL/SR-5500-62531. http://www.nrel.gov/docs/fy15osti/62531.pdf.

Kuhlman, C., and N. Zovack. 2013. "Validation of Nitrogen Dioxide Using the SKC UMEx 200 Passive Sampler Cat. No. 500-200.” SKC Inc., Eighty Four, Pennsylvania. http://www.skcinc.com/instructions/1789.pdf.

Lajoie, P., D. Aubin, V. Gingras, P. Daigneault, F. Ducharme, D. Gauvin, D. Fugler, J.-M. Leclerc, D. Won, M. Courteau, S. Gingras, M.-È Héroux, W. Yang, and H. Schleibinger. 2015. "The Ivaire Project: A Randomized Controlled Study of the Impact of Ventilation on Indoor Air Quality and the Respiratory Symptoms of Asthmatic Children in Single Family Homes." Indoor $\operatorname{Air}$ (21 January 2015):n/a-n/a. doi:10.1111/ina.12181. http://dx.doi.org/10.1111/ina.12181 
Logue J.M., T.E. Mckone, M. H. Sherman, and B.C. Singer. 2010. Hazard Assessment of Chemical Air Contaminants Measured in Residences. Berkeley, CA: Lawrence Berkeley National Laboratory. LBNL-3650-E. http://eetd.lbl.gov/sites/all/files/publications/hazardassessment-lbnl3650e.pdf.

Martin, E. for Building Science Corporation, Florida Solar Energy Center/BA-PIRC, and IBACOS. 2014. Impact of Residential Mechanical Ventilation on Energy Cost and Humidity Control. Golden, CO. National Renewable Energy Laboratory. NREL/SR-5500-60675. http://www.nrel.gov/docs/fy14osti/60675.pdf.

OSHA (Occupational Safety and Health Administration). 2016. Occupational Safety and Health Standards, Toxic and Hazardous Substances: Formaldehyde. Code of Federal Regulations. 29 CFR 1910.1048.

Offermann, F. 2009. Ventilation and Indoor Air Quality in New Homes. Public Interest Energy Research (PIER), California Energy Commission. CEC-500-2009-085. http://www.arb.ca.gov/research/apr/past/04-310.pdf.

OEHHA (Office of Environmental Health Hazard Assessment). 2014. Air Toxicology and Epidemiology: Table of 8-hour and Chronic Reference Exposure Levels (chRELs). California Environmental Protection Agency. http://oehha.ca.gov/air/allrels.html.

Prichard, H., and K. Marien. 1985. "A Passive Diffusion 222 n Sampler Based on Activated Charcoal Adsorption." Health Physics 48:797-803.

Rudd, A., and D. Bergey. 2014. Ventilation Systems Effectiveness and Tested Indoor Air Quality Impacts. Golden, CO: National Renewable Energy Laboratory. NREL/SR-5500-61128. http://www.nrel.gov/docs/fy14osti/61128.pdf.

Rudd, A., and J. Lstiburek, J. 2008. "Systems Research on Residential Ventilation." Proceedings of the 2008 ACEEE Summer Study on Energy Efficiency in Buildings. August 2008, Pacific Grove, CA. American Council for an Energy Efficient Economy, Washington, D.C.

Salthammer T, S. Mentese, and R. Marutzky. 2010. "Formaldehyde in the Indoor Environment." Chemical Reviews 110(4):2536-2572.

Spengler, JD, and K Sexton. 1983. "Indoor Air Pollution: A Public Health Perspective." Science 221:9-17.

Tsongas G. 2009. "Case Studies of Moisture Problems in Residences," Chapter 13 in Moisture Control in Buildings: The Key Factor if Mold Prevention. 2nd Edition, HR Trechsel and MT Bomberg (eds.), ASTM International, Baltimore, Maryland.

Weisel, C. P.; J. Zhang, B. J. Turpin, M. T. Morandi, S. Colome, T. H. Stock, D. M. Spektor, L. Korn, A. Winer, S. Alimokhtari, J. Kwon, K. Mohan, R. Harrington, R. Giovanetti, W. Cui, M. Afshar, S. Maberti, and D. Shendell. (2005). "Relationship of Indoor, Outdoor and Personal Air (RIOPA) Study." Journal of Exposure Analysis and Environmental Epidemiology 15(2):123-37. Environmental and Occupational Health Sciences Institute, Piscataway, NJ. 
Weschler C. J., and W. W. Nazaroff. 2008. "Semivolatile Organic Compounds in Indoor Environments." Atmospheric Environment 42:9018-9040.

WHO (World Health Organization. 2010. WHO Guidelines for Indoor Air Quality: Selected Pollutants. Copenhagen, Denmark: World Health Organization.

Wray C, I. Walker, and M. Sherman. 2002. Accuracy of Flow Hoods in Residential Applications. Berkeley, CA: Lawrence Berkeley National Laboratory. LBNL 49697. http://epb.lbl.gov/publications/pdf/lbnl-49697.pdf. 


\section{Appendix A. Sampling Protocol}

\section{Pre-Sampling Activities:}

- Weigh PFT Emitters

1. Calibrate the scale by weighing the 5-g, 10-g, and 20-g weights three times each and recording the weights. (Just record this; no zeroing is necessary if it is off.)

2. Weigh the PFT emitters using calibrated scale and record weight on field data form and/or spreadsheet.

- Sampler prep

1. Vary the home that receives the duplicate sampler for each sampler type.

2. Gather samplers for each home as specified in the IAQ_samplerlist.xls file, including field blanks (to be carried around with other samplers) and lab blank/QC samplers (to be sent with collected samplers to the lab).

3. Store the lab blank/QC samplers in the freezer until they are ready to ship collected samplers. Store all other samplers in a cooler with ice or cool packs so they stay cool in the warm car during deployment. Be sure to include the field blanks in this cooler that will go to the field with you.

\section{To Deploy Samplers at Each Home/Outdoor Sampling Location:}

\section{- PFT Emitters}

1. Retrieve the bag with appropriate house number on it.

2. Remove the PFT emitters from the bag and replace the solid cap with the perforated cap.

3. Attach all emitters at pre-defined locations as indicated on previous sampling sheet or the sampler spreadsheet (IAQ_samplerlist.xlsx). In general:

a. H\#.1 goes near the thermostat.

b. H\#.2 goes above the door near the passive return in the main bedroom.

c. H\#.3 goes above the door near the passive return in the back bedroom.

4. Record the start time of measurement.

\section{- Samplers}

1. Take all samplers out of metal pouch and record relevant information (time, date, ID\# $=$ House \# and 1, 2, 3 if multiple samplers of the same type) on the samplers. Be sure to keep any caps or accessories in the appropriate pouch for resealing and sending. See the table below for the sampler type, a visual description, the "make and model" information, the pouch description, where the sampler is located, and information to record.

2. Remove the end caps or slide open from one each of the PFT ( 2 per home), VOC, $\mathrm{HCHO}$ (two types), and $\mathrm{NO}_{2}$ (in some homes) passive samplers.

3. Hang the VOC, $\mathrm{HCHO}$ (both), $\mathrm{H \#} .1$ PFT sampler, and $\mathrm{NO}_{2}$ sampler (if applicable) in the provided indoor or outdoor sampler housing. If there are duplicates of any of the 
above, also place them on the indoor sample stand. Place the indoor sample stand on top of the refrigerator in most homes (refer to previous IAQ data sheet).

4. Place the second PFT sampler (H\#.2) on a passive return in back bedroom or other location as indicated on previous IAQ data sheet.

Wait seven days, or until the IAQ sample period has concluded.

\section{To Retrieve Samplers at Each Home/Outdoor Location:}

\section{- PFT Emitters}

1. Retrieve the three PFT emitters from their respective locations.

2. Remove the perforated caps from the bag for that house number and replace with the solid caps.

3. Place the emitters in a spare metal bag and then place the metal bag in the sealed plastic bag.

\section{- Samplers}

1. Retrieve the samplers from the indoor/outdoor sampling stand.

2. Cap each sampler as follows:

a. For the blue VOC sampler, the black and green HCHO sampler, and the black and yellow $\mathrm{NO}_{2}$ sampler, slide the door over the perforated section.

b. For the LBNL HCHO white sampler, place the small twist cap (left in the bag) on the open end of the sampler.

c. For the white circle PFT samplers, place the O-ring on the sampler and then place the white cap and closure on top and snap it into place.

d. LEAVE the radon sampler in place.

3. Record the end time on the data sheet.

4. Place each sampler in appropriate metal bag and seal the bag. You can tell the appropriate bag by matching the color/type of sampler with the label, as noted in the following table.

\section{Post-Sampling Activities:}

- PFT Emitters

1. Retrieve the emitters from the metal bags and re-weigh them using the same calibrated balance. Record the weights.

2. Place the emitters back in the metal bags and store the metal bags in the refrigerator or freezer until their next use.

\section{- Samplers}

1. For the SKC samplers:

a. Place the all the VOC, $\mathrm{HCHO}, \mathrm{NO}_{2}$, and PFT samplers retrieved from the field, as well as the field blank samplers and the lab blank/QC samplers in the preaddressed and pre-paid express mailbox going to ALS DataChem Laboratories. If 
all the samplers do not fit in one box, use a second box. If they do fit, save the second box for subsequent sampling events.

b. Record the time and date of mailing on the field metering data form.

c. Take the box to the post office to mail and notify the contact when the package ships.

2. For the LBNL HCHO samplers (small bags):

a. Place all samplers from the field, as well as field blank and any unused samplers in the pre-addressed and pre-paid express mail envelope. If space allows, include a cool pack, bubble wrap, or both.

b. Record the mailing time and data on sample form and include in the envelope.

c. Seal the envelope and take it to the post office to ship. Notify the contact that the package has been shipped.

\section{After Six Months:}

\section{- Radon Samplers}

1. Retrieve the radon sampler from each home (usually above the refrigerator; refer to the first IAQ data sheet).

2. Record the end time and date.

3. Fill out the Radon Data Card with the necessary information.

4. Place the completed Radon Data Card and sampler in pre-addressed mailer envelope.

5. Mail the card and notify the contact that the samplers have been sent. 
Table A-1. Sampler Summary

\begin{tabular}{|c|c|c|c|c|}
\hline Sampler & $\begin{array}{l}\text { Make and Model } \\
\text { Information }\end{array}$ & Physical Description & Sampler Location & Information To Record \\
\hline VOC & $\begin{array}{l}\text { SKC Ultra III Passive } \\
\text { Sampler }\end{array}$ & $\begin{array}{l}\text { Blue "band-aid" style } \\
\text { sampler }\end{array}$ & $\begin{array}{l}\text { indoor sample stand } \\
\text { on top of refrigerator } \\
\text { (for most homes) }\end{array}$ & $\begin{array}{l}\text { - on metal pouch record start date, time, and "ID" which } \\
\text { will be "Season (SUM/FALL/WIN/SPRG) }+1 / 2+H \# \text { " } \\
\text { - on data sheet record start time and location }\end{array}$ \\
\hline $\mathrm{HCHO}$ & $\begin{array}{l}\text { SKC UMEx } 100 \\
\text { Passive Sampler for } \\
\text { Formaldehyde (500- } \\
100)\end{array}$ & $\begin{array}{l}\text { Black with green } \\
\text { "band-aid" style } \\
\text { sampler }\end{array}$ & $\begin{array}{l}\text { on indoor sample } \\
\text { stand on top of } \\
\text { refrigerator (for most } \\
\text { homes) }\end{array}$ & $\begin{array}{l}\text { - on metal pouch record Name ("PNNL GVS"), Start date } \\
\text { and time, and ID ("H\#") } \\
\text { - on sampler record same information as pouch. } \\
\text { - on data sheet record start time and location and sample } \\
\text { \# }\end{array}$ \\
\hline $\begin{array}{l}\text { LBNL } \\
\mathrm{HCHO}\end{array}$ & $\begin{array}{l}\text { Water Formaldehyde } \\
\text { sampler }\end{array}$ & $\begin{array}{l}\text { White pedestal } \\
\text { sampler; small metal } \\
\text { bag has no labeling } \\
\text { except small white } \\
\text { sticker with two } \\
\text { numbers on it. }\end{array}$ & $\begin{array}{l}\text { indoor sample stand } \\
\text { on top of refrigerator } \\
\text { (for most homes) }\end{array}$ & $\begin{array}{l}\text { - on metal pouch record house number } \\
\text { - on data sheet record start time and location and sample } \\
\text { lot number (i.e., numbers on bag) }\end{array}$ \\
\hline $\begin{array}{l}\text { PFT } \\
\text { Samplers }\end{array}$ & $\begin{array}{l}\text { SKC Passive } \\
\text { (Diffusive) Samplers } \\
(575-002)\end{array}$ & White circular badge & $\begin{array}{l}\text { H\#.1: on indoor } \\
\text { sample stand on top } \\
\text { of refrigerator for } \\
\text { most homes } \\
\text { H\#.2: clipped on a } \\
\text { passive return on far } \\
\text { bedroom in most } \\
\text { homes (see pictures) }\end{array}$ & $\begin{array}{l}\text { - on sampler record start time and date and ID ("H\#.1" for } \\
\text { main and "H\#.2" for other return } \\
\text { - on data sheet record start time and location }\end{array}$ \\
\hline PM 2.5 & DustTrak & $\begin{array}{l}\text { Large active blue } \\
\text { equipment }\end{array}$ & $\begin{array}{l}\text { main (various, see } \\
\text { pictures) }\end{array}$ & - on data sheet record DT \# and start time and location \\
\hline NO2 & $\begin{array}{l}\text { SKC UMEx } 200 \\
\text { Passive Sampler for } \\
\text { Sulfur Dioxide and } \\
\text { Nitrogen Dioxide } \\
(500-200)\end{array}$ & $\begin{array}{l}\text { Black with yellow } \\
\text { "band-aid" style } \\
\text { sampler }\end{array}$ & $\begin{array}{l}\text { on indoor sample } \\
\text { stand on top of } \\
\text { refrigerator (for most } \\
\text { homes) }\end{array}$ & $\begin{array}{l}\text { - on metal pouch record Name ("PNNL GVS"), Start date } \\
\text { and time, and ID (“H\#”) } \\
\text { - on sampler record same information as pouch. } \\
\text { - on data sheet record start time and location and sample } \\
\text { \# }\end{array}$ \\
\hline Radon & $\begin{array}{l}\text { Pro Lab Long-term } \\
\text { Radon Gas Test Kit }\end{array}$ & $\begin{array}{l}\text { Black circular device } \\
\text { with no openings and } \\
\text { numbers on top }\end{array}$ & $\begin{array}{l}\text { indoor sample stand } \\
\text { on top of refrigerator } \\
\text { (for most homes) }\end{array}$ & - on data sheet, radon sampler \# and time and location \\
\hline
\end{tabular}




\section{Appendix B. Field Data Sheet}

Sampling Date:

Sampling Location:

Weather Conditions: Temp:

$\mathrm{RH}$ :

PFT Emitter Weights

\begin{tabular}{|l|l|l|l|l|l|l|}
\hline $\begin{array}{l}\text { Sample } \\
\text { Description }\end{array}$ & $\begin{array}{l}\text { Sample Location (note } \\
\text { if different) }\end{array}$ & $\begin{array}{l}\text { Pre- } \\
\text { Weight }\end{array}$ & $\begin{array}{l}\text { Start } \\
\text { Date/Time }\end{array}$ & $\begin{array}{l}\text { Post- } \\
\text { Weight }\end{array}$ & $\begin{array}{l}\text { End } \\
\text { Date/Time }\end{array}$ & Notes \\
\hline PFT Emitter & $\begin{array}{l}\text { H\#.1 = main near } \\
\text { thermostat }\end{array}$ & & & & & \\
\hline PFT Emitter & $\begin{array}{l}\text { H\#.2 = near passive } \\
\text { return over master } \\
\text { bedroom }\end{array}$ & & & & & \\
\hline PFT Emitter & $\begin{array}{l}\text { H\#.3 = near passive } \\
\text { return over back } \\
\text { bedroom }\end{array}$ & & & & & \\
\hline
\end{tabular}

IAQ Sampler Data

\begin{tabular}{|c|c|c|c|c|c|}
\hline $\begin{array}{l}\text { Sample } \\
\text { Description }\end{array}$ & $\begin{array}{l}\text { Sampler Location } \\
\text { (note if different) }\end{array}$ & $\begin{array}{l}\text { Sampling } \\
\text { Start Time }\end{array}$ & $\begin{array}{l}\text { Sampling End } \\
\text { Date }\end{array}$ & $\begin{array}{l}\text { Sampling } \\
\text { End Time }\end{array}$ & Notes \\
\hline VOC & $\begin{array}{l}\text { Main = indoor sample } \\
\text { stand on refrigerator }\end{array}$ & & & & \\
\hline $\mathrm{HCHO}$ & $\begin{array}{l}\text { Main = indoor sample } \\
\text { stand on refrigerator }\end{array}$ & & & & $\begin{array}{l}\text { Sampler } \\
\text { ID = }\end{array}$ \\
\hline LBNL HCHO & $\begin{array}{l}\text { Main = indoor sample } \\
\text { stand on refrigerator }\end{array}$ & & & & $\begin{array}{l}\text { Sampler } \\
\text { Lot \# = }\end{array}$ \\
\hline PFT Sampler & $\begin{array}{l}\mathrm{H \# .1}=\text { Main = indoor } \\
\text { sample stand on } \\
\text { refrigerator }\end{array}$ & & & & \\
\hline PFT Sampler & $\begin{array}{l}\mathrm{H \# .2}=\text { Passive return } \\
\text { elsewhere in house, not } \\
\text { directly near emitter }\end{array}$ & & & & \\
\hline $\mathrm{NO}_{2}$ & $\begin{array}{l}\text { Main = indoor sample } \\
\text { stand on refrigerator }\end{array}$ & & & & $\begin{array}{l}\text { Sampler } \\
\text { ID = }\end{array}$ \\
\hline Radon & $\begin{array}{l}\text { Main = indoor sample } \\
\text { stand on refrigerator }\end{array}$ & LEAVE FOR & 6 MONTHS & & \\
\hline
\end{tabular}

\section{Mailing Information}

Mail Date: Mail Time:

Mailed By: 


\section{Appendix C. Quality Assurance and Quality Control}

The following is a brief discussion of quality assurance and quality control (QA/QC) procedures to be followed during each sampling event.

\section{Field Procedures}

Field QA/QC procedures will include the following:

- $\quad$ TVOC, $\mathrm{HCHO}, \mathrm{NO}_{2}$, and $\mathrm{CO}_{2}$ data will be taken indoors and outdoors to ensure environmental factors are not confounding results.

- A blank sample (remains capped) of each constituent will be collected at each site for comparison.

- At least one duplicate sample of each constituent will be collected for each IAQ sampling event.

- Analysis will include a unique analysis blank and spike for each constituent and each analysis period. See Laboratory Analysis Summary [Appendix F] for details on analysis QA/QC methods.

\section{Field Logbook}

Relevant field data will be recorded on a field metering data sheet [Appendix B] for each sampling site (each home and outdoors). These data will include, at a minimum:

- Date of sample collection

- Location of sample collection

- Times and dates corresponding to the start of sampling and the end of sampling; weather conditions. 


\section{Appendix D. List of IAQ Samplers and Relevant Standards}

\begin{tabular}{|c|c|c|c|c|c|c|c|c|c|c|c|}
\hline Item Number & Model/Title & Description & Pollutant & Type of Sampling & Sensitivity & Range & Accuracy & Sampling Rate & Standard Level & Standard Referend & Expected Concentr \\
\hline \multicolumn{12}{|l|}{ IAQ Equipment } \\
\hline 1.1 & Ultra III Sorbent Badges-VOC & $\begin{array}{l}\text { Ultra II badges, fillable. Must purchase sorbant seperately (see } \\
1.2)\end{array}$ & voc & point & various $(0.027-0$ & Dvarious & |various & \multicolumn{2}{|c|}{ see http://www.skcinc.com/pdf/1 } & various & \\
\hline 2.1 & Indoor Air Formaldehyde Passive Sal & Disk treated with sodium hydrogen sulfite & $\mathrm{HCOH}$ & point & $0.01 \mathrm{ppm} \pm 30 \%$ & 0.01 to $3 \mathrm{ppm}$ & 0.025 to $1 \mathrm{ppm} \pm$ & 5-7 days & \begin{tabular}{|l|}
$0.02 \mathrm{ppm}$ (NIOSH \\
$\mathrm{REL}$ \\
$0.75 \mathrm{ppm}$ (OSHA \\
$\mathrm{PELL})$
\end{tabular} & noted in level & \\
\hline 3.1 & UMEx200 Sorbent Badges-No2 and Sd & $\begin{array}{l}\text { Tape treated with triethanolamine [TEA], accuarte to } 0.4 \mathrm{ppm} \text {. } \\
\text { collects Sox and Nox informtaion. To be sent back to Datachem for } \\
\text { analysis (see 6) }\end{array}$ & Nox/Sox & point & $0.1 \mathrm{ppm}(8$ hours & 0.4 and $8 \mathrm{ppm}$ & $\pm 30 \%$ & $17.5 \mathrm{ml} / \mathrm{min}$ with & \begin{tabular}{|l} 
ST1 ppm \\
(NIOSH) \\
5 ppm (OSHA) \\
ACGIH 3 ppm \\
\end{tabular} & noted in level & \\
\hline 4.1 & Radon Test Strips & Passive long-term test strips for Radon gas in air & Radon & point & $0.1 \mathrm{pci} / \mathrm{L}$ & $0.1 \mathrm{pci} / \mathrm{Lt}$ to.. & $\pm 10 \%$ & 7 days & $4 \mathrm{pCi} / \mathrm{L}$ & EPA & $\angle 4 \mathrm{pCi} / \mathrm{L}$ \\
\hline 5.1 & НОВО U12-011 T/RH meters & To measure T/RH 4 locations in each home & T/RH & continuous & & $\begin{array}{l}-4 \text { to } 158 \mathrm{ppm} ; \\
5 \text { to } 95 \%\end{array}$ & 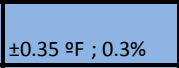 & 15 minutes & N/A & $\mathrm{N} / \mathrm{A}$ & $\begin{array}{l}5-95 \% \mathrm{RH} ; \\
32-115 \mathrm{~F}\end{array}$ \\
\hline 5.2 & EXTECH T/RH/CO2 meters & To measure $\mathrm{T} / \mathrm{RH} / \mathrm{CO} 2$ in at least on location in each home & $\mathrm{T} / \mathrm{RH} / \mathrm{CO} 2$ & continuous & & $0-9999 \mathrm{ppm}$ & $\pm 5 \%$ of the readi & 15 minutes & $380 \mathrm{ppm}$ & global mean $\mathrm{CO}_{2}$ & 380 to $800 \mathrm{ppm}$ \\
\hline \multicolumn{12}{|c|}{ Ventilation Equipment } \\
\hline 6.3 & Tracer Gas Test & To quantify natural air changes and ventilation effective & Ventilation Ra & point & $6.7 \mathrm{ppb}$ & TBD & TBD & TBD & N/A & N/A & \\
\hline \multicolumn{12}{|c|}{ Other Equipment/Materials } \\
\hline 7.1 & 14 channel eMonitor (including CT) & & & continuous & & & & hourly & $\mathrm{N} / \mathrm{A}$ & N/A & N/A \\
\hline & -acrosse T & & & |continuous & 9 to $12 \mathrm{bit}$ & -10 to $85 C$ & $\pm 0.5 \mathrm{C}$ & hourly & N/A & $\sqrt{N / A}$ & N/A \\
\hline
\end{tabular}




\section{Appendix E. Homeowner Questionnaire}

The answers to the following questions can be filled out by the homeowner in paper copy, or they can be provided verbally on the phone or in person.

\section{Initial Questions Regarding HVAC System and Home Operation} (to be asked one time)

\section{In a typical week:}

When do you use your ceiling fans (all the time, while sleeping, when you feel uncomfortable)?

Please describe typical frequency and duration (e.g., about three times per week, for about an hour each time):

How frequently do you use your bath fans (e.g., number of times per day, week, or month) and for how long each time (number of minutes)?

How frequently do you use your range hood and for how long each time?

How often do you change your return air filter(s)?

If your home has a whole-house ventilation system, how often do you change its filter?

How often do you turn off the heating/cooling system and open windows (check all that apply)?

\begin{tabular}{|l|l|l|l|l|l|}
\hline & Never & $\begin{array}{l}\text { Sometimes } \\
\text { during the day }\end{array}$ & $\begin{array}{l}\text { Sometimes at } \\
\text { night }\end{array}$ & $\begin{array}{l}\text { As much as I can } \\
\text { during the day }\end{array}$ & $\begin{array}{l}\text { As much as I can } \\
\text { at night }\end{array}$ \\
\hline Winter & & & & & \\
\hline Spring & & & & & \\
\hline Summer & & & & & \\
\hline Fall & & & & & \\
\hline
\end{tabular}

Considering typical conditions, please respond "yes" or "no" to the following statements. If "no," please describe the discomfort or dissatisfaction in terms of hot, cold, humid, dry, stuffy, clammy, drafty, unusual odors, mold, etc.

My home is generally comfortable.

Y/N If "no", please describe

All rooms in my home are equally comfortable. 
I am satisfied with the overall comfort of my home.

The indoor air quality in my home is generally good.

\section{Follow-Up Questions Regarding HVAC System and Home Operation (to be asked during each change in ventilation rate)}

Was there any change in the number or schedule of occupants in the past two weeks (e.g., occupant traveling or home from college, switch to night shift)?

Considering only the past two weeks, please indicate "yes" or "no" for the following statements. If "no," please describe the discomfort or dissatisfaction in terms of hot, cold, humid, dry, stuffy, clammy, drafty, unusual odors, mold, etc.

My home has been comfortable for the past two weeks.

$$
\mathrm{Y} / \mathrm{N} \quad \text { If "no", please describe }
$$

All rooms in my home are equally comfortable.

I am satisfied with the overall comfort of my home.

The indoor air quality in my home was good.

All indoor surfaces were free of condensation.

Have there been other changes in comfort?

If yes, please describe:

The next questions relate to changes in fans and windows operation compared to typical operation in your home. For "yes" responses, describe the change-typical frequency and typical duration. Indicate whether occupancy changes indicated in the first question were a factor. In the past two weeks, have you noticed or made any changes in the operation of:

\begin{tabular}{|l|l|l|l|l|l|}
\hline & Y/N & Change & Frequency & Duration & $\begin{array}{l}\text { Related to Q1 } \\
\text { answer? }\end{array}$ \\
\hline Ceiling fans & & & & & \\
\hline HVAC system? & & & & & \\
\hline Master Bath fan* & & & & & \\
\hline Bath 2 Fan* & & & & & \\
\hline Bath 3 Fan* & & & & & \\
\hline Kitchen exhaust fan & & & & & \\
\hline
\end{tabular}




\begin{tabular}{|l|l|l|l|l|l|}
\hline & Y/N & Change & Frequency & Duration & $\begin{array}{l}\text { Related to Q1 } \\
\text { answer? }\end{array}$ \\
\hline Dryer & & & & & \\
\hline Windows & & & & & \\
\hline
\end{tabular}

*excluding continuously operating fans

In the past two weeks, was there a continuously operating exhaust fan(s) in your home? If yes, was the fan turned off? conditions or events.

If yes, please describe frequency, duration, and

\section{Indoor Air Quality Supplement}

(only to be asked at beginning and end of IAQ Sample Events)

In the past week, did any occupants have variable work hours? If yes, please describe.

In the past week, were there any unusual events that took place (e.g., parties, larger-than-usual cooking events)? If yes, please describe.

Did you clean your home using chemicals in the past week?

Did you acquire or remove any furniture, carpets or rugs, cabinetry, window treatments, appliances, or other interior finishes or furnishings during the past week?

Were the indoor air quality samplers moved or displaced during the past weeks?

Homeowner Comments (Is there anything else you would like to add that has not been addressed?): 


\section{Appendix F. Laboratory Analysis Summary}

\section{Objectives}

This document [appendix] discusses methods and procedures for analyzing field samples for various contaminants in residential buildings. Contaminants of interest include volatile organic compounds (VOCs), formaldehyde, acetaldehyde, and nitrogen dioxide. This document addresses relevant procedures needed to analyze individual analytes so that all performance criteria can be strictly managed during the entire period of the analysis under quality assurance/quality control $(\mathrm{QA} / \mathrm{QC})$ managements.

\section{Scope}

The main works that the operator of the analysis are as follows:

- Treatments of passive samplers to be analyzed

- Verification of various performance criteria and maintenance of QA program

- Preparation of laboratory supplies such as constant temperature refrigerator, dry oven, gas chromatography (GC) columns, carrier gas, standards, and chemicals

- Calibration of instruments such as GC, mass spectrometry (MS), gas chromatograph with electron capture detectors (GC-ECD) system, ion chromatography (IC), and highperformance liquid chromatography (HPLC)

- Sample analysis by using relevant instruments

- Provision of a report demonstrating standard operating procedure (SOP) of the analysis and the results of the target contaminants described below.

\section{General Considerations}

\section{Field Sampling}

- A number of SKC passive samplers will be used: Ultra III passive sampler with Carbograph 5 TD (Cat. No. 690-102), UMEx 100 (Cat. No. 500-100), and UMEx200 passive sampler (Cat. No. 500-200).

- Field sampling may begin as early as the first week of June, and the earliest analysis date may be the second week of the month.

- Contaminants of interest will be sampled for one full week for a single sampling period.

- A total of eight sampling periods will occur, and two sampling periods will take place each season.

- The total numbers of samples for each sampling period may be different for each individual contaminant.

\section{Laboratory Analysis}

- The laboratory is responsible for inspecting samples shipped immediately when they arrive, and report condition of samples, especially visible signs of damage or contamination. 
- The laboratory may reject sample analysis if samples are damaged, unlabeled, or any relevant reasons identified during visual inspection.

- All procedures are to be strictly followed by standard methods such as EPA Compendium Methods and SKC operating instructions referred in each section below.

- Samples are to be analyzed as soon as they arrive at the laboratory, and the duration of entire analysis procedures should not exceed two weeks for each analysis cycle.

- No special treatments should be made to particular samples known as blanks.

- The performance criteria analysis can be performed once at the beginning of the sampling period. If any of the performance criteria is unmet, another attempt to such particular criterion or criteria can be followed by using duplicate samples available.

- All passive samplers delivered are supposed to be stored immediately in a refrigerator maintaining a constant temperature below $4^{\circ} \mathrm{C}$ and a clean environment, unless they are transferred on the same day upon arrival.

- All reusable samples in the forms to be analyzed such as solutions and sample extracts for $\mathrm{NO}_{2}$ analysis are supposed to be stored in the constant temperature refrigerator until data validity is verified.

- All efforts should be made to avoid possible interferences over all different types of samples being stored.

\section{VOC Analysis}

\section{Sample Treatment}

- Individual samples transferred must be labeled as indicated on the original samples.

- Duplicate samples may not be transferred, but they are to be stored in the same manner as original samples are treated. They may be transferred later if some samples fail to pass performance criteria or leak test during analyzing processes.

- No physical pressure should be applied when sorbents from individual samplers are transferred.

- Once transferred, all samples in a thermal desorption tube should be rewrapped with uncoated aluminum foil unless they are analyzed on the same day.

- A set of samples collected on a single sampling cycle are supposed to be treated on the same day, if possible. If not possible, at least individual processes, such as sorbent transfer, should occur on the same day.

- Thermal desorption tubes are to be immediately sealed and wrapped individually with uncoated aluminum foil after individual sorbent transfer from passive samplers.

- All tubes including blank ones should be stored in the refrigerator unless they are analyzed on the same day.

\section{Calculation of Concentration}

- An average room temperature during sampling duration will be provided by PNNL for each sampler. 
- Sampling site atmospheric pressure in $\mathrm{mm} \mathrm{Hg}$ can be assumed to be atmospheric pressure at the time of sampling.

- Desorption efficiency is assumed to be 1.0.

- Pre-defined sampling rates in $\mathrm{ml} / \mathrm{min}$ provided by the manufacturer can be used.

\section{Sample Analysis}

- All procedures for laboratory analysis such as thermal desorption tube conditioning, predesorption system checks, and interferences should be carefully followed by the guidance of TO-17 method.

- Portions of descriptions regarding active sampling such as sampling apparatus, calibration, and sampling rate in the method TO-17 document may not be considered.

- Among the four performance criteria listed in the document, the precision for the distributed volume pair may not be considered as it is not applicable to a passive sampling method.

- Two laboratory blanks should be analyzed every analysis cycle.

- At least one field blank should be taken from the blank/correction sorbent every analysis cycle.

- Samples should be removed from refrigerated storage at least two hours prior to analysis to equilibrate with the ambient air temperature. The duration of the sample placement before analysis can be determined by the operator of the analysis.

- Individual VOCs listed in Table 1 in the method TO-14 should be identified, and the TVOC should include both non-list VOCs and unidentified VOCs.

\section{Formaldehyde Analysis}

- Analytes of interest are formaldehyde and acetaldehyde, and other aldehydes may be analyzed if detection of other aldehydes does not need modifications to the standard analysis procedure or additional treatments.

- The analysis procedure should follow the Analysis Instructions in the document of the SKC Operating Instructions for UMEx 100 passive sampler for formaldehyde, which summarizes EPA IP-6C for diffusive sampler.

- The TO-11A method can be referred to for HPLC analysis and calibration, performance criteria, and QA/QC.

- Sample analysis including sample extraction and HPLC analysis is recommended to be performed on the same day.

- The DNPH-formaldehyde solution should be stored in the constant temperature refrigerator at blow $4{ }^{\circ} \mathrm{C}$ if HPLC analysis is scheduled another day. The stored solution must be analyzed within three days.

- The calibration process should be verified to meet all processes demonstrated in the TO-11A method. 
- Method detection limits (MDLs) may not be evaluated if they have been validated within five months and no instrument change has been made in the period.

- Remaining solutions should be stored up to three days in a constant temperature refrigerator until the data validity of the analysis has been verified.

\section{Nitrogen Dioxide Analysis}

- All analysis procedures are to be strictly followed by the operating instructions for SKC UMEx 200.

- The remaining sample extracts originally for analyzing sulfur dioxide should be stored in the constant temperature refrigerator at below $4^{\circ} \mathrm{C}$ as duplicate extracts.

\section{PFT Sample Analysis}

- The tracer gas to be used is perfluoromethylcyclohexane (PMCH), and it is analyzed by GCECD system.

- The detection limit would be considered as $0.05 \mathrm{ppb}$, or as determined by the laboratory.

- Due to lack of a standard procedure for the analysis, the laboratory may refer specific methods associated with the analysis.

\section{Laboratory Test Report}

The laboratory report should include the following information:

- Laboratory identification

- Specifications of sample transfer elements, instruments, and laboratory supplies

- Analysis methods and conditions

- Data validity depending on the performance criteria and blank tests including data analysis procedures

- Test results: Concentration of compounds of interest in $\mu \mathrm{g} / \mathrm{m}^{3}, \mathrm{ppm}$, or equivalent including individual VOC compounds listed in Table 1 in EPA Compendium Method TO-14, TVOC, $\mathrm{HCHO}$, and acetaldehyde

- Photographs ensuring individual analysis processes

- Certification of the report

- Additional information that would be relevant to reporting analysis procedure. 


\section{Appendix G. Weather Conditions in Gainesville, Florida, During} the Monitoring Period

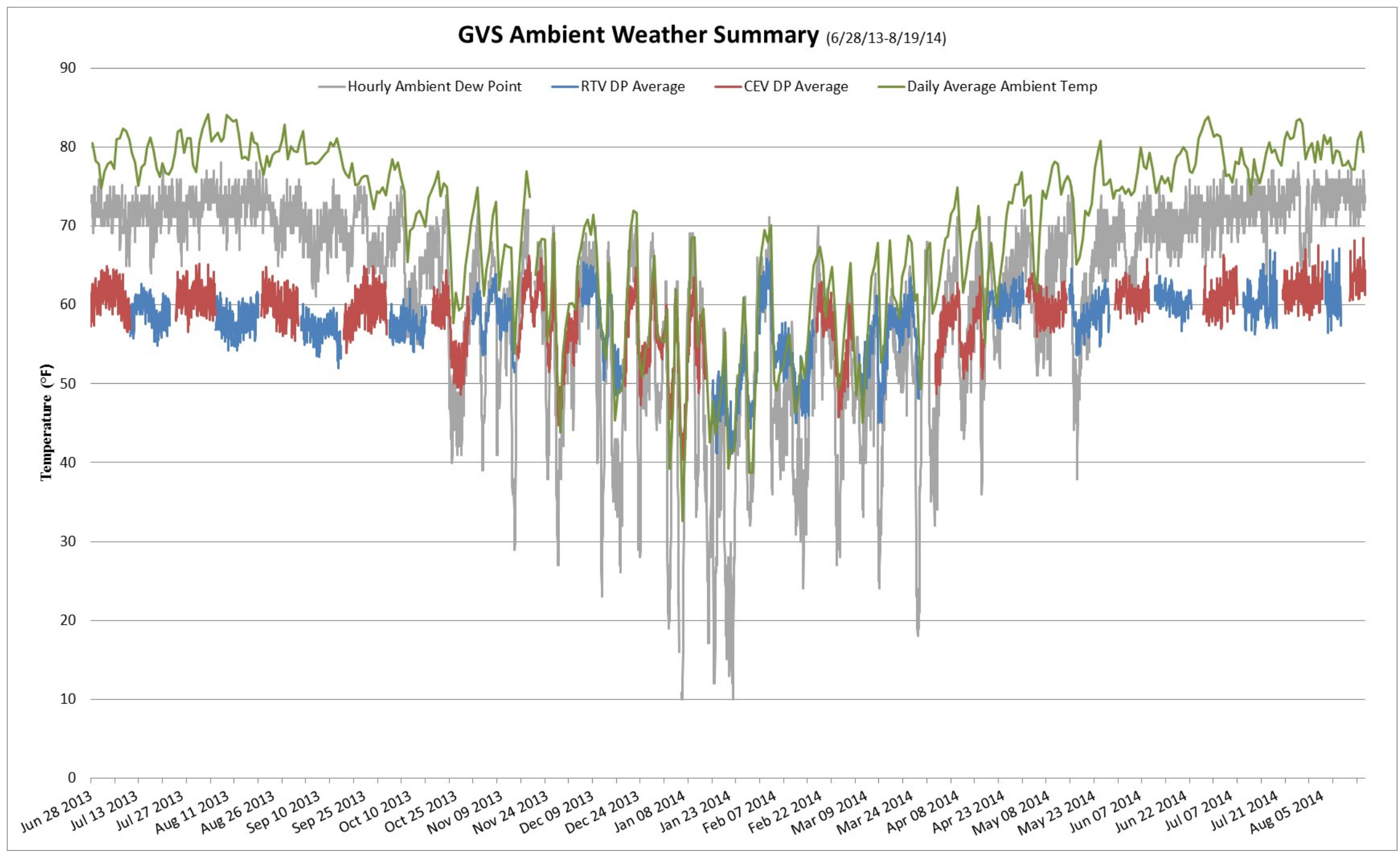

Figure G-1. Full year plot of average hourly indoor dew point temperature for six flip-flop homes plus hourly outdoor dew point and average daily dry bulb temperatures from $6 / 28 / 2013$ to $8 / 19 / 2014$ 


\section{Appendix H. Indoor Home Plots}

Figure H-1 through Figure H-10 plot the hourly indoor temperature, relative humidity, and carbon dioxide for each home for the complete study period: $6 / 28 / 2013$ to $8 / 04 / 2014$.

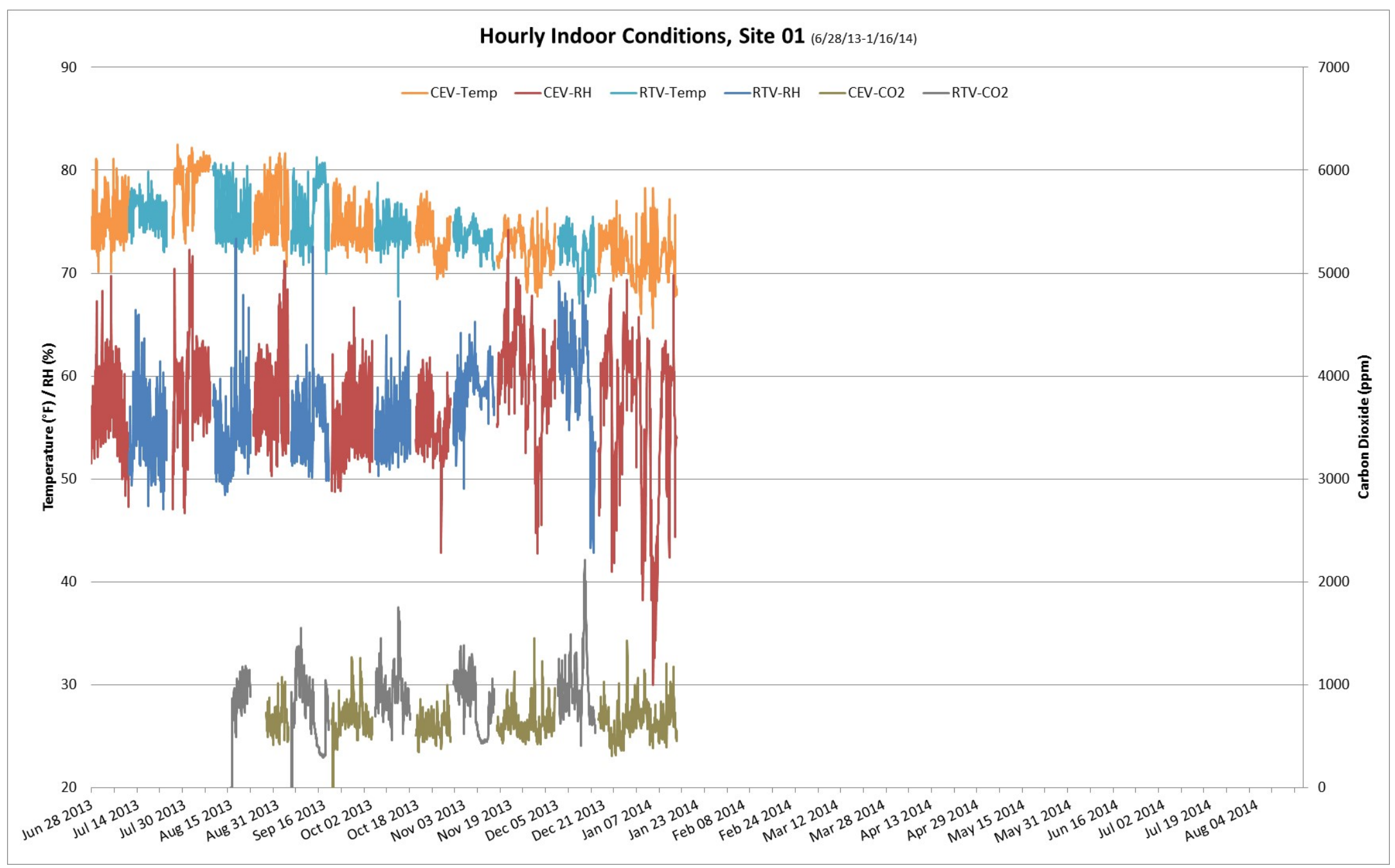

Figure H-1. Hourly indoor conditions for Home 1 


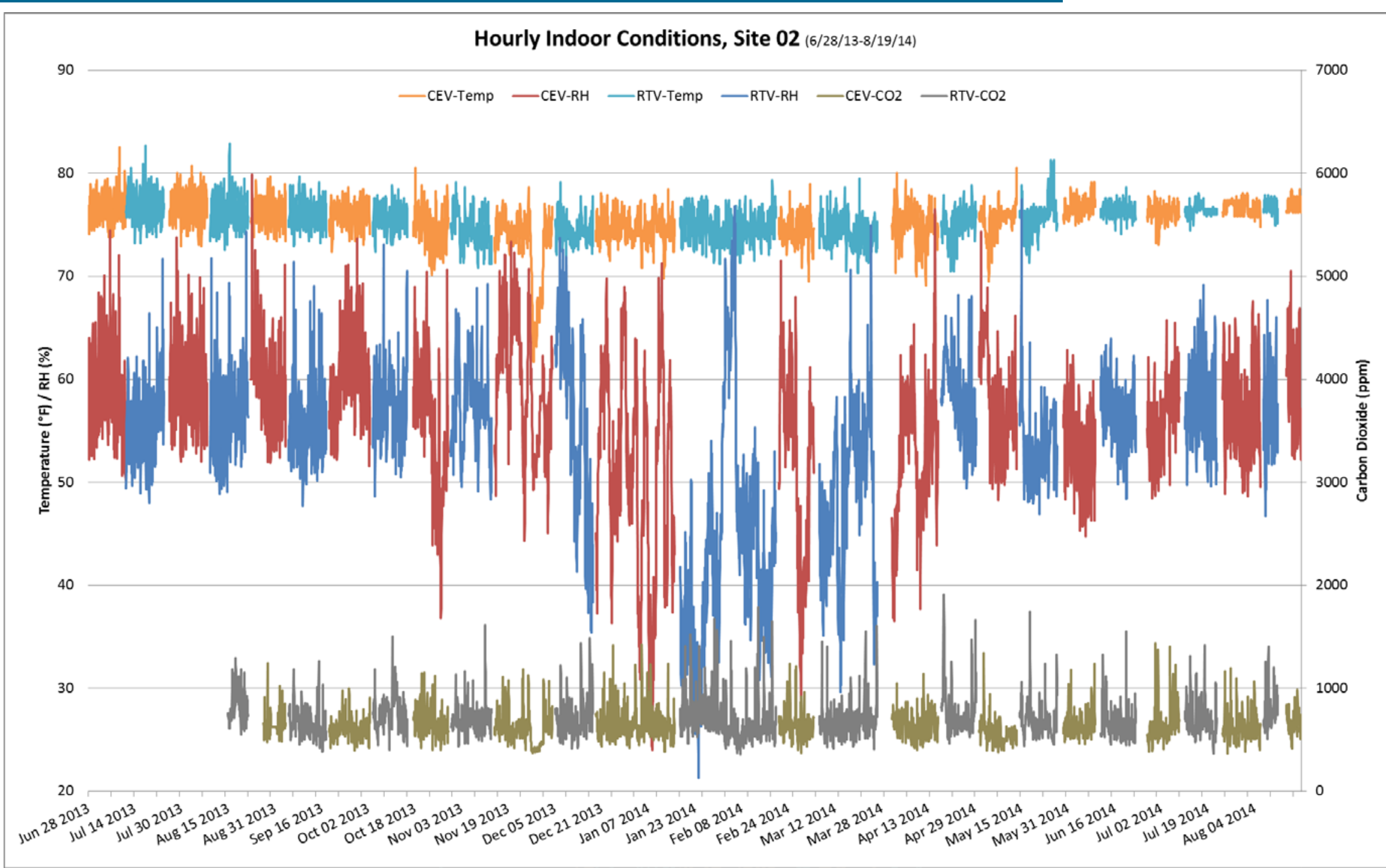

Figure H-2. Hourly indoor conditions for Home 2 
Hourly Indoor Conditions, Site $03_{(6 / 28 / 13-8 / 19 / 14)}$

90

-CEV-Temp - CEV-RH -

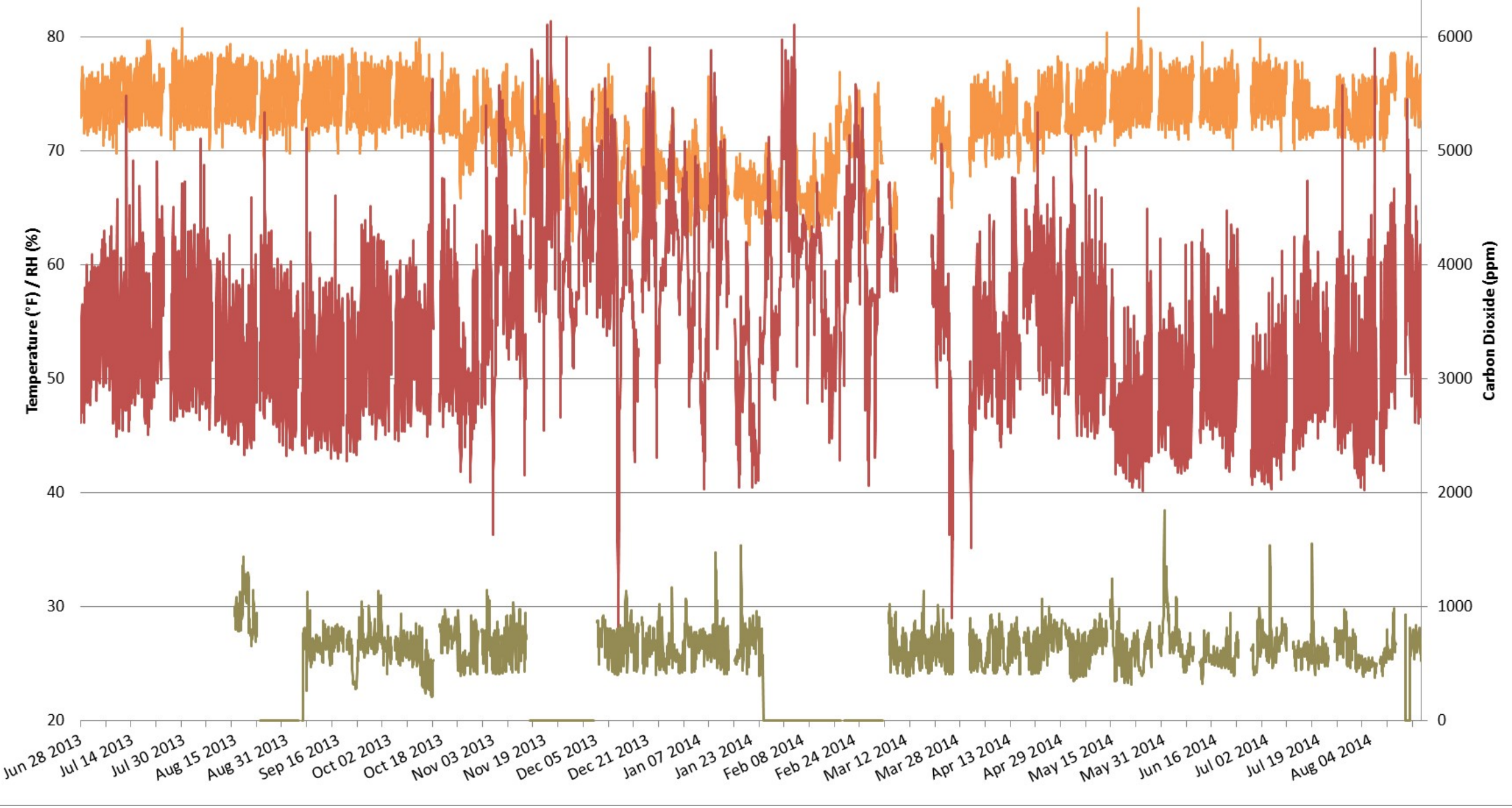

Figure H-3. Hourly indoor conditions for Home 3 


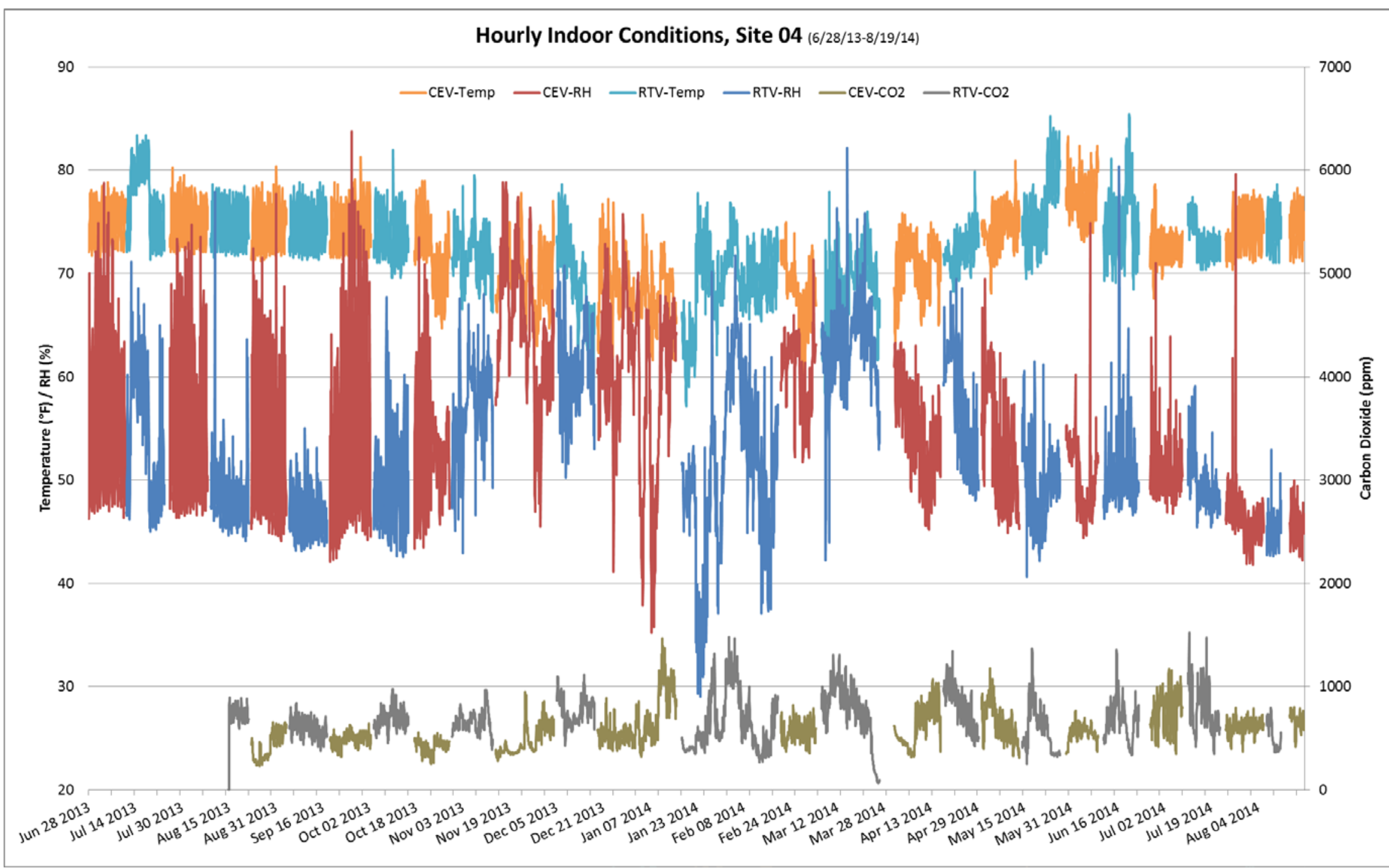

Figure H-4. Hourly indoor conditions for Home 4 


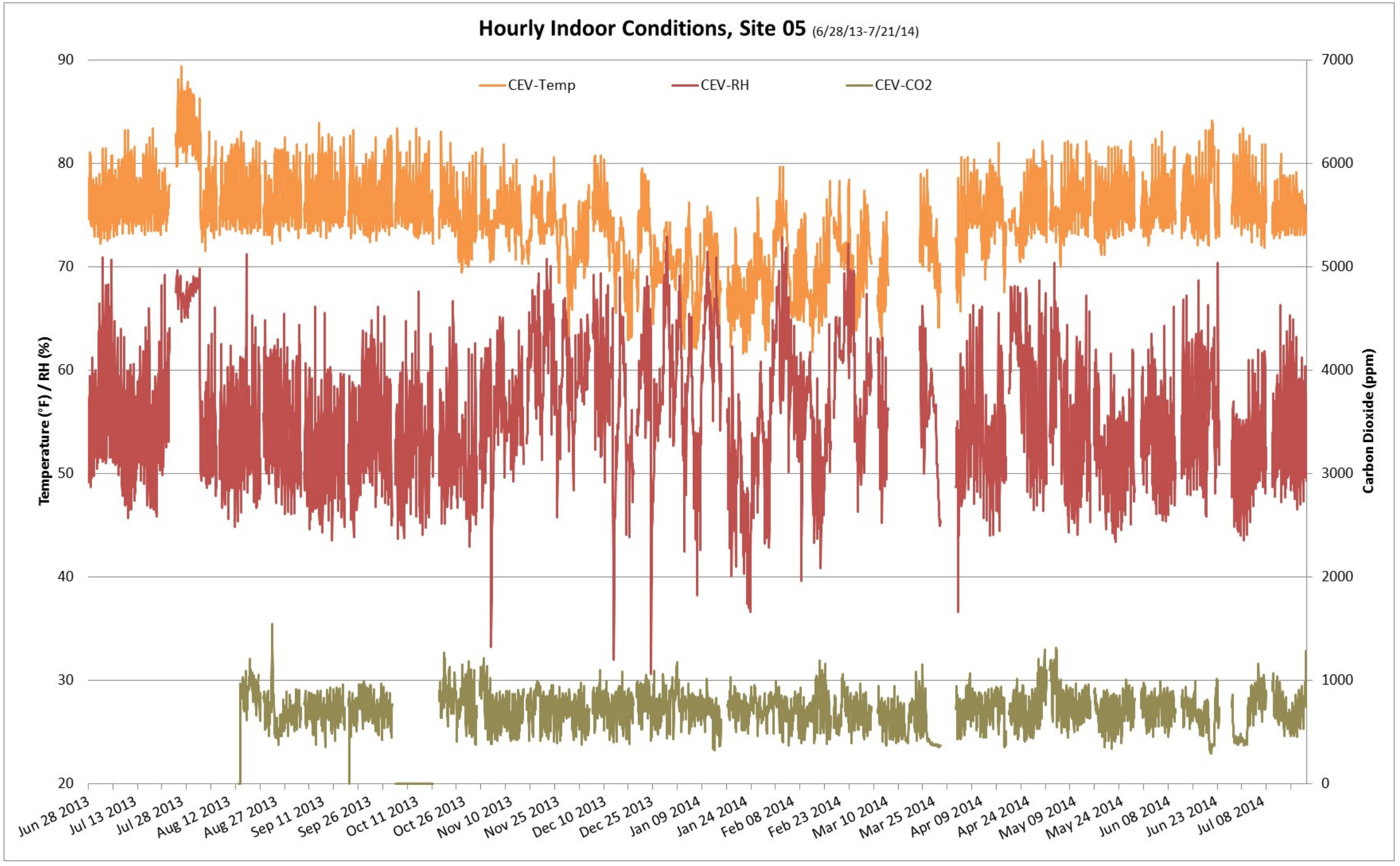

Figure H-5. Hourly indoor conditions for Home 5 


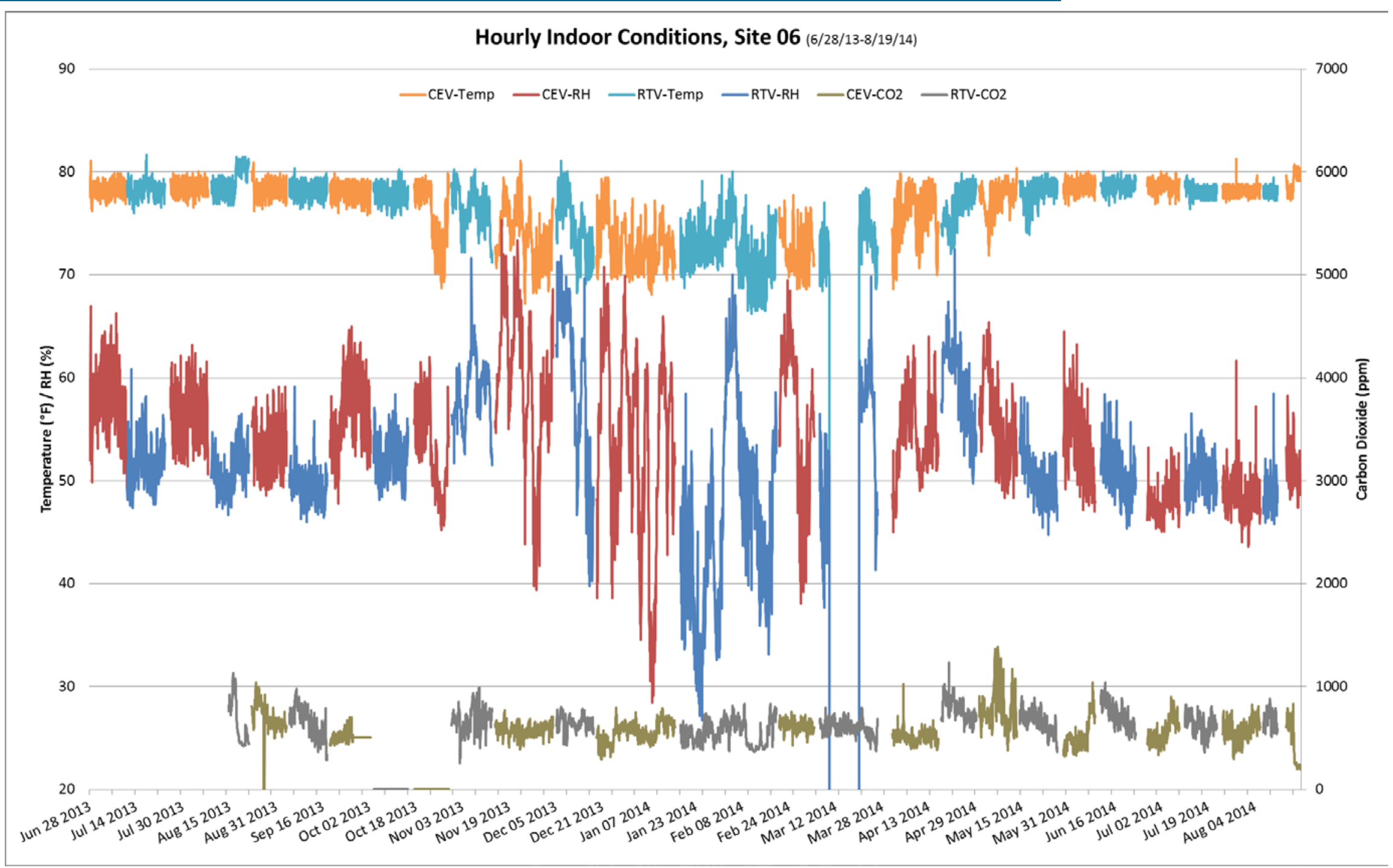

Figure H-6. Hourly indoor conditions for Home 6 
Hourly Indoor Conditions, Site 07 (6/28/13-8/19/14)

90

—RTV-Temp —RTV-RH

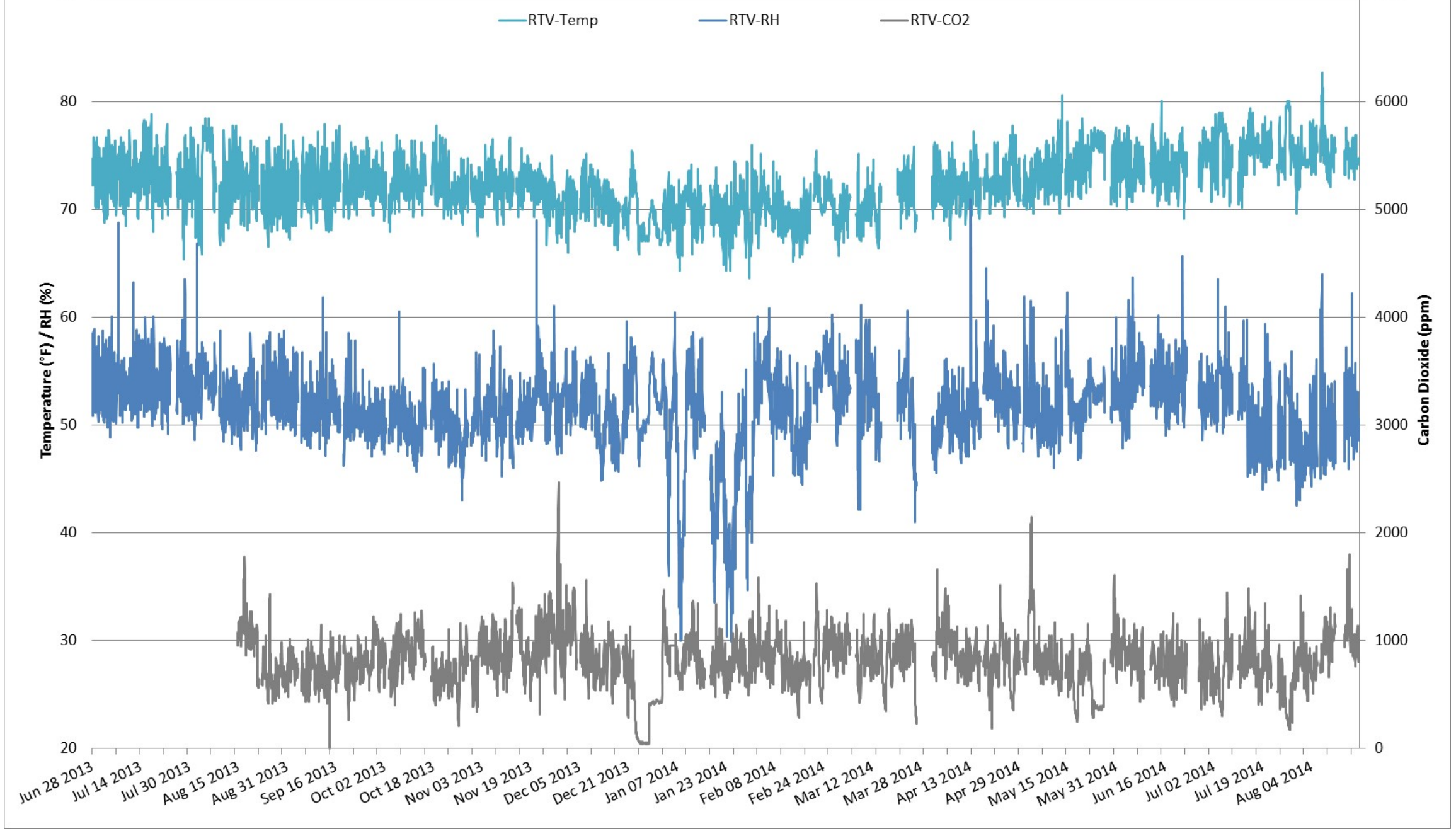

Figure H-7. Hourly indoor conditions for Home 7 


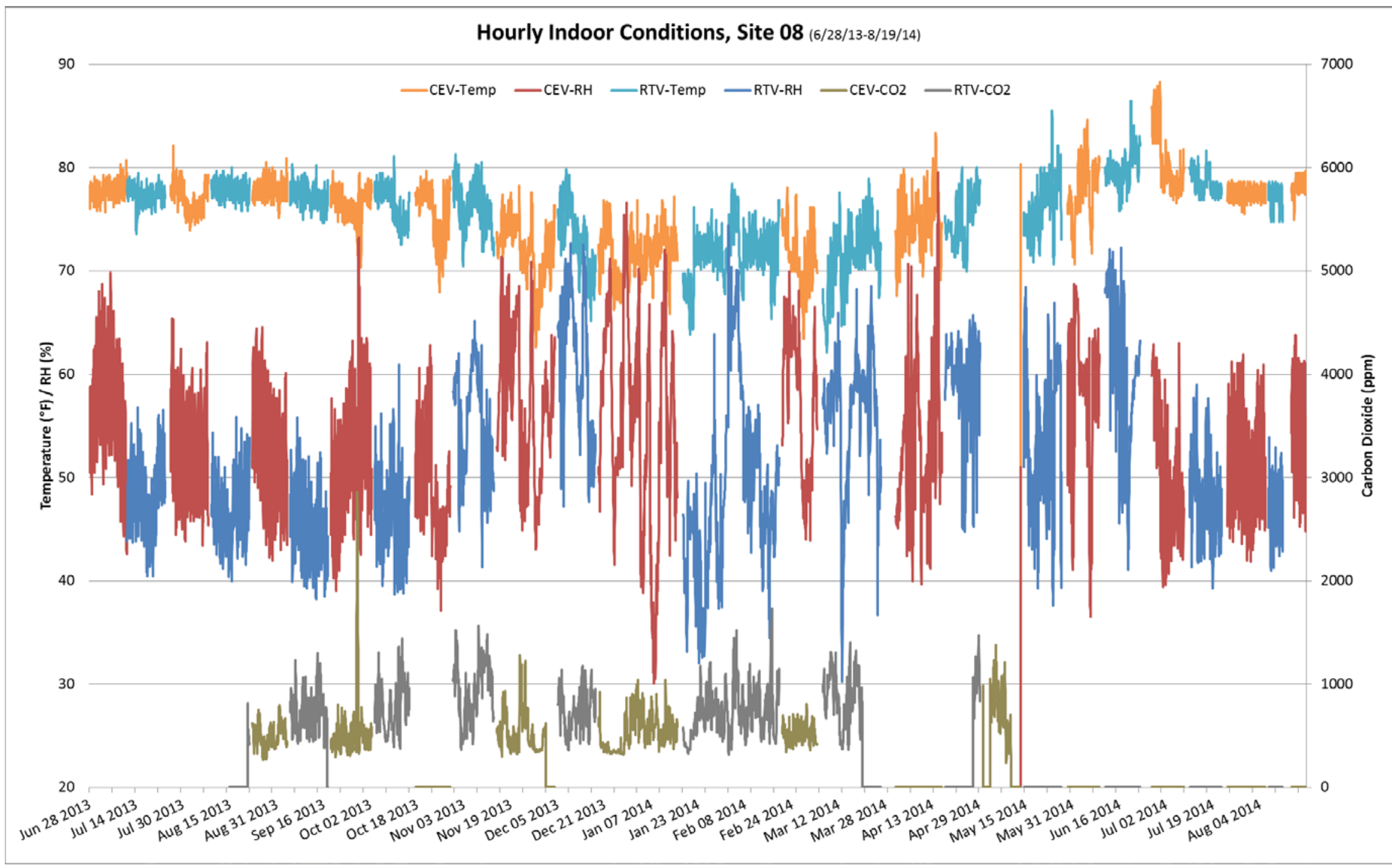

Figure H-8. Hourly indoor conditions for Home 8 


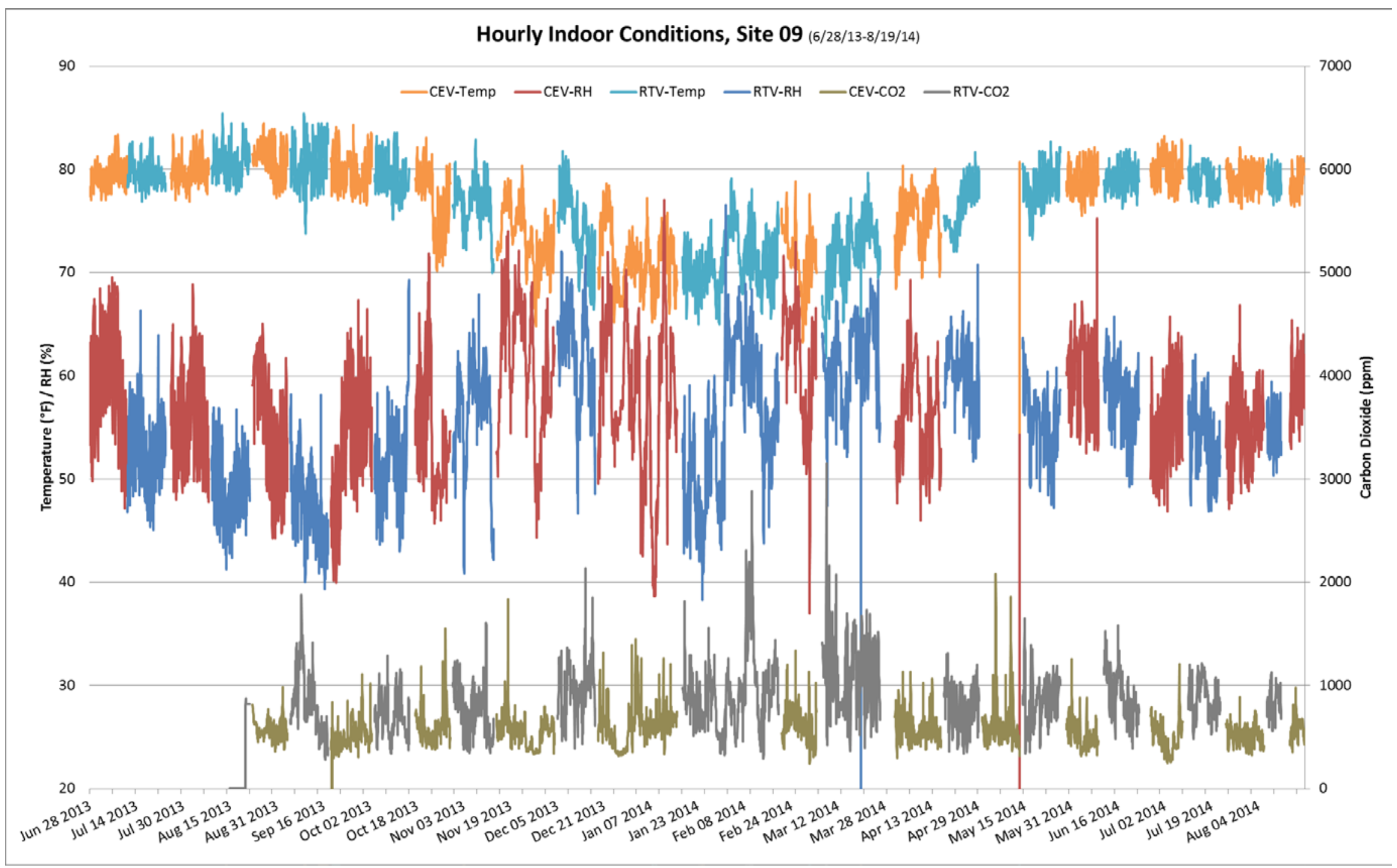

Figure H-9. Hourly indoor conditions for Home 9 
Hourly Indoor Conditions, Site 10 (6/28/13-8/19/14)

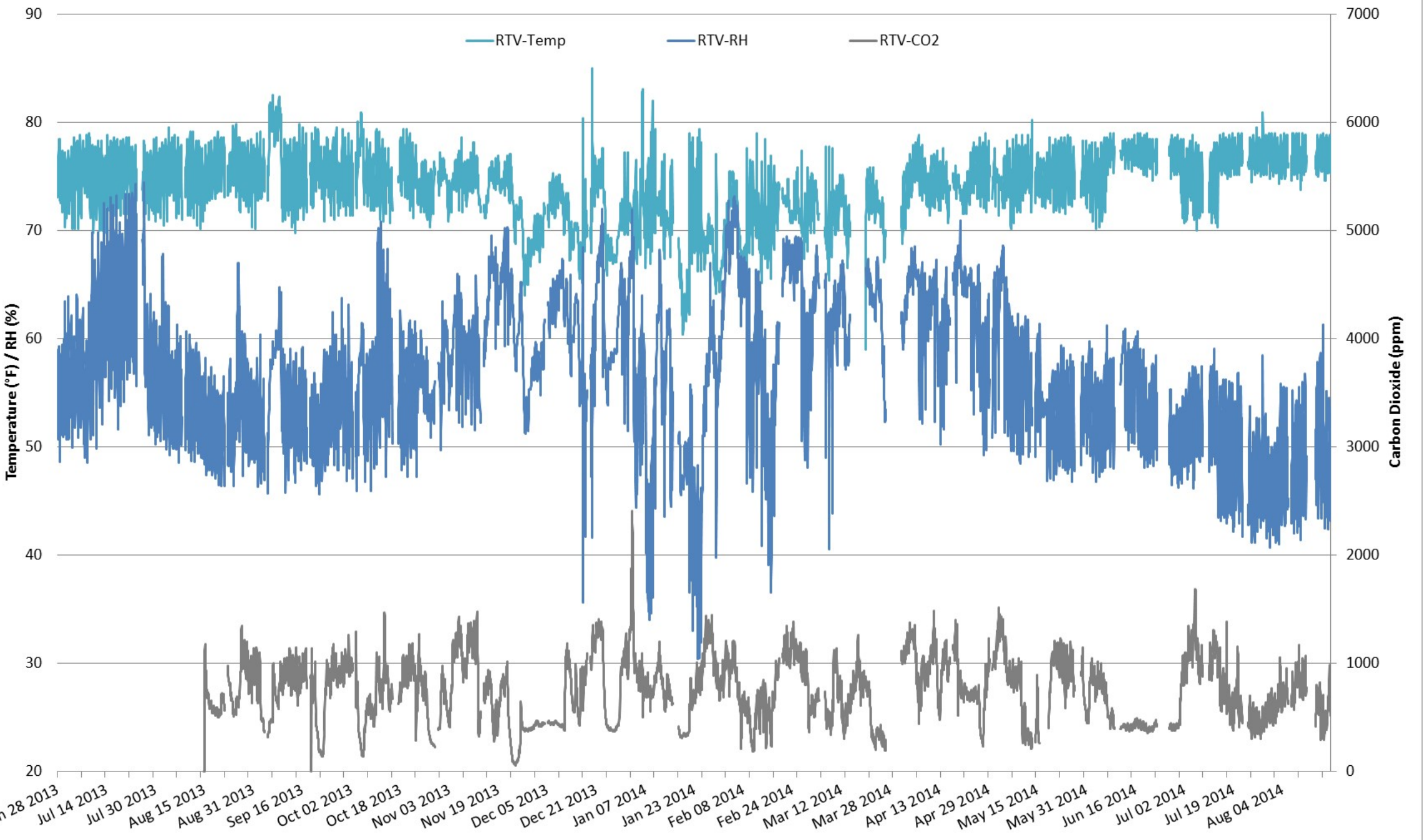

Figure H-10. Hourly indoor conditions for Home 10 


\section{Appendix I. Space-Heating Analysis, Linear Regressions}

Figure I-1 through Figure I-6.
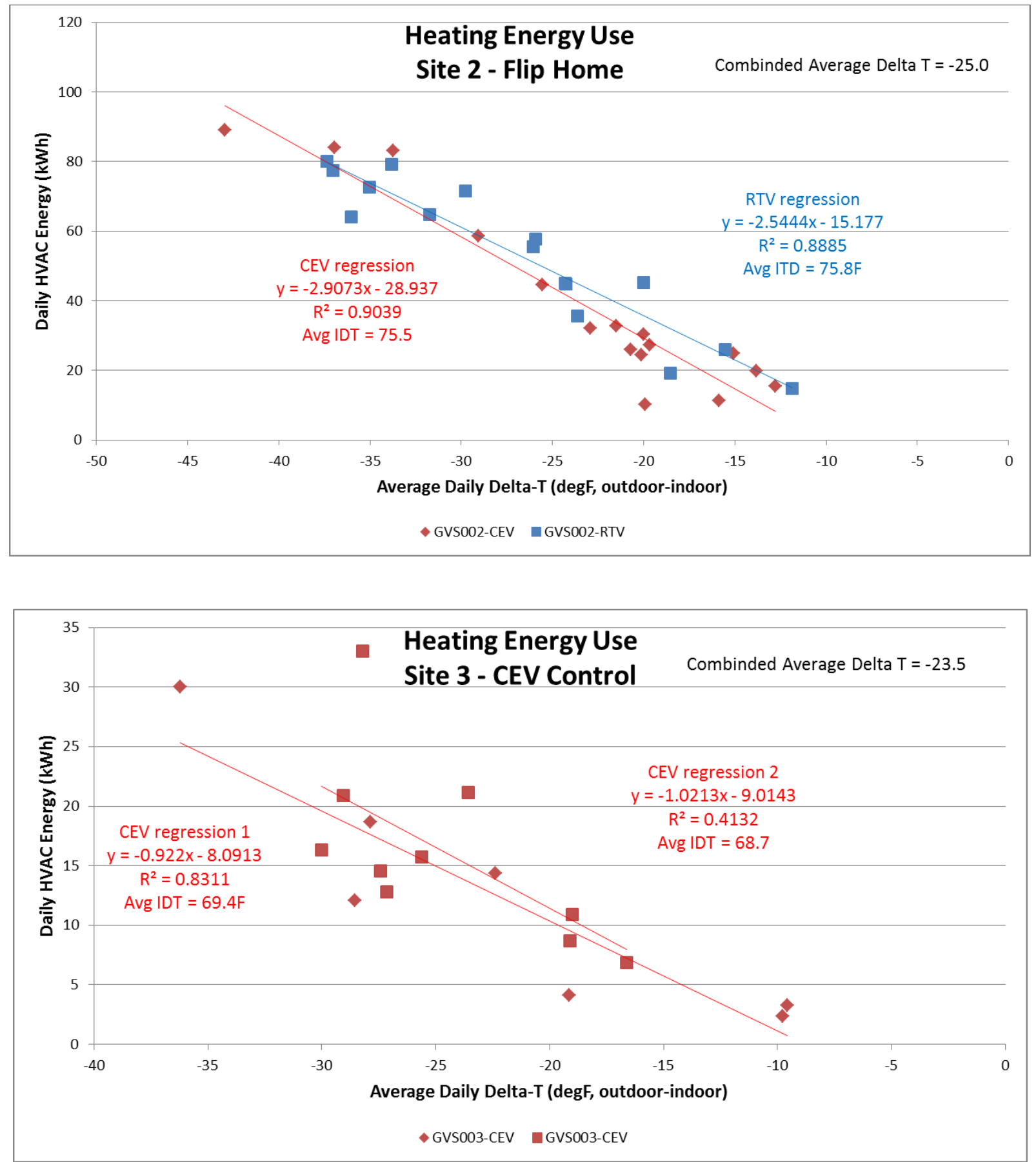

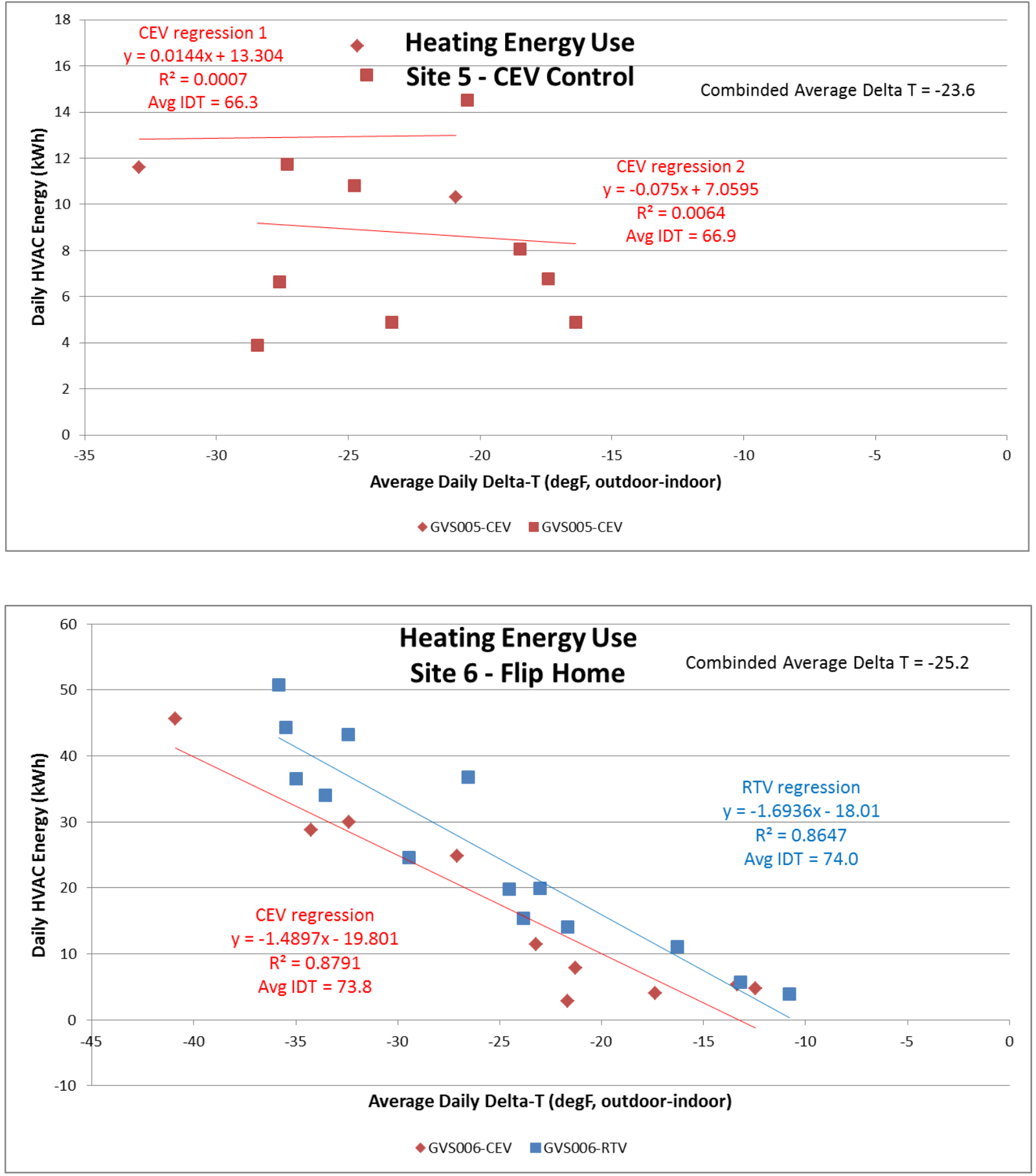

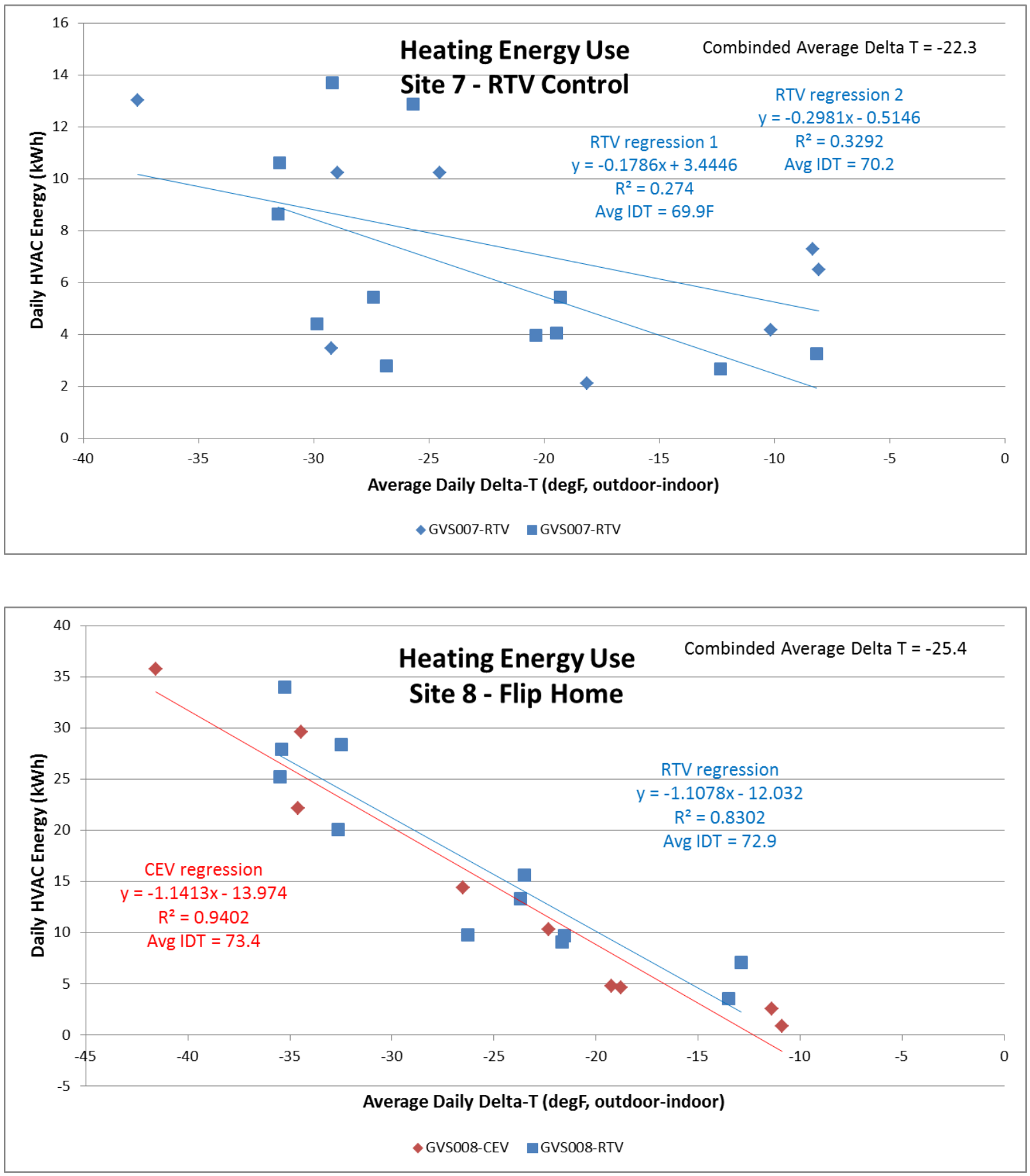

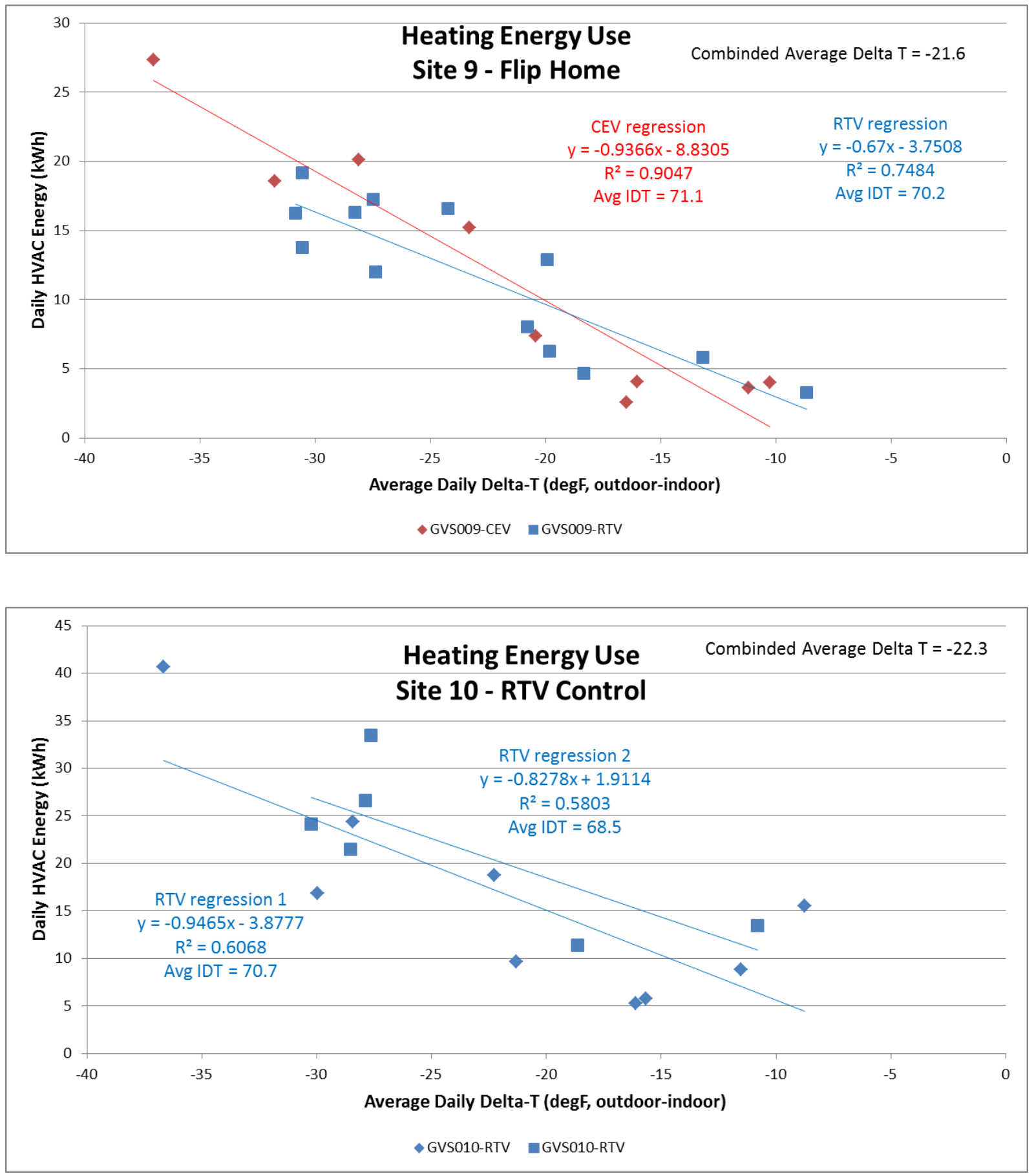


\section{Appendix J. IAQ Sampling Schedule}

Table J-1.

\begin{tabular}{|c|c|c|c|c|c|c|c|c|}
\hline \multirow[b]{3}{*}{ Season } & \multirow[b]{3}{*}{ Round \# } & \multirow[b]{3}{*}{$\begin{array}{l}\text { Flip Days } \\
\text { Begin }\end{array}$} & \multirow[b]{3}{*}{$\begin{array}{l}\text { Flip Days } \\
\text { End }\end{array}$} & \multirow[b]{3}{*}{ Length } & \multirow[b]{3}{*}{ Flip To } & \multicolumn{3}{|l|}{ Key } \\
\hline & & & & & & 62.2 & Unmodified & $\begin{array}{l}I A Q=\text { week } I A Q \\
\text { test is occurring }\end{array}$ \\
\hline & & & & & & $\begin{array}{l}\text { Control Homes } \\
\text { - CEV }\end{array}$ & $\begin{array}{l}\text { Control Homes } \\
\text { - RTV }\end{array}$ & Flip-Flop Homes \\
\hline \multirow{9}{*}{ Summer } & 1.1 & $06 / 21 / 13$ & $06 / 27 / 13$ & 6 & Fan on & \multirow{7}{*}{$I A Q$} & & \\
\hline & 1.2 & $06 / 28 / 13$ & $07 / 11 / 13$ & 13 & RTV & & \multirow{6}{*}{$\mathrm{IAQ}$} & \\
\hline & 2.1 & $07 / 12 / 13$ & $08 / 07 / 13$ & 26 & Fan on & & & \\
\hline & 2.2 & 08/08/13 & $08 / 13 / 13$ & 5 & RTV & & & \\
\hline & $2.2(\mathrm{IAQ})$ & $08 / 14 / 13$ & $08 / 20 / 13$ & 6 & no change & & & $I A Q$ \\
\hline & 3.1 & $08 / 21 / 13$ & $09 / 03 / 13$ & 13 & Fan on & & & \\
\hline & 3.2 & 09/04/13 & $09 / 17 / 13$ & 13 & RTV & & & \\
\hline & $4.1(\mathrm{IAQ})$ & 09/18/13 & 09/26/13 & 8 & Fan on & \multirow[t]{6}{*}{$\mathrm{IAQ}$} & \multirow[t]{6}{*}{$I A Q$} & $I A Q$ \\
\hline & $\begin{array}{l}4.1 \\
\text { (continued) }\end{array}$ & $09 / 27 / 13$ & $10 / 02 / 13$ & 5 & no change & & & \\
\hline \multirow{4}{*}{ Fall } & 4.2 & $10 / 03 / 13$ & $10 / 16 / 13$ & 13 & RTV & & & \\
\hline & 5.1 & 10/17/13 & $10 / 30 / 13$ & 13 & Fan on & & & \\
\hline & 5.2 & 10/31/13 & $11 / 13 / 13$ & 13 & RTV & & & \\
\hline & 6.1 & $11 / 14 / 13$ & $12 / 04 / 13$ & 20 & Fan on & & & \\
\hline
\end{tabular}




\begin{tabular}{|c|c|c|c|c|c|c|c|c|}
\hline & & & & & & Key & & \\
\hline & & & & & & 62.2 & Unmodified & $\begin{array}{l}\text { IAQ = week IAQ } \\
\text { test is occurring }\end{array}$ \\
\hline Season & Round \# & $\begin{array}{l}\text { Flip Days } \\
\text { Begin }\end{array}$ & $\begin{array}{l}\text { Flip Days } \\
\text { End }\end{array}$ & Length & Flip To & $\begin{array}{l}\text { Control Homes } \\
\text { - CEV }\end{array}$ & $\begin{array}{l}\text { Control Homes } \\
\text { - RTV }\end{array}$ & Flip-Flop Homes \\
\hline & 6.2 & $12 / 05 / 13$ & $12 / 18 / 13$ & 13 & RTV & & & \\
\hline & 7.1 & $12 / 19 / 13$ & 01/01/14 & 13 & Fan on & & & \\
\hline & 7.2 & $01 / 02 / 14$ & $02 / 18 / 14$ & 47 & RTV & & & \\
\hline & 8.1 & $02 / 19 / 14$ & $03 / 05 / 14$ & 14 & Fan on & & & \\
\hline Winter/ & 8.2 & 03/06/14 & 03/19/14 & 13 & RTV & & & \\
\hline Mixed & $8.2(\mathrm{IAQ})$ & 03/20/14 & $03 / 26 / 14$ & 6 & RTV & IAQ & $I A Q$ & $I A Q$ \\
\hline & 9.1 & $03 / 27 / 14$ & $04 / 16 / 14$ & 20 & Fan on & & & \\
\hline & $9.1(\mathrm{IAQ})$ & $04 / 10 / 14$ & $04 / 16 / 14$ & 6 & no change & $\mathrm{IAQ}$ & $I A Q$ & $I A Q$ \\
\hline & 10.1 & $04 / 17 / 14$ & $04 / 30 / 14$ & 13 & RTV & & & \\
\hline & 10.2 & $05 / 01 / 14$ & $05 / 14 / 14$ & 13 & Fan on & & & \\
\hline & 11.1 & $05 / 15 / 14$ & $05 / 28 / 14$ & 13 & RTV & & & \\
\hline & 11.2 & $05 / 29 / 14$ & $06 / 11 / 14$ & 13 & Fan on & & & \\
\hline & 12.1 & $06 / 12 / 14$ & $06 / 25 / 14$ & 13 & RTV & & & \\
\hline & 12.2 & $06 / 26 / 14$ & $07 / 09 / 14$ & 13 & Fan on & & & \\
\hline Summer & 13.1 & 07/10/14 & $07 / 16 / 14$ & 6 & RTV & & & \\
\hline & $13.1(\mathrm{IAQ})$ & 07/16/14 & $07 / 22 / 14$ & 6 & no change & $I A Q$ & $I A Q$ & $\mathrm{IAQ}$ \\
\hline & 13.2 & 07/23/14 & $08 / 11 / 14$ & 19 & Fan on & & & \\
\hline & $13.2(\mathrm{IAQ})$ & $08 / 12 / 14$ & 08/18/14 & 10 & no change & $I A Q$ & $\mathrm{IAQ}$ & $I A Q$ \\
\hline & 14.1 & $08 / 18 / 14$ & 08/18/14 & 6 & REMOVE & & & \\
\hline
\end{tabular}




\section{Appendix K. Air Exchange Rate and Indoor Air Quality Data Tables}

The following data tables present the full outdoor and field blank-corrected ppb concentrations (except as otherwise noted) of the seasonally sampling IAQ parameters, including measured and calculated AER, formaldehyde, VOCs, and $\mathrm{NO}_{2}$ not otherwise presented in the report.

\section{Air Exchange Rate}

Table K-1 presents the calculated air exchange rate and related infiltration and mechanical ventilation-related flow rates calculated based on theoretical relationships and combined in quadrature in accordance with the methods described in the ASHRAE

Fundamentals Handbook (ASHRAE 2013a).

Table K-1

\begin{tabular}{|c|c|c|c|c|c|c|c|c|c|c|}
\hline House & Configuration & $\begin{array}{l}\text { Qinf } \\
\text { (CFM) }\end{array}$ & $\begin{array}{l}\text { Runtime } \\
\text { Fraction }\end{array}$ & $\begin{array}{l}\text { Qunbalanced } \\
\text { (CFM) }\end{array}$ & $\begin{array}{l}\text { Qtot } \\
\text { (CFM) }\end{array}$ & $\begin{array}{l}\mathrm{ACHn} \\
\left(\mathrm{hr}^{-1}\right)\end{array}$ & $\begin{array}{l}\text { Runtime } \\
\text { Fraction }\end{array}$ & $\begin{array}{l}\text { Qunbalanced } \\
\text { (CFM) }\end{array}$ & $\begin{array}{l}\text { Qtot } \\
\text { (CFM) }\end{array}$ & $\begin{array}{l}\text { ACHn } \\
\left(\mathrm{hr}^{-1}\right)\end{array}$ \\
\hline \multicolumn{11}{|c|}{ First Summer Sampling Period } \\
\hline & & & \multicolumn{4}{|c|}{ SUM1.1 (RTV) } & \multicolumn{4}{|c|}{ SUM1.2 (CEV) } \\
\hline H1 & FF & 72.32 & 0.31 & 12.44 & 73.38 & 0.20 & 0.24 & 57.50 & 92.39 & 0.26 \\
\hline H2 & FF & 43.33 & 0.41 & 14.01 & 45.54 & 0.18 & 0.41 & 55.00 & 70.02 & 0.28 \\
\hline H4 & FF & 44.44 & 0.60 & 15.62 & 47.10 & 0.14 & 0.54 & 56.00 & 71.49 & 0.22 \\
\hline $\mathrm{H} 6$ & FF & 38.34 & 0.36 & 15.13 & 41.21 & 0.15 & 0.30 & 56.00 & 67.87 & 0.24 \\
\hline H8 & FF & 28.59 & 0.43 & 16.61 & 33.07 & 0.13 & 0.44 & 77.50 & 82.61 & 0.33 \\
\hline H9 & $F F$ & 48.36 & 0.27 & 6.41 & 48.78 & 0.19 & 0.34 & 64.50 & 80.61 & 0.31 \\
\hline H3 & CEV & 30.49 & 0.57 & 54.50 & 62.45 & 0.24 & 0.46 & 54.50 & 62.45 & 0.24 \\
\hline H5 & CEV & 38.97 & 0.39 & 59.50 & 71.13 & 0.22 & 0.31 & 59.50 & 71.13 & 0.22 \\
\hline H7 & RTV & 44.63 & 0.57 & 18.23 & 48.21 & 0.15 & 0.47 & 14.95 & 47.07 & 0.14 \\
\hline H10 & RTV & 42.73 & 0.26 & 9.68 & 43.81 & 0.11 & 0.24 & 8.83 & 43.63 & 0.11 \\
\hline
\end{tabular}




\begin{tabular}{|c|c|c|c|c|c|c|c|c|c|c|}
\hline House & Configuration & $\begin{array}{l}\text { Qinf } \\
\text { (CFM) }\end{array}$ & $\begin{array}{l}\text { Runtime } \\
\text { Fraction }\end{array}$ & $\begin{array}{l}\text { Qunbalanced } \\
\text { (CFM) }\end{array}$ & $\begin{array}{l}\text { Qtot } \\
\text { (CFM) }\end{array}$ & $\begin{array}{l}\mathrm{ACHn} \\
\left(\mathrm{hr}^{-1}\right)\end{array}$ & $\begin{array}{l}\text { Runtime } \\
\text { Fraction }\end{array}$ & $\begin{array}{l}\text { Qunbalanced } \\
\text { (CFM) }\end{array}$ & $\begin{array}{l}\text { Qtot } \\
\text { (CFM) }\end{array}$ & $\begin{array}{l}\mathrm{ACHn} \\
\left(\mathrm{hr}^{-1}\right)\end{array}$ \\
\hline \multicolumn{11}{|c|}{ Winter/Mixed Sampling Period } \\
\hline & & & \multicolumn{4}{|c|}{ WIN1 (RTV) } & \multicolumn{4}{|c|}{ WIN2 (CEV) } \\
\hline $\mathrm{H} 1$ & FF & 72.32 & & & & & & & & \\
\hline $\mathrm{H} 2$ & FF & 43.33 & 0.13 & 4.51 & 43.56 & 0.17 & 0.07 & 55.00 & 70.02 & 0.28 \\
\hline H4 & FF & 44.44 & 0.04 & 1.12 & 44.45 & 0.13 & 0.29 & 56.00 & 71.49 & 0.22 \\
\hline $\mathrm{H} 6$ & FF & 38.34 & 0.01 & 0.41 & 38.34 & 0.14 & 0.11 & 56.00 & 67.87 & 0.24 \\
\hline H8 & FF & 28.59 & 0.02 & 0.68 & 28.60 & 0.11 & 0.46 & 77.50 & 82.61 & 0.33 \\
\hline H9 & FF & 48.36 & 0.00 & 0.00 & 48.36 & 0.19 & 0.08 & 64.50 & 80.61 & 0.31 \\
\hline H3 & CEV & 30.49 & 0.12 & 54.50 & 62.45 & 0.24 & 0.19 & 54.50 & 62.45 & 0.24 \\
\hline H5 & CEV & 38.97 & 0.05 & 59.50 & 71.13 & 0.22 & 0.12 & 59.50 & 71.13 & 0.22 \\
\hline H7 & RTV & 44.63 & 0.12 & 3.71 & 44.79 & 0.14 & 0.21 & 6.84 & 45.15 & 0.14 \\
\hline $\mathrm{H} 10$ & RTV & 42.73 & 0.00 & 0.00 & 42.73 & 0.10 & 0.08 & 3.13 & 42.85 & 0.10 \\
\hline \multicolumn{11}{|c|}{ Second Summer Sampling Period } \\
\hline & & & \multicolumn{4}{|c|}{ SUM2.1 (RTV) } & \multicolumn{4}{|c|}{ SUM2.2 (CEV) } \\
\hline H1 & FF & 72.32 & & & & & & & & \\
\hline H2 & FF & 43.33 & 0.44 & 14.98 & 45.84 & 0.18 & 0.43 & 55.00 & 70.02 & 0.28 \\
\hline H4 & $F F$ & 44.44 & 0.58 & 14.96 & 46.89 & 0.14 & & & & \\
\hline $\mathrm{H} 6$ & $F F$ & 38.34 & 0.35 & 14.69 & 41.05 & 0.15 & 0.29 & 56.00 & 67.87 & 0.24 \\
\hline H8 & FF & 28.59 & 0.41 & 16.05 & 32.79 & 0.13 & 0.42 & 77.50 & 82.61 & 0.33 \\
\hline H9 & FF & 48.36 & 0.38 & 9.06 & 49.20 & 0.19 & 0.47 & 64.50 & 80.61 & 0.31 \\
\hline H3 & CEV & 30.49 & 0.62 & 54.50 & 62.45 & 0.24 & 0.63 & 54.50 & 62.45 & 0.24 \\
\hline H5 & CEV & 38.97 & & & & & & & & \\
\hline H7 & RTV & 44.63 & 0.64 & 20.50 & 49.12 & 0.15 & 0.54 & 17.25 & 47.85 & 0.14 \\
\hline H10 & RTV & 42.73 & 0.32 & 11.86 & 44.35 & 0.11 & 0.33 & 12.24 & 44.45 & 0.11 \\
\hline
\end{tabular}




\section{Formaldehyde}

Table K-2 shows concentrations in of formaldehyde (ppb), corrected for the outdoor concentration and field blank.

Table K-2

\begin{tabular}{|c|c|c|c|c|c|c|c|c|c|c|c|c|c|}
\hline $\begin{array}{l}\text { Ventilation } \\
\text { Configuration }\end{array}$ & Homes & $\begin{array}{l}\text { SUM1 } \\
\text { (ppb) }\end{array}$ & $\begin{array}{l}\text { SUM2 } \\
\text { (ppb) }\end{array}$ & $\begin{array}{l}\text { SUM1 } \\
\text { Diff } \\
\text { (ppb) }\end{array}$ & $\begin{array}{l}\text { SUM1 } \\
\text { Perc. } \\
\text { Diff } \\
(\%)\end{array}$ & $\begin{array}{l}\text { WIN1 } \\
\text { (ppb) }\end{array}$ & $\begin{array}{l}\text { WIN2 } \\
\text { (ppb) }\end{array}$ & $\begin{array}{l}\text { WIN } \\
\text { Diff } \\
\text { (ppb) }\end{array}$ & $\begin{array}{l}\text { WIN } \\
\text { Perc. } \\
\text { Diff } \\
(\%)\end{array}$ & $\begin{array}{l}\text { SUM2.1 } \\
\text { (ppb) }\end{array}$ & $\begin{array}{l}\text { SUM2.2 } \\
\text { (ppb) }\end{array}$ & $\begin{array}{l}\text { SUM2 } \\
\text { Diff } \\
\text { (ppb) }\end{array}$ & $\begin{array}{l}\text { SUM2 } \\
\text { Perc. } \\
\text { Diff } \\
(\%)\end{array}$ \\
\hline $\mathrm{FF}$ & $\mathrm{H} 1$ & 24.50 & 29.86 & 5.36 & 17.95 & & & & & & & & \\
\hline $\mathrm{FF}$ & $\mathrm{H} 2$ & 16.50 & 17.86 & 1.36 & 7.61 & 13.01 & 12.50 & -0.51 & -4.08 & 17.60 & 16.70 & -0.90 & -5.39 \\
\hline $\mathrm{FF}$ & $\mathrm{H} 4$ & 16.50 & 19.86 & 3.36 & 16.92 & & & & & & & & \\
\hline $\mathrm{FF}$ & $\mathrm{H} 6$ & 38.50 & 33.86 & -4.64 & -13.70 & 38.01 & 31.50 & -6.51 & -20.67 & 29.60 & & -29.60 & \\
\hline $\mathrm{FF}$ & H8 & 22.50 & 28.86 & 6.36 & 22.04 & 21.01 & 17.50 & -3.51 & -20.06 & 24.60 & 15.70 & -8.90 & -56.69 \\
\hline $\mathrm{FF}$ & $\mathrm{H} 9$ & 53.96 & 37.86 & -16.10 & -42.53 & 31.01 & 34.50 & 3.49 & 10.12 & 32.60 & 32.70 & 0.10 & 0.31 \\
\hline \multirow{4}{*}{$\mathrm{FF}$} & $A \vee G$ & 28.74 & 28.03 & -0.72 & 1.38 & 25.76 & 24.00 & -1.76 & -8.67 & 26.10 & 21.70 & -9.83 & -20.59 \\
\hline & STDEV & 14.75 & 7.81 & 8.49 & 25.05 & 11.00 & 10.66 & 4.27 & 14.69 & 6.56 & 9.54 & 13.78 & 31.39 \\
\hline & $\mathrm{N}$ & 6.00 & 6.00 & 6.00 & 6.00 & 4.00 & 4.00 & 4.00 & 4.00 & 4.00 & 3.00 & 4.00 & 3.00 \\
\hline & $95 \% \mathrm{Cl}$ & 15.48 & 8.19 & 8.91 & 26.29 & 17.50 & 16.96 & 6.80 & 23.38 & 10.43 & 23.70 & 21.93 & 77.98 \\
\hline CEV & $\mathrm{H} 3$ & 20.50 & 24.86 & 4.36 & 17.54 & 17.01 & 17.00 & -0.01 & -0.06 & 19.60 & 19.70 & 0.10 & 0.51 \\
\hline CEV & $\mathrm{H} 5$ & 24.50 & 25.86 & 1.36 & 5.26 & 14.01 & 19.50 & 5.49 & 28.15 & 26.60 & & -26.60 & \\
\hline \multirow{4}{*}{ CEV } & AVG & 22.50 & 25.36 & 2.86 & 11.40 & 15.51 & 18.25 & 2.74 & 14.05 & 23.10 & 19.70 & -13.25 & 0.51 \\
\hline & STDEV & 2.83 & 0.71 & 2.12 & 8.68 & 2.12 & 1.77 & 3.89 & 19.95 & 4.95 & & 18.88 & \\
\hline & $\mathrm{N}$ & 2.00 & 2.00 & 2.00 & 2.00 & 2.00 & 2.00 & 2.00 & 2.00 & 2.00 & 1.00 & 2.00 & 1.00 \\
\hline & $95 \% \mathrm{Cl}$ & 25.41 & 6.35 & 19.06 & 78.01 & 19.06 & 15.88 & 34.94 & 179.24 & 44.47 & & 169.63 & \\
\hline RTV & $\mathrm{H} 7$ & 12.50 & 13.86 & 1.36 & 9.81 & 12.01 & 14.50 & 2.49 & 17.17 & 12.10 & 10.70 & -1.40 & -13.08 \\
\hline RTV & $\mathrm{H} 10$ & 43.50 & 23.86 & -19.64 & -82.31 & 42.01 & 33.50 & -8.51 & -25.40 & 24.60 & 22.70 & -1.90 & -8.37 \\
\hline
\end{tabular}




\begin{tabular}{|c|c|c|c|c|c|c|c|c|c|c|c|c|c|}
\hline $\begin{array}{l}\text { Ventilation } \\
\text { Configuration }\end{array}$ & Homes & $\begin{array}{l}\text { SUM1 } \\
\text { (ppb) }\end{array}$ & $\begin{array}{l}\text { SUM2 } \\
\text { (ppb) }\end{array}$ & $\begin{array}{l}\text { SUM1 } \\
\text { Diff } \\
\text { (ppb) }\end{array}$ & $\begin{array}{l}\text { SUM1 } \\
\text { Perc. } \\
\text { Diff } \\
\text { (\%) }\end{array}$ & $\begin{array}{l}\text { WIN1 } \\
\text { (ppb) }\end{array}$ & $\begin{array}{l}\text { WIN2 } \\
\text { (ppb) }\end{array}$ & $\begin{array}{l}\text { WIN } \\
\text { Diff } \\
\text { (ppb) }\end{array}$ & $\begin{array}{l}\text { WIN } \\
\text { Perc. } \\
\text { Diff } \\
(\%)\end{array}$ & $\begin{array}{l}\text { SUM2.1 } \\
\text { (ppb) }\end{array}$ & $\begin{array}{l}\text { SUM2.2 } \\
\text { (ppb) }\end{array}$ & $\begin{array}{l}\text { SUM2 } \\
\text { Diff } \\
\text { (ppb) }\end{array}$ & $\begin{array}{l}\text { SUM2 } \\
\text { Perc. } \\
\text { Diff } \\
(\%)\end{array}$ \\
\hline \multirow{2}{*}{ RTV } & STDEV & 21.92 & 7.07 & 14.85 & 65.14 & 21.21 & 13.44 & 7.78 & 30.11 & 8.84 & 8.49 & 0.35 & 3.33 \\
\hline & $\mathrm{N}$ & 2.00 & 2.00 & 2.00 & 2.00 & 2.00 & 2.00 & 2.00 & 2.00 & 2.00 & 2.00 & 2.00 & 2.00 \\
\hline
\end{tabular}

Table K-3 shows concentrations in of acetaldehyde (ppb), corrected for the outdoor concentration and field blank.

Table K-3

\begin{tabular}{|c|c|c|c|c|c|c|c|c|c|c|c|c|c|}
\hline $\begin{array}{l}\text { Ventilation } \\
\text { Configuration }\end{array}$ & Homes & $\begin{array}{l}\text { SUM1 } \\
\text { (ppb) }\end{array}$ & $\begin{array}{l}\text { SUM2 } \\
\text { (ppb) }\end{array}$ & $\begin{array}{l}\text { SUM1 } \\
\text { Diff } \\
\text { (ppb) }\end{array}$ & $\begin{array}{l}\text { SUM1 } \\
\text { Perc. } \\
\text { Diff } \\
(\%)\end{array}$ & $\begin{array}{l}\text { WIN1 } \\
\text { (ppb) }\end{array}$ & $\begin{array}{l}\text { WIN2 } \\
\text { (ppb) }\end{array}$ & $\begin{array}{l}\text { WIN } \\
\text { Diff } \\
\text { (ppb) }\end{array}$ & $\begin{array}{l}\text { WIN } \\
\text { Perc. } \\
\text { Diff } \\
(\%)\end{array}$ & $\begin{array}{l}\text { SUM2.1 } \\
\text { (ppb) }\end{array}$ & $\begin{array}{l}\text { SUM2.2 } \\
\text { (ppb) }\end{array}$ & $\begin{array}{l}\text { SUM2 } \\
\text { Diff } \\
\text { (ppb) }\end{array}$ & $\begin{array}{l}\text { SUM2 } \\
\text { Perc. Diff } \\
(\%)\end{array}$ \\
\hline FF & $\mathrm{H} 1$ & 4.76 & 2.28 & -2.48 & -108.77 & & & 0.00 & & & & 0.00 & \\
\hline $\mathrm{FF}$ & $\mathrm{H} 2$ & 1.16 & 0.79 & -0.37 & -46.84 & 1.35 & 0.79 & -0.56 & -70.89 & 0.70 & 0.37 & -0.33 & -89.19 \\
\hline FF & $\mathrm{H} 4$ & 3.76 & 2.48 & -1.28 & -51.61 & & & 0.00 & & & & 0.00 & \\
\hline FF & $\mathrm{H} 6$ & 2.76 & 2.58 & -0.18 & -6.98 & 2.35 & 2.34 & -0.01 & -0.43 & 4.30 & & -4.30 & \\
\hline FF & $\mathrm{H} 8$ & 5.96 & 4.38 & -1.58 & -36.07 & 3.55 & 1.14 & -2.41 & -211.40 & 4.90 & 0.88 & -4.02 & -456.82 \\
\hline $\mathrm{FF}$ & $\mathrm{H} 9$ & -0.14 & 1.88 & 2.02 & 107.45 & 2.75 & 3.54 & 0.79 & 22.32 & 3.20 & 0.65 & -2.55 & -392.31 \\
\hline \multirow{4}{*}{$\mathrm{FF}$} & AVG & 3.04 & 2.40 & -0.65 & -23.80 & 2.50 & 1.95 & -0.37 & -65.10 & 3.28 & 0.63 & -1.87 & -312.77 \\
\hline & STDEV & 2.27 & 1.17 & 1.55 & 72.37 & 0.91 & 1.25 & 1.09 & 105.30 & 1.86 & 0.26 & 2.02 & 196.30 \\
\hline & $N$ & 6.00 & 6.00 & 6.00 & 6.00 & 4.00 & 4.00 & 6.00 & 4.00 & 4.00 & 3.00 & 6.00 & 3.00 \\
\hline & $95 \% \mathrm{Cl}$ & 2.38 & 1.23 & 1.63 & 75.94 & 1.46 & 1.99 & 1.14 & 167.55 & 2.95 & 0.63 & 2.12 & 487.63 \\
\hline CEV & $\mathrm{H} 3$ & 3.66 & 3.28 & -0.38 & -11.59 & 1.75 & 2.59 & 0.84 & 32.43 & 1.80 & 1.28 & -0.52 & -40.63 \\
\hline CEV & $\mathrm{H} 5$ & 4.86 & 3.88 & -0.98 & -25.26 & 0.35 & 1.44 & 1.09 & 75.69 & 1.70 & & & \\
\hline
\end{tabular}




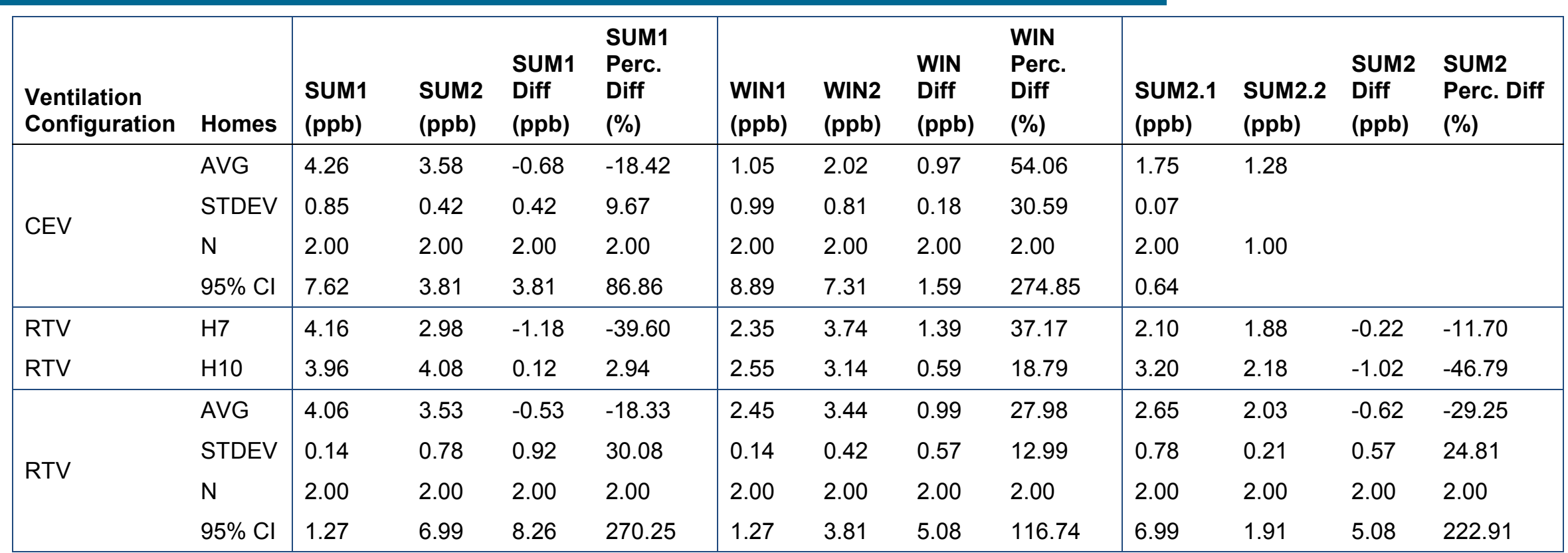




\section{Volatile Organic Compounds}

Table K-4 shows raw concentrations for all resolved compounds (ppb) for each home, including the outdoor and field blank measurements.

\section{Table K-4}

\begin{tabular}{|c|c|c|c|c|c|c|c|c|c|c|c|c|c|c|}
\hline \multirow[b]{2}{*}{ Sampling Period } & \multirow[b]{2}{*}{ Analyte Name } & \multicolumn{13}{|c|}{ Concentrations in Each House Corrected for Outdoor and Field Blank (ppb) } \\
\hline & & H1 & H2 & H3 & H4 & H5 & H6 & H6D & H7 & H8 & H9 & H10 & FB & OUT \\
\hline SUM1 & 1,1,1-Trichloroethane & 0 & 0 & 0 & 0 & 0 & 0 & 0 & 0 & 0 & 0 & 0 & 0 & 0 \\
\hline SUM1 & 1,1,2,2-Tetrachloroethane & 0 & 0 & 0 & 0 & 0 & 0 & 0 & 0 & 0 & 0 & 0.16 & 0 & 0 \\
\hline SUM1 & 1,1,2-Trichloroethane & 0 & 0 & 0 & 0 & 0 & 0 & 0 & 0 & 0 & 0 & 0 & 0 & 0 \\
\hline SUM1 & 1,1-Dichloroethane & 0 & 0 & 0 & 0 & 0 & 0 & 0 & 0 & 0 & 0 & 0 & 0 & 0 \\
\hline SUM1 & 1,1-Dichloroethene & 0 & 0 & 0 & 0 & 0 & 0 & 0 & 0 & 0 & 0 & 0 & 0 & 0 \\
\hline SUM1 & 1,2,4-Trichlorobenzene & 0 & 0 & 0 & 0 & 0 & 0 & 0 & 0 & 0 & 0 & 0 & 0 & 0 \\
\hline SUM1 & 1,2,4-Trimethylbenzene & 0.12 & 0 & 0 & 0 & 0 & 0 & 0 & 0 & 0 & 0 & 0.23 & 0 & 0 \\
\hline SUM1 & 1,2-Dibromoethane & 0 & 0 & 0 & 0 & 0 & 0 & 0 & 0 & 0 & 0 & 0 & 0 & 0 \\
\hline SUM1 & 1,2-Dichlorobenzene & 0 & 0 & 0 & 0 & 0 & 0 & 0 & 0 & 0 & 0 & 0 & 0 & 0 \\
\hline SUM1 & 1,2-Dichloroethane & 3.8 & 0 & 0.14 & 0.23 & 0.14 & 0 & 0 & 0.2 & 0.75 & 2.9 & 0.96 & 0 & 0 \\
\hline SUM1 & 1,2-Dichloropropane & 0 & 0 & 0 & 0 & 0 & 0 & 0 & 0 & 0 & 0 & 0.087 & 0 & 0 \\
\hline SUM1 & 1,3,5-Trimethylbenzene & 0.15 & 0 & 0 & 0 & 0 & 0 & 0 & 0 & 0 & 0 & 0.2 & 0 & 0 \\
\hline SUM1 & 1,3-Butadiene & 0 & 0 & 0 & 0 & 0 & 0 & 0 & 0 & 0 & 0 & 0 & 0 & 0 \\
\hline SUM1 & 1,3-Dichlorobenzene & 0 & 0 & 0 & 0 & 0 & 0 & 0 & 0 & 0 & 0 & 0 & 0 & 0 \\
\hline SUM1 & 1,4-Dichlorobenzene & 0 & 0 & 0 & 0 & 0 & 0 & 0 & 0 & 0 & 0 & 0 & 0 & 0 \\
\hline SUM1 & 2-Hexanone & 0.19 & 0.1 & 0.23 & 0.11 & 0.17 & 0 & 0 & 0.16 & 0 & 0.21 & 0.57 & 0 & 0 \\
\hline SUM1 & 4-Ethyl toluene & 0.2 & 0 & 0 & 0 & 0 & 0 & 0 & 0 & 0 & 0 & 0.37 & 0 & 0 \\
\hline SUM1 & Acetone & 15 & 3.8 & 9.9 & 7.6 & 8.3 & 12 & 11 & 12 & 5.3 & 34 & 5.6 & 3.7 & 0 \\
\hline SUM1 & Benzene & 1.9 & 0.23 & 0.25 & 0.44 & 1.1 & 0.15 & 0.21 & 0.73 & 0.44 & 1.1 & 2.7 & 0 & 0.11 \\
\hline SUM1 & Benzyl chloride & 0 & 0 & 0 & 0 & 0 & 0 & 0 & 0 & 0 & 0 & 0 & 0 & 0 \\
\hline SUM1 & Bromodichloromethane & 0.25 & 0.072 & 0.12 & 0 & 0.062 & 0.069 & 0.091 & 0.14 & 0.11 & 0 & 0.33 & 0 & 0 \\
\hline
\end{tabular}




\begin{tabular}{|c|c|c|c|c|c|c|c|c|c|c|c|c|c|c|}
\hline \multirow[b]{2}{*}{ Sampling Period } & \multirow[b]{2}{*}{ Analyte Name } & \multicolumn{13}{|c|}{ Concentrations in Each House Corrected for Outdoor and Field Blank (ppb) } \\
\hline & & H1 & $\mathrm{H} 2$ & H3 & H4 & H5 & H6 & H6D & H7 & H8 & H9 & H10 & FB & OUT \\
\hline SUM1 & Bromoform & 0 & 0 & 0 & 0 & 0 & 0 & 0 & 0 & 0 & 0 & 0 & 0 & 0 \\
\hline SUM1 & Bromomethane & 0 & 0 & 0 & 0 & 0 & 0 & 0 & 0 & 0 & 0 & 0 & 0 & 0 \\
\hline SUM1 & Carbon disulfide & 2.8 & 0.99 & 3.3 & 2.4 & 2.9 & 3.5 & 4.1 & 2.2 & 2.5 & 6.6 & 1.7 & 1.3 & 2.4 \\
\hline SUM1 & Carbon tetrachloride & 0 & 0 & 0 & 0 & 0 & 0.037 & 0.057 & 0.044 & 0.05 & 0.15 & 0.096 & 0 & 0 \\
\hline SUM1 & Chlorobenzene & 0 & 0 & 0 & 0 & 0 & 0 & 0 & 0 & 0 & 0 & 0 & 0 & 0 \\
\hline SUM1 & Chloroform & 0.5 & 0.28 & 0.53 & 1.3 & 0.21 & 0 & 0 & 0.63 & 0.83 & 1.3 & 0.27 & 0 & 0 \\
\hline SUM1 & cis-1,2-Dichloroethene & 0 & 0 & 0 & 0 & 0 & 0 & 0 & 0 & 0 & 0 & 0 & 0 & 0 \\
\hline SUM1 & cis-1,3-Dichloropropene & 0 & 0 & 0 & 0 & 0 & 0 & 0 & 0 & 0 & 0 & 0 & 0 & 0 \\
\hline SUM1 & Cyclohexane & 0.86 & 0.12 & 0.65 & 0.58 & 0.51 & 0.11 & 0.1 & 0.49 & 0.13 & 0.55 & 1.6 & 0 & 0 \\
\hline SUM1 & Dibromochloromethane & 0 & 0 & 0 & 0 & 0 & 0.019 & 0.025 & 0 & 0 & 0 & 0 & 0 & 0 \\
\hline SUM1 & Dichlorodifluoromethane & 0 & 0 & 0 & 0 & 0 & 0 & 0 & 0 & 0 & 0 & 0 & 0 & 0 \\
\hline SUM1 & Ethanol & 11 & 3.9 & 14 & 11 & 8.1 & 14 & 15 & 8.1 & 7.8 & 22 & 2.5 & 14 & 0 \\
\hline SUM1 & Ethyl acetate & 2.1 & 1.1 & 10 & 6.8 & 3.1 & 50 & 49 & 4 & 5.4 & 24 & 1.4 & 0.3 & 0.087 \\
\hline SUM1 & Ethyl benzene & 0.97 & 0 & 0.085 & 0.11 & 0.26 & 0.093 & 0.078 & 0.15 & 0 & 0 & 11 & 0 & 0 \\
\hline SUM1 & Ethyl chloride & 0 & 0 & 0 & 0 & 0 & 0 & 0 & 0 & 0 & 0 & 0 & 0 & 0 \\
\hline SUM1 & Freon 11 & 0.047 & 0.078 & 0.085 & 0.11 & 0.057 & 0.099 & 0.083 & 0.05 & 0.065 & 0.085 & 0 & 0 & 0.17 \\
\hline SUM1 & Freon 113 & 0 & 0.043 & 0.085 & 0.11 & 0.061 & 0.3 & 0.31 & 0.054 & 0.11 & 0.17 & 0.023 & 0 & 0.11 \\
\hline SUM1 & Freon 114 & 0 & 0 & 0 & 0 & 0 & 0 & 0 & 0 & 0 & 0 & 0 & 0 & 0 \\
\hline SUM1 & Heptane & 1.2 & 0.11 & 0.33 & 1.7 & 0.41 & 0.23 & 0.28 & 0.74 & 0.58 & 0.25 & 2.5 & 0 & 0 \\
\hline SUM1 & Hexachloro-1,3-butadiene & 0 & 0 & 0 & 0 & 0 & 0 & 0 & 0 & 0 & 0 & 0 & 0 & 0 \\
\hline SUM1 & Isopropyl alcohol & 3.8 & 2 & 4.8 & 5.1 & 3.5 & 9.1 & 8.1 & 7.6 & 6.1 & 59 & 6.1 & 1.8 & 0 \\
\hline SUM1 & m,p-Xylene & 0.97 & 0 & 0.056 & 0.063 & 0.23 & 0.099 & 0.066 & 0.14 & 0 & 0 & 6.2 & 0 & 0 \\
\hline SUM1 & Methyl chloride & 0 & 0 & 0 & 0 & 0 & 0 & 0 & 0 & 0 & 0 & 0 & 0 & 0 \\
\hline SUM1 & Methyl ethyl ketone & 6.7 & 4.1 & 9.2 & 5.5 & 3.6 & 24 & 25 & 4.7 & 4.6 & 20 & 6.5 & 0.21 & 0 \\
\hline SUM1 & Methyl isobutyl ketone & 0 & 0.29 & 0.55 & 1.1 & 0.33 & 0.48 & 0.6 & 0.18 & 0.47 & 0.7 & 2.4 & 0 & 0 \\
\hline SUM1 & Methyl t-butyl ether & 0 & 0 & 0 & 0 & 0 & 0 & 0 & 0 & 0 & 0 & 0 & 0 & 0 \\
\hline
\end{tabular}




\begin{tabular}{|c|c|c|c|c|c|c|c|c|c|c|c|c|c|c|}
\hline \multirow[b]{2}{*}{ Sampling Period } & \multirow[b]{2}{*}{ Analyte Name } & \multicolumn{13}{|c|}{ Concentrations in Each House Corrected for Outdoor and Field Blank (ppb) } \\
\hline & & H1 & $\mathrm{H} 2$ & H3 & H4 & H5 & H6 & H6D & H7 & H8 & $\mathrm{H} 9$ & H10 & FB & OUT \\
\hline SUM1 & Methylene chloride & 4.7 & 6.8 & 8.1 & 12 & 5.4 & 37 & 28 & 11 & 12 & 41 & 8.6 & 2.9 & 14 \\
\hline SUM1 & n-Hexane & 2.8 & 0.39 & 0 & 0 & 1.2 & 0.27 & 0.36 & 0.9 & 0.3 & 0.72 & 3.7 & 0.2 & 0.22 \\
\hline SUM1 & o-Xylene & 0.78 & 0 & 0 & 0 & 0.16 & 0.084 & 0.055 & 0.097 & 0 & 0 & 7.9 & 0 & 0 \\
\hline SUM1 & Propene & 0 & 0 & 0 & 0 & 0 & 0 & 0 & 0 & 0 & 0 & 0 & 0 & 0 \\
\hline SUM1 & Styrene & 0.11 & 0 & 0.061 & 0 & 0 & 0.19 & 0.13 & 0.1 & 0 & 0 & 1.4 & 0 & 0 \\
\hline SUM1 & Tetrachloroethene & 0.16 & 0 & 0.039 & 0.56 & 0 & 0 & 0 & 0.059 & 0 & 0 & 0.044 & 0 & 0 \\
\hline SUM1 & Tetrahydrofuran & 1.3 & 0.63 & 2 & 1.4 & 0.75 & 4.9 & 4.9 & 1.3 & 0.79 & 2.8 & 1.4 & 0.19 & 0 \\
\hline SUM1 & Toluene & 4.9 & 1.5 & 1.6 & 1.9 & 3.4 & 0.88 & 0.84 & 2 & 1.3 & 3 & 5.7 & 0.14 & 0.4 \\
\hline SUM1 & Total Volatile Organics & 52 & 18 & 35 & 35 & 39 & 44 & 39 & 43 & 32 & 51 & 160 & 5.3 & 4.7 \\
\hline SUM1 & trans-1,2-Dichloroethene & 0 & 0 & 0 & 0 & 0 & 0 & 0 & 0 & 0 & 0 & 0 & 0 & 0 \\
\hline SUM1 & trans-1,3-Dichloropropene & 0 & 0 & 0 & 0 & 0 & 0 & 0 & 0 & 0 & 0 & 0 & 0 & 0 \\
\hline SUM1 & Trichloroethene & 0.8 & 0 & 0 & 0 & 0 & 0 & 0 & 0 & 0 & 0 & 0 & 0 & 0 \\
\hline SUM1 & Vinyl acetate & 0 & 0 & 0 & 0 & 0 & 0 & 0 & 0 & 0 & 0 & 0 & 0 & 0 \\
\hline SUM1 & Vinyl chloride & 0 & 0 & 0 & 0 & 0 & 0 & 0 & 0 & 0 & 0 & 0 & 0 & 0 \\
\hline SUM2 & 1,1,1-Trichloroethane & 0 & 0 & 0 & 0 & 0 & 0 & & 0 & 0 & 0 & 0 & & 0 \\
\hline SUM2 & 1,1,2,2-Tetrachloroethane & 0 & 0 & 0 & 0 & 0 & 0 & & 0 & 0 & 0 & 0 & & 0 \\
\hline SUM2 & 1,1,2-Trichloroethane & 0 & 0 & 0 & 0 & 0 & 0 & & 0 & 0 & 0 & 0 & & 0 \\
\hline SUM2 & 1,1-Dichloroethane & 0 & 0 & 0 & 0 & 0 & 0 & & 0 & 0 & 0 & 0 & & 0 \\
\hline SUM2 & 1,1-Dichloroethene & 0 & 0 & 0 & 0 & 0 & 0 & & 0 & 0 & 0 & 0 & & 0 \\
\hline SUM2 & 1,2,4-Trichlorobenzene & 0 & 0 & 0 & 0 & 0 & 0 & & 0 & 0 & 0 & 0 & & 0 \\
\hline SUM2 & 1,2,4-Trimethylbenzene & 0.18 & 0 & 0 & 0.068 & 0 & 0.076 & & 0 & 0 & 0 & 0.1 & & 0 \\
\hline SUM2 & 1,2-Dibromoethane & 0 & 0 & 0 & 0 & 0 & 0 & & 0 & 0 & 0 & 0 & & 0 \\
\hline SUM2 & 1,2-Dichlorobenzene & 0 & 0 & 0 & 0 & 0 & 0 & & 0 & 0 & 0 & 0 & & 0 \\
\hline SUM2 & 1,2-Dichloroethane & 4.3 & 0 & 0.093 & 0 & 0.17 & 0 & & 0.41 & 0.35 & 0.6 & 0.92 & & 0 \\
\hline SUM2 & 1,2-Dichloropropane & 0 & 0 & 0 & 0 & 0 & 0 & & 0 & 0 & 0 & 0 & & 0 \\
\hline SUM2 & 1,3,5-Trimethylbenzene & 0.12 & 0 & 0 & 0 & 0 & 0.058 & & 0 & 0 & 0 & 0.079 & & 0 \\
\hline
\end{tabular}




\begin{tabular}{|c|c|c|c|c|c|c|c|c|c|c|c|c|c|c|}
\hline \multirow[b]{2}{*}{ Sampling Period } & \multirow[b]{2}{*}{ Analyte Name } & \multicolumn{13}{|c|}{ Concentrations in Each House Corrected for Outdoor and Field Blank (ppb) } \\
\hline & & H1 & $\mathbf{H} 2$ & H3 & H4 & H5 & H6 & H6D & $\mathrm{H} 7$ & H8 & H9 & H10 & FB & OUT \\
\hline SUM2 & 1,3-Butadiene & 0 & 0 & 0 & 0 & 0 & 0 & & 0 & 0 & 0 & 0 & & 0 \\
\hline SUM2 & 1,3-Dichlorobenzene & 0 & 0 & 0 & 0 & 0 & 0 & & 0 & 0 & 0 & 0 & & 0 \\
\hline SUM2 & 1,4-Dichlorobenzene & 0 & 0 & 0 & 0 & 0 & 0 & & 0 & 0 & 0 & 0 & & 0 \\
\hline SUM2 & 2-Hexanone & 0 & 0.12 & 0 & 0.24 & 0.11 & 0.2 & & 0.17 & 0.17 & 0.19 & 0.61 & & 0 \\
\hline SUM2 & 4-Ethyl toluene & 0.2 & 0 & 0 & 0 & 0 & 0 & & 0 & 0 & 0 & 0.17 & & 0 \\
\hline SUM2 & Acetone & 6.7 & 5.9 & 11 & 6 & 14 & 12 & & 7.4 & 13 & 7 & 18 & & 1.7 \\
\hline SUM2 & Benzene & 3.1 & 0.28 & 0.24 & 2.3 & 1.1 & 0.5 & & 0.62 & 0.48 & 0.93 & 1.7 & & 0 \\
\hline SUM2 & Benzyl chloride & 0 & 0 & 0 & 0 & 0 & 0 & & 0 & 0 & 0 & 0 & & 0 \\
\hline SUM2 & Bromodichloromethane & 0 & 0.075 & 0.069 & 0 & 0.11 & 0.082 & & 0.16 & 0.086 & 0.074 & 0.21 & & 0 \\
\hline SUM2 & Bromoform & 0 & 0 & 0 & 0 & 0 & 0 & & 0 & 0 & 0 & 0 & & 0 \\
\hline SUM2 & Bromomethane & 0 & 0 & 0 & 0 & 0 & 0 & & 0 & 0 & 0 & 0 & & 0 \\
\hline SUM2 & Carbon disulfide & 2.2 & 0.72 & 1.8 & 1.3 & 1.3 & 1.1 & & 1.1 & 2 & 1.5 & 1.2 & & 0.11 \\
\hline SUM2 & Carbon tetrachloride & 0.044 & 0.043 & 0.045 & 0.038 & 0 & 0.057 & & 0.075 & 0.077 & 0.087 & 0.047 & & 0 \\
\hline SUM2 & Chlorobenzene & 0 & 0 & 0 & 0 & 0 & 0 & & 0 & 0 & 0 & 0 & & 0 \\
\hline SUM2 & Chloroform & 0.25 & 0.25 & 0.29 & 1.1 & 0.27 & 0.32 & & 0.57 & 0.4 & 0.2 & 0.63 & & 0 \\
\hline SUM2 & cis-1,2-Dichloroethene & 0 & 0 & 0 & 0 & 0 & 0 & & 0 & 0 & 0 & 0 & & 0 \\
\hline SUM2 & cis-1,3-Dichloropropene & 0 & 0 & 0 & 0 & 0 & 0 & & 0 & 0 & 0 & 0 & & 0 \\
\hline SUM2 & Cyclohexane & 1.2 & 0.13 & 0.32 & 0.96 & 0.49 & 0.13 & & 0.4 & 0.13 & 0.3 & 0.75 & & 0 \\
\hline SUM2 & Dibromochloromethane & 0 & 0 & 0 & 0 & 0 & 0 & & 0.045 & 0 & 0 & 0.039 & & 0 \\
\hline SUM2 & Dichlorodifluoromethane & 0 & 0 & 0 & 0 & 0 & 0 & & 0 & 0 & 0 & 0 & & 0 \\
\hline SUM2 & Ethanol & 13 & 3.7 & 21 & 11 & 10 & 13 & & 9.6 & 12 & 6 & 6.3 & & 4 \\
\hline SUM2 & Ethyl acetate & 3.4 & 3.3 & 6 & 2 & 2.9 & 9 & & 2.9 & 8.5 & 5 & 2.5 & & 0 \\
\hline SUM2 & Ethyl benzene & 1.4 & 0.1 & 0.081 & 0.43 & 0.088 & 0.12 & & 0.29 & 0.061 & 0.22 & 5.9 & & 0 \\
\hline SUM2 & Ethyl chloride & 0 & 0 & 0 & 0 & 0 & 0 & & 0 & 0 & 0 & 0 & & 0 \\
\hline SUM2 & Freon 11 & 0.036 & 0.068 & 0.053 & 0.026 & 0.07 & 0.088 & & 0 & 0.047 & 0.075 & 0.06 & & 0.075 \\
\hline SUM2 & Freon 113 & 0 & 0.028 & 0.045 & 0 & 0.034 & 0.062 & & 0.02 & 0.056 & 0.039 & 0 & & 0 \\
\hline
\end{tabular}




\begin{tabular}{|c|c|c|c|c|c|c|c|c|c|c|c|c|c|c|}
\hline \multirow[b]{2}{*}{ Sampling Period } & \multirow[b]{2}{*}{ Analyte Name } & \multicolumn{13}{|c|}{ Concentrations in Each House Corrected for Outdoor and Field Blank (ppb) } \\
\hline & & H1 & $\mathrm{H} 2$ & H3 & H4 & H5 & $\mathrm{H} 6$ & H6D & H7 & H8 & H9 & H10 & FB & OUT \\
\hline SUM2 & Freon 114 & 0 & 0 & 0 & 0 & 0 & 0 & & 0 & 0 & 0 & 0 & & 0 \\
\hline SUM2 & Heptane & 2 & 0.13 & 0.34 & 2.3 & 0.13 & 0.2 & & 0.43 & 0.72 & 0.32 & 1.5 & & 0 \\
\hline SUM2 & Hexachloro-1,3-butadiene & 0 & 0 & 0 & 0 & 0 & 0 & & 0 & 0 & 0 & 0 & & 0 \\
\hline SUM2 & Isopropyl alcohol & 2.8 & 1.5 & 1.8 & 3 & 8.9 & 5.7 & & 8.2 & 5.2 & 5.4 & 6.2 & & 0.78 \\
\hline SUM2 & m,p-Xylene & 1.4 & 0.076 & 0.061 & 0.36 & 0.075 & 0.13 & & 0.25 & 0.046 & 0.22 & 4.9 & & 0.04 \\
\hline SUM2 & Methyl chloride & 0 & 0 & 0 & 0 & 0 & 0 & & 0 & 0 & 0 & 0 & & 0 \\
\hline SUM2 & Methyl ethyl ketone & 7.5 & 4.4 & 4.5 & 4.5 & 4 & 7.4 & & 6 & 5.3 & 6.6 & 6.1 & & 0.14 \\
\hline SUM2 & Methyl isobutyl ketone & 0.13 & 0.27 & 0.28 & 0.98 & 0.47 & 0.34 & & 0.3 & 0.74 & 0.53 & 1.4 & & 0 \\
\hline SUM2 & Methyl t-butyl ether & 0 & 0 & 0 & 0 & 0 & 0 & & 0 & 0 & 0 & 0 & & 0 \\
\hline SUM2 & Methylene chloride & 9.4 & 5.4 & 4.4 & 6.3 & 7.5 & 9.9 & & 7 & 9 & 10 & 7.7 & & 11 \\
\hline SUM2 & n-Hexane & 5.8 & 0.59 & 0.61 & 5.4 & 1.6 & 0.61 & & 1.2 & 0.59 & 1.2 & 3.7 & & 0 \\
\hline SUM2 & o-Xylene & 1.1 & 0 & 0 & 0.28 & 0 & 0.11 & & 0.2 & 0 & 0.15 & 5.5 & & 0 \\
\hline SUM2 & Propene & 0 & 0 & 0 & 0 & 0 & 0 & & 0 & 0 & 0 & 0 & & 0 \\
\hline SUM2 & Styrene & 0.27 & 0.11 & 0.082 & 0.16 & 0 & 0.12 & & 0.29 & 0 & 0.16 & 0.75 & & 0 \\
\hline SUM2 & Tetrachloroethene & 0.21 & 0.041 & 0.037 & 0.5 & 0 & 0 & & 0.072 & 0.11 & 0 & 0.055 & & 0 \\
\hline SUM2 & Tetrahydrofuran & 1.7 & 1 & 1.1 & 1.1 & 0.97 & 2 & & 1.5 & 1.1 & 0.36 & 1.4 & & 0 \\
\hline SUM2 & Toluene & 6.3 & 2 & 1.9 & 4 & 4.2 & 2 & & 0.82 & 2.2 & 3 & 5.4 & & 0 \\
\hline SUM2 & Total Volatile Organics & 93 & 30 & 49 & 110 & 60 & 82 & & 99 & 59 & 79 & 93 & & 5 \\
\hline SUM2 & trans-1,2-Dichloroethene & 0 & 0 & 0 & 0 & 0 & 0 & & 0 & 0 & 0 & 0 & & 0 \\
\hline SUM2 & trans-1,3-Dichloropropene & 0 & 0 & 0 & 0 & 0 & 0 & & 0 & 0 & 0 & 0 & & 0 \\
\hline SUM2 & Trichloroethene & 0.23 & 0 & 0 & 0 & 0 & 0 & & 0 & 0 & 0 & 0 & & 0 \\
\hline SUM2 & Vinyl acetate & 0 & 0 & 0 & 0 & 0 & 0 & & 0 & 0 & 0 & 0 & & 0 \\
\hline SUM2 & Vinyl chloride & 0 & 0 & 0 & 0 & 0 & 0 & & 0 & 0 & 0 & 0 & & 0 \\
\hline SUM2.1 & 1,1,1-Trichloroethane & & 0 & 0 & & 0 & 0 & & & 0 & 0 & 0 & 0 & 0 \\
\hline SUM2.1 & 1,1,2,2-Tetrachloroethane & & 0 & 0 & & 0 & 0 & & & 0 & 0 & 0 & 0 & 0 \\
\hline SUM2.1 & 1,1,2-Trichloroethane & & 0 & 0 & & 0 & 0 & & & 0 & 0 & 0.075 & 0 & 0 \\
\hline
\end{tabular}




\begin{tabular}{|c|c|c|c|c|c|c|c|c|c|c|c|c|c|c|}
\hline \multirow[b]{2}{*}{ Sampling Period } & \multirow[b]{2}{*}{ Analyte Name } & \multicolumn{13}{|c|}{ Concentrations in Each House Corrected for Outdoor and Field Blank (ppb) } \\
\hline & & H1 & $\mathrm{H} 2$ & H3 & H4 & H5 & H6 & H6D & H7 & H8 & H9 & H10 & FB & OUT \\
\hline SUM2.1 & 1,1-Dichloroethane & & 0 & 0 & & 0 & 0 & & & 0 & 0 & 0 & 0 & 0 \\
\hline SUM2.1 & 1,1-Dichloroethene & & 0 & 0 & & 0 & 0 & & & 0 & 0 & 0 & 0 & 0 \\
\hline SUM2.1 & 1,2,4-Trichlorobenzene & & 0 & 0 & & 0 & 0 & & & 0 & 0 & 0 & 0 & 0 \\
\hline SUM2.1 & 1,2,4-Trimethylbenzene & & 0 & 0 & & 0 & 0 & & & 0 & 0 & 0 & 0 & 0 \\
\hline SUM2.1 & 1,2-Dibromoethane & & 0 & 0 & & 0 & 0 & & & 0 & 0 & 0 & 0 & 0 \\
\hline SUM2.1 & 1,2-Dichlorobenzene & & 0 & 0 & & 0 & 0 & & & 0 & 0 & 0 & 0 & 0 \\
\hline SUM2.1 & 1,2-Dichloroethane & & 0 & 0 & & 0.2 & 0.071 & & & 1.2 & 2.1 & 0.97 & 0 & 0 \\
\hline SUM2.1 & 1,2-Dichloropropane & & 0 & 0 & & 0 & 0 & & & 0 & 0 & 0.05 & 0 & 0 \\
\hline SUM2.1 & 1,3,5-Trimethylbenzene & & 0 & 0 & & 0 & 0 & & & 0 & 0 & 0 & 0 & 0 \\
\hline SUM2.1 & 1,3-Butadiene & & 0 & 0 & & 0 & 0 & & & 0 & 0 & 0 & 0 & 0 \\
\hline SUM2.1 & 1,3-Dichlorobenzene & & 0 & 0 & & 0 & 0 & & & 0 & 0 & 0 & 0 & 0 \\
\hline SUM2.1 & 1,4-Dichlorobenzene & & 0 & 0 & & 0 & 0 & & & 0 & 0 & 0 & 0 & 0 \\
\hline SUM2.1 & 2-Hexanone & & 0 & 0 & & 0 & 0 & & & 0 & 0 & 0 & 0 & 0 \\
\hline SUM2.1 & 4-Ethyl toluene & & 0 & 0 & & 0 & 0 & & & 0 & 0 & 0 & 0 & 0 \\
\hline SUM2.1 & Acetone & & 22 & 59 & & 27 & 14 & & & 24 & 16 & 15 & 0 & 1.8 \\
\hline SUM2.1 & Benzene & & 0.4 & 1.2 & & 0.66 & 1.2 & & & 0.26 & 0.46 & 1.4 & 0 & 0 \\
\hline SUM2.1 & Benzyl chloride & & 0 & 0 & & 0 & 0 & & & 0 & 0 & 0 & 0 & 0 \\
\hline SUM2.1 & Bromodichloromethane & & 0 & 0 & & 0 & 0.06 & & & 0 & 0.1 & 0 & 0 & 0 \\
\hline SUM2.1 & Bromoform & & 0 & 0 & & 0 & 0 & & & 0 & 0 & 0 & 0 & 0 \\
\hline SUM2.1 & Bromomethane & & 0 & 0 & & 0 & 0 & & & 0 & 0 & 0 & 0 & 0 \\
\hline SUM2.1 & Carbon disulfide & & 1.4 & 3.5 & & 1.6 & 0.85 & & & 0.79 & 1.1 & 0.81 & 0 & 0.099 \\
\hline SUM2.1 & Carbon tetrachloride & & 0 & 0 & & 0 & 0 & & & 0 & 0.079 & 0 & 0 & 0 \\
\hline SUM2.1 & Chlorobenzene & & 0 & 0 & & 0 & 0 & & & 0 & 0 & 0 & 0 & 0 \\
\hline SUM2.1 & Chloroform & & 0 & 0.32 & & 0.11 & 0.5 & & & 0.28 & 1.1 & 0.32 & 0 & 0 \\
\hline SUM2.1 & cis-1,2-Dichloroethene & & 0 & 0 & & 0 & 0 & & & 0 & 0 & 0 & 0 & 0 \\
\hline SUM2.1 & cis-1,3-Dichloropropene & & 0 & 0 & & 0 & 0 & & & 0 & 0 & 0 & 0 & 0 \\
\hline
\end{tabular}




\begin{tabular}{|c|c|c|c|c|c|c|c|c|c|c|c|c|c|c|}
\hline \multirow[b]{2}{*}{ Sampling Period } & \multirow[b]{2}{*}{ Analyte Name } & \multicolumn{13}{|c|}{ Concentrations in Each House Corrected for Outdoor and Field Blank (ppb) } \\
\hline & & H1 & H2 & H3 & H4 & H5 & H6 & H6D & H7 & H8 & H9 & $\mathrm{H} 10$ & FB & OUT \\
\hline SUM2.1 & Cyclohexane & & 0.22 & 0.78 & & 2.6 & 0.5 & & & 0.35 & 0.41 & 1.4 & 0 & 0 \\
\hline SUM2.1 & Dibromochloromethane & & 0 & 0 & & 0 & 0 & & & 0 & 0 & 0 & 0 & 0 \\
\hline SUM2.1 & Dichlorodifluoromethane & & 0 & 0 & & 0 & 0 & & & 0 & 0 & 0 & 0 & 0 \\
\hline SUM2.1 & Ethanol & & 17 & 170 & & 22 & 21 & & & 9.5 & 14 & 6.4 & 0 & 13 \\
\hline SUM2.1 & Ethyl acetate & & 1.8 & 0 & & 2.6 & 18 & & & 3.9 & 17 & 0 & 0 & 0 \\
\hline SUM2.1 & Ethyl benzene & & 0 & 0 & & 0 & 0 & & & 0 & 0.12 & 0.71 & 0 & 0 \\
\hline SUM2.1 & Ethyl chloride & & 0 & 0 & & 0 & 0 & & & 0 & 0 & 0 & 0 & 0 \\
\hline SUM2.1 & Freon 11 & & 0.36 & 1 & & 0.26 & 0.15 & & & 0.04 & 0.15 & 0.12 & 0 & 0.086 \\
\hline SUM2.1 & Freon 113 & & 0.12 & 0.32 & & 0.11 & 0.073 & & & 0 & 0.093 & 0.023 & 0 & 0 \\
\hline SUM2.1 & Freon 114 & & 0 & 0 & & 0 & 0 & & & 0 & 0 & 0.21 & 0 & 0 \\
\hline SUM2.1 & Heptane & & 0 & 0 & & 0 & 0 & & & 0 & 0.18 & 0.76 & 0 & 0 \\
\hline SUM2.1 & Hexachloro-1,3-butadiene & & 0 & 0 & & 0 & 0 & & & 0 & 0 & 0 & 0 & 0 \\
\hline SUM2.1 & Isopropyl alcohol & & 12 & 79 & & 25 & 15 & & & 310 & 15 & 11 & 0 & 3.1 \\
\hline SUM2.1 & m,p-Xylene & & 0 & 0 & & 0.042 & 0 & & & 0.082 & 0.16 & 0.98 & 0 & 0 \\
\hline SUM2.1 & Methyl chloride & & 0 & 0 & & 0 & 0 & & & 0.38 & 0 & 0 & 0 & 0 \\
\hline SUM2.1 & Methyl ethyl ketone & & 1.7 & 6.2 & & 2.6 & 9.1 & & & 2 & 1.1 & 3.1 & 0 & 0 \\
\hline SUM2.1 & Methyl isobutyl ketone & & 0 & 0 & & 0.33 & 0 & & & 0.15 & 0.58 & 0 & 0 & 0 \\
\hline SUM2.1 & Methyl t-butyl ether & & 0 & 0 & & 0 & 0 & & & 0 & 0 & 0 & 0 & 0 \\
\hline SUM2.1 & Methylene chloride & & 110 & 410 & & 99 & 47 & & & 39 & 49 & 66 & 0 & 33 \\
\hline SUM2.1 & n-Hexane & & 1.1 & 3.5 & & 1.6 & 0 & & & 0.86 & 0 & 4.1 & 0 & 0.51 \\
\hline SUM2.1 & o-Xylene & & 0 & 0 & & 0 & 0 & & & 0 & 0.1 & 0.83 & 0 & 0 \\
\hline SUM2.1 & Propene & & 0 & 0 & & 0 & 0 & & & 0 & 0 & 0 & 0 & 0 \\
\hline SUM2.1 & Styrene & & 0 & 0 & & 0 & 0 & & & 0 & 0.12 & 0.095 & 0 & 0 \\
\hline SUM2.1 & Tetrachloroethene & & 0 & 0.2 & & 0 & 0 & & & 0.087 & 0.053 & 0.52 & 0 & 0 \\
\hline SUM2.1 & Tetrahydrofuran & & 2.7 & 4.4 & & 0.73 & 3.7 & & & 0.61 & 1.9 & 2.3 & 0 & 0.18 \\
\hline SUM2.1 & Toluene & & 0.4 & 0.69 & & 3.1 & 0.73 & & & 0.44 & 1.9 & 3.4 & 0 & 0 \\
\hline
\end{tabular}




\begin{tabular}{|c|c|c|c|c|c|c|c|c|c|c|c|c|c|c|}
\hline \multirow[b]{2}{*}{ Sampling Period } & \multirow[b]{2}{*}{ Analyte Name } & \multicolumn{13}{|c|}{ Concentrations in Each House Corrected for Outdoor and Field Blank (ppb) } \\
\hline & & H1 & H2 & H3 & H4 & H5 & H6 & H6D & H7 & H8 & H9 & H10 & FB & OUT \\
\hline SUM2.1 & Total Volatile Organics & & 19 & 37 & & 27 & 31 & & & 78 & 54 & 57 & 0 & 11 \\
\hline SUM2.1 & trans-1,2-Dichloroethene & & 0 & 0 & & 0 & 0 & & & 0 & 0 & 0 & 0 & 0 \\
\hline SUM2.1 & trans-1,3-Dichloropropene & & 0 & 0 & & 0 & 0 & & & 0 & 0 & 0 & 0 & 0 \\
\hline SUM2.1 & Trichloroethene & & 0 & 0 & & 0 & 0 & & & 0 & 0 & 0 & 0 & 0 \\
\hline SUM2.1 & Vinyl acetate & & 0 & 0 & & 0 & 0 & & & 0 & 0 & 0 & 0 & 0 \\
\hline SUM2.1 & Vinyl chloride & & 0 & 0 & & 0 & 0 & & & 0 & 0 & 0 & 0 & 0 \\
\hline SUM2.2 & 1,1,1-Trichloroethane & & 0 & 0 & & & & & 0 & 0 & 0 & 0 & 0 & 0 \\
\hline SUM2.2 & 1,1,2,2-Tetrachloroethane & & 0 & 0 & & & & & 0 & 0 & 0 & 0 & 0 & 0 \\
\hline SUM2.2 & 1,1,2-Trichloroethane & & 0 & 0 & & & & & 0 & 0 & 0 & 0 & 0 & 0 \\
\hline SUM2.2 & 1,1-Dichloroethane & & 0 & 0 & & & & & 0 & 0 & 0 & 0 & 0 & 0 \\
\hline SUM2.2 & 1,1-Dichloroethene & & 0 & 0 & & & & & 0 & 0 & 0 & 0 & 0 & 0 \\
\hline SUM2.2 & 1,2,4-Trichlorobenzene & & 0 & 0 & & & & & 0 & 0 & 0 & 0 & 0 & 0 \\
\hline SUM2.2 & 1,2,4-Trimethylbenzene & & 0 & 0 & & & & & 0 & 0 & 0 & 0 & 0 & 0 \\
\hline SUM2.2 & 1,2-Dibromoethane & & 0 & 0 & & & & & 0 & 0 & 0 & 0 & 0 & 0 \\
\hline SUM2.2 & 1,2-Dichlorobenzene & & 0 & 0 & & & & & 0 & 0 & 0 & 0 & 0 & 0 \\
\hline SUM2.2 & 1,2-Dichloroethane & & 0 & 0 & & & & & 1 & 1.8 & 1.1 & 0.83 & 0 & 0 \\
\hline SUM2.2 & 1,2-Dichloropropane & & 0 & 0 & & & & & 0 & 0 & 0 & 0 & 0 & 0 \\
\hline SUM2.2 & 1,3,5-Trimethylbenzene & & 0 & 0 & & & & & 0 & 0 & 0 & 0 & 0 & 0 \\
\hline SUM2.2 & 1,3-Butadiene & & 0 & 0 & & & & & 0 & 0 & 0 & 0 & 0 & 0 \\
\hline SUM2.2 & 1,3-Dichlorobenzene & & 0 & 0 & & & & & 0 & 0 & 0 & 0 & 0 & 0 \\
\hline SUM2.2 & 1,4-Dichlorobenzene & & 0 & 0 & & & & & 0 & 0 & 0 & 0 & 0 & 0 \\
\hline SUM2.2 & 2-Hexanone & & 0 & 0 & & & & & 0 & 0 & 0 & 0.7 & 0 & 0 \\
\hline SUM2.2 & 4-Ethyl toluene & & 0 & 0 & & & & & 0 & 0 & 0 & 0 & 0 & 0 \\
\hline SUM2.2 & Acetone & & 14 & 12 & & & & & 24 & 37 & 51 & 16 & 0 & 0 \\
\hline SUM2.2 & Benzene & & 0.5 & 2 & & & & & 1.2 & 0.31 & 3.2 & 1.5 & 0 & 0 \\
\hline SUM2.2 & Benzyl chloride & & 0 & 0 & & & & & 0 & 0 & 0 & 0 & 0 & 0 \\
\hline
\end{tabular}




\begin{tabular}{|c|c|c|c|c|c|c|c|c|c|c|c|c|c|c|}
\hline \multirow[b]{2}{*}{ Sampling Period } & \multirow[b]{2}{*}{ Analyte Name } & \multicolumn{13}{|c|}{ Concentrations in Each House Corrected for Outdoor and Field Blank (ppb) } \\
\hline & & H1 & $\mathrm{H} 2$ & H3 & H4 & H5 & H6 & H6D & H7 & H8 & H9 & H10 & FB & OUT \\
\hline SUM2.2 & Bromodichloromethane & & 0 & 0 & & & & & 0 & 0 & 0 & 0.2 & 0 & 0 \\
\hline SUM2.2 & Bromoform & & 0 & 0 & & & & & 0 & 0 & 0 & 0 & 0 & 0 \\
\hline SUM2.2 & Bromomethane & & 0 & 0 & & & & & 0 & 0 & 0 & 0 & 0 & 0 \\
\hline SUM2.2 & Carbon disulfide & & 0.95 & 0.82 & & & & & 0.83 & 0.36 & 4.6 & 0.93 & 0 & 0 \\
\hline SUM2.2 & Carbon tetrachloride & & 0 & 0 & & & & & 0 & 0.041 & 0.047 & 0 & 0 & 0 \\
\hline SUM2.2 & Chlorobenzene & & 0 & 0 & & & & & 0 & 0 & 0 & 0 & 0 & 0 \\
\hline SUM2.2 & Chloroform & & 0.069 & 0.13 & & & & & 0.49 & 0.1 & 0.49 & 0.68 & 0 & 0 \\
\hline SUM2.2 & cis-1,2-Dichloroethene & & 0 & 0 & & & & & 0 & 0 & 0 & 0 & 0 & 0 \\
\hline SUM2.2 & cis-1,3-Dichloropropene & & 0 & 0 & & & & & 0 & 0 & 0 & 0 & 0 & 0 \\
\hline SUM2.2 & Cyclohexane & & 0.32 & 1.2 & & & & & 1.8 & 0.28 & 3.1 & 1 & 0 & 0 \\
\hline SUM2.2 & Dibromochloromethane & & 0 & 0 & & & & & 0 & 0 & 0 & 0 & 0 & 0 \\
\hline SUM2.2 & Dichlorodifluoromethane & & 0 & 0 & & & & & 0 & 0 & 0 & 0 & 0 & 0 \\
\hline SUM2.2 & Ethanol & & 15 & 19 & & & & & 0 & 6.1 & 42 & 16 & 0 & 0 \\
\hline SUM2.2 & Ethyl acetate & & 3.8 & 5 & & & & & 5.1 & 4.6 & 11 & 4.7 & 0 & 0 \\
\hline SUM2.2 & Ethyl benzene & & 0 & 0.17 & & & & & 0.091 & 0 & 0 & 0.35 & 0 & 0 \\
\hline SUM2.2 & Ethyl chloride & & 0 & 0 & & & & & 0 & 0 & 0 & 0 & 0 & 0 \\
\hline SUM2.2 & Freon 11 & & 0.16 & 0.14 & & & & & 0.12 & 0.094 & 0.15 & 0.12 & 0 & 0 \\
\hline SUM2.2 & Freon 113 & & 0.074 & 0.033 & & & & & 0.05 & 0 & 0.059 & 0.05 & 0 & 0 \\
\hline SUM2.2 & Freon 114 & & 0 & 0 & & & & & 0 & 0 & 0 & 0 & 0 & 0 \\
\hline SUM2.2 & Heptane & & 0 & 0.43 & & & & & 0.3 & 0 & 0.68 & 0.4 & 0 & 0 \\
\hline SUM2.2 & Hexachloro-1,3-butadiene & & 0 & 0 & & & & & 0 & 0 & 0 & 0 & 0 & 0 \\
\hline SUM2.2 & Isopropyl alcohol & & 7.1 & 9 & & & & & 79 & 1200 & 66 & 9.9 & 0 & 0 \\
\hline SUM2.2 & $\mathrm{m}, \mathrm{p}$-Xylene & & 0.039 & 0.18 & & & & & 0.091 & 0 & 0.061 & 0.47 & 0 & 0 \\
\hline SUM2.2 & Methyl chloride & & 0 & 0 & & & & & 0 & 0 & 0 & 0 & 0 & 0 \\
\hline SUM2.2 & Methyl ethyl ketone & & 0.98 & 1.9 & & & & & 1.9 & 2.1 & 5.7 & 3.7 & 0 & 0 \\
\hline SUM2.2 & Methyl isobutyl ketone & & 0.29 & 0 & & & & & 0.47 & 0.23 & 1 & 1.2 & 0 & 0 \\
\hline
\end{tabular}




\begin{tabular}{|c|c|c|c|c|c|c|c|c|c|c|c|c|c|c|}
\hline \multirow[b]{2}{*}{ Sampling Period } & \multirow[b]{2}{*}{ Analyte Name } & \multicolumn{13}{|c|}{ Concentrations in Each House Corrected for Outdoor and Field Blank (ppb) } \\
\hline & & H1 & H2 & H3 & H4 & H5 & H6 & H6D & H7 & H8 & H9 & H10 & FB & OUT \\
\hline SUM2.2 & Methyl t-butyl ether & & 0 & 0 & & & & & 0 & 0 & 0 & 0 & 0 & 0 \\
\hline SUM2.2 & Methylene chloride & & 46 & 42 & & & & & 44 & 26 & 100 & 35 & 0 & 15 \\
\hline SUM2.2 & n-Hexane & & 0.7 & 3 & & & & & 2.4 & 0.47 & 6.7 & 2.6 & 0 & 0 \\
\hline SUM2.2 & o-Xylene & & 0 & 0.12 & & & & & 0.076 & 0 & 0 & 0.36 & 0 & 0 \\
\hline SUM2.2 & Propene & & 0 & 0 & & & & & 0 & 0 & 0 & 0 & 0 & 0 \\
\hline SUM2.2 & Styrene & & 0 & 0 & & & & & 0 & 0 & 0 & 0 & 0 & 0 \\
\hline SUM2.2 & Tetrachloroethene & & 0 & 0.22 & & & & & 0 & 0.083 & 0 & 0.12 & 0 & 0 \\
\hline SUM2.2 & Tetrahydrofuran & & 1.9 & 1.3 & & & & & 2 & 0.17 & 1.4 & 2 & 0 & 0 \\
\hline SUM2.2 & Toluene & & 1.1 & 2.2 & & & & & 2.4 & 0.69 & 2.1 & 2.8 & 0 & 0.081 \\
\hline SUM2.2 & Total Volatile Organics & & 20 & 42 & & & & & 40 & 58 & 54 & 54 & 0 & 0.39 \\
\hline SUM2.2 & trans-1,2-Dichloroethene & & 0 & 0 & & & & & 0 & 0 & 0 & 0 & 0 & 0 \\
\hline SUM2.2 & trans-1,3-Dichloropropene & & 0 & 0 & & & & & 0 & 0 & 0 & 0 & 0 & 0 \\
\hline SUM2.2 & Trichloroethene & & 0 & 0 & & & & & 0 & 0.067 & 0 & 0 & 0 & 0 \\
\hline SUM2.2 & Vinyl acetate & & 0 & 0 & & & & & 0 & 0 & 0 & 0 & 0 & 0 \\
\hline SUM2.2 & Vinyl chloride & & 0 & 0 & & & & & 0 & 0 & 0 & 0 & 0 & 0 \\
\hline WIN1 & 1,1,1-Trichloroethane & & 0 & 0 & & 0 & 0 & & 0 & 0 & 0 & 0 & 0 & 0 \\
\hline WIN1 & 1,1,2,2-Tetrachloroethane & & 0 & 0 & & 0 & 0 & & 0 & 0 & 0 & 0 & 0 & 0 \\
\hline WIN1 & 1,1,2-Trichloroethane & & 0 & 0 & & 0 & 0 & & 0 & 0 & 0 & 0 & 0 & 0 \\
\hline WIN1 & 1,1-Dichloroethane & & 0 & 0 & & 0 & 0 & & 0 & 0 & 0 & 0 & 0 & 0 \\
\hline WIN1 & 1,1-Dichloroethene & & 0 & 0 & & 0 & 0 & & 0 & 0 & 0 & 0 & 0 & 0 \\
\hline WIN1 & 1,2,4-Trichlorobenzene & & 0 & 0 & & 0 & 0 & & 0 & 0 & 0 & 0 & 0 & 0 \\
\hline WIN1 & 1,2,4-Trimethylbenzene & & 0 & 0 & & 0 & 0 & & 0 & 0 & 0 & 0.068 & 0 & 0 \\
\hline WIN1 & 1,2-Dibromoethane & & 0 & 0 & & 0 & 0 & & 0 & 0 & 0 & 0 & 0 & 0 \\
\hline WIN1 & 1,2-Dichlorobenzene & & 0 & 0 & & 0 & 0 & & 0 & 0 & 0 & 0 & 0 & 0 \\
\hline WIN1 & 1,2-Dichloroethane & & 0 & 0.18 & & 0.094 & 0 & & 1.7 & 0.11 & 3 & 1 & 0 & 0 \\
\hline WIN1 & 1,2-Dichloropropane & & 0 & 0 & & 0 & 0 & & 0 & 0 & 0 & 0.052 & 0 & 0 \\
\hline
\end{tabular}




\begin{tabular}{|c|c|c|c|c|c|c|c|c|c|c|c|c|c|c|}
\hline \multirow[b]{2}{*}{ Sampling Period } & \multirow[b]{2}{*}{ Analyte Name } & \multicolumn{13}{|c|}{ Concentrations in Each House Corrected for Outdoor and Field Blank (ppb) } \\
\hline & & H1 & $\mathrm{H} 2$ & H3 & H4 & H5 & H6 & H6D & H7 & H8 & H9 & H10 & FB & OUT \\
\hline WIN1 & 1,3,5-Trimethylbenzene & & 0 & 0 & & 0 & 0 & & 0 & 0 & 0 & 0 & 0 & 0 \\
\hline WIN1 & 1,3-Butadiene & & 0 & 0 & & 0 & 0 & & 0 & 0 & 0 & 0 & 0 & 0 \\
\hline WIN1 & 1,3-Dichlorobenzene & & 0 & 0 & & 0 & 0 & & 0 & 0 & 0 & 0 & 0 & 0 \\
\hline WIN1 & 1,4-Dichlorobenzene & & 0 & 0 & & 0 & 0 & & 0 & 0 & 0 & 0 & 0 & 0 \\
\hline WIN1 & 2-Hexanone & & 0 & 0 & & 0.12 & 0.091 & & 0.12 & 0 & 0 & 0.33 & 0 & 0 \\
\hline WIN1 & 4-Ethyl toluene & & 0 & 0 & & 0 & 0 & & 0 & 0 & 0 & 0 & 0 & 0 \\
\hline WIN1 & Acetone & & 17 & 36 & & 8.6 & 14 & & 12 & 28 & 300 & 20 & 0.59 & 3.4 \\
\hline WIN1 & Benzene & & 0.28 & 0.22 & & 0.34 & 0.5 & & 1.4 & 0.54 & 0.43 & 1.3 & 0 & 0.27 \\
\hline WIN1 & Benzyl chloride & & 0 & 0 & & 0 & 0 & & 0 & 0 & 0 & 0 & 0 & 0 \\
\hline WIN1 & Bromodichloromethane & & 0 & 0 & & 0 & 0 & & 0.11 & 0 & 0.078 & 0.13 & 0 & 0 \\
\hline WIN1 & Bromoform & & 0 & 0 & & 0 & 0 & & 0 & 0 & 0 & 0 & 0 & 0 \\
\hline WIN1 & Bromomethane & & 0 & 0 & & 0 & 0 & & 0 & 0 & 0 & 0 & 0 & 0 \\
\hline WIN1 & Carbon disulfide & & 0.47 & 1.9 & & 0.59 & 0.94 & & 0.4 & 1.1 & 2 & 0.66 & 0.026 & 1.1 \\
\hline WIN1 & Carbon tetrachloride & & 0 & 0 & & 0 & 0 & & 0.035 & 0 & 0.066 & 0 & 0 & 0 \\
\hline WIN1 & Chlorobenzene & & 0 & 0 & & 0 & 0 & & 0 & 0 & 0 & 0 & 0 & 0 \\
\hline WIN1 & Chloroform & & 0 & 0 & & 0.25 & 0.2 & & 0.36 & 0.6 & 0 & 0.53 & 0 & 0 \\
\hline WIN1 & cis-1,2-Dichloroethene & & 0 & 0 & & 0 & 0 & & 0 & 0 & 0 & 0 & 0 & 0 \\
\hline WIN1 & cis-1,3-Dichloropropene & & 0 & 0 & & 0 & 0 & & 0 & 0 & 0 & 0 & 0 & 0 \\
\hline WIN1 & Cyclohexane & & 0.11 & 0.1 & & 0.1 & 0.12 & & 0.8 & 0.097 & 0.41 & 0.93 & 0 & 0 \\
\hline WIN1 & Dibromochloromethane & & 0 & 0 & & 0 & 0 & & 0 & 0 & 0 & 0 & 0 & 0 \\
\hline WIN1 & Dichlorodifluoromethane & & 0 & 0 & & 0 & 0 & & 0 & 0 & 0 & 0 & 0 & 0 \\
\hline WIN1 & Ethanol & & 10 & 140 & & 4.7 & 34 & & 7.2 & 19 & 68 & 16 & 13 & 9.1 \\
\hline WIN1 & Ethyl acetate & & 2.3 & 78 & & 2.2 & 8.3 & & 1.8 & 7.5 & 97 & 3.6 & 0 & 0.17 \\
\hline WIN1 & Ethyl benzene & & 0 & 0 & & 0.098 & 0 & & 0.13 & 0 & 0.047 & 1.6 & 0 & 0 \\
\hline WIN1 & Ethyl chloride & & 0 & 0 & & 0 & 0 & & 0 & 0 & 0 & 0 & 0 & 0 \\
\hline WIN1 & Freon 11 & & 0.071 & 0.2 & & 0.041 & 0.067 & & 0.017 & 0.066 & 0 & 0.076 & 0 & 0.097 \\
\hline
\end{tabular}




\begin{tabular}{|c|c|c|c|c|c|c|c|c|c|c|c|c|c|c|}
\hline \multirow[b]{2}{*}{ Sampling Period } & \multirow[b]{2}{*}{ Analyte Name } & \multicolumn{13}{|c|}{ Concentrations in Each House Corrected for Outdoor and Field Blank (ppb) } \\
\hline & & H1 & H2 & H3 & H4 & H5 & H6 & H6D & H7 & H8 & $\mathrm{H} 9$ & H10 & FB & OUT \\
\hline WIN1 & Freon 113 & & 0.056 & 0.18 & & 0.041 & 0.058 & & 0 & 0.051 & 0.041 & 0.025 & 0 & 0.036 \\
\hline WIN1 & Freon 114 & & 0 & 0 & & 0 & 0 & & 0 & 0 & 0 & 0 & 0 & 0 \\
\hline WIN1 & Heptane & & 0 & 0 & & 0.13 & 0.098 & & 0.33 & 0 & 0.11 & 0.54 & 0 & 0 \\
\hline WIN1 & Hexachloro-1,3-butadiene & & 0 & 0 & & 0 & 0 & & 0 & 0 & 0 & 0 & 0 & 0 \\
\hline WIN1 & Isopropyl alcohol & & 4.3 & 8.3 & & 4.3 & 3.9 & & 8.6 & 3.4 & 45 & 5.5 & 0.22 & 1.4 \\
\hline WIN1 & m,p-Xylene & & 0.054 & 0 & & 0.1 & 0.036 & & 0.11 & 0 & 0.038 & 2.1 & 0.026 & 0.068 \\
\hline WIN1 & Methyl chloride & & 0 & 0 & & 0 & 0 & & 0 & 0 & 0 & 0 & 0 & 0 \\
\hline WIN1 & Methyl ethyl ketone & & 1.2 & 3.6 & & 3.2 & 3.4 & & 4.8 & 2.5 & 4.2 & 2.5 & 0 & 0.14 \\
\hline WIN1 & Methyl isobutyl ketone & & 0.082 & 0 & & 0.31 & 0.21 & & 0.48 & 0.12 & 0.39 & 1.7 & 0 & 0 \\
\hline WIN1 & Methyl t-butyl ether & & 0 & 0 & & 0 & 0 & & 0 & 0 & 0 & 0 & 0 & 0 \\
\hline WIN1 & Methylene chloride & & 1 & 5.1 & & 0.98 & 1.9 & & 0.74 & 2 & 2.3 & 0.66 & 0.062 & 1 \\
\hline WIN1 & n-Hexane & & 0.3 & 0.24 & & 0.35 & 0.34 & & 2.3 & 0.29 & 1.6 & 2.2 & 0.065 & 0.26 \\
\hline WIN1 & o-Xylene & & 0 & 0 & & 0.073 & 0 & & 0.081 & 0 & 0 & 1.9 & 0 & 0 \\
\hline WIN1 & Propene & & 0 & 0 & & 0 & 0 & & 0 & 0 & 0 & 0 & 0 & 0 \\
\hline WIN1 & Styrene & & 0 & 0 & & 0.039 & 0 & & 0.043 & 0 & 0 & 0.18 & 0 & 0 \\
\hline WIN1 & Tetrachloroethene & & 0.035 & 0 & & 0 & 0 & & 0.072 & 0.041 & 0 & 0.06 & 0 & 0 \\
\hline WIN1 & Tetrahydrofuran & & 0.66 & 2.1 & & 0.49 & 1.9 & & 1.4 & 0.8 & 4.1 & 2.4 & 0 & 0.17 \\
\hline WIN1 & Toluene & & 0.54 & 0.32 & & 1.7 & 1.2 & & 2.3 & 0.69 & 1.7 & 3.4 & 0.11 & 0.37 \\
\hline WIN1 & Total Volatile Organics & & 22 & 36 & & 40 & 46 & & 59 & 37 & 71 & 98 & 7.2 & 16 \\
\hline WIN1 & trans-1,2-Dichloroethene & & 0 & 0 & & 0 & 0 & & 0 & 0 & 0 & 0 & 0 & 0 \\
\hline WIN1 & trans-1,3-Dichloropropene & & 0 & 0 & & 0 & 0 & & 0 & 0 & 0 & 0 & 0 & 0 \\
\hline WIN1 & Trichloroethene & & 0 & 0 & & 0 & 0 & & 0.027 & 0 & 0 & 0 & 0 & 0 \\
\hline WIN1 & Vinyl acetate & & 0 & 0 & & 0 & 0 & & 0 & 0 & 0 & 0 & 0 & 0 \\
\hline WIN1 & Vinyl chloride & & 0 & 0 & & 0 & 0 & & 0.037 & 0 & 0 & 0 & 0 & 0 \\
\hline WIN2 & 1,1,1-Trichloroethane & & 0 & 0 & & 0 & 0 & & 0 & 0 & 0 & 0 & 0 & 0 \\
\hline WIN2 & 1,1,2,2-Tetrachloroethane & & 0 & 0 & & 0 & 0 & & 0 & 0 & 0 & 0 & 0 & 0 \\
\hline
\end{tabular}




\begin{tabular}{|c|c|c|c|c|c|c|c|c|c|c|c|c|c|c|}
\hline \multirow[b]{2}{*}{ Sampling Period } & \multirow[b]{2}{*}{ Analyte Name } & \multicolumn{13}{|c|}{ Concentrations in Each House Corrected for Outdoor and Field Blank (ppb) } \\
\hline & & H1 & $\mathrm{H} 2$ & H3 & H4 & H5 & H6 & H6D & H7 & H8 & H9 & $\mathrm{H} 10$ & FB & OUT \\
\hline WIN2 & 1,1,2-Trichloroethane & & 0 & 0 & & 0 & 0 & & 0 & 0 & 0 & 0 & 0 & 0 \\
\hline WIN2 & 1,1-Dichloroethane & & 0 & 0 & & 0 & 0 & & 0 & 0 & 0 & 0 & 0 & 0 \\
\hline WIN2 & 1,1-Dichloroethene & & 0 & 0 & & 0 & 0 & & 0 & 0 & 0 & 0 & 0 & 0 \\
\hline WIN2 & 1,2,4-Trichlorobenzene & & 0 & 0 & & 0 & 0 & & 0 & 0 & 0 & 0 & 0 & 0 \\
\hline WIN2 & 1,2,4-Trimethylbenzene & & 0 & 0 & & 0 & 0 & & 0 & 0 & 0 & 0 & 0 & 0 \\
\hline WIN2 & 1,2-Dibromoethane & & 0 & 0 & & 0 & 0 & & 0 & 0 & 0 & 0 & 0 & 0 \\
\hline WIN2 & 1,2-Dichlorobenzene & & 0 & 0 & & 0 & 0 & & 0 & 0 & 0 & 0 & 0 & 0 \\
\hline WIN2 & 1,2-Dichloroethane & & 0 & 0.054 & & 0.13 & 0 & & 1.7 & 0.11 & 0.65 & 1.2 & 0 & 0 \\
\hline WIN2 & 1,2-Dichloropropane & & 0 & 0 & & 0 & 0 & & 0 & 0 & 0 & 0 & 0 & 0 \\
\hline WIN2 & 1,3,5-Trimethylbenzene & & 0 & 0 & & 0 & 0 & & 0 & 0 & 0 & 0 & 0 & 0 \\
\hline WIN2 & 1,3-Butadiene & & 0 & 0 & & 0 & 0 & & 0 & 0 & 0 & 0 & 0 & 0 \\
\hline WIN2 & 1,3-Dichlorobenzene & & 0 & 0 & & 0 & 0 & & 0 & 0 & 0 & 0 & 0 & 0 \\
\hline WIN2 & 1,4-Dichlorobenzene & & 0 & 0 & & 0 & 0 & & 0 & 0 & 0 & 0 & 0 & 0 \\
\hline WIN2 & 2-Hexanone & & 0 & 0 & & 0 & 0 & & 0 & 0 & 0 & 0.13 & 0 & 0 \\
\hline WIN2 & 4-Ethyl toluene & & 0 & 0 & & 0 & 0 & & 0 & 0 & 0 & 0 & 0 & 0 \\
\hline WIN2 & Acetone & & 12 & 2.2 & & 4.9 & 5.6 & & 6.7 & 7.2 & 51 & 8.5 & 0.36 & 0.73 \\
\hline WIN2 & Benzene & & 0.23 & 0.23 & & 0.35 & 0.43 & & 1.6 & 0.72 & 0.71 & 1.1 & 0 & 0.14 \\
\hline WIN2 & Benzyl chloride & & 0 & 0 & & 0 & 0 & & 0 & 0 & 0 & 0 & 0 & 0 \\
\hline WIN2 & Bromodichloromethane & & 0 & 0 & & 0 & 0 & & 0 & 0 & 0 & 0 & 0 & 0 \\
\hline WIN2 & Bromoform & & 0 & 0 & & 0 & 0 & & 0 & 0 & 0 & 0 & 0 & 0 \\
\hline WIN2 & Bromomethane & & 0 & 0 & & 0 & 0 & & 0 & 0 & 0 & 0 & 0 & 0 \\
\hline WIN2 & Carbon disulfide & & 0.5 & 0.4 & & 0.49 & 0.63 & & 0.42 & 0.81 & 1.7 & 1.1 & 0.06 & 0.64 \\
\hline WIN2 & Carbon tetrachloride & & 0 & 0 & & 0 & 0 & & 0 & 0 & 0 & 0 & 0 & 0 \\
\hline WIN2 & Chlorobenzene & & 0 & 0 & & 0 & 0 & & 0 & 0 & 0 & 0 & 0 & 0 \\
\hline WIN2 & Chloroform & & 0 & 0 & & 0.065 & 0.085 & & 0.24 & 0.081 & 0.36 & 0.53 & 0 & 0 \\
\hline WIN2 & cis-1,2-Dichloroethene & & 0 & 0 & & 0 & 0 & & 0 & 0 & 0 & 0 & 0 & 0 \\
\hline
\end{tabular}




\begin{tabular}{|c|c|c|c|c|c|c|c|c|c|c|c|c|c|c|}
\hline \multirow[b]{2}{*}{ Sampling Period } & \multirow[b]{2}{*}{ Analyte Name } & \multicolumn{13}{|c|}{ Concentrations in Each House Corrected for Outdoor and Field Blank (ppb) } \\
\hline & & H1 & H2 & H3 & H4 & H5 & H6 & H6D & $\mathrm{H} 7$ & H8 & H9 & H10 & FB & OUT \\
\hline WIN2 & cis-1,3-Dichloropropene & & 0 & 0 & & 0 & 0 & & 0 & 0 & 0 & 0 & 0 & 0 \\
\hline WIN2 & Cyclohexane & & 0.13 & 0.18 & & 0.17 & 0.14 & & 1 & 0.14 & 0.35 & 0.68 & 0 & 0 \\
\hline WIN2 & Dibromochloromethane & & 0 & 0 & & 0 & 0 & & 0 & 0 & 0 & 0 & 0 & 0 \\
\hline WIN2 & Dichlorodifluoromethane & & 0 & 0 & & 0 & 0 & & 0 & 0 & 0 & 0 & 0 & 0 \\
\hline WIN2 & Ethanol & & 3.1 & 13 & & 7.4 & 19 & & 7.1 & 5.3 & 26 & 11 & 4.2 & 2.3 \\
\hline WIN2 & Ethyl acetate & & 1.1 & 4.6 & & 5.7 & 6.9 & & 2.6 & 2.1 & 19 & 4.3 & 0 & 0 \\
\hline WIN2 & Ethyl benzene & & 0 & 0 & & 0 & 0 & & 0 & 0 & 0 & 0.41 & 0 & 0 \\
\hline WIN2 & Ethyl chloride & & 0 & 0 & & 0 & 0 & & 0 & 0 & 0 & 0 & 0 & 0 \\
\hline WIN2 & Freon 11 & & 0.1 & 0.12 & & 0.056 & 0.14 & & 0.042 & 0.11 & 0.15 & 0.05 & 0 & 0.17 \\
\hline WIN2 & Freon 113 & & 0.056 & 0.066 & & 0.051 & 0.079 & & 0 & 0.064 & 0.1 & 0.032 & 0 & 0.057 \\
\hline WIN2 & Freon 114 & & 0 & 0 & & 0 & 0 & & 0 & 0 & 0 & 0 & 0 & 0 \\
\hline WIN2 & Heptane & & 0 & 0 & & 0 & 0 & & 0.26 & 0 & 0 & 0.23 & 0 & 0 \\
\hline WIN2 & Hexachloro-1,3-butadiene & & 0 & 0 & & 0 & 0 & & 0 & 0 & 0 & 0 & 0 & 0 \\
\hline WIN2 & Isopropyl alcohol & & 5.8 & 3.6 & & 16 & 5.9 & & 22 & 2.8 & 12 & 6.2 & 1 & 2.4 \\
\hline WIN2 & m,p-Xylene & & 0 & 0 & & 0 & 0 & & 0.055 & 0 & 0 & 0.48 & 0 & 0 \\
\hline WIN2 & Methyl chloride & & 0 & 0 & & 0 & 0 & & 0 & 0 & 0 & 0 & 0 & 0 \\
\hline WIN2 & Methyl ethyl ketone & & 1.1 & 1 & & 2.9 & 2.2 & & 4.4 & 1.3 & 5.1 & 6.3 & 0 & 0 \\
\hline WIN2 & Methyl isobutyl ketone & & 0 & 0 & & 0.2 & 0 & & 0.19 & 0.098 & 0.14 & 1.3 & 0 & 0 \\
\hline WIN2 & Methyl t-butyl ether & & 0 & 0 & & 0 & 0 & & 0 & 0 & 0 & 0 & 0 & 0 \\
\hline WIN2 & Methylene chloride & & 5.4 & 3.9 & & 4.1 & 4.5 & & 3.4 & 4.1 & 7 & 4.2 & 3.7 & 4.9 \\
\hline WIN2 & n-Hexane & & 0.6 & 0.37 & & 0.58 & 0.49 & & 2.9 & 0.42 & 0.88 & 2.3 & 0.3 & 0.37 \\
\hline WIN2 & o-Xylene & & 0 & 0 & & 0 & 0 & & 0 & 0 & 0 & 0.36 & 0 & 0 \\
\hline WIN2 & Propene & & 0 & 0 & & 0 & 0 & & 0 & 0 & 0 & 0 & 0 & 0 \\
\hline WIN2 & Styrene & & 0 & 0 & & 0 & 0 & & 0 & 0 & 0 & 0 & 0 & 0 \\
\hline WIN2 & Tetrachloroethene & & 0 & 0 & & 0 & 0 & & 0.04 & 0 & 0 & 0 & 0 & 0 \\
\hline WIN2 & Tetrahydrofuran & & 0.7 & 0.23 & & 0.28 & 0.4 & & 0.37 & 0.21 & 0.61 & 0.89 & 0.082 & 0 \\
\hline
\end{tabular}




\begin{tabular}{|c|c|c|c|c|c|c|c|c|c|c|c|c|c|c|}
\hline \multirow[b]{2}{*}{ Sampling Period } & \multirow[b]{2}{*}{ Analyte Name } & \multicolumn{13}{|c|}{ Concentrations in Each House Corrected for Outdoor and Field Blank (ppb) } \\
\hline & & H1 & H2 & H3 & H4 & H5 & H6 & H6D & H7 & H8 & H9 & H10 & FB & OUT \\
\hline WIN2 & Toluene & & 0.4 & 0.2 & & 1.3 & 0.54 & & 2.5 & 0.37 & 0.93 & 2.4 & 0 & 0 \\
\hline WIN2 & Total Volatile Organics & & 11 & 13 & & 24 & 17 & & 37 & 14 & 27 & 48 & 4.6 & 3.5 \\
\hline WIN2 & trans-1,2-Dichloroethene & & 0 & 0 & & 0 & 0 & & 0 & 0 & 0 & 0 & 0 & 0 \\
\hline WIN2 & trans-1,3-Dichloropropene & & 0 & 0 & & 0 & 0 & & 0 & 0 & 0 & 0 & 0 & 0 \\
\hline WIN2 & Trichloroethene & & 0 & 0 & & 0 & 0 & & 0 & 0 & 0 & 0 & 0 & 0 \\
\hline WIN2 & Vinyl acetate & & 0 & 0 & & 0 & 0 & & 0 & 0 & 0 & 0 & 0 & 0 \\
\hline WIN2 & Vinyl chloride & & 0 & 0 & & 0 & 0 & & 0 & 0 & 0 & 0 & 0 & 0 \\
\hline
\end{tabular}




\section{Nitrogen Dioxide}

$\mathrm{NO}_{2}$ was only sampled in one home with gas and one home without gas during each sampling period. Samples have been corrected for outdoor concentrations and the field blank as shown in Table K-5.

Table K-5

\begin{tabular}{|l|llll|llll|}
\hline & \multicolumn{4}{|c|}{ Concentration (ppb) } & \multicolumn{5}{c|}{ Concentration Difference (ppb) } \\
Season & GAS & & \multicolumn{3}{c|}{ NONE } & \multicolumn{2}{c|}{ Concentration Difference (ppb) } & Percent Difference (\%) \\
Status & RTV & CEV & RTV & CEV & GAS & NONE & GAS & NONE \\
N & $\mathbf{3}$ & $\mathbf{3}$ & $\mathbf{3}$ & $\mathbf{3}$ & $\mathbf{3}$ & $\mathbf{3}$ & $\mathbf{3}$ & $\mathbf{3}$ \\
\hline & 2.900 & 1.280 & 1.300 & 0.910 & 1.62 & 0.39 & $56 \%$ & $30 \%$ \\
& 8.100 & 7.000 & 5.600 & 8.400 & 1.10 & -2.80 & $14 \%$ & $-50 \%$ \\
& 6.800 & 1.300 & 0.700 & 0.000 & 5.50 & 0.70 & $81 \%$ & $100 \%$ \\
\hline MIN & $\mathbf{2 . 9 0 0}$ & $\mathbf{1 . 2 8 0}$ & $\mathbf{0 . 7 0 0}$ & $\mathbf{0 . 0 0 0}$ & $\mathbf{1 . 1 0}$ & $\mathbf{- 2 . 8 0}$ & $\mathbf{0 . 1 4}$ & $\mathbf{- 0 . 5 0}$ \\
QUARTILE 1 & $\mathbf{4 . 8 5 0}$ & $\mathbf{1 . 2 9 0}$ & $\mathbf{1 . 9 2 5}$ & $\mathbf{0 . 4 5 5}$ & $\mathbf{1 . 3 6}$ & $\mathbf{- 1 . 2 1}$ & $\mathbf{0 . 3 5}$ & $\mathbf{- 0 . 1 0}$ \\
MEDIAN & $\mathbf{6 . 8 0 0}$ & $\mathbf{1 . 3 0 0}$ & $\mathbf{3 . 1 5 0}$ & $\mathbf{0 . 9 1 0}$ & $\mathbf{1 . 6 2}$ & $\mathbf{0 . 3 9}$ & $\mathbf{0 . 5 6}$ & $\mathbf{0 . 3 0}$ \\
QUARTILE 3 & $\mathbf{7 . 4 5 0}$ & $\mathbf{4 . 1 5 0}$ & $\mathbf{4 . 3 7 5}$ & $\mathbf{4 . 6 5 5}$ & $\mathbf{3 . 5 6}$ & $\mathbf{0 . 5 5}$ & $\mathbf{0 . 6 8}$ & $\mathbf{0 . 6 5}$ \\
MAX & $\mathbf{8 . 1 0 0}$ & $\mathbf{7 . 0 0 0}$ & $\mathbf{5 . 6 0 0}$ & $\mathbf{8 . 4 0 0}$ & $\mathbf{5 . 5 0}$ & $\mathbf{0 . 7 0}$ & $\mathbf{0 . 8 1}$ & $\mathbf{1 . 0 0}$ \\
\hline
\end{tabular}




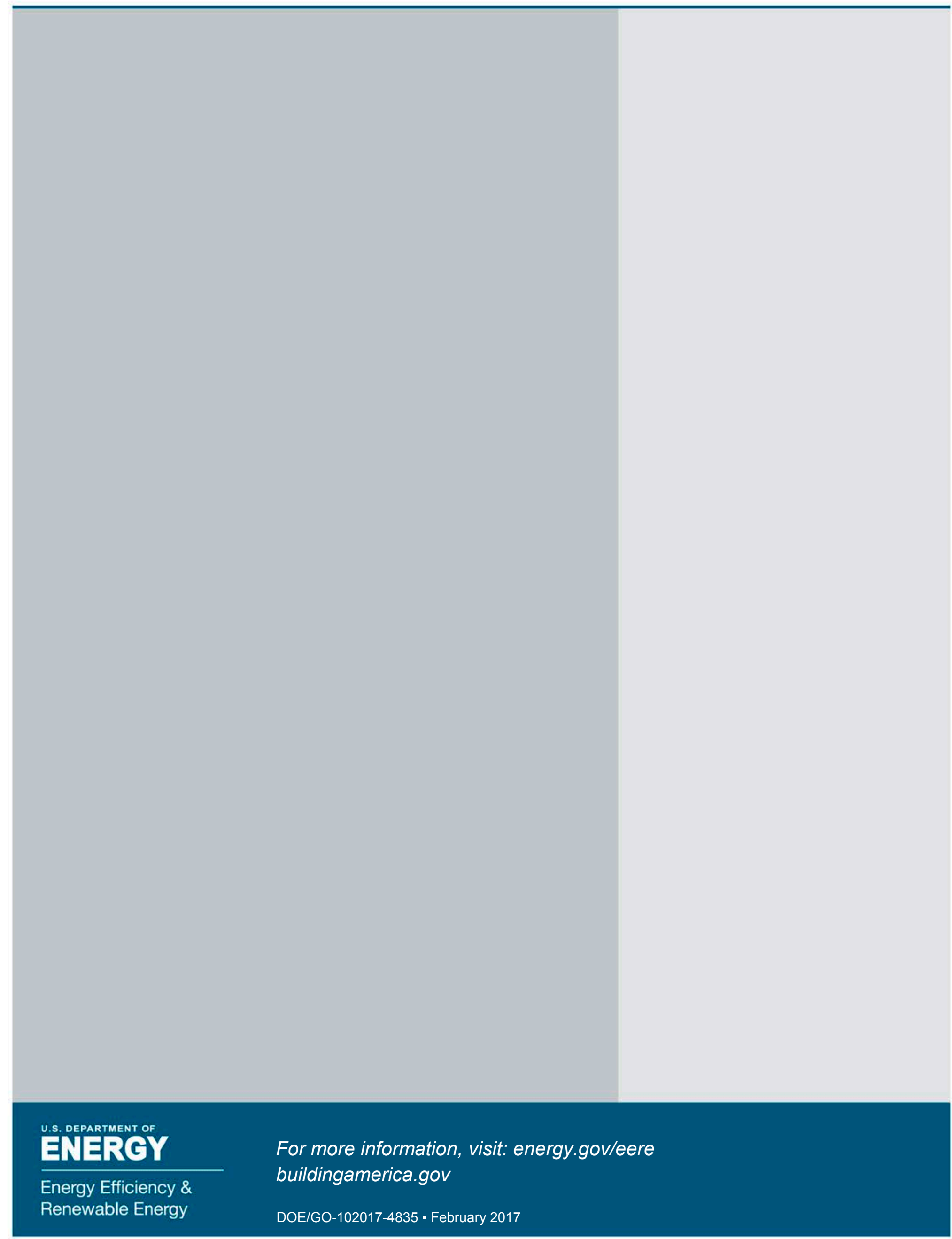

